University of Nebraska - Lincoln

DigitalCommons@University of Nebraska - Lincoln

$12-2016$

\title{
Reactions of Sandhill Cranes Approaching a Marked Transmission Power Line
}

Robert K. Murphy

James F. Dwyer

Elizabeth K. Mojica

Michelle M. McPherron

Richard E. Harness

Follow this and additional works at: https://digitalcommons.unl.edu/usarmyceomaha

This Article is brought to you for free and open access by the U.S. Department of Defense at

DigitalCommons@University of Nebraska - Lincoln. It has been accepted for inclusion in US Army Corps of Engineers by an authorized administrator of DigitalCommons@University of Nebraska - Lincoln. 


\title{
Notes \\ Reactions of Sandhill Cranes Approaching a Marked Transmission Power Line
}

\author{
Robert K. Murphy, James F. Dwyer,* Elizabeth K. Mojica, Michelle M. McPherron, Richard E. Harness \\ R.K. Murphy, M.M. McPherron \\ Department of Biology, University of Nebraska-Kearney, Kearney, Nebraska 68849 \\ Present address of R.K. Murphy: U.S. Fish and Wildlife Service, Albuquerque, New Mexico 87103 \\ Present address of M.M. McPherron: U.S. Army Corps of Engineers, 1616 Capitol Avenue, Omaha, Nebraska 68102
}

\author{
J.F. Dwyer, E.K. Mojica, R.E. Harness
}

EDM International, Inc., 4001 Automation Way, Fort Collins, Colorado 80525

\begin{abstract}
Sandhill cranes Antigone canadensis, formerly Grus canadensis, are of widespread management focus, particularly where collisions with power lines are an important cause of mortality. Collision mitigation focuses on marking power lines to increase visibility, but collisions persist, perhaps because power line markers are not sufficiently visible in all conditions. Our objective was to compare reaction distances and reaction behaviors during daylight when power lines are presumably more visible, and during darkness when power lines are less visible. The power line we studied was fitted with glow-in-the-dark power line markers intended to increase nocturnal visibility. We found that during daylight, flocks generally avoided the power line by climbing gradually and passed above without making sudden evasive maneuvers. During darkness, flocks, particularly small flocks, were almost equally likely to make sudden evasive maneuvers as to climb gradually. Collision monitoring on the power line we studied conducted concurrent to our study indicated that $94 \%$ of collisions occurred during darkness, linking the behaviors we observed to actual mortality. Sandhill cranes also reacted at greater distances and with fewer sudden evasive maneuvers to the glow-in-the-darkmarked power line we studied than to nearby power lines without glowing markers evaluated in a prior study, suggesting that either glowing markers, smaller gaps between markers, or both, improved sandhill cranes' ability to perceive and react to the power line we studied. By correlating behavioral observations with mortality, our study indicates that proactive low-intensity behavioral observations might be useful surrogates to reactive high-intensity carcass searches in identifying high-risk spans. This approach may also be effective for other species.
\end{abstract}

Keywords: Antigone canadensis; collision; Lillian Rowe Sanctuary; mortality; Platte River

Received: May 18, 2016; Accepted: September 26, 2016; Published Online Early: September 2016; Published: December 2016

Citation: Murphy RK, Dwyer JF, Mojica EK, McPherron MM, Harness RE. 2016. Reactions of sandhill cranes approaching a marked transmission power line. Journal of Fish and Wildlife Management 7(2):480-489; e1944-687X. doi: 10.3996/ 052016-JFWM-037

Copyright: All material appearing in the Journal of Fish and Wildlife Management is in the public domain and may be reproduced or copied without permission unless specifically noted with the copyright symbol @. Citation of the source, as given above, is requested.

The findings and conclusions in this article are those of the author(s) and do not necessarily represent the views of the U.S. Fish and Wildlife Service.

* Corresponding author: jdwyer@edmlink.com

\section{Introduction}

Sandhill cranes Antigone canadensis, formerly Grus canadensis, are of management focus throughout the species' range (Gerber et al. 2014, 2015) due primarily to three factors: recovery from population lows in the early 20th century, high value as a game bird, and utility as a model species for endangered whooping cranes Grus 
americana. Nonhunting mortality of sandhill cranes is poorly understood (Gerber et al. 2014) beyond observations that predation is a primary cause of mortality on breeding grounds (Olsen 2004; Nesbitt et al. 2008), and collisions with power lines are an important cause of mortality during migration and wintering (Brown et al. 1987; Morkill and Anderson 1991; Murphy et al. 2009). Collisions with power lines also cause mortality of species of conservation concern such as whooping crane (Miller et al. 2010; Folk et al. 2013; Stehn and HaralsonStrobel 2014), sarus crane Antigone antigone (Sundar and Choudhury 2005), and blue crane Anthropoides paradiseus (Shaw et al. 2010). Because sandhill crane is ecologically and physiologically similar to other crane species, but more abundant than some at-risk species, this species can serve as a model to facilitate assessment of the effectiveness of collision mitigation measures for crane species in general (Morkill and Anderson 1991; Brown and Drewien 1995).

The primary assumptions underlying mitigation of avian collisions are that birds fail to see wires in their flight path until the wires are too close to avoid and that increasing the visibility of wires can reduce collisions (Martin and Shaw 2010; Avian Power Line Interaction Committee [APLIC] 2012). Collision mitigation is typically accomplished by installing power line markers on suspended wires (Sporer et al. 2013; Luzenski et al. 2016; Murphy et al. 2016). On transmission power lines ( $\geq 60$ kV; APLIC 2012), markers are typically installed only on overhead shield wires for two reasons: first, because corona discharge produces electromagnetic interference, audible noise, a visible glow, and reduced transmission efficiency when power line markers are installed on energized conductor wires (Hurst 2004); and second, because overhead shield wires are involved in collisions more often than are energized conductor wires $(76 \%$ on average; Faanes 1987; Pandey et al. 2008; Murphy et al. 2016).

Power line markers seem least effective for species with high wing loading and high flight speeds (Sporer et al. 2013) and for species flying at night (Murphy et al. 2016). The effectiveness of power line marking may be limited by the distance at which the markers become visually prominent in flight. Birds such as sandhill cranes with relatively poor maneuverability may not perceive markers until they are too close to the power line to make effective evasive maneuvers, particularly during nocturnal flights (Murphy et al. 2016). This may be particularly true if the field of vision for a bird in flight fails to include all wires of a power line upon close approach (Martin and Shaw 2010).

Given that collisions tend to persist on marked power lines (Morkill and Anderson 1991; Brown and Drewien 1995; Barrientos et al. 2011), there may be room for improvement in collision mitigation through increasing the low-light visibility of, or decreasing the spacing between, power line markers. To evaluate these hypotheses, we investigated reaction distances and reaction behaviors of flocks of sandhill cranes as they approached a transmission power line during daylight and during darkness. The markers included glow-in-the-dark com- ponents to improve low-light prominence. We compared our behavioral data to data collected in a previous study on power lines marked with more widely spaced nonglowing markers, and on unmarked power lines (Morkill and Anderson 1991). We compared our reaction distance and reaction behavior data to actual collision mortality in a previous study (Morkill and Anderson 1991) and to a concurrent study (Murphy et al. 2016) on the power line we monitored, to correlate reaction data to mortality data. We also evaluated the relationship between the field of vision of blue cranes described by Martin and Shaw (2010) in the context of the actual power line dimensions at our study site to identify whether any types of power line markers were likely to occur within visual fields of crane species generally during flight.

\section{Study Site}

Greater than 500,000 sandhill cranes, and most of the migratory population of whooping cranes, migrate annually through Nebraska (Krapu et al. 2014; Pearse et al. 2015; Urbanek and Lewis 2015). Many of these sandhill and whooping cranes use the Platte River Valley in south central Nebraska as a migratory stopover site (Harner et al. 2015). Within the valley, the Platte River was historically described as a mile wide and an inch deep, and it remains composed of a wide, shallow, braided river channel with extensive sandbar habitat (Krapu et al. 2014). The National Audubon Society's Lillian Rowe Sanctuary (hereafter Rowe) near Gibbon, Nebraska, is a $9.8-\mathrm{km}^{2}$ wildlife refuge along the banks of the Platte River and is situated among a matrix of roosting and foraging habitats. Rowe has been a focal point for studies of sandhill crane collisions with power lines because two sets of $69-\mathrm{kV}$ transmission lines cross the Platte River within the sanctuary (Figure 1). Each of the two power lines has a history of sandhill crane collision mortalities (Murphy et al. 2009, 2016; Wright et al. 2009).

\section{Methods}

From 4 March to 8 April 2009, we observed the 283-m span of a power line where it crossed the Platte River within Rowe. This was the same span observed in a concurrent study of crippling and nocturnal biases in estimates of collision mortality of sandhill cranes (Murphy et al. 2016), and the eastern span of two spans studied in 2006 and 2007 (Wright et al. 2009) to identify baseline values for sandhill crane collision mortalities at Rowe. The span we studied was marked with both spiral vibration dampers (PreFormed Line Products, Cleveland, $\mathrm{OH}$ ) and FireFly ${ }^{\mathrm{TM}} \mathrm{HW}$ Bird Flapper devices (FireFly Diverters LLC, Grantsville, UT; P\&R Tech, Beaverton, OR), the latter of which included a reflective sticker and $a$ glow-in-the-dark sticker on each side (e.g., Figure 2). Reflective stickers were intended to increase the FireFly's visual contrast, improving daytime visibility. Glow-in-thedark stickers were charged daily by exposure to full sun while hanging on the power line, and they were intended to increase nocturnal visibility. FireFlys were 


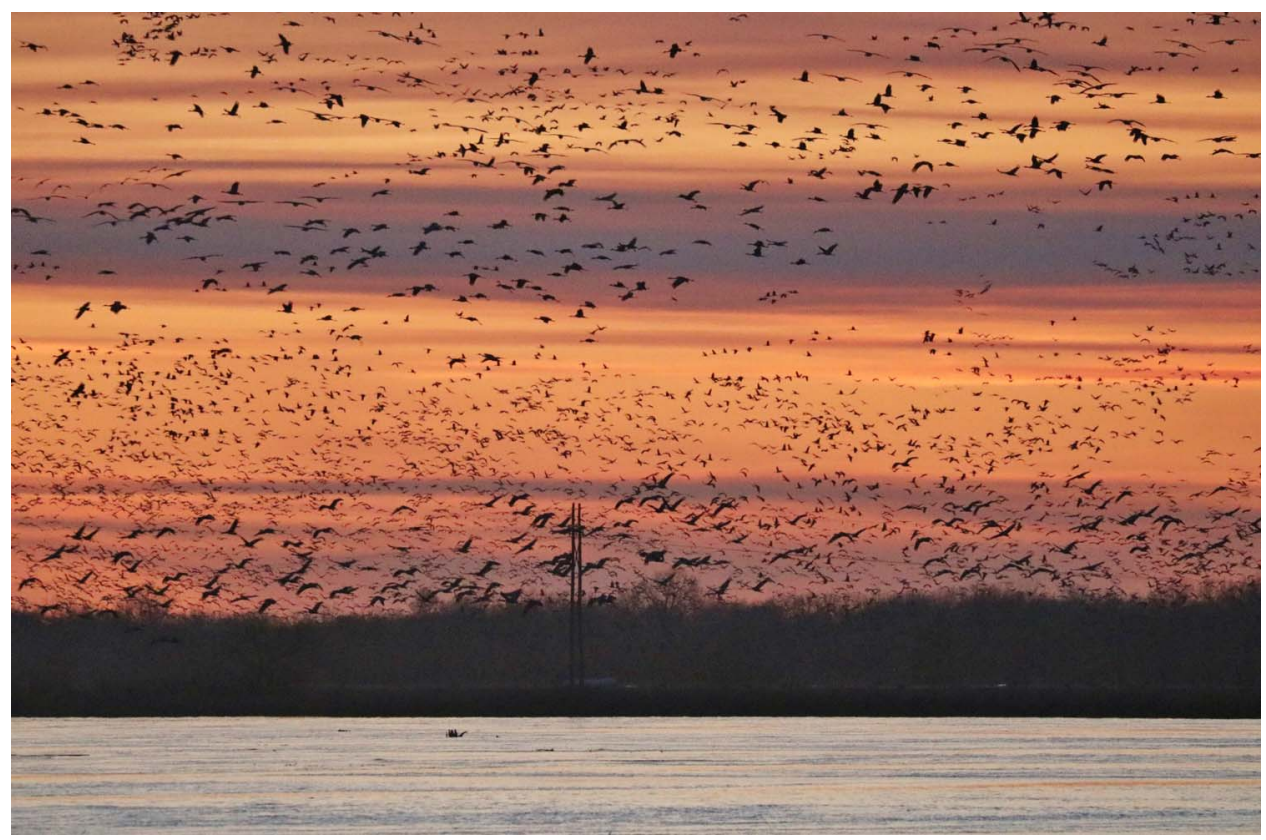

Figure 1. Sandhill cranes Antigone canadensis in flight at a migratory stopover roost on the Platte River where from 4 March to 8 April 2009 we studied their reactions to a marked transmission power line bisecting the National Audubon Society's Lillian Rowe Sanctuary in Gibbon, Nebraska (credit: JFD).

attached at 12-m intervals to each of the two overhead shield wires, in an alternating arrangement so that when viewed from perpendicular to the power line, FireFlys occurred at 6-m intervals. These were interspersed with spiral vibration dampers installed several years prior (Wright et al. 2009). We placed a blind on the river bank at each end of the observed span and recorded flocks of sandhill cranes reacting to the power line from $0.5 \mathrm{~h}$ before sunset through $2 \mathrm{~h}$ after sunset. We used $10 \times 50$ binoculars to observe sandhill cranes during daylight, and $3 \times$ or $5 \times$ generation II night-vision spotting scopes to observe sandhill cranes during darkness (Murphy et al. 2016). We used radios to communicate between blinds to avoid creating duplicate records.

We documented flock size, reaction distance, and reaction behavior for sandhill cranes flying toward the power line, making flocks rather than individual sandhill cranes our sampling unit. To maintain independence of samples, we defined a flock as any individual or group separated by at least $30 \mathrm{~m}$ from any other individual or group (Morkill and Anderson 1991), and we only collected data for the first flock observed in each 5-min interval during each survey. We categorized flock sizes as small (one to three individuals) or large (more than four individuals; as in Morkill and Anderson 1991). We categorized reaction distances as $1-5,6-25$, and $>25$ $\mathrm{m}$ from the power line, to facilitate comparison to Morkill and Anderson (1991) who studied similarly configured power lines over uplands within the Platte River Valley. Similar to Morkill and Anderson (1991), we categorized reaction behaviors as 1) no reaction, 2) gradual climb, 3) flare (i.e., sudden climb), and 4) reversed flight path. We only recorded data for flocks flying $<10 \mathrm{~m}$ above the overhead shield wires because flocks flying higher were not at risk of collision (Morkill and Anderson 1991).

For analysis, we divided our data into two temporal subsets: 1) diurnal (30 min before to $45 \mathrm{~min}$ after sunset) and 2) nocturnal (46-120 $\mathrm{min}$ after sunset). This facilitated comparison of our diurnal data with the evening diurnal data collected by Morkill and Anderson (1991). We used $\chi^{2}$ tests of independence to compare reaction distances and behaviors by flock size and time period. We excluded "no reaction" data from analyses because in our study, sample sizes were prohibitively small for inclusion in $\chi^{2}$ tests. This occurred by design because we specifically focused on flocks at risk of collision (i.e., flying $<10 \mathrm{~m}$ above the power line). In Morkill and Anderson (1991) more than half of all flocks recorded were well above the power lines involved. In these flocks, there was no collision risk, and thus no reactions by sandhill cranes. Our design prevented disproportionate sample sizes of flocks not likely to result in a collision from precluding detection of an effect of power line markers for flocks that were at risk of collision.

We also used $\chi^{2}$ tests to compare reaction distances and behaviors in this study to data reported in Morkill and Anderson (1991) from nearby power lines marked with yellow aviation balls, and from nearby unmarked transmission power lines. In this analysis, we compared only data where sandhill cranes reacted to power lines because Morkill and Anderson (1991) included hundreds of records of sandhill cranes not reacting when flying well above power lines, as would be expected given that no collision risk existed in those overflights. Thus, we conducted four $\chi^{2}$ tests: 1 ) reaction distances by lighting and flock size (Table 1, reaction distances block), 2) 


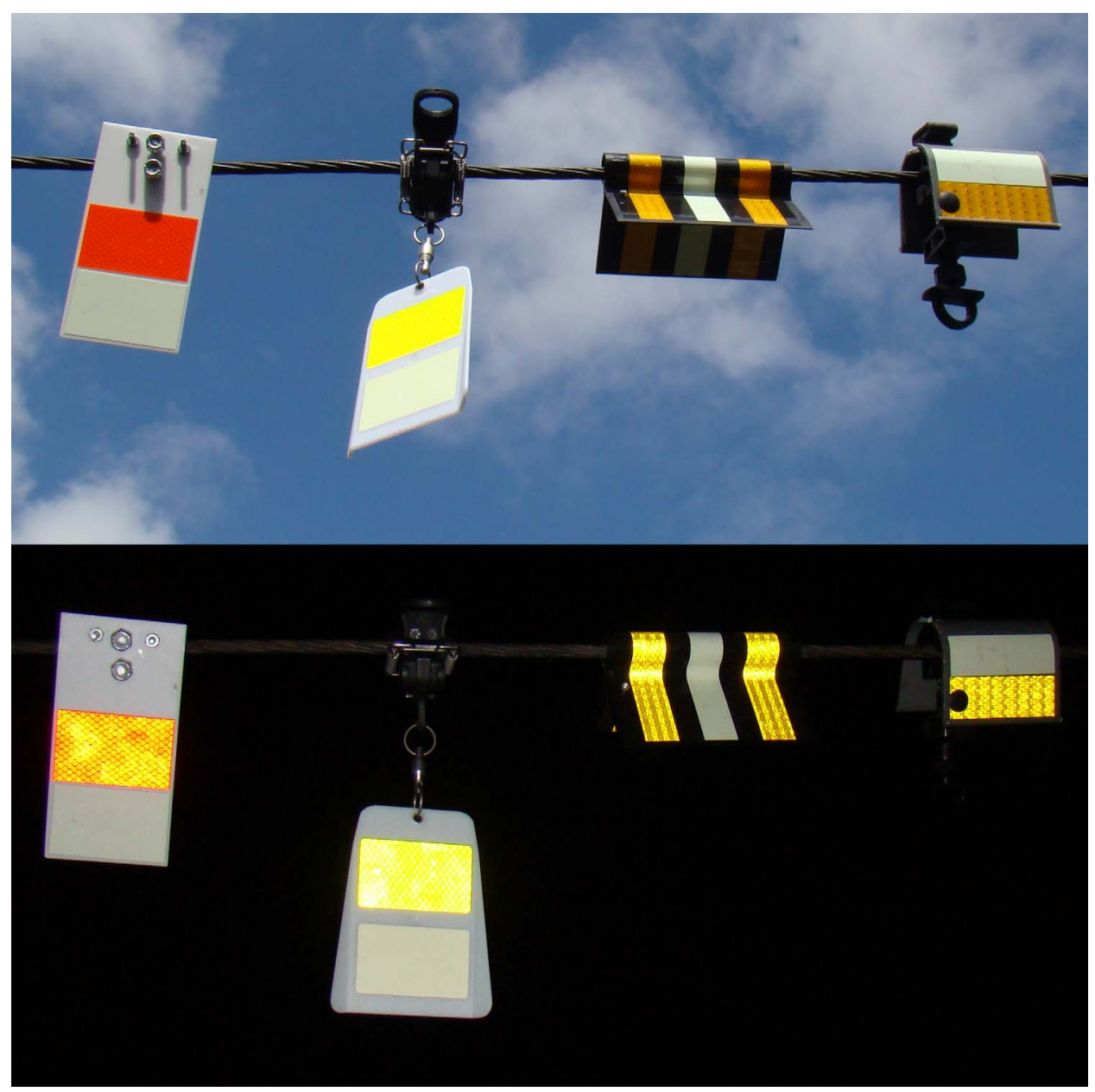

Figure 2. Examples of power line markers with reflective and glow-in-the-dark components designed to increase visual prominence to birds during low-light conditions and thus maximize their effectiveness in reducing avian collisions with power lines in a study of sandhill crane Antigone canadensis reaction behavior. Manufacturers are, from left to right, P\&R Tech (Beaverton, OR), P\&R Tech, Power Line Sentry (Fort Collins, CO), and TE Connectivity (Berwyn, PA). The two P\&R Tech markers on the left are the most similar to those we observed in a study of reaction behavior from 4 March to 8 April 2009 at a marked transmission power line bisecting the National Audubon Society's Lillian Rowe Sanctuary in Gibbon, Nebraska.

Table 1. Counts of reaction distances and reaction behaviors by flocks of sandhill cranes Antigone canadensis in flight toward a marked transmission power line bisecting the National Audubon Society's Lillian Rowe Sanctuary in Gibbon, Nebraska, from 4 March to 8 April 2009. Small flocks were composed of one to three individuals; large flocks were composed of four or more individuals (Morkill and Anderson 1991).

\begin{tabular}{|c|c|c|c|c|c|}
\hline & \multicolumn{3}{|c|}{ Reaction distance (m) } & \multirow[b]{2}{*}{ No reaction } & \multirow[b]{2}{*}{ Row total } \\
\hline & $>25$ & $6-25$ & $1-5$ & & \\
\hline Diurnal small flocks & 92 & 27 & 3 & $N A^{a}$ & 122 \\
\hline Diurnal large flocks & 98 & 24 & 0 & NA & 122 \\
\hline Nocturnal small flocks & 20 & 69 & 44 & NA & 133 \\
\hline Nocturnal large flocks & 29 & 36 & 6 & NA & 71 \\
\hline \multirow[t]{3}{*}{ Reaction distance total } & 239 & 156 & 53 & NA & 448 \\
\hline & \multicolumn{3}{|c|}{ Reaction behavior } & & \\
\hline & Climb & Flare & Reverse & No reaction ${ }^{b}$ & Row total \\
\hline Diurnal small flocks & 105 & 8 & 9 & 0 & 122 \\
\hline Diurnal large flocks & 102 & 3 & 16 & 1 & 122 \\
\hline Nocturnal small flocks & 53 & 44 & 30 & 6 & 133 \\
\hline Nocturnal large flocks & 44 & 11 & 16 & 0 & 71 \\
\hline Reaction behavior total & 304 & 66 & 71 & 7 & 448 \\
\hline
\end{tabular}

${ }^{\text {a }} \mathrm{NA}=$ not applicable.

${ }^{\mathrm{b}}$ No reaction data were not included in analyses because small sample sizes violated assumptions of $\chi^{2}$ tests. 
Table 2. Counts of reaction distances and reaction behaviors by flocks of sandhill cranes Antigone canadensis in flight toward a transmission power line marked with FireFlys and Swan Flight Diverters bisecting the National Audubon Society's Lillian Rowe Sanctuary in Gibbon, Nebraska, from 4 March to 8 April 2009, compared to flights toward power lines marked with aviation balls and toward unmarked power lines reported in Morkill and Anderson (1991). Small flocks were composed of one to three individuals; large flocks were composed of four or more individuals (Morkill and Anderson 1991).

\begin{tabular}{|c|c|c|c|c|c|}
\hline & \multicolumn{3}{|c|}{ Reaction distance (m) } & \multirow[b]{2}{*}{ No reaction } & \multirow[b]{2}{*}{ Row total } \\
\hline & $>25$ & $6-25$ & $1-5$ & & \\
\hline FireFlys & 190 & 51 & 3 & $N A^{a}$ & 244 \\
\hline Aviation balls & 128 & 197 & 106 & NA & 431 \\
\hline Unmarked & 100 & 189 & 119 & NA & 408 \\
\hline \multirow[t]{3}{*}{ Reaction distance total } & 418 & 437 & 228 & NA & 1,083 \\
\hline & \multicolumn{3}{|c|}{ Reaction behavior } & & \\
\hline & Climb & Flare & Reverse & No reaction ${ }^{\mathbf{b}}$ & Row total \\
\hline FireFlys & 207 & 11 & 25 & 1 & 244 \\
\hline Aviation balls & 454 & 19 & 114 & 768 & 587 \\
\hline Unmarked & 397 & 36 & 92 & 1,200 & 525 \\
\hline Reaction distance total & 1,058 & 66 & 231 & 1,969 & 1,355 \\
\hline
\end{tabular}

${ }^{a} \mathrm{NA}=$ not applicable.

${ }^{\mathrm{b}}$ No reaction data were not included in analyses because Morkill and Anderson (1991) included hundreds of records of sandhill cranes not reacting when flying well above power lines, as would be expected given that no collision risk existed in those overflights.

reaction distances by power line marker type (Table 2, reaction distances block), 3) reaction behaviors by lighting and flock size (Table 1, reaction behaviors block), and 4) reaction behaviors by power line marker type (Table 2, reaction behaviors block). We applied Bonferroni corrections for multiple comparisons (Sokal and Rohlf 1995). Given an initial critical value of $\alpha=0.05$, for the four comparisons made, we considered $\alpha=0.01$ to indicate statistical significance.

In a concurrent study on crippling and nocturnal biases in collision mortality estimates, Murphy et al. (2016) documented collisions of sandhill cranes with the power line observed in this study. Therein, 117 collisions were observed via night-vision optics, and 321 collisions were recorded via automated electronic Bird Strike Indicators (EDM International, Fort Collins, CO). We compared the reaction timing and behaviors observed in our study to collision timing in Murphy et al. (2016) to examine the assumption that increased reaction intensity and decreased reaction distances correlated with increased collision risk.

\section{Results}

We recorded the reactions of 448 flocks of sandhill cranes to the eastern power line at Rowe in 2009 (Table 1; Table S1). Flock size averaged $18.5 \quad(\mathrm{SE}=4.8)$ individuals, with a minimum of 1 , median of 3 , and maximum of 2,000. Consolidating across analyses, flocks tended to climb gradually $>25 \mathrm{~m}$ from the power line marked with spiral vibration dampers and FireFly Bird Flapper devices, and flare or reverse direction $<25 \mathrm{~m}$ from power lines marked with aviation balls or from unmarked power lines.

\section{Reaction distances}

Proportions of reaction distances differed in daylight vs. night $\left(\chi^{2}=171.34 ; d f=6 ; P<0.001\right)$. Specifically, flocks tended to react $>25 \mathrm{~m}$ from the power line during daylight and $<25 \mathrm{~m}$ from the power line during darkness, regardless of flock size. Reactions within $5 \mathrm{~m}$ were particularly different; the reactions of only $1.2 \%$ of 244 diurnal flights occurred within $5 \mathrm{~m}$, and the reactions of $24.5 \%$ of 204 nocturnal flights occurred within $5 \mathrm{~m}$. Proportions of reaction distances also differed in our study compared to the Morkill and Anderson (1991) study of sandhill cranes approaching power lines marked with yellow aviation balls and unmarked power lines $\left(\chi^{2}\right.$ $=217.7 ; d f=4 ; P<0.001$; Table 2; Figure 3). Specifically, flocks tended to react from $>25 \mathrm{~m}$ away when approaching the power line we studied $(85.2 \%$ of diurnal observations). Flocks tended to react from $<25 \mathrm{~m}$ away

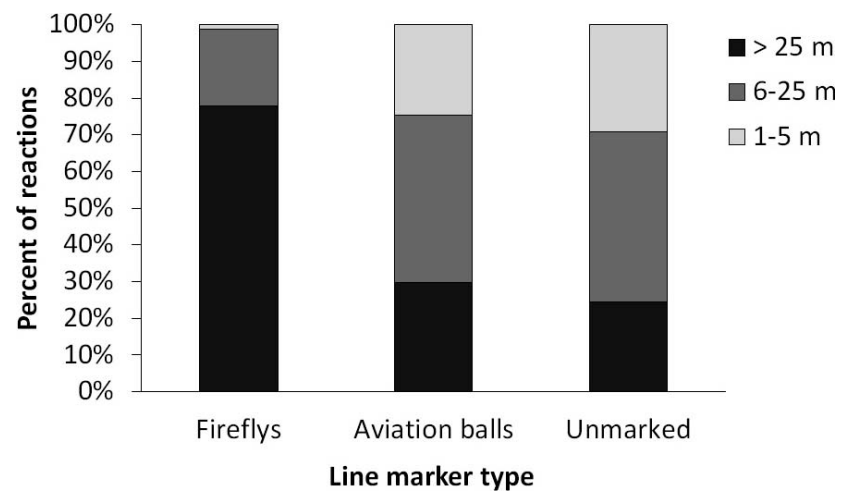

Figure 3. Frequency distribution of reaction distances by sandhill cranes Antigone canadensis from 4 March to 8 April 2009 to a marked transmission power line bisecting the National Audubon Society's Lillian Rowe Sanctuary in Gibbon, Nebraska, compared to other nearby power lines. Flock reactions $(n=244)$ to FireFlys were observed in this study; reactions to power lines marked with aviation balls $(n=1,199)$ and unmarked power lines $(n=1,608)$ and to were observed by Morkill and Anderson (1991). 


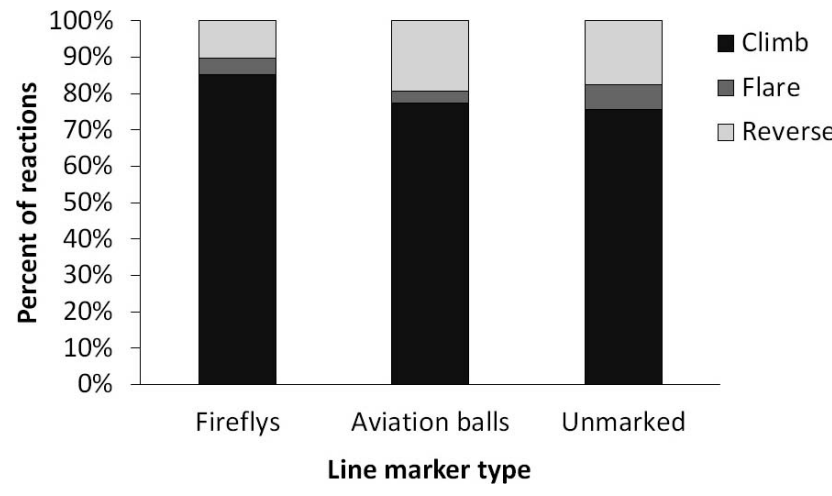

Figure 4. Frequency distribution of behavioral responses by sandhill cranes Antigone canadensis from 4 March to 8 April 2009 to a marked transmission power line bisecting the National Audubon Society's Lillian Rowe Sanctuary in Gibbon, Nebraska, compared to other nearby power lines. Flock reactions $(n=243)$ to FireFlys were observed in this study; reactions to power lines marked with aviation balls $(n=587)$ and unmarked power lines $(n=525)$ and to were observed by Morkill and Anderson (1991).

when approaching aviation balls $(70.3 \%$ of aviation ball observations), or unmarked power lines $(75.5 \%$ of unmarked power line observations; Morkill and Anderson 1991).

\section{Reaction behaviors}

Proportions of reaction behaviors differed with daylight versus night $\left(\chi^{2}=89.6 ; d f=6 ; P<0.001\right)$. Specifically, flocks tended to react with gradual climbs during daylight, and to flare or reverse flight paths during darkness, regardless of flock size. Reactions involving gradual climbs were particularly different, including on $85.2 \%$ of diurnal flights and $49.0 \%$ of nocturnal flights. Proportions of reaction behaviors also differed between our study and the Morkill and Anderson (1991) study for sandhill cranes approaching power lines marked with yellow aviation balls and unmarked power lines $\left(\chi^{2}=18.1 ; d f=4 ; P=0.001\right.$; Table 3; Figure 4). Specifically, flocks tended to react with gradual climbs when approaching the power line we studied (85.2\% of diurnal observations). Flocks were less likely to climb gradually when approaching aviation balls (77.3\% of aviation ball observations) or unmarked power lines $(75.6 \%$ of unmarked power line observations; Morkill and Anderson 1991).

\section{Mortalities}

Murphy et al. (2016) found $6 \%$ of 117 observed collisions during daylight and $94 \%$ during darkness, where diurnal and nocturnal survey periods were identical to those used in this study. Consolidating across analyses, flocks tended to climb gradually $>25 \mathrm{~m}$ away from the power line during daylight $(37.5 \%$ of all observations; $68.9 \%$ of diurnal observations) when collisions were rare. Flocks more often flared or reversed directions $<25 \mathrm{~m}$ from the power line during darkness
(19.9\% of all observations; $43.6 \%$ of nocturnal observations) when collisions were comparatively frequent. Of 36 collisions reported in Morkill and Anderson (1991), $69.4 \%$ occurred on unmarked power lines, correlating reaction distances and behaviors with actual mortality because the number of cranes flying over marked power lines and unmarked power lines did not statistically differ.

\section{Discussion}

Sandhill cranes reacted at greater distances and with more gradual avoidance behaviors during daylight than during darkness. Sandhill cranes also reacted at greater distances and with more gradual avoidance behaviors to the power line marked with FireFlys and Swan Flight Diverters than to the power line marked with aviation balls, and reaction distances were greater when approaching the power line marked with aviation balls compared to unmarked power lines (Morkill and Anderson 1991). Mortalities also were less prevalent during daylight than during darkness on the power line we studied (Murphy et al. 2016), and they were less prevalent on power lines marked with aviation balls than on unmarked power lines (Morkill and Anderson 1991), confirming that flight reaction behavior has direct inference to collision mortality. Thus, closely spaced glow-in-the-dark markers were more effective in mitigating collision mortality than widely spaced nonglowing markers, although nonglowing markers did reduce collision compared to unmarked wires.

The differences we found in reaction distances and behaviors were particularly pronounced for small flocks. In previous studies, individual birds in larger flocks were perceived as being at higher risk of collision (Brown 1993; APLIC 2012) because maneuvering room can be reduced within flocks, and because leading birds obscure the view of trailing birds. The apparent paradox between our findings and previous studies is resolved by considering relative detection probabilities of power lines for individuals within flocks during diurnal and nocturnal flights. During a diurnal flight, the odds that an individual bird within a small flock will see an approaching power line may be relatively high, as may be the odds that trailing birds in that flock, if present, will see and follow the bird into a gradual climb. During a nocturnal flight, the odds that an individual bird within a small flock will see an approaching power line may be relatively low, as may be the odds that trailing birds in that flock, if present, will be able to precisely follow a sudden evasive maneuver immediately before collision if they do not know what the obstacle is or where in their path the obstacle lies.

These observations facilitate increased understanding of when and how collision mitigation devices work and thus where continued innovation may facilitate increased effectiveness. Apparently, when sandhill cranes flew together, the likelihood that one of them would see and react to power line markers earlier upon approach increased with increasing numbers of birds. This indicates that power line markers were visible, but not 
always sufficiently prominently for sandhill cranes to correctly conceptualize in three-dimensional space. Presumably, if power line markers were more prominent, either through increased visibility of individual markers or though reduced spacing between markers, then markers would become apparent to sandhill cranes at a greater distance, even to small flocks. Increased visibility may be achieved by incorporating materials with brighter and longer lasting glow-in-the-dark characteristics. Reduced spacing of glowing markers may help birds avoid a wire suspended between markers either through illumination of the wire itself or through avoidance of flying between markers. Although these approaches seem intuitive, three potential concerns exist. First, very prominent glowing power line markers suspended on wires may be disagreeable to the public. Second, reduced spacing between power line markers would add weight and loading to power lines, particularly during high winds and ice storms. Third, birds can be attracted to nocturnally lit structures (Jones and Francis 2003; Poot et al. 2008), so bird's reactions to markers with increased illumination may not be entirely as desired. Consequently, the relative effectiveness of increasing power line marker prominence should be quantitatively evaluated within the context of a study designed to consider negative impacts.

Avian collision risk can be exacerbated during poor weather (Brown et al. 1987; Jones and Francis 2003; Kirsh et al. 2015). Our study did not report weather effects in reaction distances because we had too few days with weather-obscured power lines to draw statistically meaningful comparisons. However, Brown et al. (1987) also recorded reaction behaviors of sandhill cranes approaching a power line, and they were able to consider weather effects. In their study, sandhill cranes' maneuverability and control were impaired by high winds, and $69 \%$ of sandhill crane mortality occurred on days with high winds, fog, or precipitation. Kirsch et al. (2015) also found that sandhill crane flight behavior differed when fog covered roost sites, leading to reduced flight distances and increased circling. If a power line exists in or near a roost, then increased circling during fog may increase collision risk. Future study should include weather data in multivariate analyses of the effectiveness of power line markers.

Martin and Shaw (2010) postulated that the field of view of some bird species during flight may preclude detection of suspended obstacles directly ahead, a reasonable hypothesis given that birds did not evolve in the presence of suspended obstacles. Evaluation of this hypothesis is critical, because if correct, then power line marking may not be effective mitigation measure regardless of type, glow, or spacing. Martin and Shaw (2010) specifically identified the field of view of blue cranes Anthropoides paradiseus as extending from $15^{\circ}$ below the bill to $60^{\circ}$ above the bill. A blue crane rotating its head $>60^{\circ}$ downward during flight could lose sight of suspended obstacles within its flight path (Martin and Shaw 2010). Following this logic, blue cranes, and presumably similarly structured sandhill cranes and whooping cranes, could hypothetically approach and collide with a power line without the power line ever entering the blue crane's field of view. Our finding that reactions of sandhill cranes to marked power lines in proportion to the level of marking (none, aviation balls, power line markers) refutes this hypothesis, at least with respect to drawing inference beyond blue cranes to sandhill cranes. Future research could compare studies of collision mortality among various crane species, including at-risk whooping cranes, sarus cranes, and free-flying blue cranes to identify whether solutions implemented to protect some might also protect others. Future research also should include other migratory stopover locations, such as the San Luis Valley in southern Colorado, where sandhill cranes and whooping cranes also experience collision mortality (Brown et al. 1987; Brown 1993; Brown and Drewien 1995), but where roost sites are distributed through scattered wetlands rather than along a linear river feature.

\section{Management Implications}

Our study provides a novel behavior-based approach to evaluating avian collision risk that may be useful elsewhere. Resource managers with concerns about the occurrence of avian collisions may not need to rely on a carcass survey that can be a time- and labor-intensive task; yield low sample sizes; and be fundamentally reactive because first a mortality has to be detected. Rather, managers may be able to evaluate flight reaction behavior to identify whether proactive collision mitigation may be warranted. This could be a particularly important surrogate for mortality monitoring if the species hypothesized to be involved are small bodied, because small-bodied carcasses can be quickly removed by scavengers (Rogers et al. 2014). The approach could be coupled with Bird Strike Indicators (EDM International, Inc.; Murphy et al. 2016) in areas where power lines of concern traverse water, preventing effective carcass surveys.

\section{Supplemental Material}

Please note: The Journal of Fish and Wildlife Management is not responsible for the content or functionality of any supplemental material. Queries should be directed to the corresponding author for the article.

Table S1. Counts of reaction distances and reaction behaviors by flocks of sandhill cranes Antigone canadensis in flight toward a marked transmission power line bisecting the National Audubon Society's Lillian Rowe Sanctuary in Gibbon, Nebraska, from 4 March to 8 April 2009. Small flocks were composed of one to three individuals; large flocks were composed of four or more individuals (Morkill and Anderson 1991).

Found at DOI: http://dx.doi.org/10.3996/052016JFWM-037.S1 (31 KB XLSX).

Reference S1. Brown WM, Drewien RC, Bizeau EG. 1987. Mortality of cranes and waterfowl from power line collisions in the San Luis Valley, Colorado. Pages 128-136 in Lewis, JC, editor. Proceedings of the 1985 North American Crane Workshop. Platte River Whooping Crane 
Maintenance Trust, Grand Island, Nebraska, and U.S. Fish and Wildlife Service, Washington, D.C.

Found at DOI: http://dx.doi.org/10.3996/052016JFWM-037.S2 (430 KB PDF); also available at http:// www.nacwg.org/proceedings4.html.

Reference S2. Faanes CA. 1987. Bird behavior and mortality in relation to power lines in prairie habitats. Washington, D.C: U.S. Fish and Wildlife Service Technical Report 7.

Found at DOI: http://dx.doi.org/10.3996/052016JFWM-037.S3 (2119 KB PDF); also available at https:// pubs.er.usgs.gov/publication/2000102.

Reference S3. Hurst N. 2004. Corona testing devices used to mitigate bird collisions. California Energy Commission, PIER energy-related environmental research 50004-086F. EDM International, Inc., Fort Collins, Colorado.

Found at DOI: http://dx.doi.org/10.3996/052016JFWM-037.S4 (1198 KB PDF); also available at http:// www.energy.ca.gov/reports/CEC-500-2004-086F.PDF.

Reference S4. Miller JL, Spalding MG, Folk MJ. 2010. Leg problems and power line interactions in the Florida resident flock of whooping cranes. Pages 156-165 in Hartup, BK, editor. Proceedings of the Eleventh North American Crane Workshop. North American Crane Working Group, Wisconsin Dells, Wisconsin.

Found at DOI: http://dx.doi.org/10.3996/052016JFWM-037.S5 (510 KB PDF); also available at https:// www.saving cranes.org/proceedings-of-the-eleventhnorth-american-crane-workshop/. (September 2016).

Reference S5. Murphy RK, McPherron SM, Wright GD, Serbousek KL. 2009. Effectiveness of avian collision averters in preventing migratory bird mortality from powerline strikes in the central Platte River, Nebraska. 2008-2009 Final Report. Nebraska Game and Parks Commission (NGPC) via US Fish and Wildlife Service Section 6 Program.

Found at DOI: http://dx.doi.org/10.3996/052016JFWM-037.S6 (1069 KB PDF); also available at http:// www.thesis.com/data/literature/effectiveness $\% 20$ of\% 20avian\%20collision\%20averters\%20in\%20preventing\% 20 migratory $\% 20$ bird\%20mortality\%20from\%20powerline\% 20strikes.pdf.

Reference S6. Nesbitt SA, Schwikert ST, Spalding MG. 2008. Survival and sources of mortality in Florida sandhill crane chicks - hatching to fledging. Pages 86-89 in Hartup BK, editor. Proceedings of the Eleventh North American Crane Workshop. North American Crane Working Group, Grand Island, Nebraska.

Found at DOI: http://dx.doi.org/10.3996/052016JFWM-037.S7 (236 KB PDF); also available at http:// digitalcommons.unl.edu/cgi/viewcontent.cgi?article $=1190 \&$ context $=$ nacwgproc.

Reference S7. Pandey AK, Harness RE, Schriner MK. 2008. Bird strike indicator field deployment at the Audubon National Wildlife Refuge in North Dakota: phase two. California Energy Commission, Public Interest Energy Research energy-related environmental research program, CEC-500-2008-020, Sacramento, California.

Found at DOI: http://dx.doi.org/10.3996/052016JFWM-037.S8 (2241 KB PDF); also available at http:// www.energy.ca.gov/2008publications/CEC-500-2008020/CEC-500-2008-020.PDF.

Reference S8. Stehn TV, Haralson-Strobel C. 2014. An update on mortality of fledged whooping cranes in the Aransas/Wood Buffalo population. Pages 43-50 in Proceedings of the Twelfth North American Crane Workshop. North American Crane Working Group, Grand Island, Nebraska.

Found at DOI: http://dx.doi.org/10.3996/052016JFWM-037.S9 (936 KB PDF); also available at http:// www.nacwg.org/proceedings12.html.

\section{Acknowledgments}

We thank C. Kemper, W. Brown, and two anonymous reviewers for comments that greatly improved this writing. Funding from the Nebraska Game and Parks Commission through the U.S. Fish and Wildlife Service's Section 6 program supported our fieldwork. Dawson Public Power District installed spiral vibration dampers and FireFlys. We thank Nebraska Game and Parks Commission, Nebraska Rural Electric Association, National Audubon Society's Lillian Rowe Sanctuary, and the U.S. Fish and Wildlife Service for additional support. We are grateful to University of Nebraska-Kearney students C. Fickel, M. Morten, and K. Serbousek for field assistance and to G. Wright for laying much of the groundwork for this study. M. Fritz, B. Taddicken, R. Harms, and J. Runge facilitated study implementation.

Any use of trade, product, or firm names is for descriptive purposes only and does not imply endorsement by the U.S. Government.

\section{References}

[APLIC] Avian Power Line Interaction Committee. 2012. Reducing avian collisions with power lines: the state of the art in 2012. Unpublished report, Edison Electric Institute and APLIC, Washington, D.C.

Barrientos R, Alonso JC, Ponce C, Palaćin C. 2011. Metaanalysis of the effectiveness of marked wire in reducing avian collisions with power lines. Conservation Biology 25:893-903.

Brown W. 1993. Avian collisions with utility structures: biological perspectives. Pages 13-16 in Proceedings of the International Workshop on Avian Interactions with Utility Structures. Electric Power Research Institute and Avian Power Line Interaction Committee.

Brown WM, Drewien RC. 1995. Evaluation of two power line markers to reduce crane and waterfowl mortality. Wildlife Society Bulletin 23:217-227.

Brown WM, Drewien RC, Bizeau EG. 1987. Mortality of cranes and waterfowl from power line collisions in the 
San Luis Valley, Colorado. Pages 128-136 in Lewis, JC, editor. Proceedings of the 1985 North American Crane Workshop. Platte River Whooping Crane Maintenance Trust, Grand Island, Nebraska, and U.S. Fish and Wildlife Service, Washington, D.C (see Supplemental Material, Reference S1. Found at DOI: http://dx.doi. org/10.3996/052016-JFWM-037.S2 (430 KB PDF); also available: http://www.nacwg.org/proceedings4.html (September 2016).

Faanes CA. 1987. Bird behavior and mortality in relation to power lines in prairie habitats. Washington, D.C.: U.S. Fish and Wildlife Service, Technical Report 7 (see Supplemental Material, Reference S2. Found at DOI: http://dx.doi.org/10.3996/052016-JFWM-037.S3 (2119 KB PDF); also available: https://pubs.er.usgs.gov/ publication/2000102 (September 2016).

Folk MJ, Dellinger T, Leone EH. 2013. Is male-biased collision mortality of whooping cranes (Grus americana) in Florida associated with flock behavior? Waterbirds 36:214-219.

Gerber BD, Dwyer JF, Nesbitt SA, Drewien RC, Littlefield CD, Tacha TC, Vohs PA. 2014. Sandhill crane (Grus canadensis). In Poole A, editor. The birds of North America online. Ithaca, New York: Cornell Lab of Ornithology. Retrieved from The birds of North America online: http://bna.birds.cornell.edu/bna/ species/031 (September 2016).

Gerber BD, Kendall WL, Hooten MB, Dubovsky JA, Drewien RC. 2015. Optimal population prediction of sandhill crane recruitment based on climate-mediated habitat limitations. Journal of Animal Ecology 84:1299-1310.

Harner MJ, Wright GD, Geluso K. 2015. Overwintering sandhill cranes (Grus Canadensis) in Nebraska, USA. Wilson Journal of Ornithology 127:457-466.

Hurst N. 2004. Corona testing devices used to mitigate bird collisions. California Energy Commission, PIER energy-related environmental research 500-04-086F. EDM International, Inc., Fort Collins, Colorado (see Supplemental Material, Reference S3. Found at DOI: http://dx.doi.org/10.3996/052016-JFWM-037.S4 (1198 KB PDF); also available: http://www.energy.ca.gov/ reports/CEC-500-2004-086F.PDF (September 2016).

Jones J, Francis CM. 2003. The effects of light characteristics on avian mortality at lighthouses. Journal of Avian Biology 34:328-333.

Kirsch EM, Wellik MJ, Suarez M, Diehl RH, Lutes, J, Woyczik, W Krapfl, J, Sojda R. 2015. Observation of sandhill cranes' (Grus canadensis) flight behavior in heavy fog. Wilson Journal of Ornithology 127:281-288.

Krapu GL, Brandt DA, Kinzel PJ, Pearse AT. 2014. Spring migration ecology of the mid-continent sandhill crane population with an emphasis on use of the Central Platte River Valley, Nebraska. Wildlife Monographs 189:1-41.

Luzenski J, Rocca CE, Harness RE, Cummings JL, Austin DD, Landon MA, Dwyer JF. 2016. Collision avoidance by migrating raptors encountering a new transmission power line. Condor 118:402-410.

Martin GR, Shaw JM. 2010. Bird collisions with power lines: failing to see the way ahead? Biological Conservation 143:2695-2702.

Miller JL, Spalding MG, Folk MJ. 2010. Leg problems and power line interactions in the Florida resident flock of whooping cranes. Pages 156-165 in Hartup, BK, editor. Proceedings of the Eleventh North American Crane Workshop. North American Crane Working Group, Wisconsin Dells, Wisconsin (see Supplemental Material, Reference S4. Found at DOI: http://dx.doi.org/10.3996/ 052016-JFWM-037.S5 (510 KB PDF); also available: https://www.savingcranes.org/proceedings-of-theeleventh-north-american-crane-workshop/ (September 2016).

Morkill AE, Anderson SH. 1991. Effectiveness of marking powerlines to reduce sandhill crane collisions. Wildlife Society Bulletin 19:442-449.

Murphy RK, McPherron SM, Wright GD, Serbousek KL. 2009. Effectiveness of avian collision averters in preventing migratory bird mortality from powerline strikes in the central Platte River, Nebraska. 2008-2009 Final Report. Nebraska Game and Parks Commission (NGPC) via US Fish and Wildlife Service Section 6 program (see Supplemental Material, Reference S5. Found at DOI: http://dx.doi.org/10.3996/052016JFWM-037.S6 (1069 KB PDF); also available: http:// www.the-eis.com/data/literature/effectiveness $\% 20$ of\% 20avian\%20collision\%20averters \%20in\%20preventing\% 20 migratory $\% 20$ bird $\% 20$ mortality $\% 20$ from $\%$ 20powerline\%20strikes.pdf (September 2016).

Murphy RK, Mojica EK, Dwyer JF, McPherron MM, Wright GD, Harness RE, Pandey AK, Serbousek KL. 2016. Crippling and nocturnal biases in a study of sandhill crane (Grus canadensis) collisions with a transmission line. Waterbirds 39:312-317.

Nesbitt SA, Schwikert ST, Spalding MG. 2008. Survival and sources of mortality in Florida sandhill crane chicks hatching to fledging. Pages $86-89$ in Hartup BK, editor. Proceedings of the Eleventh North American Crane Workshop. North American Crane Working Group, Grand Island, Nebraska (see Supplemental Material, Reference S6. Found at DOI: http://dx.doi. org/10.3996/052016-JFWM-037.S7 (236 KB PDF); also available: http://digitalcommons.unl.edu/cgi/ viewcontent.cgi?article $=1$ 190\&context $=$ nacwgproc (September 2016).

Olsen G. 2004. Mortality of Mississippi sandhill crane chicks. Journal of Avian Medicine and Surgery 18:269272.

Pandey AK, Harness RE, Schriner MK. 2008. Bird strike indicator field deployment at the Audubon National Wildlife Refuge in North Dakota: phase two. California Energy Commission, Public Interest Energy Research energy-related environmental research program, CEC500-2008-020, Sacramento, California (see Supplemental Material, Reference S7. Found at DOI: http://dx.doi. 
org/10.3996/052016-JFWM-037.S8 (2241 KB PDF); also available: http://www.energy.ca.gov/2008publications/ CEC-500-2008-020/CEC-500-2008-020.PDF (September 2016).

Pearse AT, Krapu GL, Brandt DA, Sargeant GA. 2015. Timing of spring surveys for midcontinent sandhill cranes. Wildlife Society Bulletin 39:87-93.

Poot $\mathrm{H}$, Ens $\mathrm{BJ}$, de Vries $\mathrm{H}$, Donners MAH, Wernand MR, Marquenie JM. 2008. Green light for nocturnally migrating birds. Ecology and Society 13:47. Available at: http://www.ecologyandsociety.org/vol13/iss2/ art47/ (September 2016).

Rogers AM, Gibson MR, Pockette T, Alexander JL, Dwyer JF. 2014. Scavenging of migrant carcasses in the Sonoran Desert. Southwestern Naturalist 59:542-547.

Shaw JM, Jenkins AR, Smallie JJ, Ryan PG. 2010. Modelling power-line collision risk for the blue crane Anthropoides paradiseus in South Africa. Ibis 152:590599.

Sokal RR, Rohlf FJ. 1995. Biometry. 3rd edition. New York: W. H. Freeman.

Sporer MK, Dwyer JF, Gerber BD, Harness RE, Pandey AK. 2013. Marking power lines to reduce avian collisions near the Audubon National Wildlife Refuge, North Dakota. Wildlife Society Bulletin 37:796-804.
Stehn TV, Haralson-Strobel C. 2014. An update on mortality of fledged whooping cranes in the Aransas/Wood Buffalo population. Pages 43-50 in Proceedings of the Twelfth North American Crane Workshop. North American Crane Working Group, Grand Island (see Supplemental Material, Reference S8. Found at DOI: http://dx.doi.org/10.3996/052016JFWM-037.S9 (936 KB PDF); also available: http:// www.nacwg.org/proceedings12.html (September 2016)

Sundar KSG, Choudhury BC. 2005. Mortality of sarus cranes Grus antigone due to electricity wires in Uttar Pradesh, India. Environmental Conservation 32:260269.

Urbanek RP, Lewis JC. 2015. Whooping crane (Grus americana). In Poole $\mathrm{A}$, editor. The birds of North America online. Ithaca, New York: Cornell Lab of Ornithology. Retrieved from The birds of North America online: http://bna.birds.cornell.edu/bna/ species/153 (September 2016).

Wright GD, Smith TJ, Murphy RK, Runge JR, Harms RR. 2009. Mortality of cranes (Gruidae) associated with powerlines over a major roost on the Platte River, Nebraska. Prairie Naturalist 41:116-120. 
MORTAL ITY OF CRANES AND WATERFOWL FROM POWERL INE COLLIS IONS IN THE SAN LUIS VALLEY, COLORADO

WENDY M. BROWN, Idaho Cooperative WIIdlife Research Unit, College of Forestry, WildIIfe and Range Sclences, University of Idaho, Moscow, ID 83843.

RODERICK C. DREWIEN, Idaho Cooperative WII II Ife Research Unit, Coll ege of Forestry, WIIdl ife and Range Sclences, University of Idaho, Moscow, ID 83843.

ELWOOD G. BIZEAU, Idaho Cooperative WIIdlife Research Unit, College of For estry, WIIdIIfe and Range Sclences, University of Idaho, Moscow, ID 83843.

Abstract: Crane and waterfowl mortality from collisions with powerlines in the San Luis Valley, Colorado, was investigated during two spring and two fall periods of 1983-84. Powerline segments were searched for dead birds and cranes were observed as they flew over the IInes. Factors contributing to the incidence of powerl ine strikes were analyzed. Sandhill cranes (Grus canadensis tablda), and particularly whooping cranes (G. americana), were more vul nerable to wire strikes than waterfowl. Juvenlle cranes struck power I ines more frequently than adults $(p=0.001)$. The incidence of collislons was influenced by the proximity of powerlines to roosting and feeding sites and by adverse weather conditions (fog, precipitation, and wind) which affected visibillty and filght control $(p=0.001)$. Evaluation of experimental modification of a $115 \mathrm{kv}$ transmission Iine indicated that static wire removal substantially reduced strikes; however, In a Ilmited study, static wire enlargement was not shown to reduce strikes. We recommend locating new powerll nes at least $2.0 \mathrm{~km}$ from traditlonal roost and feeding sites, and investigating techniques of color marking static wires to increase visibility and minimize collisions at perennial problem locations.

1985 CRANE WORKSHOP PROCEEDINGS

The San Luis Valley in south-central Colorado is the major spring and fall migration stop for the Rocky Mountain populations of greater sandh lll cranes and cross-fostered whooping cranes (Drewlen and Blzeau 1974, 1978, Kauffeld 1981). These populations currently number 17,000-20,000 sandhIII cranes and 30-35 whooping cranes. Cranes use the valley for 3-4 months annually, primarlly from October through mid-November and $\mathrm{mid}=\mathrm{February}$ through $\mathrm{mid}-\mathrm{Apr} i \mathrm{l}$. The valley also provides Important habltat for 8,000-10,000 Canada geese (Branta canadensis) and over 25,000 other waterfow I (M. Suthers, pers. comm.).

Barley, wheat, and potato farming are the primary land uses in the valley, and additional lands are converted annually to agriculture. Recently, several large power transmission IInes and numerous distribution lines have been constructed to service the expanslon of overhead sprinkler irrigation. Many power lines cross traditional crane and waterfowl concentration areas.

It is well established that powerl Ine collisions are a source of avian mortality (Walkinshaw 1956, Cornwell and Hochbaum 1971, Drowlen 1973, Krapu 1974, Stout and Cornwell 1976, Anderson 1978, Tacha et al. 1978, Malcom 1982, Brown et al. 1984). The potential effect of collision mortality on populations of rare and endangered specles has been noted by Lee (1978), Thompson (1978), and Faanes (1983. Assessment of powerline siting in relation to bird strikes in the Northern Great Plalns, Unpubl. Rept., Northern Prairle Wildl. Res. Cent., Jamestown, North Dakota. $90 \mathrm{pp})$. Since 1956, six powerline collislons resulting in injury or death of whooping cranes have been documented in the Wood Buffalo-Aransas population (J. Lew is 1985, Whooping crane mortality/Injurles. Unpubl. Table. U. S. FIsh and Wildlife Service, Albuquerque, N. M.). A minimum of elght cross-fostered whooping cranes in the Rocky Mountain population have struck powerlines since 1977. Seven of these were killed or incapacitated accounting for $39 \%$ of all known losses of fledged birds to date (unpubl. data, id. Coop. Wild . Res. Unit). Six of these I ine strlkes occurred in the San Luis Valley.

This study was initiated to assess crane and waterfowl mortality from powerline collisions in the San Luis Valley, to evaluate factors which contribute to collisions, and to provide insight on how to reduce that mortality.

We thank G. Halvorson, U. S. FIsh and Wildlife Service, Albuquerque, for obtaining funds and assisting with project initiation for fall 1983 studies. D. Walker substantially contributed to data collection and summary during fall 1983, and D. Kingery generally donated her time 
walking powerlines throughout the study. We especlally appreclate the assistance, facll itles, and equipment made avallable by $M_{0}$. Nall and staff of Al amosa-Monte Vista National Wildilfe Refuge. We are grateful to San Luls Valley Rural Electric Cooperative, Inc., Publ Ic Service Company of Colorado, and Colorado Ute Electric Association, Inc. for their cooperation in modifying a transmission line and providing technical information. K. Reese assisted with statistical analysis, and helpful revlews of the manuscript were provided by S. Derrickson, and C. Rice. E. Myers typed the manuscript.

\section{METHODS}

\section{Mortality Surveys}

Powerline collision (strike) mortality data were collected during two spring (February-April) and two fall (October-November) periods 1983-84. Selected segments of el ectric transmission (69 and $155 \mathrm{kv}$ ) and distribution (7.2-24 kv) lines were thoroughly searched one or more times each season (Fig. 1). Weekly searches of 14 transects along 10 different powerlines were conducted during fall 1983. Supplemental information on strike mortality was provided by Al amosa-Monte Vista Natlonal Wild Ife Refuge personnel.

The area searched under all I ines included an adjolning strip approximateiy $30 \mathrm{~m}$ on each side of support poles. One or two observers walked a zig-zag pattern, or when terrain offered good visibility, an all terrain cycle or truck was used.

All dead birds, or parts thereof, found within the search area were considered strikes, including feather spots Indicating a bird had hit the ground and left the area. For subsequent identiflcation, all avian carcasses were marked with red enamel paint and numbered strips of or ange flagging tape. Species, age, sex, type of injurles, carcass condition, and date of death were recorded when possible. Strike locations were plotted on maps and the surrounding habitat, approximate distance from roost and feeding sites, and recent weather conditions were noted.

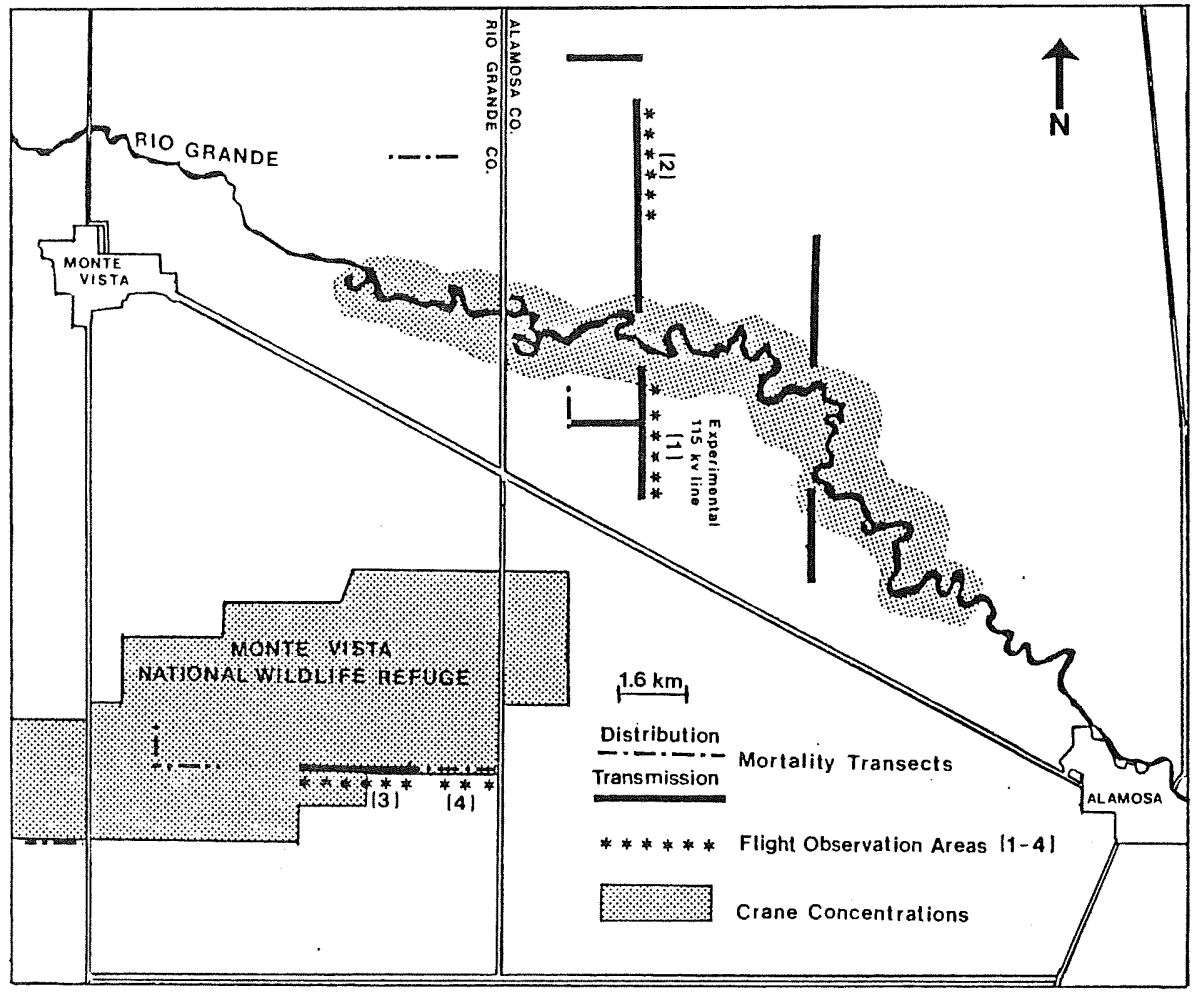

FIg. 1. Locations of major powerline transects for bird mortality surveys (two spring and two fall periods 1983-84) and bird flight observation areas (fall 1983) in the San Luis Vailey, Col or ado. 
Experimental Modification of a 115 kv Transmission Line

A $3.2 \mathrm{~km}$ segment of $115 \mathrm{kv}$ transmission line (Fig. 1) was experimentally modifled and monitored through a cooperative effort by Colorado Ute Electric Association, Inc. (CUEA), the U. S. FIsh and Wildlife Service (FWS), and Edison Electric Institute (EEI). We began intensive surveys of this IIne in March 1983, after a whooping crane with impact injuries was found nearby.

In an effort to reduce crane strikes, the static wire was experimentally removed in August 1983. The static wire is the nonconducting, topmost wire on a powerline used to minimize power outages from Ilghtening strikes. It is normally smaller than the conductor, and appears to be the wire most often struck by birds in flight (Thompson 1978, Faanes 1983 loc. cit.).

In October, CUEA and FWS initiated thrice-weekly searches of the experimental segment for dead birds, and their effort contl nued throughout fall 1983 and spring 1984 ( $H_{0}$ G. Lalre. 1984, San Luls Valley - Waverly $115 \mathrm{kv}$ transmission IIno - 1983, Unpubl. Rept., Colorado Ute Electric Association, Montrose). Their mortality data for these two perlods are included in this paper.

In September 1984, cooperators with EEI experimentally replaced two spans (ca. $560 \mathrm{~m}$ ) of static wire with standard $0.95-\mathrm{cm}$ dlameter wire, and two spans with $2.54-\mathrm{cm}$ diameter self-damping wire to determine if the larger wire would be more visible to flying birds and thereby reduce collision frequency. The remaining nine spans were left without static wire. Using remote cameras, EEI contractors fllmed crane flights over six experimental spans ( $T$. $\mathrm{Nel}$ son, pers. comm.). We continued searches of the entire segment for dead birds.

\section{Bird Flight Observations}

Bird flight observations were made at four locations from 8 October-12 November 1983 (FIg. 1). Area 1 comprised a segment of the experimental $115 \mathrm{kv}$ transmission line without static wire. It was situated immediately adjacent to and between heavily-used roost and feeding sites. Area 2 transected cropl and feedling areas north of the Rlo Grande River and represented a segment of the experimental transmission I ine with static wire intact. Areas 3 and 4 represented typical segments of $69 \mathrm{kv}$ transmission and $7.2 \mathrm{kv}$ distribution I ines, respectively. Both separated a nearby roost on Monte VIsta Refuge from feeding sites $3 \mathrm{~km}$ or more away.

Observations were made from vehicles, primarlly at sunrise and sunset when large numbers of birds were moving to and from roosts. We attempted to gain supplemental observations when large groups of birds were flushed (wild flush) and during adverse weather.

During all observations the specles, flock size, reactlon distance, al titude above II ne, flight direction, and weather conditions were recorded for each flight. A flight was def Ined as a flock of birds, moving together without any break in the unit.

\section{Data Anaiysis}

Dally weather data were complled from National Weather Service records in Alamosa. Wind speed, fog, and precipitation were considered potentially important to strikes due to their adverse ef fects on flight maneuverability and visibility. For the purposes of our analysis, weather for each day of the study perlod was classifled as fair or foul. A foul weather day was one having fog, rain, snow, or wind exceeding an average of $32 \mathrm{~km} / \mathrm{hr}$ for a 3 hour perlod.

The relationship between weather and bird strikes was determined using a chi-square contingency table (Zar 1974). The proportion of fresh bird strikes found on foul weather days was compared to the proportion of foul weather days in the survey perlod. Chi-square analysis was also used to compare the proportion of Juvenile sandhill crane strikes found with the proportion of juveniles in the population.

RESULTS

Mortal ity Surveys

During spring and fall 1983-84, 115 dead blrds were found. Sandhlll cranes were the most frequent mortalities $(67.8 \%)$, followed by ducks $(17.4 \%)$, Canada geese $(7.0 \%)$, and whooping cranes $(2.6 \%)$. Five other species $(5.2 \%)$ were recorded (Table 1 ). 
Table 1. Powerline strike mortallty in the San Luis Valley, Colorado during spring and fall crane use perlods 1983-84.

\begin{tabular}{|c|c|c|c|c|c|c|c|c|}
\hline \multirow[b]{2}{*}{$\begin{array}{l}\text { Season and } \\
\text { line type }\end{array}$} & \multirow[b]{2}{*}{$\begin{array}{l}\text { No. I Ines } \\
\text { surveyed }\end{array}$} & \multirow[b]{2}{*}{ Distance $(\mathrm{km})$} & \multicolumn{5}{|c|}{ Species } & \multirow[b]{2}{*}{$\begin{array}{l}\text { Total } \\
\text { birds }\end{array}$} \\
\hline & & & $\begin{array}{l}\text { Whooping } \\
\text { crane }\end{array}$ & $\begin{array}{l}\text { Sandh III } \\
\text { crane }\end{array}$ & $\begin{array}{l}\text { Canada } \\
\text { geese }\end{array}$ & Ducks ${ }^{a}$ & other ${ }^{b}$ & \\
\hline \multicolumn{9}{|l|}{ Spring 1983} \\
\hline Transmission & 2 & 8.8 & 1 & 18 & 4 & 5 & 1 & 29 \\
\hline $\begin{array}{l}\text { Distr Ibution } \\
\text { Fall } 1983\end{array}$ & n & 2.4 & 0 & 5 & 1 & 4 & 1 & 11 \\
\hline Transmission & 4 & 16.2 & 0 & 9 & 1 & 1 & 0 & 11 \\
\hline Distribution & 6 & 6.0 & 0 & 3 & 0 & 0 & 0 & 3 \\
\hline \multicolumn{9}{|l|}{ Spring 1984} \\
\hline Transmission & 3 & 5.1 & 1 & 7 & 0 & 3 & 1 & 12 \\
\hline $\begin{array}{l}\text { Distr lbution } \\
\text { Fall } 1984\end{array}$ & 12 & 4.8 & 1 & 15 & 0 & 0 & 2 & 18 \\
\hline Transmission & 1 & 3.2 & 0 & 13 & 1 & 4 & 0 & 18 \\
\hline Distribution & 2. & 3.2 & 0 & 8 & 1 & 3 & 1 & 13 \\
\hline Totai & & & 3 & 78 & 8 & 20 & 6 & 115 \\
\hline
\end{tabular}

a Eleven mallards (Anas platyrynchos), 2 bl ue-winged teal (Anas discors), 1 green-winged teal

(Anas crecca), 1 ruddy duck (exyura Lamaicensls), and 5 unidentlfled.

b Two Amerlcan coots (Eulcla americana), 1 great bl ue heron (Ardea herodias), 1 lesser yell owlegs (Iringa flavipes), 1 northern harrler (Clrcus cyaneus), and 1 hor ned lark (Eremoph lla alpestris).

In proportion to their abundance, whooping cranes were the most frequent casualties. The number of whooping cranes sighted in the San Luis Valley during 1983-84 ranged from 13-29. In addition to the three powerl ine kills documented during this period, two whooping cranes struck powerlines and survived. One was apparently unhurt; another sustained a fractured wing near Grand Junction, Colorado, was subsequently captured, its wing amputated, and transferred to Patuxent WIIdlife Research Center In Maryland In May 1984. All but one of these five birds were Juveniles.

Juvenile sandhill cranes collided with power lines far more frequently than adults ( Chi-square $=72.98,1$ d. f., $p<0.001)$. Age was determined for 43 crane strik.es: 21 (48.8\%) were juveniles. The mean percent Juveniles in the San Luis Valley during 1983-84 was 9.9\%.

Seventy birds $(60.9 \%)$ were found under transmission IInes and $45(39.1 \%)$ under distribution IInes. Relatively short sections of a fow transmission I ines accounted for most strikes; distribution I Ine strlkes were generally Isolated incidents scattered throughout the valley.

Powerllne distance from roost and feeding areas appeared critical to the incldence of strikes. Bird strlkes were not found where the dlstance exceeded $1.6 \mathrm{~km}$, whereas, 101 (87.8\%) occurred where a Ilne bordered or blsected a major use area and birds were taking off and landing in the immediate vicinity.

Experimental $115 \mathrm{kv}$ Transmission L.ine

Fifty-four birds ( $36 \mathrm{cranes)}$ were found under the 13 spans of experimental transmission IIne in four seasons. The highest number (25) was found in spring 1983. After removal of the static wire, strikes declined substantlally during fall 1983 and spring 1984 . When four spans of statlc wire were replaced in fall 1984, bird strikes increased to 18 (Flg. 2). Most strikes (12) occurred where elther standard or experimental wire was present. The number of strikes/span of standard and experimental static wire were two and four, respectively. Only six strikes were found under the nine spans without a static wire $(0.7$ str ikes/span).

Proceedings 1985 Crane Workshop 
Effect of Weather

Dates and existing weather conditions were identifled for 29 crane strikes. Twenty strikes (69.0\%) occurred on days with high winds, fog, or precipitation. By contrast, only 73 of 196 (37.2\%) total survey days had foul weather. A highly significant proportion of collisions occurred during foul weather (Chi-square $=12.48,1 \mathrm{~d}$. $f_{0}, p<0.001$ )。

There was also a strong relationship between the proportion of foul weather days in each seasonal survey perlod and the number of strikes found per kilometer of powerllne monitored (Fig. 3). Strikes kilometer of I Ine ranged from 3.0-4.8 during spring 1983 and $5 p r \mid n g$ and fall 1984 surveys; foul weather occurred on $38-50 \%$ of the days during these perlods. In contrast, we found only $0.6 \mathrm{strikes/kilometer}$ of I ine during the exceptionally mild weather (15\% foul weather days) of fall 1983 surveys.

\section{Bird FI ight Observations}

We observed 1,694 crane fl Ights over powerl ines. Flocks of 1-4 and 5-20 birds occurred with about equal frequency, comprising $92.5 \%$ of al I observations. Larger flocks usually occurred when birds were disturbed. Flocks of $21-50$ made up $6.9 \%$; flocks $>50$ comprised only $0.6 \%$.

Most cranes $(71 \%)$ reacted to powerlines by flaring and adjusting their altitude at some distance away, usually at 25-100 m. Altitude above the top wire was $>6 \mathrm{~m}$ for $61.9 \%$ of all flights. Only two cranes were observed flying under the conductor wire; none between the conductor and static wire. No collisions were observed.

Reaction distance and altitude appeared directly related to distance from filght or igin and destination. For example, despite removal of the static wire, Area 1 had the highest proportion of birds reacting at $<25 \mathrm{~m}$ (44.9\%) and the highest proportion crossing at 1-3 $\mathrm{m}$ above the IIne (Table 2). Area 1 is situated between Immediately adjacent roost and feeding sites, and birds fly $<0.8 \mathrm{~km}$ before crossing this transmission I ine. Altitude is normally low for short flight distances and cranes require considerable adjustment to clear the top wire (about $18 \mathrm{~m} \mathrm{high).}$

Reaction distance and altitude were greater at Area 2, desplte presence of the static wire which increased height of the powerline to $22 \mathrm{~m}$. Roost and feeding sites at this segment of I I ne are separated by $>2 \mathrm{~km}$. Area 4 , a small distribution I ine separating roost and feeding sites by $>3.5 \mathrm{~km}$ had the fewest birds $(11.1 \%)$ reacting at $<25 \mathrm{~m}$ : most showed no reaction. Additionally, $77.9 \%$ of $\mathrm{fl}$ ights cleared the top wire by $>6 \mathrm{~m}$.

It was apparent that cranes' maneuverability and control are Impaired by high winds; several near-colllsons were observed. Cameramen for EEI al so noted the detrimental ef fect of wind (EEI Crane Study, Unpubl. Rept.). Meaningful observations during fog and precipitation were difficult to obtain, because these conditions limited visibility for observers as well as birds.

Wild flushes were observed on two different occasions at Area 1. Both incidents resulted when a large group of cranes was disturbed by a farmer entering his adjacent fleld. Fifty-two ilights involving a total of over 700 individual s were recorded; 37 flights (71.2\%) reacted at $<25 \mathrm{~m} ; 4(7.7 \%)$ of these reacted at $<5 \mathrm{~m}$, and $30 \mathrm{flights}(55.7 \%)$ cleared the top wire by only 1-6 m. A third wild flush, during which four cranes struck the powerline, was filmed by EEl cameramen at Area 1.

\section{DISCUSSION}

Mortality Surveys and FI ight Observations

Our surveys provide an index rather than a true measure of powerline mortality in the valley. Because of the large number of powerlines, it was impossible to monitor every potential problem site. Further, unrecorded crippling loss probably adds significantly to strike mortality. Anderson (1978) and Faanes (1983 loc. cit.) estimated thelr searches accounted for only $58 \%$ and $26 \%$ of mortality, respectively.

Our results Indicate that cranes are more vul nerable to wire strikes than waterfowl, and whooping cranes more vul nerable than sandhills. This is undoubtedly related to the large size and low maneuverability of cranes, particularly whooping cranes. Thompson (1978) noted that large birds in flocks are especlally susceptible to collisons. However, some bias towards large species is probably inherent in mortality searches, because smaller birds are more readily removed by scavengers or simply overlooked. 


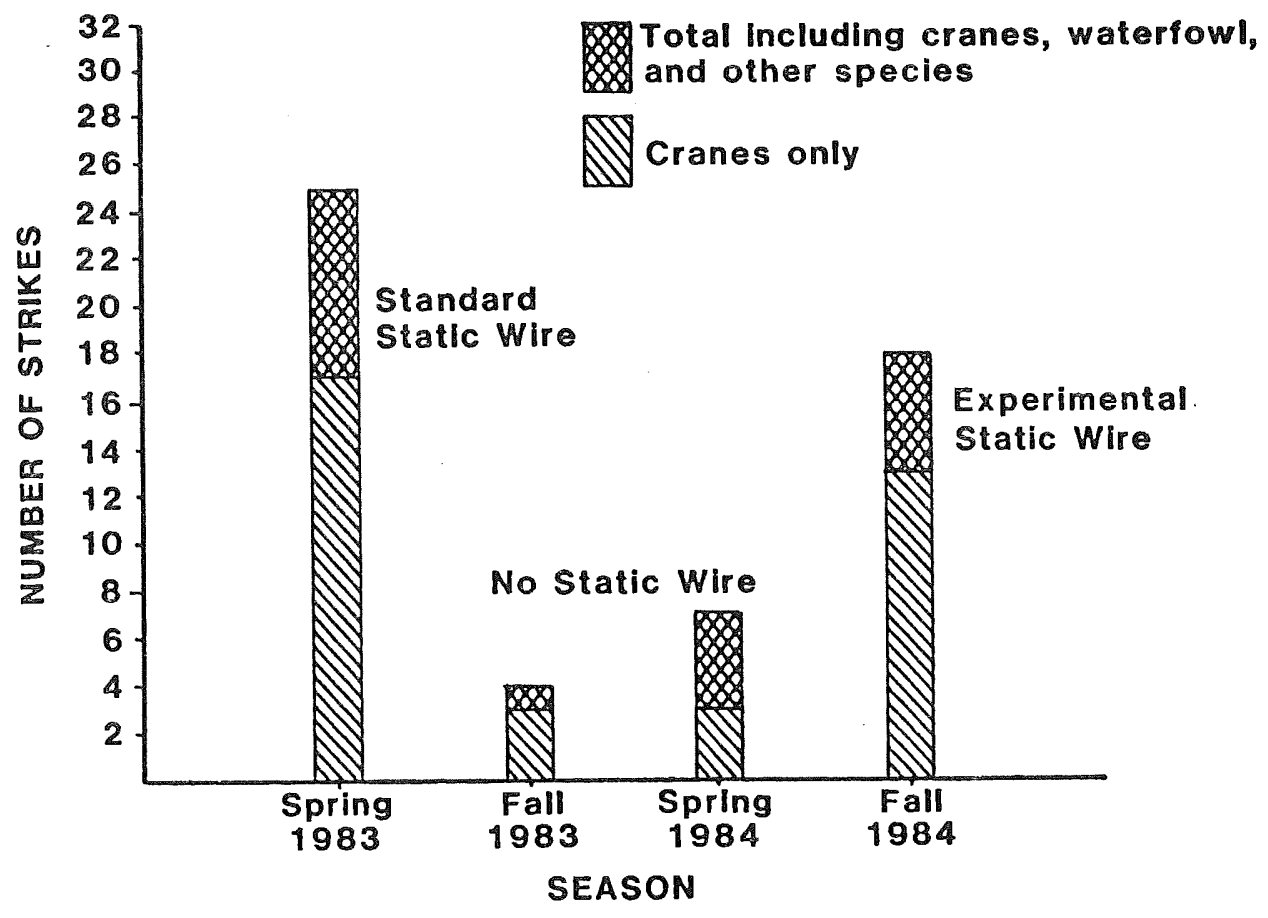

Fig 2. Number of bird strikes found beneath 13 spans of a $115 \mathrm{kV}$ transmission line with experimental static wire modification during spring and fall crane concentration perlods in the San Luls Valley, Col orado 1983-84.

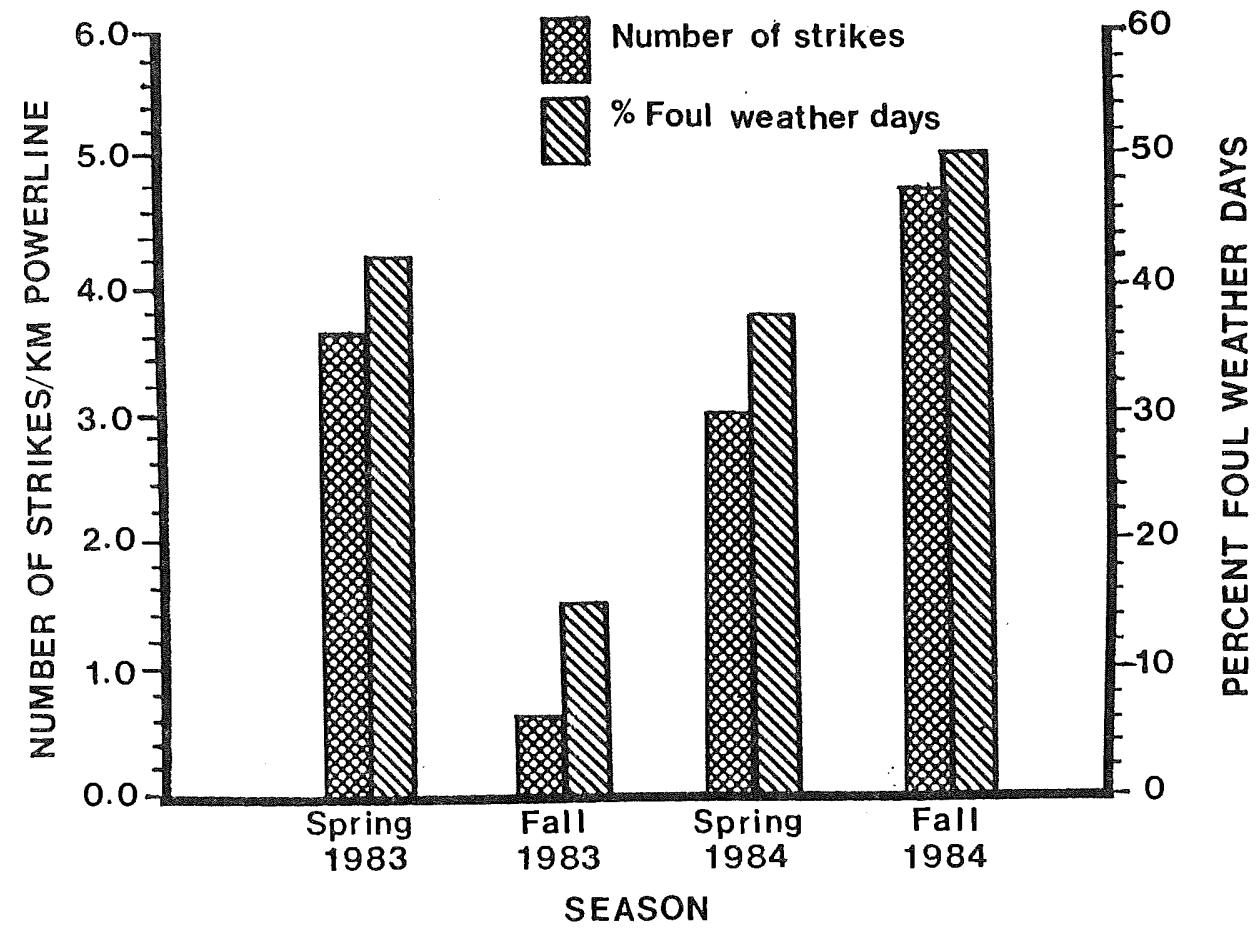

Fig. 3. Number of bird strikes found per kllometer of powerline and percent foul weather days during spring and fall crane concentration perlods in the San Luls Valley, Colorado 1983-84.

Proceedings 1985 Crane Workshop 
Table 2. Reaction distance and altitude above IIne exhibited by cranes at four powerline study sites.

Observation area and No. flights

power I ine

characteristics observed
Reaction distance ( $m$ ) and percent of observations

$<5 \quad 5-25 \quad 25-100 \quad>100$ or

Distance (m) above I Ine and percent of observations.

no reaction

\author{
$1115 \mathrm{kv}$ without \\ static wire \\ $2115 \mathrm{kv}$ with \\ static wire \\ $369 \mathrm{kv}$ \\ $47.2 \mathrm{kv}$ \\ distribution
}

\begin{tabular}{llllllllll}
463 & 0.9 & 44.9 & 41.7 & 12.5 & 0.2 & 0.0 & 6.5 & 39.3 & 54.0 \\
311 & 0.3 & 28.3 & 43.4 & 28.0 & 0.0 & 0.0 & 4.5 & 37.6 & 57.9 \\
353 & 0.0 & 27.2 & 46.2 & 26.6 & 0.0 & 0.0 & 2.6 & 42.2 & 55.2 \\
515 & 0.1 & 11.1 & 41.0 & 47.8 & 0.2 & 0.0 & 3.1 & 18.8 & 77.9 \\
\hline
\end{tabular}

Our results indicate that juvenile cranes strike powerlines more frequently than adults $(p<0.001)$. Young birds lack flight experlence and are no doubt less aglle; they also lack famlliarity with the area and its obstacles. Most researchers agree that these factors influence strike mortality (Thompson 1978). The proportion of juveniles in the cross-fostered whooping crane flock ranged from 35.7-59.4\% during 1983-84 surveys, a factor which probably contributed to the high mortality of this species.

Although the magnitude of mortality from powerlines is unlikely to affect thriving populations of sandhIII cranes and waterfowl in the valley, the Impact on endangered specles may be biologically signiflcant (Lee 1978, Thompson 1978, Faanes 1983 loc. cit.). In the circumstance of cross-fostered whooping cranes, high juvenile mortality from powerllne collisions impedes the buildup of a mature bird population necessary for intraspecies interaction and pair-bond formation.

Strikes occurred at both transmission and distrlbution I Ines, but were concentrated where transmission lines bordered heavy use areas. In equivalent locations, transmission I Ines are probably more hazardous than distribution I Ines because of their greater helght.

Proximity of powerlines to roost and feeding sites appears most critical. No strikes were found $>1.6 \mathrm{~km}$ from a roost or feeding slte; most strikes occurred where at least one of these two habitats was adjacent to the line. Bird flight observations demonstrated that reaction distance and altitude are most reduced where a powerline separates two closely adjacent use-areas. The frequency of collisions increases because bird concentrations are high in such areas and frequent low-level flights are made across the IIne. Faanes (1983 loc. clt.) al so found that interspersion of habitats at powerl ines was important to the magnitude of mortality.

Inclement weather was a primary factor Influencling the frequency of crane strikes at problem locations. The overall relationship between foul weather and strikes was highly slgniflcant ( $p<0.001)$ However, our sample size was Insufficlent to partition the individual effects of high winds, fog, or precipitation for statistical analysis.

The apparent increased vul nerabllity of cranes to wire collislons during inclement weather or poor visibility has been previously noted by Walkinshaw (1956), Wheeler (1966), Nesbitt and GIlbert (1976), and Tacha et al. (1978). Measures to Increase visibility of problem IInes are especially needed in the San Luis Valley, because adverse weather is common during crane-use periods. Increased strike mortality during inclement weather has been reported for other specles by Scott et al. (1972) and Lee (1978), however, researchers were unable to establ Ish a def initive relationship between fog and increased mortality of gulls and waterfowl in an Oregon powerline study (James, B. W., and B. A. Haak. 1979. Factors affecting avlan flight behavlor and collision mortallty at transmission lines. Unpubl. Rept., Bonneville Power Admin., Portl and).

Observations also indicated that strikes are likely to occur when birds are flushed near powerlines. Feeding sites in the valley are primarlly agrlcultural flelds with easy access by county roads, af for ding ample opportunity for human di sturbance.

Experimental Transmission Line 
Because of its location between adjacent, heavily used roost and feeding sites, the experimental line (Fig. 1) presents the greatest hazard of any powerl ine studied. However, results indicate that static wire removal significantly reduced mortality. Str ikes declined markedly after the static wire was removed from the experimental segment (13 spans) in fall 1983, and increased only slightly during the adverse weather of spring 1984. When four spans of static wire were replaced in fall 1984, the number of strikes in the experimental segment increased substantially. Furthermore, $67 \%$ of strikes in the experimental segment occurred under spans where static wire (standard and enlarged) was present, whereas, these spans constitued only $31 \%$ of the total experimental area. Similarly, a study in Oregon reported $35 \%$ and $69 \%$ reduction in avlan mortality after static wire removal at two sites (Beaurlaurier, D. L. 1981. Mitigation of bird collisions with transmission Il nes. Unpubl. Rept., Bonnevilie Power Admin., Portland). Faanes (1983 loc. cit.) estimated static wire removal could reduce strikes by $80 \%$ at one site in North Dakota.

Al though larger samples are needed for statistical evaluation, preliminary results obtained in fall 1984 suggest that the enlarged static wire was much less effective than static wire removal in preventing collisions. Because of the small sample size, it is impossible to analyze the difference in the number of strikes found beneath standard and enlarged static wire ( 4 and 8 birds, respectively), however, the results certainly suggest that the enlarged static wire represented no improvement.

These preliminary findlings do not support the hypothesis posed by Thompson (1978) and Faanes ( 1983 loc. cit.) that increasing the slze of static wire should reduce mortality. It may be that larger size alone does not sufficiently increase visibility under varlable light conditions. The dark, non-specular wire used in this study shows up well agalnst overcast skies, but is less visible on sunny days because it falls to reflect Ilght (Thompson 1978).

Color-marking the static wire may have more potential. Beaulaurier (1981 loc. cit.) summarlzed the results of 17 studies and found that marking powerlines with colored devices such as or ange avlation marker balls, black and white ribbons, and luminous tape reduced avian mortality by an average of $45 \%$. Similarly, installation of various yellow marking devices reduced powerline mortallty of red-crowned cranes (G. japonensis) by about $43 \%$ in Japan (from $60 \%$ of total deaths to 34\%, Yamaguchi, M. 1984, Letter to Chief, Endangered Species, Region 2. U. S. FIsh and Wildlife Service).

\section{RECOMMENDATIONS}

Construction of new transmission lines within $2 \mathrm{~km}$ of traditional roost or feeding sites should be avolded. Under no circumstances should new transmission or distribution lines divide adjacent, heavlly-used roost and feeding sites. New distribution Il nes needed In critical crane-use areas might be burled underground; this is technically feasible and in some situations less expensive than overhead construction (Thompson 1978).

Line modification or other measures to reduce mortality are needed where powerlines are already present in critical areas. Habitat modification to discourage crane use of hazardous areas seems unlikely on private lands. However, education of the local public regarding the danger of frightening birds near powerlines might reduce strikes caused by wild flushes. Static wire removal has been demonstrated to reduce mortallty in this and other studies and should be employed when possible. However, because statlc wire removal increases the probabllity of I ightening-caused power outages, other means of static wire modification should be explored. Comparative studies of the enlarged static wire with technically and economically feasible color marking devices are needed so that effective modification can be made at specific, critical areas where strikes perennially occur.

\section{LITERATURE CITED}

Anderson, W. L. 1978. Waterfowl collisions with power II nes at a coal-flred power plant. Wildi. Soc. Bull. 6:77-83.

Brown, W. M., R. C. Drewlen, and D. L. Walker. 1984. Crane flight behavlor and mortality associated with power I ines in the San Luis Valley, Colorado. For., Wildl., and Range Exper. Sta., Univ. Idaho, Moscow. 16 pp.

Cornwell, G., and H. A. Hochbaum. 1971. Collisions with wires--a source of anatid mortality.

Proceedings 1985 Crane Workshop 
Wil son Bull. 83:305-306.

Drewien, R. C. 1973. Ecology of Rocky Mountaln greater sandhill cranes. Ph. D. dissertation, Univ. Idaho, Moscow. 152 pp. , and E. G. Blzeau. 1974. Status and distribution of greater sandhill cranes in the Rocky Mountains. J. Will dl. Manage. 38:720-742. , and 1978. Cross-fostering whoopling cranes to sandhill crane foster parents. Pages 201-222 in S. A. Temple, ed. Endangered birds: management techniques for preserving threatened species. Univ. Wisconsin, Madison.

Kauffeld, J. S. 1981. Management of migratory crane habitat on Alamosa and Monte Vista National Wild ife Refuges. Pages 117-121 in J.C. Lew Is, ed. Proceedings 1981 crane workshop. Natl. Audubon Soc. Tavernier, Florida.

Krapu, G. L. 1974. Avian mortality from collislons with overhead wires in North Dakota. Prairie Nat. $6: 1-6$.

Lee, J. M. 1978. Effects of transmission I ines on bird flights: studies of Bonneville Power Administration Lines. Pages 93-116 in M. L. Avery, ed. Impacts of transmission IInes on birds in flight. U. S. FIsh and Wildl. Serv., Washington, D. C.

Malcom, J. M. 1982. Bird collisions with a power transmission line and thelr relation to botul ism at a Montana wetland. WII dl. Soc. Bull. 10:297-304.

Nesbitt, S. A., and D. T. Gllbert. 1976. Power Iline and fence hazards to birds. Fla. Nat. $29: 23$.

Scott, R. E., L. J. Roberts, and C. J. Cadbury. 1972. Bird deaths from powerlines at Dungeness. British Birds $65: 273-286$.

Stout, J., and Cornwell, G. W. 1976. Nonhunting mortality of fledged North American waterfowl. J. WII dl. Manage. 40:681-693.

Tacha, T. C., D. C. Martin, and C. G. Endicott. 1978. Mortality of sandhill cranes associated with utility highl Ines in Texas. Pages 175-176 in J. C. Lew is, ed. Proceedings $1978 \mathrm{crane}$ workshop. Natl. Audubon Soc., New York.

Thompson, L. S. 1978. Mitigation through engineering and habitat modification. Pages $51-92$ in M. L. Avery, ed. Impacts of transmission IInes on birds in fIlght. U. S. Fish and WIIdl. Serv., Wash ington. D. C.

Walkinshaw, L. H. 1956. Sandhill cranes killed by flying Into a powerline. Wilson Bull. 68:325-326.

Wheeler, R. H. 1966. Sandh III cranes casualties in the blizzard of March 2, 1966. Nebr. Bird Rev. 34:69-70.

Zar, J. H. 1974. Biostatistical analysis. Prentice-Hall, Inc. Englewood Cliffs, New Jersey 620 Pp. 


\section{Fish and Wildlife Technical Reports}

This publication series of the Fish and Wildlife Service comprises reports of investigations related to fish or wildlife. Each is published as a separate paper, but for economy several may be issued in a single cover. The Service distributes a limited number of these reports for the use of Federal and State agencies and cooperators. See inside back cover for a list of recent Fish and Wildlife Technical Reports.

Copies of this publication may be obtained from the Publications Unit, U.S. Fish and Wildlife Service, Matomic Building, Room 148, Washington, DC 20240, or may be purchased from the National Technical Information Service (NTIS), 5258 Port Royal Road, Springfield, VA 22161.

Library of Congress Cataloging-in-Publication Data

Faanes, Craig A.

Bird behavior and mortality in relation to power lines in prairie habitats.

(Fish and wildlife technical report ; no. 7)

Supt. of Docs. no.: I 49.100:8

1. Birds-North Dakota-Mortality. 2. Birds-North Dakota-Behavior. 3. Electric lines-Environmental aspects-North Dakota. 4. Prairie ecology-North Dakota. I. United States. Fish and Wildlife Service. II. Title. III. Series.

QL684.N9F33 $\quad 1987 \quad 598.25^{\prime} 222 \quad 87-600064$ 


\title{
Bird Behavior and Mortality in Relation
}

to Power Lines in Prairie Habitats

\author{
By Craig A. Faanes
}

UNITED STATES DEPARTMENT OF THE INTERIOR FISH AND WILDLIFE SERVICE Fish and Wildlife Technical Report 7 Washington, D.C. 1987 


\section{Contents}

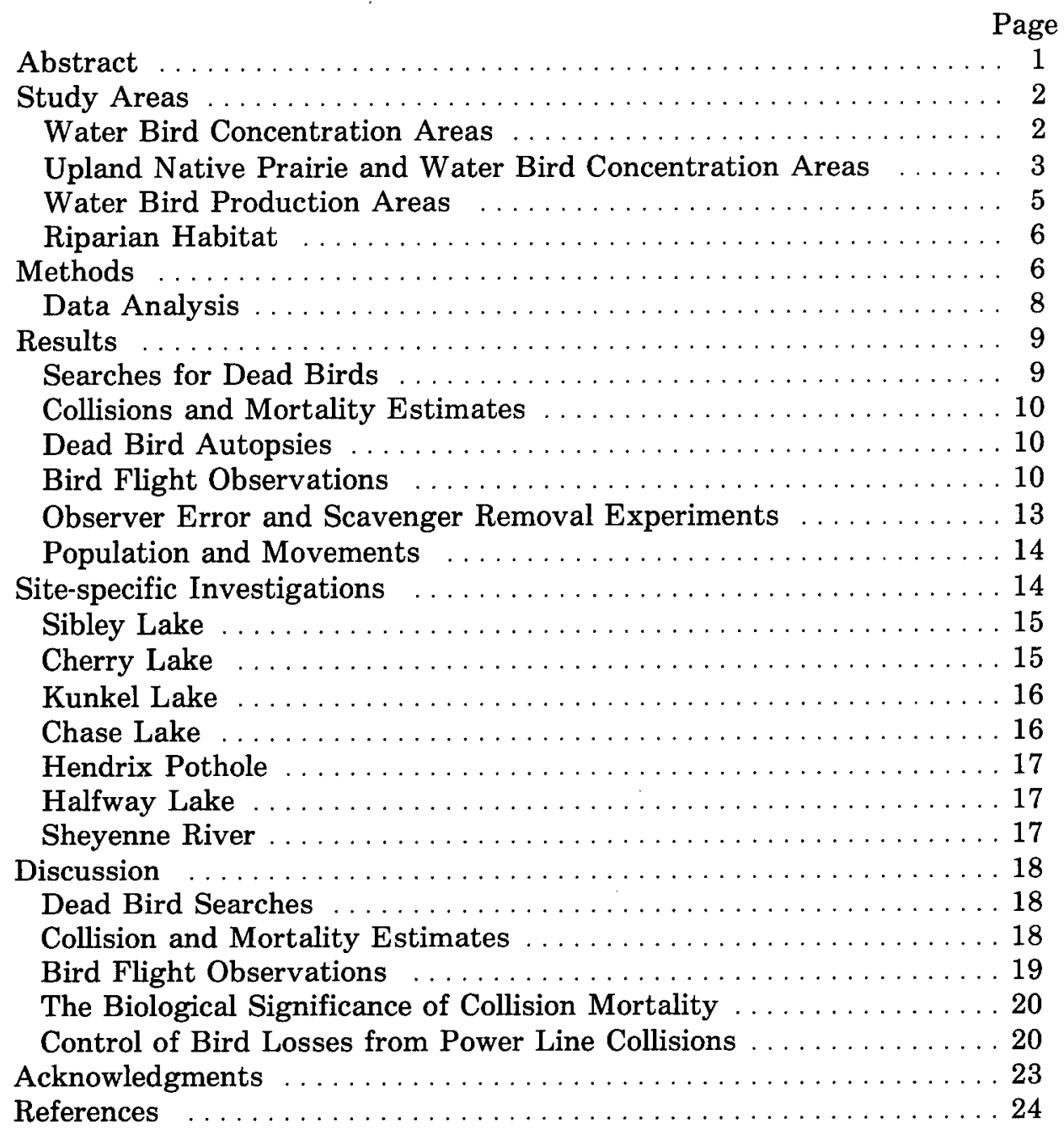




\title{
Bird Behavior and Mortality in Relation to Power Lines in Prairie Habitats
}

\author{
by \\ Craig A. Faanes \\ U.S. Fish and Wildlife Service \\ Northern Prairie Wildlife Research Center \\ Jamestown, North Dakota 58402
}

\begin{abstract}
Research was conducted to determine the magnitude of avian mortality caused by power transmission lines in prairie habitats during the two spring and two fall migration periods between July 1980 and May 1982 . Searches for dead birds were made at least twice weekly during each migration period. Study sites were selected to include "worst-case" situations involving potentially large concentrations of birds.

In total, 633 dead birds were found beneath $9.6 \mathrm{~km}$ of power lines. About $81 \%$ of the birds were found during fall migration. Removal of birds by scavengers was of minor, although local, importance, and observer error in finding birds was greatest in areas of dense vegetation. Total kill was estimated at 1,332 birds.

Data were gathered on more than 7,000 bird flights observed in the vicinity of the power lines. Sixty-eight percent of the birds did not respond to the presence of the power lines. Flaring and climbing over the conductor or overhead ground wire occurred in about $25 \%$ of the flights. One hundred nine birds in 82 flocks were observed to collide with a power line. Of these birds, $87 \%$ flared to climb over the power line before colliding. The overhead ground wire was responsible for most deaths, as 102 of 109 birds collided with it.

Whereas none of the mortality observed was considered to be biologically significant at the particular sites examined, the cumulative effect of mortality sustained from collisions with power lines may be important, particularly to populations of rare or endangered birds.
\end{abstract}

For most regions of the United States, no studies have examined the significance of wire strikes as a mortality factor in bird populations. Electric companies are concerned about the paucity of data on bird losses that may be occurring because of the increasing numbers of power lines. Although not considered a national problem
(Nagel 1978), bird collisions with electric transmission lines occur frequently and provided the impetus for this study. The need for additional information has increased with energy development in recent years, accompanied by construction of additional power lines transporting electricity to distant population centers. 
Available literature suggests that waterfowl casualties tend to be isolated events; additionally, losses of migrating passerines have been reported (Stout and Cornwell 1976). Poor light and inclement weather, particularly wind and fog, may increase the number of wire strikes (Krapu 1974; Stout and Cornwell 1976). Although occurrences of birds striking wires are common, most are unnoticed and unreported (Cornwell and Hochbaum 1971). Public awareness of the bird strike problem is diminished because most power lines are in remote areas, and dead birds are readily concealed by marsh and upland vegetation. Predators and scavengers frequently remove injured and dead birds from these areas, further reducing the apparent size of this loss.

Meyer (1978) and James and Haak (1979) reported that avian mortality from power line strikes in the Pacific Northwest was not biologically significant. Their research, however, pointed out that a measurable amount of mortality did occur, and methods were sought to reduce it (Beaulaurier 1981). Malcolm (1982) encountered

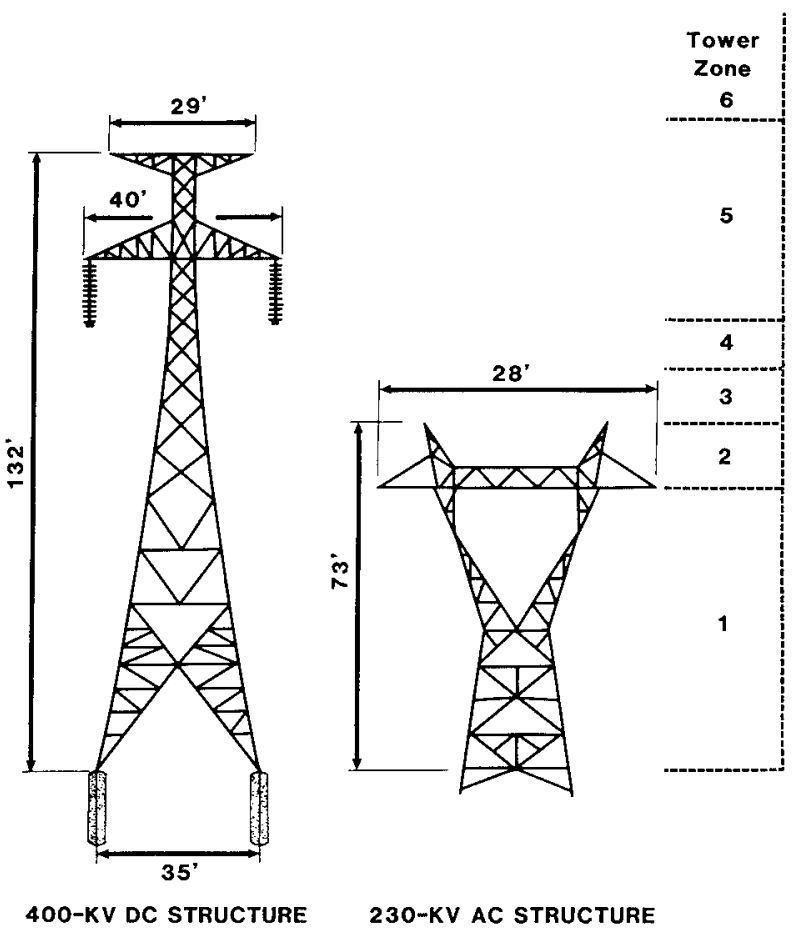

Fig. 1. Dimensions of typical support towers for 400and $230-\mathrm{kV}$ power transmission lines. Also shown are the tower zones used for recording bird behavior in flight. large numbers of wire-killed birds at a Montana wetland.

During 1980-82, I studied the effect of power transmission lines on bird populations in North Dakota. Study sites were selected to represent "worst-case" situations. My original impetus for this research was to determine if avian mortality was occurring along portions of power lines that crossed areas where large numbers of birds were present. Study sites represented the three major natural communities of the northern Great Plains region: grasslands, wetlands, and woodlands. My objectives were to (1) determine the magnitude of bird mortality caused by collisions with power lines at selected sites, and (2) identify factors contributing to this mortality. Support towers for the two types of lines $(400-\mathrm{kV} \mathrm{DC}$ and $230-\mathrm{kV} \mathrm{AC})$ studied are illustrated in Fig. 1.

Names of bird species used follow the American Ornithologist's Union checklist (A.O.U. 1983). Plant species names follow Stewart (1975).

\section{Study Areas}

\section{Water Bird Concentration Areas}

\section{Cherry Lake}

The Cherry Lake site is about $7 \mathrm{~km}$ northwest of Dawson, Kidder County, North Dakota (Fig. 2). About $1.9 \mathrm{~km}$ (five spans) of transmission line were studied (Fig. 3). The site was crossed by a singlecircuit $230-\mathrm{kV}$ AC line (three conductors) in a flat configuration suspended on self-supporting steel lattice towers (Fig. 1). One tower on span 1 was guyed.

Habitats associated with this site were predominantly heavily grazed upland native prairie, cropland (including wheat [Triticum vinter] and summer fallow), and emergent aquatic vegetation. Cherry Lake is a large class V (Stewart and Kantrud 1971) alkali wetland. Vegetation along the periphery of the lake was sparse because of the high salt content. Saltwater widgeongrass (Ruppia maritima) was the main submerged aquatic species. Numerous small fens (class VII in Stewart and Kantrud 1971) and several freshwater lakes occurred along the northern border of the lakes. Vegetation of these wetlands beneath the power line consisted of dense growths of hardstem bulrushes (Scirpus acutus) and cattail (Typha sp.). 


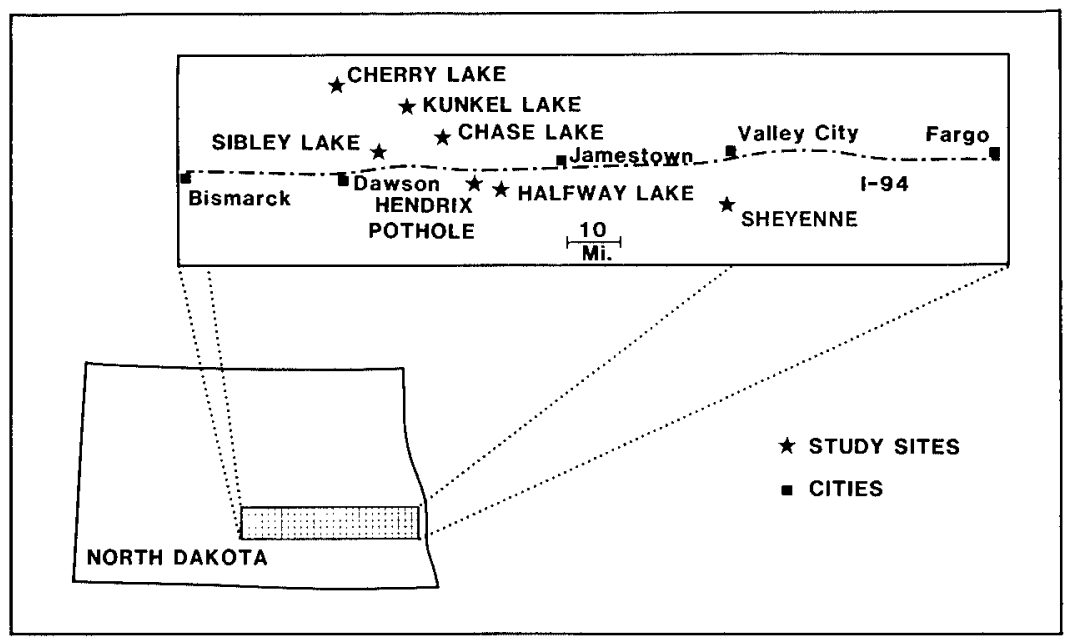

Fig. 2. Geographic location of the seven study sites in southcentral North Dakota.

Bird use of this site was characterized by concentrations of sandhill cranes (Grus canadensis) from late August to mid-October and large populations of various shorebirds from August to midSeptember. No concentrations of waterfowl were noted, except for occasional flocks of snow (Chen caerulescens) and Canada geese (Branta canadensis) in late October.

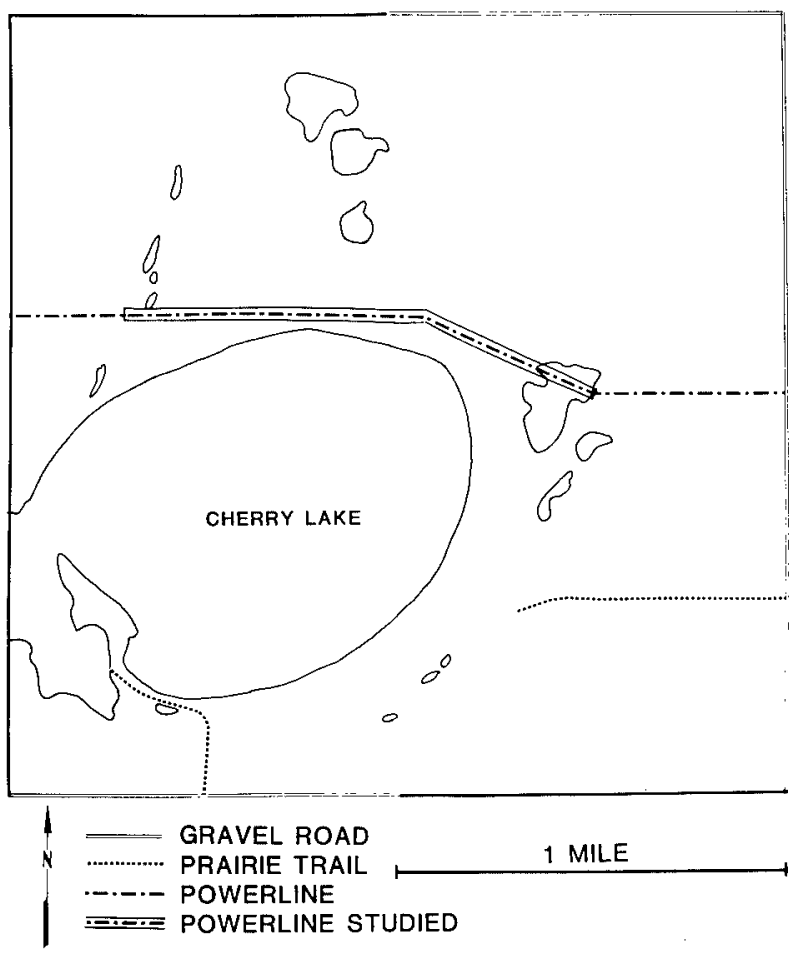

Fig. 3. Location of the power line corridor at the Cherry Lake study site.

\section{Kunkel Lake}

The Kunkel Lake site is about $10 \mathrm{~km}$ south of Lake Williams, Kidder County, North Dakota (Fig. 2). About $1.1 \mathrm{~km}$ (three spans) of line were studied (Fig. 4). The site was crossed by a singlecircuit 230-kV AC line (three conductors; Fig. 1).

Habitats associated with this site were predominantly cropland, heavily grazed upland native prairie, and emergent aquatic vegetation. Kunkel Lake is a large class V (Stewart and Kantrud 1971) wetland. Emergent vegetation is generally lacking along the periphery of most of the wetland. However, subsurface conditions are apparently less alkaline. A lush growth of cattails and hardstem bulrushes grew along the northern shoreline. The shoreline turned sharply northward along the northeastern corner of the wetland, and the emergent vegetation grew to within $50 \mathrm{~m}$ of a fresh (class IV) wetland. One span of the power line crossed the area of emergent vegetation.

Avian use of Kunkel Lake was characterized by concentrations of Franklin's gulls (Larus pipixcan) during August and early September, and sandhill cranes and Canada geese during late September through October. Moderate numbers of other waterfowl and shorebirds occurred throughout the study period.

\section{Upland Native Prairie and Water Bird Concentration Areas}

\section{Chase Lake National Wildlife Refuge}

The Chase Lake National Wildlife Refuge site is about $20 \mathrm{~km}$ southwest of Woodworth, Stuts- 
man County, North Dakota (Fig. 1). About $1.8 \mathrm{~km}$ (five spans) of line were studied (Fig. 5). The site was crossed by a single-circuit $230-\mathrm{kV}$ AC line (three conductors; Fig. 1).

Habitats associated with this site consisted of mixed-grass native prairie and various introduced grass species. The power line crossed within $0.4 \mathrm{~km}$ of Chase Lake, a large class V wetland. The refuge is used by a large breeding colony of American white pelicans (Pelecanus erythrorhynchos) and other water birds. Because of the proximity of the lake to the power line corridor, Chase Lake served as a study site for both native upland prairie and water bird concentration areas.

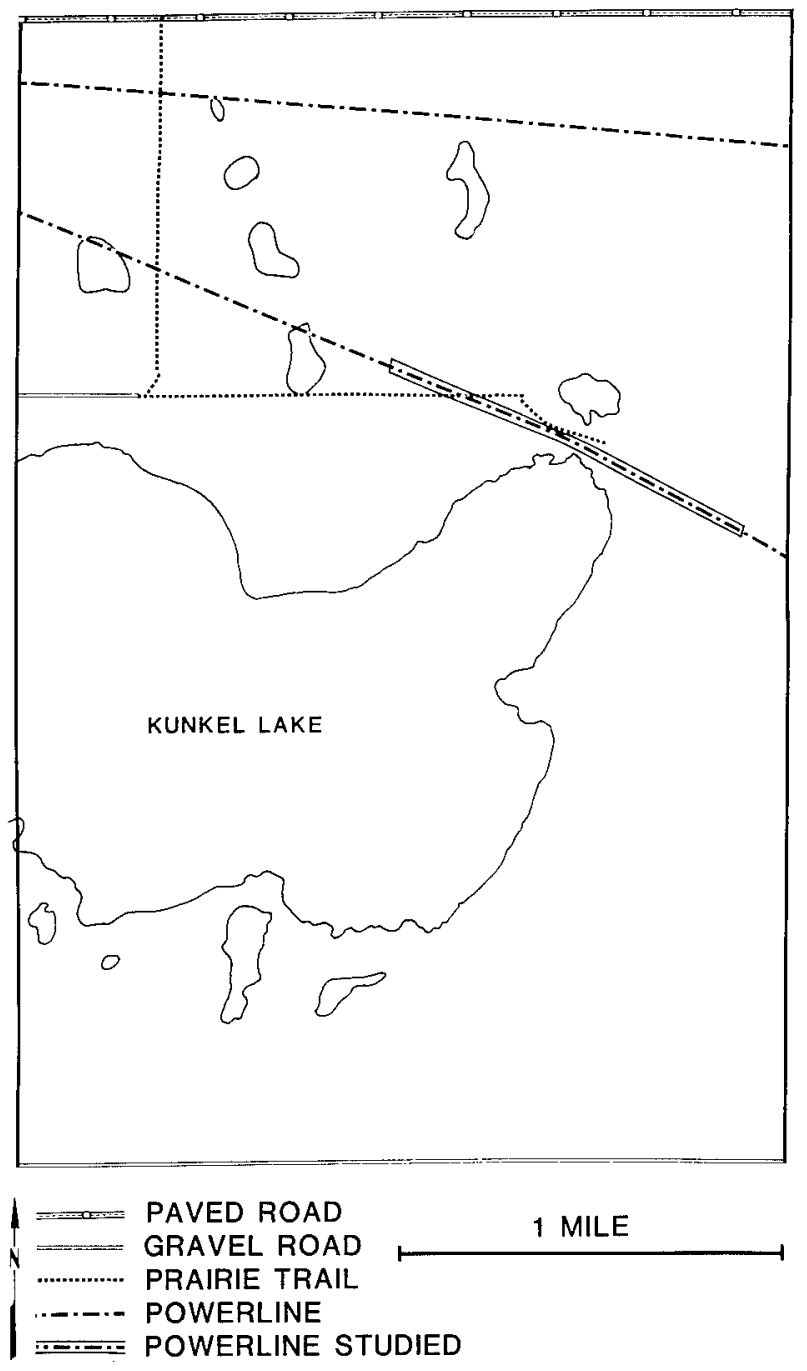

Fig. 4. Location of the power line corridor at the Kunkel Lake study site.
The Chase Lake site supported a varied avifauna in relation to the diversity of available habitats. Particularly prominent in the grasslands were western meadowlarks (Sturnella neglecta), grasshopper sparrows (Ammodramus savannarum), and eastern kingbirds (Tyrannus tyrannus). The lake supported populations of pelicans, California gulls (Larus californicus), double-crested cormorants (Phalacrocorax auritus), and American avocets (Recurvirostra americana) during and immediately following the breeding season. During spring and fall migration periods, use of grasslands by passerines was relatively low. The lake, however, received heavy use by colonial nesting water birds, shorebirds, and waterfowl.

\section{Sibley Lake}

The Sibley Lake site is about $6.5 \mathrm{~km}$ north of Dawson, Kidder County, North Dakota (Fig. 1). About $1.8 \mathrm{~km}$ (five spans) of line were studied (Fig. 6). The site was crossed by a bipolar $400-\mathrm{kV}$ $\mathrm{DC}$ line (four conductors in two bundles) in a flat configuration suspended on self-supporting steel lattice towers (Fig. 1).

The principal habitat at the site was heavily grazed native prairie. Adjacent lands near the site were predominantly used for wheat or summer fallow. A large class V wetland (Stewart and Kantrud 1971) occurred within $0.8 \mathrm{~km}$ of the study site. Populations of migrant Canada geese, sandhill cranes, and double-crested cormorants used Sibley Lake and adjoining fields and wetlands in fall. Because of the proximity of the wetland to the power line, Sibley Lake was considered a study site for both upland prairie and water bird concentration areas.

Grazing of the native grassland reduced its attractiveness to many typical grassland nesting species, although horned larks (Eremophila alpestris) and chestnut-collared longspurs (Calcarius ornatus) were present. Sibley Lake has been known to support unusually large numbers of migrant water birds in past years. In late September 1979, about 15,000 redheads (Aythya americana), 5,000 snow and Canada geese, and sandhill cranes were present. Use of the lake by migrant water birds during the study varied with water conditions. In fall 1981, large numbers of birds were attracted to the exposed shorelines, which were extensively used as roost sites. 


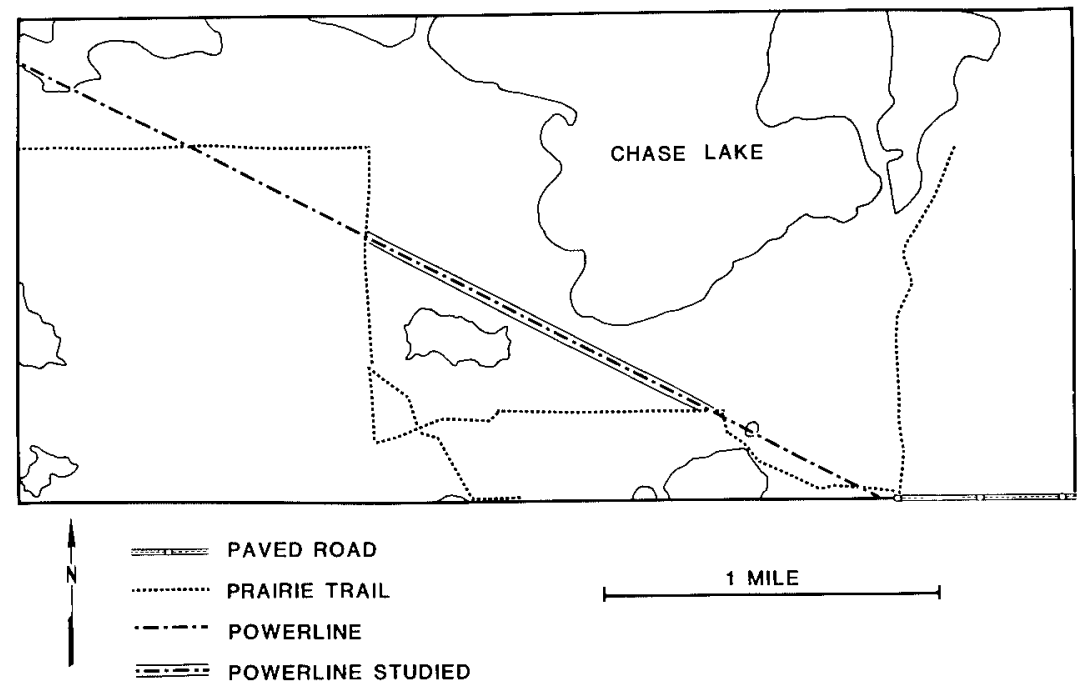

Fig. 5. Location of the power line corridor at the Chase Lake study site.
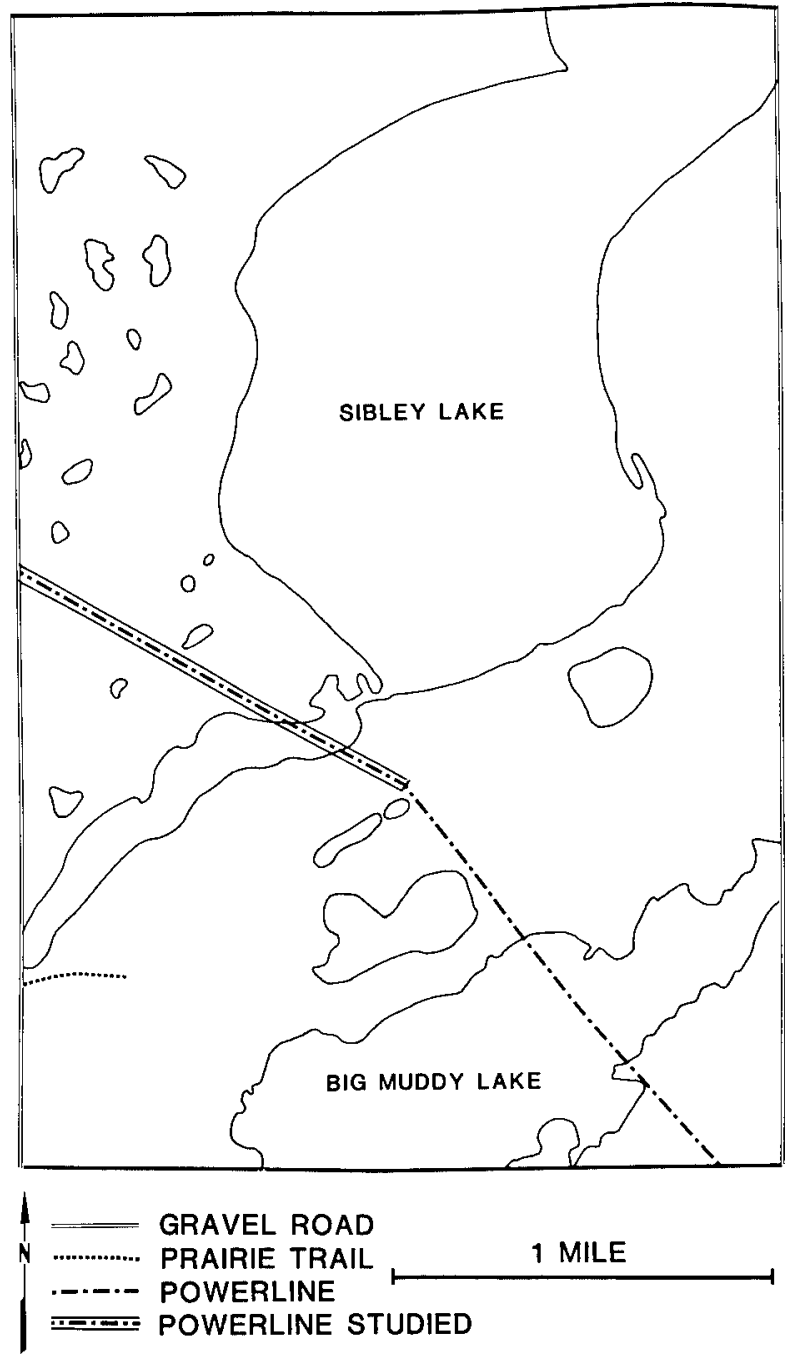

Fig. 6. Location of the power line corridor at the Sibley Lake study site.

\section{Water Bird Production Areas}

\section{Halfway Lake}

The Halfway Lake site is about $8 \mathrm{~km}$ east of Medina, Stutsman County, North Dakota (Fig. 1). About $1.2 \mathrm{~km}$ (five spans) of line were studied (Fig. 7). The site was crossed by a single-circuit 230-kV AC line (three conductors; Fig. 1).

The primary habitat associated with this site was moderately grazed native prairie. Interspersed throughout this pasture were nine class III wetlands which held water throughout late summer and fall. Emergent vegetation in these wetlands consisted of cattails, bulrushes, and sedges.

Avian use of the wetlands during the study was limited, primarily because of the fresh conditions of the water. Blue-winged teal (Anas discors) and mallards ( $A$. platyrhynchos) were the most frequently encountered species. Each year occasional mixed foraging flocks of red-winged blackbirds (Agelaius phoeniceus) and yellow-headed blackbirds (Xanthocephalus xanthocephalus) were observed in September and early October.

\section{Hendrix Pothole}

The Hendrix Pothole site is about $3 \mathrm{~km}$ southwest of Cleveland, Stutsman County, North Dakota (Fig. 1). About $0.7 \mathrm{~km}$ (12 spans) of line were studied (Fig. 8). This site consisted of one class IV wetland bordered on the west by a gravel road, and surrounded on the north, east, and south by a single-strand $12-\mathrm{kV}$ distribution line supported by single wood poles. 


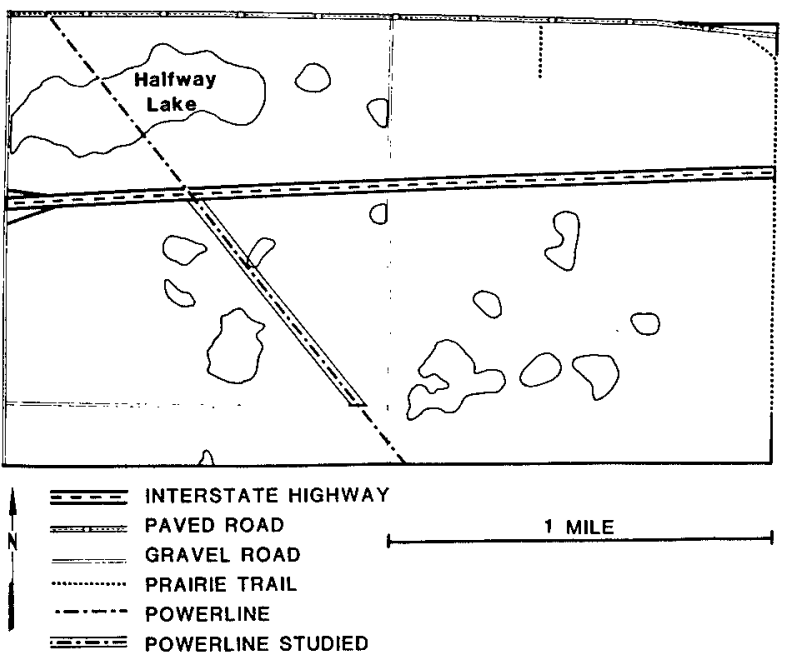

Fig. 7. Location of the power line corridor at the Halfway Lake study site.

Habitats of the study area were predominantly wheat fields that occupied the uplands adjacent to the wetland. Wetland vegetation consisted of cattails around the periphery of the wetland and various submerged aquatic species in the marsh center.

Avian use of this site was dominated by waterfowl (particularly mallards, northern pintails [Anas acuta], and blue-winged teal), American coots (Fulica americana), and mixed flocks of red-winged

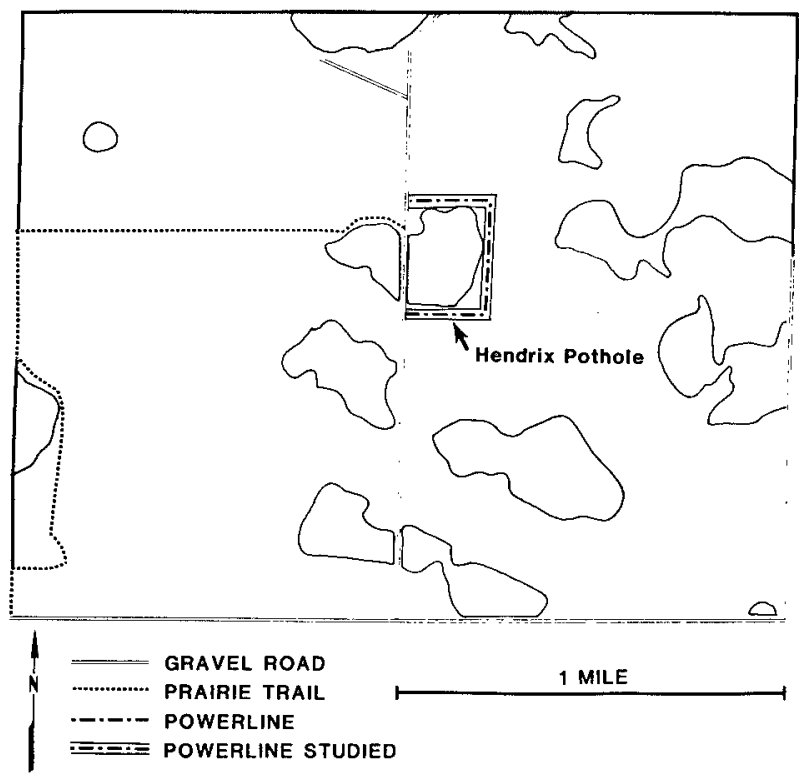

Fig. 8. Location of the power line corridor at the Hendrix Pothole study site. blackbirds and yellow-headed blackbirds. Occasional use was made by pied-billed (Podilymbus podiceps) and eared grebes (Podiceps nigricollis) and California gulls during September.

\section{Riparian Habitat}

\section{Sheyenne River}

The Sheyenne River site is about $14 \mathrm{~km}$ south of Valley City, Barnes County, North Dakota (Fig. 1). About $1.1 \mathrm{~km}$ (four spans) of line were studied (Fig. 9). The site was crossed by a singlecircuit 230-kV AC line (three conductors; Fig. 1).

Habitats associated with this site included a wheat field and ungrazed floodplain forest characterized by American elm (Ulmus americana), box elder (Acer negundo), and green ash (Fraxinus pennsylvanica). The corridor occupied by the power line crossing was made up of numerous patches of western snowberry (Symphoricarpos occidentalis) and shrub-sized box elder.

Passerine birds characterized this site including American robins (Turdus migratorius), blackcapped chickadees (Parus atricapillus), whitebreasted nuthatches (Sitta carolinensis), red-eyed vireos (Vireo olivaceus), common yellowthroats (Geothlypis trichas), and clay-colored sparrows (Spizella pallida). The riparian habitat was used by various passerines during migration. Foraging flocks of mixed species of blackbirds were also encountered.

\section{Methods}

Most study sites were searched for dead birds twice weekly during spring and fall. Study periods included July-November 1980, April-May 1981, 1982, and August-November 1981. Bird use of Hendrix Pothole and Halfway Lake was limited; therefore, these sites were searched only once weekly. Portions of the upland along each study segment were searched by two observers walking in a zigzag pattern under one side of the line and returning under the adjacent areas. After initial investigations revealed that dead birds were being removed by scavengers, the Kunkel Lake site was searched three times weekly in fall.

Search areas consisted of the right-of-ways between spans and portions of adjacent land. 


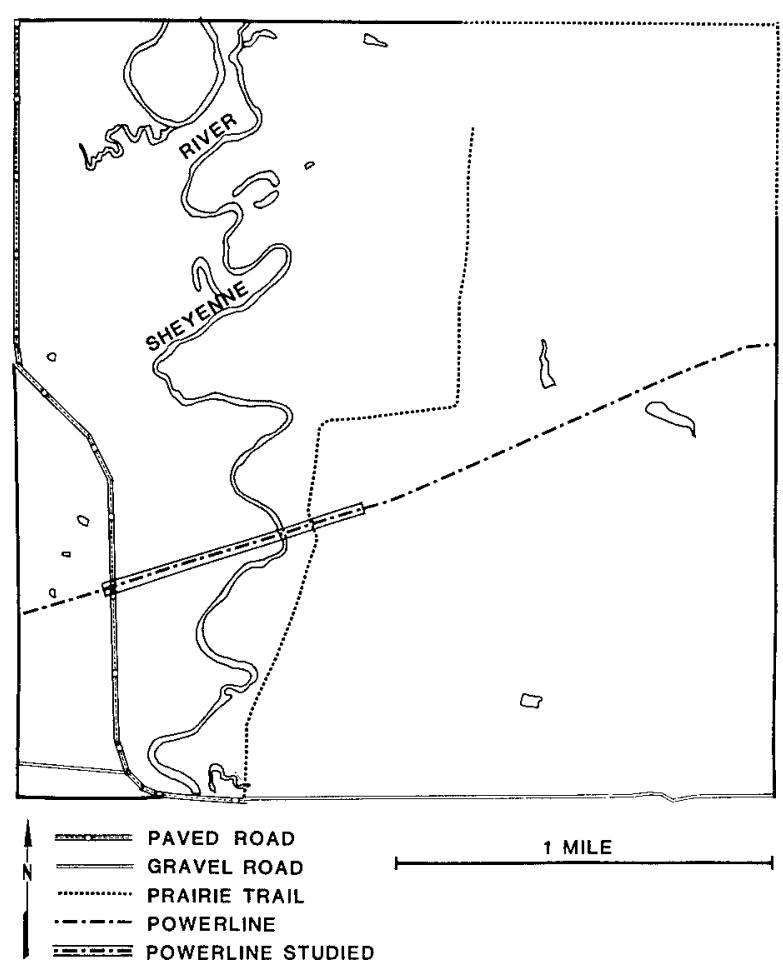

Fig. 9. Location of the power line corridor at the Sheyenne River study site.

Lengths of search areas varied from 0.7 to $1.9 \mathrm{~km}$. Search widths were dependent on the line heights because higher power lines caused birds to fall farther from the center line. On power lines $\geq 230 \mathrm{kV}$, search widths were $45 \mathrm{~m}$ from the edge of the center conductors. At Hendrix Pothole, the search width was $15 \mathrm{~km}$ from the center line.

Searches for dead birds were conducted as early in the day as possible to reduce the number of birds lost to scavengers. Two study sites were searched each day, generally between sunrise and $1000 \mathrm{~h}$. Search times were alternated so each site was visited at dawn at least once weekly. The location of each dead bird or feather spot (a group of feathers remaining after scavenging or decomposition) found was marked on a map of each study site. Dead birds and feather spots were collected and removed from the area during each search.

All birds found dead or injured under the lines were examined to determine the probable cause of death or injury. The following data were recorded for each dead bird found: species, sex, age, physical condition (broken bones, lacerations, abra- sions), and other observable signs of death, including gunshot wounds.

To estimate the amount of loss to scavengers, we placed a known number of dead birds under the wires at each site during each season. Birds of various species were used to simulate actual mortality caused by the power lines. The marked birds were monitored two or three times weekly to determine their rate of disappearance. Radio transmitters were attached to dead and injured sandhill cranes and Franklin's gulls during fall 1981 to monitor their removal by scavengers.

Observer error in searches for dead birds was examined by having another person place a known number of dead birds beneath each search line at each site. The principal investigators walked the searched area and recorded the number of placed birds they found. A comparison of the number of marked birds found with the number placed provided a basis for determining observer error.

The number of live birds present at each study site was estimated before each search. In upland study sites, bird populations were estimated by recording the number of birds on two plots in each habitat type. Surveys of water birds were made by estimating the number present before each search. Avian numbers were not determined with standardized sampling techniques, nor were the data gathered daily throughout the study periods. The data provided relative population indices that cannot be used to determine bird mortality rates at power lines. Throughout the test, values for populations by time period are the mean values combined between years for those periods.

Data were gathered to determine bird movements, flight intensities, behavior, and reactions to power lines within each study area. Nocturnal observations were conducted during fall 1980 but were discontinued because few birds were observed at night. Primarily, we determined the number of birds passing above, beneath, and through the power lines. Observations were made during early morning $(0.5 \mathrm{~h}$ before sunrise to $0900 \mathrm{~h})$ and evening $(2 \mathrm{~h}$ before sunset to $0.5 \mathrm{~h}$ after).

Data collected for each flight of birds observed included flight altitude, reaction of the bird(s) to the presence of the ground wire or conductor, the distance from the power line when the bird flock reacted to the presence of the ground wire or conductor, and the altitude maintained by the bird(s) 
after crossing the exit zone. The exit zone was that portion of airspace from the ground wire or conductor out $15 \mathrm{~m}$.

The following data were gathered for each flight of birds approaching the power lines: time, flock size, species or type of bird, approach height, crossing height, and exit height. Height above ground was divided into six categories (Fig. 1): Zone 1-ground level to the base of the conductors; Zone 2 -area between conductor and ground wire; Zone 3 -top of the ground wire to $3 \mathrm{~m}$; Zone $4-3-8 \mathrm{~m}$ above ground wire; Zone 5-8-15 $\mathrm{m}$ above ground wire; and Zone $6->15 \mathrm{~m}$ above ground wire.

Reactions exhibited by birds in flight were placed in eight categories: (1) no reaction, maintained constant altitude and unaltered flight; (2) flared and crossed higher than original altitude; (3) flared and continued to climb after crossing into the exit zone; (4) aborted flight upon seeing power line, reversed flight, and continued flying away from power line (usually occurred at least $50 \mathrm{~m}$ from the power line); (5) turned and left area (usually occurred more than $50 \mathrm{~m}$ of the power line); (6) flared from power line and left area (usually occurred within $50 \mathrm{~m}$ of the power line); (7) crossed and then recrossed the power line; and (8) landed and sat on the ground wire or conductor.

\section{Data Analysis}

All field data collected during this investigation were recorded on field sheets, and then entered into a computer system for later analysis. Various bias and expansion factors were calculated for each study site by totaling values for each year and obtaining mean values for each variable. Included in this effort were calculations of the number of dead birds not recorded because of observer error, scavenger removal, habitat, and crippling loss. The formulas for these factors (adapted with one minor correction) are from Beaulaurier (1981).

Search bias was a measure of observer error in finding dead birds at the power line sites. The formula for calculating search bias was

$$
\mathrm{SB}=\frac{\mathrm{TDBF}}{\mathrm{PBF}}-\mathrm{TDBF}
$$

where

$$
\mathrm{SB}=\text { search bias }
$$

TDBF $=$ the total number of dead birds and feather spots found at each site during the study

$\mathrm{PBF}=$ the proportion of birds found of those placed during observer error experiments

Scavenger removal was calculated with the assumption, based on field studies, that $10 \%$ of the birds planted for removal studies were removed before the search. Removal bias was calculated by

$$
\mathrm{SR}=\frac{\mathrm{TDBF}+\mathrm{SB}}{\mathrm{PNR}}-(\mathrm{TDBF}+\mathrm{SB})
$$

where

$$
\begin{aligned}
\mathrm{SR}= & \text { scavenger removal } \\
\mathrm{PNR}= & \text { the proportion of planted birds not } \\
& \text { removed by scavengers (this number } \\
& \text { was assumed constant at } 0.9 \text { for each } \\
& \text { site) }
\end{aligned}
$$

A habitat expansion factor was calculated to account for differential search abilities resulting from the degree of vegetation cover. Habitat bias was calculated by

$$
\mathrm{HF}=\frac{\mathrm{TDBF}+\mathrm{SB}+\mathrm{SR}}{\mathrm{PS}}-(\mathrm{TDBF}+\mathrm{SB}+\mathrm{SR})
$$

where

$$
\begin{aligned}
\mathrm{HF}= & \text { habitat expansion factor } \\
\mathrm{PS}= & \text { the proportion of the study area that } \\
& \text { was searchable }
\end{aligned}
$$

Crippling bias was a measure of the number of birds that struck a power line, but continued flying out of the search area. This statistic was calculated by assuming that $74 \%$ of the birds that hit a power line continued flying out of the area. This figure is the average of values recorded by Meyer (1978) and James and Haak (1979), and reported by Beaulaurier (1981).

The estimated total collisions for each site equal the sum of the number of dead birds found plus the bias estimates:

$$
\mathrm{ETC}=\frac{\mathrm{TDBF}+\mathrm{SB}+\mathrm{SR}+\mathrm{HF}}{1-\mathrm{CB}}
$$


where

$$
\begin{aligned}
\mathrm{CB} & =\text { crippling bias } \\
\mathrm{ETC} & =\text { estimated total collisions }
\end{aligned}
$$

\section{Results}

\section{Searches for Dead Birds}

Six hundred thirty-three dead birds were found beneath the power line study sites. The seasonal breakdown included 122 in spring and 511 in fall. The number of dead birds was greatest at Sibley Lake where 205 were found, representing $32 \%$ of the total observed mortality. The 164 birds found at Kunkel Lake formed about $26 \%$ of total mortality. The combined total for the four water bird concentration areas was 596 birds, or $94 \%$ of the total. These percentages were consistent between years. Avian mortality at the water bird production wetlands totaled 20 birds ( $3 \%$ ), and 17 birds $(3 \%)$ were found at the wooded river valley site.

Waterfowl made up $26 \%$ of total mortality, $24 \%$ of fall mortality, and $38 \%$ of spring mortality (Table 1). Gulls made up the second highest mortality among bird groups, with $23 \%$ of the total.
The Franklin's gull accounted for most gull mortality. Dead Franklin's gulls were commonly found beneath the power lines during fall migration, but seldom in spring, as Franklin's gulls gathered in large flocks only during fall migration. Similarly, most of the sandhill crane mortality occurred during fall migration (93\%), reflecting the tendency of sandhill cranes to form large aggregations in central North Dakota only during fall migration; they are, however, uncommon in spring. The largest number of dead sandhill cranes was found at Sibley and Kunkel lakes.

Comparison of mortality and bird populations during 10-day periods in fall (Fig. 10) revealed that peak mortality was consistent with peak numbers of birds present. This finding suggests that periods when high mortality from power lines occur may be predictable.

Physical evidence of collision with a solid object was found in $74 \%$ of the dead birds. Cause of death for the remaining 164 birds was unknown. No mortality from gunshots was evident. Typical injuries included broken wings, broken legs, lacerations, puncture wounds, and abrasions. Faanes (unpublished report) provided a description of internal and external wounds exhibited on dead birds during the 1980 field season. Fresh kills (i.e., those

Table 1. Total dead birds found, by major avian groups and seasons, at seven study sites in North Dakota, $1980-82$.

\begin{tabular}{lrrrrrr}
\hline & \multicolumn{7}{c}{ No. dead birds found } \\
\cline { 2 - 7 } Group & Spring & $(\%)$ & Fall & $(\%)$ & Total & $(\%)$ \\
\hline Waterfowl & 46 & $(37.7)$ & 120 & $(23.6)$ & 166 & $(26.2)$ \\
Gulls & 14 & $(11.5)$ & 129 & $(25.3)$ & 143 & $(22.6)$ \\
Cranes & 4 & $(3.3)$ & 58 & $(11.2)$ & 62 & $(9.8)$ \\
Shorebirds & 9 & $(7.4)$ & 43 & $(8.4)$ & 52 & $(8.2)$ \\
Rails and coots & 11 & $(9.0)$ & 35 & $(6.9)$ & 46 & $(7.3)$ \\
Cormorants & 0 & & 40 & $(7.8)$ & 40 & $(6.3)$ \\
Other passerines & 14 & $(11.5)$ & 16 & $(3.1)$ & 30 & $(4.7)$ \\
Blackbirds & 8 & $(6.6)$ & 18 & $(3.5)$ & 26 & $(4.1)$ \\
Grebes & 4 & $(3.3)$ & 8 & $(1.6)$ & 12 & $(1.9)$ \\
Unknown & 0 & & 11 & $(2.2)$ & 11 & $(1.7)$ \\
Grouse & 4 & $(3.3)$ & 7 & $(1.4)$ & 11 & $(1.7)$ \\
Pelicans & 0 & & 10 & $(2.0)$ & 10 & $(1.6)$ \\
Raptors & 2 & $(1.6)$ & 8 & $(1.6)$ & 10 & $(1.6)$ \\
Doves & 5 & $(4.1)$ & 3 & $(0.4)$ & 8 & $(1.3)$ \\
Herons & 0 & & 3 & $(0.4)$ & 3 & $(0.5)$ \\
Woodpeckers & 1 & $(0.8)$ & 2 & $(0.4)$ & 3 & $(0.5)$ \\
Total & 122 & & 511 & & 633 & $(100.0)$ \\
\hline
\end{tabular}




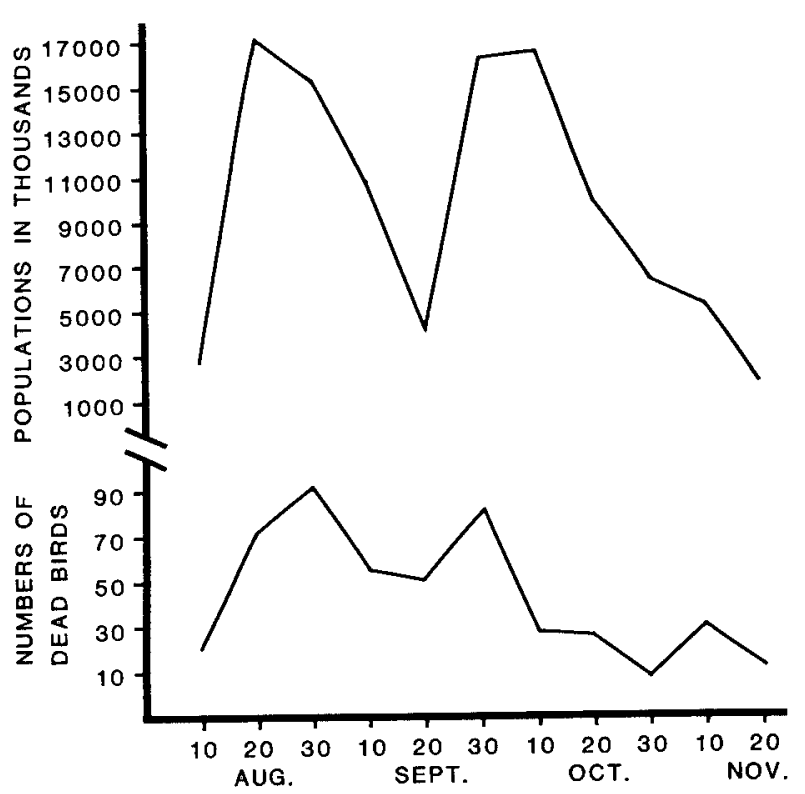

Fig. 10. Relations between avian numbers at study sites and observed mortality during fall migration.

found within 3 days of death) were most numerous, totaling 412 , or $65 \%$ (Table 2). Bird mortality as indicated by feather spots totaled $135(21 \%)$. Birds in various stages of decomposition totaled 57 , including 27 birds with only wings remaining, and two with only the head remaining.

\section{Collision and Mortality Estimates}

Mortality data for each site and season were pooled among years. These data were then subjected to several bias estimates to provide esti-

Table 2. Physical condition of dead birds found beneath power line study sites in North Dakota, 1980-82.

\begin{tabular}{lrrrr}
\hline & \multicolumn{4}{c}{ No. dead birds found } \\
\cline { 2 - 5 } Condition & Spring & Fall & Total & $(\%)$ \\
\hline Fresh & 76 & 336 & 412 & $(65.0)$ \\
Feather spot & 32 & 103 & 135 & $(21.4)$ \\
Wing only remaining & 4 & 23 & 27 & $(4.3)$ \\
Head only remaining & 0 & 2 & 2 & $(0.3)$ \\
Decomposition beginning & 10 & 47 & 57 & $(9.0)$ \\
Total & 122 & 511 & 633 & $(100.0)$ \\
\hline
\end{tabular}

mated total kills and estimated number of collisions with a power line (Table 3); total estimated mortality was 1,332 birds. Highest mortality occurred at Cherry Lake where $29 \%$ of the dead birds were found. Kunkel Lake made up $26 \%$ of the estimated mortality and collisions, and Sibley Lake made up nearly $23 \%$ of this total.

Overall percentages of total mortality at study sites changed little throughout the study. The large water bird concentration areas accounted for $92 \%$ of the estimated kills and collisions, and water bird production wetlands and the wooded river valley site each made up $4 \%$ of the total.

\section{Dead Bird Necropsies}

To verify the accuracy of field diagnosis, 11 birds found beneath the power line study sites in 1980 were submitted to the National Wildlife Health Laboratory, Madison, Wisconsin, for necropsy. These individuals were selected to reflect differences in size and also different study sites. Birds in this sample included four ducks, two shorebirds, one gull, one coot, one grebe, one cormorant, and one sparrow. Ten of the 11 birds were of sufficient size to necropsy. All 10 birds were diagnosed as having died from trauma caused by striking some solid object. The most frequently mentioned cause of death was massive or extensive hemorrhage in the thoracic cavity. An injury of this type probably results from colliding with a solid object, rather than from falling to the ground (G. L. Pearson, D.V.M., personal communication).

All birds found in subsequent years were examined in the field to determine the extent and type of external injury. No evidence was found to suggest that injuries were resulting from causes other than collisions with a solid object. Hunter activity at the study sites was practically nonexistent during our observations, and no birds had gunshot wounds.

\section{Bird Flight Observations}

Data were collected on 7,596 bird flights. A bird flight consisted of one or more birds physically independent from others, flying through the power line corridor. The most numerous birds observed were Franklin's gulls, sandhill cranes, red-winged blackbirds, yellow-headed blackbirds, and several 
Table 3. Estimates of total mortality and total collision with power lines at seven study sites in North Dakota, 1980-82.

\begin{tabular}{lccccc}
\hline Site & $\begin{array}{c}\text { Line span } \\
(\mathrm{km})\end{array}$ & $\begin{array}{c}\text { Line type } \\
(\mathrm{kV})\end{array}$ & $\begin{array}{c}\text { Observed } \\
\text { mortality }\end{array}$ & $\begin{array}{c}\text { Estimated } \\
\text { dead birds }\end{array}$ & $\begin{array}{c}\text { Estimated total } \\
\text { collisions }\end{array}$ \\
\hline Cherry Lake & 1.9 & 230 & 129 & 388 & 1,488 \\
Kunkel Lake & 1.1 & 230 & 164 & 353 & 1,357 \\
Sibley Lake & 1.8 & 400 & 205 & 297 & 1,142 \\
Chase Lake & 1.8 & 230 & 98 & 192 & 738 \\
Sheyenne River & 1.1 & 230 & 17 & 46 & 177 \\
Halfway Lake & 1.2 & 230 & 10 & 29 & 108 \\
Hendrix Pothole & 0.7 & 12 & 10 & 28 & 108 \\
Total & 9.6 & - & 633 & 1,332 & 5,118 \\
\hline
\end{tabular}

waterfowl species. During spring migration, the largest number of flights at all sites was recorded in mid-April, with a secondary peak during the first 10 days of May (Table 4). The early movements coincided with peak flights of waterfowl and initial movements of shorebirds. The May peak consisted principally of shorebirds and passerines. During 11-20 May, one-third of all flights recorded were passerines at the Sheyenne River site.

Two numerical peaks of abundance were also observed during fall migration (Table 5). The first peak, during 11-20 August, involved about 19\% of the total flights and was primarily Franklin's gulls; shorebird numbers also peaked during this period. The number of flights observed during 21 August-20 September was much lower, corresponding with the general egress of Franklin's gulls and shorebirds.

The second fall peak occurred 21-30 September, coincident with the first sandhill cranes to arrive in the lake region of Kidder County and the peak blue-winged teal migration. The number of flights observed slowly declined during October and the first week of November. Water began to freeze after 10 November each year, causing most waterfowl and sandhill cranes to depart. By midNovember, few birds remained on the study area and the last large lakes froze about 15 November each year.

Among the 7,051 flights having sufficient data for analysis, two-thirds exhibited no reaction to the power lines (Table 6). Results in both seasons were similar $(68 \%$ in spring and $67 \%$ in fall). The next most common reaction of flocks was to see the power line (apparently most often the conductor) and then flare to climb in altitude until they were safely over the ground wire. This reaction was shown by about $25 \%$ of all flights throughout the year-28\% in spring, and $24 \%$ in fall. Although these data were not analyzed for species, general observations suggested that Franklin's gull was the species most susceptible to the pres-

Table 4. Bird flights observed at seven study sites in North Dakota during two spring migrations, 1981 and 1982.

\begin{tabular}{|c|c|c|c|c|c|c|}
\hline \multirow[b]{2}{*}{ Site } & \multicolumn{3}{|c|}{ April } & \multicolumn{2}{|c|}{ May } & \multirow[b]{2}{*}{ Total } \\
\hline & $1-10$ & $11-20$ & $21-30$ & $1-10$ & $11-20$ & \\
\hline Sheyenne River & 8 & 90 & 7 & 139 & 218 & 462 \\
\hline Halfway Lake & 7 & 55 & 28 & 75 & 98 & 263 \\
\hline Hendrix Pothole & 32 & 46 & 44 & 33 & 53 & 208 \\
\hline Chase Lake & 105 & 119 & 82 & 172 & 127 & 605 \\
\hline Kunkel Lake & 25 & 396 & 79 & 183 & 67 & 750 \\
\hline Sibley Lake & 27 & 10 & 55 & 43 & 42 & 177 \\
\hline Cherry Lake & 0 & 23 & 142 & 21 & 57 & 343 \\
\hline Total & 204 & 739 & 437 & 766 & 662 & 2,808 \\
\hline
\end{tabular}


Table 5. Bird flights observed at seven study sites in North Dakota during two fall migrations, 1980 and 1981.

\begin{tabular}{|c|c|c|c|c|c|c|c|c|c|c|c|}
\hline \multirow[b]{2}{*}{ Site } & \multicolumn{3}{|c|}{ August } & \multicolumn{3}{|c|}{ September } & \multicolumn{3}{|c|}{ October } & \multicolumn{2}{|c|}{ November } \\
\hline & $1-10$ & $11-20$ & $21-31$ & $1-10$ & $11-20$ & $21-30$ & $\overline{1-10}$ & $11-20$ & $21-31$ & $1-10$ & $11-20$ \\
\hline Sheyenne River & 11 & 176 & 40 & 73 & 58 & 52 & 50 & - & - & - & - \\
\hline Halfway Lake & 17 & 55 & 7 & 15 & 23 & 2 & 16 & - & - & - & - \\
\hline Hendrix Pothole & 37 & 66 & 33 & 29 & 76 & 72 & 54 & - & - & - & - \\
\hline Chase Lake & 157 & 136 & 26 & 72 & 30 & 103 & 69 & 40 & 53 & 23 & 6 \\
\hline Kunkel Lake & 39 & 417 & 334 & 89 & 102 & 162 & 112 & 85 & 190 & 148 & 18 \\
\hline Sibley Lake & 28 & 13 & 53 & 44 & 23 & 193 & 115 & 161 & 183 & 133 & 10 \\
\hline Cherry Lake & 6 & 50 & 34 & 63 & 87 & 49 & 84 & 36 & 22 & 17 & 11 \\
\hline Total & 295 & 913 & 527 & 385 & 399 & 633 & 500 & 322 & 440 & 321 & 45 \\
\hline
\end{tabular}

ence of a conductor or ground wire, and most of the fall observations of this reaction were attributed to that species.

Birds that aborted flights upon seeing a power line made up 99 of the total flights, or $17 \%$. Most of these were Franklin's gulls. Less than $1 \%$ of the birds observed either continually crossed and recrossed the power lines, or sat on a line (usually a ground wire). Swallows most frequently recrossed; species sitting on a line were either swallows or raptors.

At all sites, flaring and climbing over the power line (Table 7) was the second most common reaction. This reaction was usually exhibited in Zone 3. Of the 1,782 flights exhibiting this reaction, 1,118 or $63 \%$ were in Zone 3 . This reaction was especially evident among Franklin's gulls.

In 82 flights, 109 birds struck a wire while observations were being recorded (Table 8). In total, 102
$(93 \%)$ birds collided with the ground wire, and 7 (7\%) struck the conductor. During 1980, 46 birds collided with a power line, and $39(85 \%)$ of these encountered the ground wire (Faanes unpublished data). The range of bird flight sizes involved in a collision was 1 to 1,000 . The observed collision rate during this study was about $1 \%$ (82 of 7,596 total observed flights).

Most collisions were observed in early evening. The largest number of birds seen colliding at one time was eight Franklin's gulls at Kunkel Lake in mid-August 1981, and 19 Franklin's gulls in late August 1980. These birds collided within $15 \mathrm{~min}$ of sunset on clear nights with light north winds. More than $61 \%(N=67)$ of all observed bird collisions occurred at the Kunkel Lake site. The most commonly observed reaction that resulted in a collision was flaring and climbing, which made up $87 \%$ of the total.

Table 6. Reactions exhibited by birds in flight at all power line study sites in North Dakota, 1980-82.

\begin{tabular}{|c|c|c|c|c|c|c|}
\hline \multirow[b]{2}{*}{ Reaction } & \multicolumn{6}{|c|}{ No. birds observed } \\
\hline & Spring & $(\%)$ & Fall & $(\%)$ & Total & $1 \%)$ \\
\hline No reaction & 1,780 & $(37.2)$ & 3,016 & $(62.8)$ & 4,776 & $(68.0)$ \\
\hline Flared and climbed & 732 & $(41.0)$ & 1,050 & $(59.0)$ & 1,782 & $(25.3)$ \\
\hline Flared and continued climbing & 57 & $(30.1)$ & 132 & (69.9) & 189 & $(2.7)$ \\
\hline Aborted flight and turned & 40 & $(40.4)$ & 59 & $(59.6)$ & 99 & (1.4) \\
\hline Flared and went under structures & 25 & $(32.0)$ & 53 & $(68.0)$ & 78 & (1.1) \\
\hline Crossed and recrossed & 3 & $(6.5)$ & 43 & (93.5) & 46 & $(0.7)$ \\
\hline Flared and left area & 6 & $(19.3)$ & 25 & $(80.7)$ & 31 & $(0.4)$ \\
\hline Sat on wire & 1 & $(3.7)$ & 26 & $(96.3)$ & 27 & $(0.4)$ \\
\hline Total & 2,645 & & 4,406 & & 7,051 & \\
\hline
\end{tabular}


Table 7. Total flights and flock reactions within each power line zone (see text for explanation of zone heights and location) at all study sites in North Dakota, 1980-82.

\begin{tabular}{|c|c|c|c|c|c|c|c|c|}
\hline \multirow[b]{2}{*}{ Reaction } & \multicolumn{6}{|c|}{ Zone } & \multirow[b]{2}{*}{ Total } & \multirow[b]{2}{*}{$(\%)$} \\
\hline & 1 & 2 & 3 & 4 & 5 & 6 & & \\
\hline No reaction & 1,679 & 314 & 850 & 842 & 603 & 456 & 4,744 & $(68.0)$ \\
\hline Flared and climbed & 6 & 204 & 1,118 & 389 & 61 & 4 & 1,782 & $(25.4)$ \\
\hline Flared and continued climbing & 1 & 7 & 139 & 40 & 0 & 1 & 188 & $(2.7)$ \\
\hline Aborted flight and turned & 14 & 49 & 15 & 3 & 0 & 1 & 82 & $(1.2)$ \\
\hline Flared and went under structure & 53 & 22 & 2 & 0 & 1 & 0 & 78 & (1.1) \\
\hline Crossed and recrossed & 13 & 7 & 13 & 6 & 4 & 2 & 45 & $(0.6)$ \\
\hline Flared and left area & 1 & 9 & 18 & 1 & 0 & 1 & 30 & $(0.4)$ \\
\hline Sat on wire & 1 & 5 & 18 & 0 & 0 & 0 & 24 & $(0.3)$ \\
\hline Total & 1,768 & 617 & 2,174 & 1,281 & 669 & 465 & 6,973 & \\
\hline All flights in zone (\%) & $(25.3)$ & $(8.9)$ & (31) & (18.4) & $(9.6)$ & $(6.7)$ & $(100.0)$ & \\
\hline
\end{tabular}

\section{Observer Error and Scavenger Removal Experiments}

Scavenger removal experiments, using dead birds, were conducted at all sites during the spring and fall migration periods. The species of birds used ranged from the northern flicker (Colaptes auratus) to the sandhill crane. Scavenger removal was virtually nonexistent at most sites during 1981 or 1982 , as planted birds remained undisturbed for as long as 2 weeks before decomposing.

Scavenger removal was a problem at Kunkel Lake during fall migration in 1980. During the first experiment at Kunkel Lake, five ducks were planted on 15 August; by 17 August, all five had been removed. Five more ducks were planted on 17 August at $1630 \mathrm{~h}$, and by 18 August at $0800 \mathrm{~h}$ all five birds had been removed. On 19 August, five ducks were again planted, and these had been removed by 20 August. Two Havahart live traps were baited with dead American coots and placed in the wetland vegetation on that date. Two adult raccoons (Procyon lotor) were trapped on 22 August; a third was captured on 23 August. Removal experiments were then discontinued to avoid providing additional food sources which may have attracted more scavengers.

During fall migration in 1981, virtually no scavenger removal problem occurred at any site until late October, when several partially eaten sandhill cranes were found at Sibley Lake. Three dead radio-tagged sandhill cranes were placed beneath the single span where most of the scavenging was occurring. These birds remained in place 11 days before one was removed. On the twelfth day, we tracked the movement of one removed bird and found in about $300 \mathrm{~m}$ away. The carcass had been partially buried and tracks at the site indicated that an American badger (Taxidea taxus) had removed the crane.

I performed a scavenger removal test with two injured Franklin's gulls at Kunkel Lake in late August 1981. Each bird suffered from two broken wings after flying into the ground wire. The birds were marked with radio transmitters and moni-

Table 8. Reactions exhibited by birds in flight that resulted in a collision with a power line structure.

\begin{tabular}{lrrrrr}
\hline & \multicolumn{5}{c}{ No. birds observed } \\
\cline { 2 - 6 } Reaction & 1980 & 1981 & 1982 & Total & $(\%)$ \\
\hline No reaction & 9 & 4 & 0 & 13 & $(11.9)$ \\
Flared and climbed & 40 & 52 & 3 & 95 & $(87.1)$ \\
Flared and went under structure & 1 & 0 & 0 & 1 & $(1.0)$ \\
Total & 50 & 56 & 3 & 109 & $(100.0)$ \\
\hline
\end{tabular}


tored for 3 days before both died. During that period, movements were limited to $2-3 \mathrm{~m}$ from their original location. I had hypothesized that injured birds would move about and be more conspicuous to a scavenger; however, neither bird was removed by a scavenger and the birds remained in place until after decomposition had begun.

During spring migration in 1982, no difference from previous years was discernible in scavenger removal. Seven to 10 birds were placed at each site throughout the period, but the only observed removal occurred at Chase Lake where a yellowheaded blackbird disappeared 1 week after planting, and a Swainson's hawk (Buteo swainsoni) at the Sheyenne River site was removed after 9 days. A red fox (Vulpes vulpes) was probably responsible for the removal at Sheyenne River.

\section{Populations and Movements}

The study periods coincided with the migration of most species, and the data enable useful comparisons. During spring migration each year, most geese had departed for northern nesting areas in early April, generally before the initiation of field work; data for these species are incomplete. Population data for the fall migration were gathered throughout the main migration periods of virtually all bird species using wetland, prairie, and riparian woodland habitats in this region of the northern Great Plains.

Populations during spring migration were characterized by a gradual buildup during late April, reaching peak numbers during 1-10 May at the wetland and prairie study sites. These numbers generally coincided with the regular influx of blue-winged teal and shorebirds during late April, and typical peak populations during early to midMay. At the Chase Lake site, increases in bird numbers resulted primarily from a rapid increase in the American white pelican population. Use of riparian woodlands along the Sheyenne River reflected the general northward pulsing movement of passerines during late April and early May. Large numbers of birds are usually recorded throughout eastern North Dakota about 10-15 May, and a rapid decline in numbers usually occurs thereafter.

Fall migration at the wetland sites was characterized by two numerical peaks (Fig. 10). The first occurred during mid- to late August, and the sec- ond from late September to mid-October. The early peak coincided with the main movements of Franklin's gulls on Sibley and Kunkel lakes. American white pelicans, especially on Chase Lake, reached peak levels during this period. The number of Franklin's gulls peaked on Sibley Lake in late August each year. Populations of Franklin's gulls throughout the study area diminished rapidly after late August. At the same time, numbers of sandhill cranes began to increase.

The second peak in bird numbers later in the season corresponded to maximum numbers of geese (primarily Canada geese) and, to a lesser extent, ducks. Peak numbers of sandhill cranes were recorded about 1 October at Sibley, Cherry, and Kunkel lakes. In mid- to late October, a general increase in numbers of Canada geese occurred. Smaller peaks observed at Sibley and Chase lakes were related to late influxes of snow geese at these sites in 1981.

Bird populations at Hendrix Pothole peaked during early September and consisted primarily of red-winged blackbirds. Numbers of birds declined rapidly afterwards, corresponding to the general movements of blackbirds out of the region. By early October, most birds had departed this site. Bird numbers at Halfway Lake peaked during late August and included large numbers of blackbirds. By early September each year, wetlands began to dry rapidly and bird numbers also declined rapidly.

Bird numbers at the Sheyenne River site built rapidly through mid- to late August, reaching a peak during the first 10 days of September. The population buildup and peak generally consisted of migrant warblers, vireos, and thrushes. Numbers dropped sharply after the early September peak. A general influx of sparrows was observed during late September. However, by early October each year, only nonmigratory species such as the black-capped chickadee, white-breasted nuthatch, and downy woodpecker (Picoides pubescens) remained.

\section{Site-specific Investigations}

Detailed descriptions of bird use, mortality, and bird flights follow, to show how individual site characteristics affected bird mortality and movements. 


\section{Sibley Lake}

\section{Dead Birds}

Two hundred five dead birds found at Sibley Lake were the most recorded during the study (Table 3). Twenty-nine birds were found during spring surveys and 176 during fall surveys. Gulls were most frequently encountered and made up $21 \%$ of the mortality. The sandhill crane was second highest with 40 birds (19\%), followed by the double-crested cormorant with 39 birds, also $19 \%$ of total mortality. All sandhill cranes but one were found during fall migration.

Seasonal variation in mortality at this site was especially pronounced. Double-crested cormorants were most numerous during fall migration, making up $23 \%$ of the season's mortality. High mortality was due primarily to an exceptionally large number of cormorants found during the 1981 fall migration. Passerines, primarily finches, made up more than one-third of all mortality in spring migration.

Mortality along the power line corridor during fall occurred principally along spans 3 and 4 where 50 and 59 birds were found. This area crossed a major southwest-northeast flight corridor. During fall 1980 , this corridor was used heavily by Canada geese, and in 1981 by double-crested cormorants. Although this portion of the transmission line route was about $0.4 \mathrm{~km}$ from the edge of Sibley Lake, the incidence of strikes was not lowered, as had been earlier hypothesized. I believe the mortality at this site was influenced by the presence of two natural drainageways that served to funnel the birds through specific areas of the power line corridor, and probably increased the incidence of collision.

\section{Bird Flight Observations}

Data were analyzed for 1,054 bird flights at Sibley Lake during this study. Sandhill cranes, double-crested cormorants, and Canada geese were the most regularly observed species. The largest number of flights observed was 193 during 21-30 September and 183 during 21-30 October.

Of the flights where bird reaction data were recorded, $779(74 \%)$ involved birds that exhibited no reaction to the power line, and $163(15 \%)$ that flared to climb over the power line. Nearly $55 \%$ of the flights were recorded in Zone 3 and $18 \%$ were in Zone 4 . The second most frequent reaction observed in Zone 3 was flaring to climb over the power line. Nearly $83 \%$ of all observations of this reaction at Sibley Lake occurred in Zone 3. The third most frequent reaction was flaring and continuing to climb, which accounted to $7 \%$ of all flights. Most of these reactions involved birds in Zone 3.

During fall migration, most sandhill cranes observed at this site flew away from or toward the lake in a southeasterly direction, thus paralleling the power line up to span 1. Double-crested cormorants, on the other hand, exhibited a north-south flight line through the area, which probably contributed to the number of dead cormorants found.

\section{Cherry Lake}

\section{Dead Birds}

A total mortality of 129 birds at Cherry Lake was third highest among the sites studied (Table 3), consisting of 18 birds during spring and 111 during fall. Waterfowl made up nearly half of all mortality, followed by shorebirds (14\%) and gulls $(13 \%)$. This pattern of abundance was identical in spring and fall.

Mortality during fall was evenly distributed wherever the power line was in proximity to the large water body. Nearly $70 \%$ of the dead birds were found beneath spans 3,4 , and 5 , which were closest to the lake. Only 21 birds (16\%) were found beneath span 1, which crossed open water for most of its length. The presence of water may have contributed to observers finding fewer birds there because wave action could easily carry birds away from the search area.

\section{Bird Flight Observations}

Data were collected on 719 bird flights at Cherry Lake during this study. Sandhill cranes, shorebirds, and several waterfowl species accounted for most of the observations. The largest number of flights observed at this site was 142 during 21-30 April and 87 during 11-20 September.

Of the flights where reaction data were recorded, $519(72 \%)$ involved birds that exhibited no reaction to the power line and $121(17 \%)$ that flared to climb over the line. About $41 \%$ of the flights 
were recorded within Zone 1 and $21 \%$ were in Zone 3 . The second most frequent reaction among birds in Zone 1 was flaring and going under the conductor $(5 \%)$. This reaction occurred among waterfowl and shorebirds as they flew to and from the lake while on feeding flights.

The most frequently observed reaction among birds in Zone 3 was flaring to climb over the power line $(47 \%)$, whereas birds exhibiting no reaction in this zone made up $40 \%$ of the total.

\section{Kunkel Lake}

\section{Dead Birds}

One hundred sixty-four dead birds were found at Kunkel Lake during this study (Table 3). Twenty-eight birds were found during spring and 136 during fall. Franklin's gull was the most numerous species, making up $49 \%$ of the total. All Franklin's gulls were found during fall migration. This gull was the most numerous species at Kunkel Lake throughout the study. Sandhill cranes were the second most numerous, and ringbilled gulls (Larus delawarensis) ranked third.

Gulls accounted for $40 \%$ of the mortality, followed by waterfowl with $21 \%$. Waterfowl made up most of the mortality during spring migration with about $46 \%$ of total mortality. Gulls made up about $47 \%$ of the fall mortality.

More than $81 \%$ of the dead birds were found beneath span 2. Mortality at the other spans was evenly distributed and was consistent throughout the investigation, with $93 \%$ during 1981 and $75 \%$ during fall 1908. Span 2 crossed the nearest point between Kunkel Lake and nearby fresh wetlands and thus crossed a major flight line for Franklin's gulls moving between feeding and roosting sites. The flight pattern of sandhill cranes during fall 1980 crossed the northern end of the lake, but in 1981, most sandhill cranes were observed flying into or away from Kunkel Lake in easterly or southerly directions. This change resulted from different cropping practices in 1981 that provided suitable food sources in an opposite direction from the previous fall.

\section{Bird Flight Observations}

Data were collected on 2,318 bird flights at Kunkel Lake. Franklin's gull was by far the most frequently observed species at this site. Sandhill cranes were of secondary abundance, and Canada geese added to the total later in fall. The largest number of flights observed was 396 during 11-20 April and 417 during 11-20 August. The latter period corresponded with peak populations of Franklin's gull.

Of the flights where reaction data were recorded, $1,130(49 \%)$ involved birds that exhibited no reaction and 1,026 (44\%) involved birds that flared to climb over the power line. The proportion of birds exhibiting these two reactions varied considerably. During spring $1981,31 \%$ of all flights involved no reaction and $62 \%$ involved flaring, whereas during fall migration in $1981,56 \%$ involved no reaction, but only $36 \%$ involved flaring.

About $40 \%$ of all flights observed at Kunkel Lake were in Zone 3 and $25 \%$ were in Zone 4; only $11 \%$ were in Zone 1 . The most frequently observed reaction in Zone 3 was flaring to climb over the power line $(70 \%)$; no reaction was second most frequent $(21 \%)$. General observations suggest that most birds exhibiting flaring reactions, especially those in Zone 3, were Franklin's gulls.

\section{Chase Lake}

\section{Dead Birds}

Ninety-eight dead birds were found at Chase Lake, 31 in spring and 67 in fall (Table 3). Franklin's gull was most numerous during fall 1980 , making up $13 \%$ of the mortality (Faanes, unpublished report); gadwall and blue-winged teal were second in abundance. The seasonal breakdown of mortality among waterfowl included 16 birds in spring and 24 during fall. Waterfowl made up $41 \%$ of the total, followed by gulls $(22 \%)$ and American coots $(7 \%)$.

Mortality occurred principally between spans 2 and 3 , with span 2 accounting for $29 \%$ ( 28 birds) of the mortality and span 3 for $26 \%$ (26 birds). Span 1 accounted for 13 dead birds, span 4 for 17 , and span 5 for 14 .

\section{Bird Flight Observations}

Data were analyzed on 1,320 bird flights at Chase Lake, 605 during spring and 715 during fall. American white pelicans, several waterfowl species, and California and ring-billed gulls made up most of the observations. The largest number of flights observed included 172 during 1-10 May 
and 157 during 1-10 August. The latter period coincided with movements of double-crested cormorants and shorebirds in the area.

Of flights where reaction data were recorded, $874(73 \%)$ involved birds that exhibited no reaction and $262(22 \%)$ involved birds that flared to climb over the power line. About $24 \%$ of all flights observed at Chase Lake were in Zone 3 and $22 \%$ were in Zone 4 . The most frequently observed reaction in Zone 3 was flaring to climb over the power line $(52 \%)$, whereas $41 \%$ of the flights in this zone exhibited no reaction. Of those flights observed in Zone 4, 74\% exhibited no reaction and only $22 \%$ flared. More than $92 \%$ of the birds in Zone 1 exhibited no reaction.

\section{Hendrix Pothole}

\section{Dead Birds}

Field work during fall was curtailed after the first week in October 1980 and 1981 because most birds departed after the start of the waterfowl hunting season. Ten dead birds were found at Hendrix Pothole (Table 3) and included five ducks, two American coots, two blackbirds, and one grebe. Mortality along this power line appeared to be randomly distributed.

\section{Bird Flight Observations}

Data were collected on 575 bird flights at Hendrix Pothole, 208 in spring and 367 in fall. Yellowheaded blackbirds, red-winged blackbirds, and several species of dabbling ducks (especially mallard and blue-winged teal) made up most of the observations. The largest number of flights recorded at this site was 53 during 11-20 May and 76 during 11-20 September.

Of the flights where reaction data were recorded, $394(79 \%)$ involved birds that exhibited no reaction and $84(17 \%)$ involved birds flaring to climb over the power line. About $26 \%$ of the flights observed at this site were in Zone 3 and about $20 \%$ were in Zones 1 and 4 . The most frequent reaction observed within these zones was no reaction $176 \%$ of all flights).

\section{Halfway Lake}

Dead Birds

Ten dead birds were found at Halfway Lake. Waterfowl made up $50 \%$ of the observed mortal- ity (Table 3). Seven of the dead birds were found beneath span 1 , which crossed between two seasonal wetlands. Two dead birds were found beneath span 3 , which was associated with one seasonal wetland. The two gray partridges (Perdix perdix) found at this site were typical of upland habitats.

\section{Bird Flight Observations}

Data were collected on 398 bird flights at Halfway Lake, 263 during spring and 135 during fall. Blackbirds and dabbling ducks made up most of the observations. The peak number of flights included 98 during 11-20 May and 55 during 11-20 August.

Of the flights where reaction to the power line was recorded, $273(80 \%)$ exhibited no reaction and $65(19 \%)$ flared to climb over the power line. About $65 \%$ of the flights were within Zone 1 and $12 \%$ were in Zone 2. Of those flights in Zone 1, all but two showed no reaction, whereas 25 of 41 in Zone 2 flared to climb over the power line. No bird collisions were observed at this site.

\section{Sheyenne River}

\section{Dead Birds}

Field work was initiated in late April each year because few migrant woodland birds arrive in eastern North Dakota before that time. Fall field work was stopped about 10 October after the major movement of migrant woodland birds had passed.

Seventeen dead birds were found at the Sheyenne River (Table 3). Passerines made up the bulk of the kill with $35 \%$ of the total, followed by doves and woodpeckers ( $18 \%$ each). Fourteen birds $(82 \%)$ were found beneath span 2 , which included the riparian woodland and the edge of a crop field. Two birds were beneath span 1 , which crossed upland native prairie, and one bird was found beneath span 4 , which crossed a county highway and upland native prairie. No birds were found beneath span 3 , which crossed cropland.

\section{Bird Flight Observations}

Data were collected on 922 bird flights at the Sheyenne River site. This total was almost identical between seasons, 462 during spring and 460 during fall. Mourning doves (Zenaida macroura), red-winged blackbirds, and several species of pas- 
serines including warblers, thrushes, flycatchers, and gray catbirds (Dumetella carolinensis) were most commonly observed. The largest number of flights at this site was 218 during 11-20 May and 176 during 11-20 August.

Of the flights where reaction data were recorded, $777(92 \%)$ involved birds showing no reaction and $54(6 \%)$ involved birds that flared to climb over the power line. I observed 586 flights $(69 \%)$ in Zone 1 and $106(13 \%)$ in Zone 2. Of those in Zone 1, 99\% showed no reaction and $1 \%$ flared to go under the conductor, whereas among those in Zone 2, 65\% showed no reaction and $25 \%$ flared to climb over the conductor.

\section{Discussion}

\section{Dead Bird Searches}

Waterfowl accounted for most of the observed mortality but ranked third in total abundance at the study sites, behind gulls and sandhill cranes. One condition that seemed to influence waterfowl mortality during spring migration was inattentiveness by males. Several instances of mortality to male ducks were noted when a male or group of males were in aerial pursuit of a female and collided with a power line.

The high percentage of Franklin's gulls among the total mortality, particularly during fall migration, was related to the behavior of this species during migration. Franklin's gull is a locally abundant nesting species on large marshes in North Dakota (Stewart 1975). While on southward migration, Franklin's gulls typically occur in large concentrations on alkali wetlands in central North Dakota, and more than 15,000 gulls are regularly encountered on some wetlands. Most Franklin's gulls found dead in this study were at Kunkel Lake, a site typically supporting large gull concentrations. At Kunkel Lake, virtually all dead Franklin's gulls were found beneath span 2, which crossed the upper portion of the lake, closest to nearby fresh wetlands.

Habitat conditions at Kunkel Lake contributed to the high mortality there. Birds were attracted to alkali wetlands because food is abundant and extensive mud flats provide roosting areas. Because of the high salt content of alkali wetlands, birds must seek fresh wetlands to obtain water and are required to fly between these wetlands to satisfy their dietary needs. Placing a power line between alkali wetlands and fresh wetlands can lead to substantial mortality.

Sandhill cranes made up the third highest mortality among groups. This species typically occurs in concentrations during fall migration throughout central North Dakota, where they roost on alkali wetlands. The number of sandhill cranes in central Kidder County during mid-October 1982 was estimated at 35,000 birds. Sandhill cranes collide with power lines in areas where the species occurs in abundance, including western Texas (Tacha et al. 1979), Nebraska (Wheeler 1966), and in the southeastern portion of the Central Flyway (Lewis 1974). In most instances, sandhill crane mortality results from birds moving between feeding areas and roost sites. Central North Dakota is especially attractive to this species because of the alkali wetlands and the presence of extensive areas of cropland adjacent to roost sites.

Shorebirds ranked fourth in observed mortality. This group is also attracted to alkali wetlands for feeding and roosting, especially in fall migration. The dietary needs of shorebirds are apparently met on their feeding wetlands, so the amount of interwetland movement in this group is probably much reduced when compared with waterfowl or gulls. Mortality among shorebirds results from collisions occurring when birds are arriving from or departing to the next migration staging area along their route.

\section{Collision and Mortality Estimates}

In the present study, mortality to migratory birds from collisions with power transmission lines appears to be greater than most other results reported from North America. Lee (1978) summarized two Oregon studies where 60 dead birds were found at a water bird concentration area during 3 months, and 19 dead birds were found at a second area. Lee estimated that at the first site, $0.05 \%$ of the estimated total flights resulted in a fatal collision; his collision rate was one per 3,370 flights. The collision rate in my study was one per 86 flights. The total number of flights observed in my study during 3 years was about half of Lee's observations for 3 months, suggesting that local conditions in North Dakota resulted in a greater frequency of observed collisions. I observed no 
indication that inclement weather contributed to the number of dead birds found.

Thompson (1978) summarized several studies and reported collision rates of $0.01-0.05 \%$. Meyer (1978) reported 31 dead birds of 12 species found beneath $5.9 \mathrm{~km}$ of power transmission line in Oregon. In summarizing several other studies, Wirth Associates (unpublished report) advised that collisions with overhead wires were strongly weighted toward waterfowl, pelicans, herons, and other large species possessing relatively low maneuverability. They went on to state from Boyd (1961), Krapu (1974), and Thompson (1978) that dabbling ducks are more likely to sustain mortality than diving ducks. My research supports these statements. In fact, more than $91 \%$ of the observed mortality in this study was made up of nonpasserine birds; most are generally not as maneuverable as the passerines.

The interspersion of habitats on the study areas contributed greatly to avian mortality from power lines in North Dakota. Willard et al. (unpublished report) believed that power lines with the same habitat on each side of them were more likely to cause bird collisions than a line running between two different habitats. They suggested that a bird was less likely to fly from one habitat type to another than to fly across a power line in the same habitat, especially when feeding.

My observations contradict the hypothesis of Willard et al. (unpublished report). The extensive alteration of the northern Great Plains for cropland development has resulted in the loss of much habitat homogeneity in North Dakota. Much of central North Dakota that was once mixed-grass prairie has been converted to various forms of crop production, which greatly increases the mosaic pattern of different habitat types and reduces the probability of having sizable areas of natural habitat. The three study sites that contributed the highest mortality (Table 3) were each characterized by a mosaic of habitat types in proximity to the power line corridors.

\section{Bird Flight Observations}

Observations of Franklin's gull, primarily at Kunkel Lake, suggested that this bird may have been affected by the presence of power lines more than any other species observed in this study. Most of the observed collisions of Franklin's gull resulted from flocks of gulls moving as a group between fresh and alkali wetlands. During one evening in late August 1980, I observed 24 Franklin's gulls collide with the ground wire within a 15-min period. Most of these gulls appeared to be immatures. The collisions occurred as immature gulls at the front of the flock flared to climb over the conductor, encountered the ground wire, and turned to fly away from the site. These birds were followed by about 300 adult gulls. The forward movement of the adult gulls at the rear of the flock seemed to influence the movement of immatures and may have caused them to collide with the ground wire.

Among waterfowl, the diving ducks appeared to encounter few problems when in flight near a power line. I attributed this to their rapid movement from the water and their rapid altitude gain, which was important in carrying them above the ground wire by the time they crossed the power line. James and Haak (1979) reported similar observations for two diving duck species. Dabbling ducks, on the other hand, exhibited much slower flight and were generally slower in gaining altitude to clear the power line. This difference may have contributed to the number of dabbling ducks found dead.

The bird flight data were gathered to record information on movements within various distances above ground. Birds within Zones 1-4 were used in this analysis because they would be most likely to encounter a power line. Zone 3 included the area from the top of the ground wire to about $4 \mathrm{~m}$ above the ground wire. Nearly two-thirds of all bird flights within Zone 3 flared to climb over the ground wire. About one-third of the flights within Zone 2 flared to climb, which suggests that birds changing their flight altitude within these zones may be responding to the presence of the ground wire and conductor. Among birds observed colliding with a power line, more than $93 \%$ collided with the ground wire. Among all birds colliding, $87 \%$ flared to climb before the collisions. In most instances, this involved flaring to clear the conductor and colliding with the ground wire. Others (Thompson 1978; James and Haak 1979; Meyer 1980) have stated that the ground wire contributes the most to bird mortality from power lines. 


\section{The Biological Significance of Collision Mortality}

Social and ecological aspects affect biological significance. The social aspects relate to public awareness of power lines and bird mortality. Prominent among the concerned public are hunters and conservationists. The ecological aspects relate to the impact of mortality on bird populations locally and throughout the range of a species.

Most studies of bird mortality at power lines have attempted to address the issue of the significance of mortality to a local bird population. Thompson (1978) concluded that losses of waterfowl from power line collisions are probably not biologically significant when considering the total population. Willard et al. (unpublished report), who evaluated the potential effect of a proposed power line in Oregon, concluded that although a measurable rate of mortality by power lines occurs where lines cross aquatic habitats, the significance of this mortality on total populations was unknown. They stated that the probability of significant mortality to waterfowl by a proposed power transmission line was greatest in feeding areas. Stout and Cornwell (1976) summarized records of nonhunting mortality among waterfowl and concluded that collision mortality made up less than $0.1 \%$ of the sample. Kroodsma (1978) concluded that collisions with power transmission lines by waterfowl made up a very small part of hunting and nonhunting mortality. My data agree with Kroodsma. Conversely, Drewien (1973) concluded that $37 \%$ of observed mortality among sandhill cranes in the Rocky Mountains resulted from power line collisions. Owen and Cadbury (1975) found that $38 \%$ of the known mortality among three swan species in England was attributable to power line collisions. However, to more fully evaluate the biological significance of mortality from power lines on populations, the cumulative effect of losses sustained throughout migration must be addressed.

Power lines are a potentially serious hazard to rare bird species. About $72 \%$ of the entire world's population of about 130 wild whooping cranes (Grus americana) cross the Great Plains twice each year on migration. At least 10 instances of whooping cranes colliding with power lines occurred in Colorado, Idaho, Kansas, Saskatchewan, Texas, and Wyoming. One of three whooping cranes born in the wild in 1981 died after colliding with a power line near Saskatoon, Saskatchewan, in September 1981. A second bird from the 1981 production was killed by colliding with a power line near Waco, Texas, in October 1982. That bird had been observed on the ground about $10 \mathrm{~km}$ north of the Kunkel Lake study site 2 days before it was found dead in Texas.

A major part of avian mortality from collisions with power lines can be avoided through careful planning. When power line routes intersect important flight lines near areas supporting large bird concentrations, substantial mortality occurs, as observed at Cherry, Kunkel, and Sibley lakes, where power lines were placed close to the edge of the water. These three sites accounted for $75 \%$ of the observed mortality in my study. Power lines placed across major feeding flight lines or natural drainageways that act to funnel the birds seem to contribute to increased mortality at specific sites. Additional research on methods for reducing bird mortality from power lines, such as ground wire removal, sleeving, or marking, needs to be conducted to determine ways to reduce the losses that are occurring.

\section{Control of Bird Losses from Power Line Collisions}

My findings and a review of available literature provide a basis for making several recommendations concerning the siting and design of power lines.

\section{Water Bird Concentration Areas}

One of the most important ecological factors contributing to avian mortality from power lines in the northern Great Plains is the juxtaposition of line placement with wetlands that support concentrations of water birds. My study revealed that more than $90 \%$ of the observed mortality occurred at sites supporting large concentrations of water birds (Table 3). Among the sites I examined, power lines situated $400 \mathrm{~m}$ or more from the edge of the water generally had lower observed mortality than sites where the power line was within this distance.

From information obtained in this study and at other sites in western North America, I believe that the distance of power lines from the edge of the water, in areas of high bird collision potential, 
affects the rate of avian mortality and merits further investigation. Mortality can occur at sites where extensive low altitude bird flights are associated with a power line crossing close to the water's edge (Kunkel Lake) or directly through a wetland (Malcolm 1982). It may not be justifiable economically to reroute an existing power line except in instances where avian mortality is extremely high. Avoidance of known water bird concentration areas during the route planning stage is probably the most cost effective method of lowering avian mortality levels. A first step in identifying potential risk areas is to identify large wetlands. Information on the use of particular sites by birds can usually be obtained from each State's Department of Natural Resources, or the U.S. Fish and Wildlife Service's Habitat Resources Field Offices, or National Wildlife Refuges.

Avian mortality from power lines also occurred at small wetlands, but at a much lower rate than larger alkali wetlands (Table 3). About $70 \%$ of the observed mortality at the Halfway Lake (small wetland) study site occurred at a single span that crossed two seasonal wetlands. Five of seven birds found beneath this span were along the segment of power line that passed adjacent to two seasonal wetlands. These findings reflect the high use of seasonal wetlands as major feeding sites for breeding waterfowl (Swanson et al. 1979).

Within the $97,700-\mathrm{km}^{2}$ prairie pothole region of North Dakota, the density of wetland basins averages about $24 / \mathrm{km}^{2}$ (H. A. Kantrud, unpublished data). Thus, it may be difficult to avoid placing power lines in nonlethal locations. In such situations, placement near large wetlands should be avoided. It is also important to avoid placing power lines near large semipermanent wetlands that hold water into the fall migration period and are attractive to water birds for a longer time.

My observations of birds in flight at power lines $\geq 230 \mathrm{kV}$ revealed two aspects of placement that may prove useful for future routings. Observations of flying birds and of dead bird distribution suggested that birds tended to avoid the airspace within about $50 \mathrm{~m}$ of the towers. Avoidance of the area near the towers was probably caused by the high visibility of the structures. Most of the observed birds appeared to fly over the lines in the mid-span region, and birds were found beneath the mid-span areas.
Consideration should be given to placing towers in locations that will make the structures more visible to flying birds. I believe this is especially important when power lines are to be routed through areas containing seasonal and semipermanent wetlands.

Few dead birds were found at the Hendrix Pothole study site. Birds in flight crossed randomly over this power line and the wooden poles supporting the line. The various locations where dead birds were found beneath this line reflected their random flight paths. I believe that the most effective routing consideration for distribution lines through small prairie wetland areas is to allow a sufficient distance between the water's edge and the power line.

Many thousand hectares of land in the northern Great Plains and upper Midwest have been acquired by State and Federal resource agencies to provide habitat for waterfowl and other birds. Prominent among these lands are National Wildlife Refuges and Waterfowl Production Areas managed by the U.S. Fish and Wildlife Service, and Wildlife Management Areas managed by various State resource agencies. Because of their inherent wildlife values and associated concentrations of bird life, certain Federal laws have been enacted to regulate power line placement through National Wildlife Refuge lands. Specifically, the laws state that no right-of-ways will be approved unless the Regional Director of the U.S. Fish and Wildlife Service has determined the crossing is compatible with the purposes for which the refuge was established. In instances where power line placement is compatible, consideration should be given to maximizing distances from the edge of water to the line, tower placement, and various modifications of the ground wire.

\section{Riparian Habitats}

Riparian vegetation in the northern Great Plains provides important habitat for many bird species. Forests located along north-south oriented streams, including the Missouri, Sheyenne, Red, and James rivers (Avery et al. 1976) in North Dakota, are used heavily by migrant passerines. My research in riparian habitats suggests that avian mortality there can be reduced by design and placement changes of power line conductors and ground wires. 
Trees at the Sheyenne River site grew about $15-20 \mathrm{~m}$ tall. The conductors of the $230-\mathrm{kV}$ power line at the area of greatest sag were about 2-5 m above the vegetation. The open area right-of-way beneath the power line was used extensively for hunting insects by birds perched near the opening and during many short-duration flights beneath the conductors. About $25 \%$ of the birds observed in flight during the study (Table 7) and about $70 \%$ at this site were in the airspace between the conductors and the ground (Zone 1). Ninetyfive percent of these birds showed no reaction when flying beneath the conductors (Table 7).

Passerine birds fly at various heights above $215 \mathrm{~m}$ in nocturnal migration (Able 1970). My observations suggest that diurnal movements of passerine birds are principally beneath the conductors. Avian mortality in riparian vegetation may increase when power lines are at or below the forest canopy (Goddard 1975) probably because visibility of the power lines is obscured by foliage. I recommend that future power lines routed through riparian vegetation be designed to keep conductors above the forest vegetation.

\section{Species of Concern}

Several areas in the prairie pothole region are well known for their use by species of concern, including the whooping crane. Among these areas are several alkali lakes in central and northwestern North Dakota, and specific reaches of the Platte and Niobrara rivers in Nebraska. I recommend that special consideration be given to avoiding construction of power lines through areas used by these birds. Locations of traditional use areas by whooping cranes can be obtained from the U.S. Fish and Wildlife Service's Habitat Resources Field Offices.

Raptors are regularly given consideration during resource development projects. Data from this study suggest that power lines in the prairie region probably are not a serious hazard to diurnal raptors such as the prairie falcon (Falco mexicanus), red-tailed hawk (Buteo jamaicensis), Swainson's hawk, or ferruginous hawk (B. regalis), or to owls. During my bird flight observations, raptors were frequently seen hunting beneath power lines or perched on towers, but few dead raptors were found. Raptors frequently nested on towers (Gilmer and Wiehe 1977).
Bald eagles (Haliaeetus leucocephalus) are locally common along large rivers during migration and winter. Most concentrations of wintering bald eagles in this region appear to be associated with open water areas downstream from dams along the Missouri and Mississippi rivers, or near warmwater discharge areas along the Platte River in Nebraska.

Diurnal movements of bald eagles during the winter are usually from night roost sites (Faanes 1976). Typical feeding activities consist of short flights from a perch site over the water to capture prey and then a return flight to the perch site. Forest vegetation along the stream bank and along open water channels serve to limit bald eagle movements. Thus, most flights are at low altitudes. I believe the greatest potential for collisions with power lines exists in the mid-span area where power lines cross open expanses of river. I recommend that markers be placed on the ground wire where power lines pass through or near known areas of bald eagle concentrations. Jackson et al. (1982) found no negative effect of a $500-\mathrm{kV}$ line on wintering eagles on the Columbia River when the lines studied had a combination of orange marker balls and ground wire removal on various spans.

\section{Topographic Features}

Local and migratory movements of many bird species are influenced by topographic features (Welty 1962). Prominent landscape features in the prairie region are rivers, natural basin wetlands, eskers, and natural drainageways that are part of the watershed for intermittent streams. Natural drainageways at Chase and Sibley lakes probably influenced avian mortality at those sites, where more than 55 and $53 \%$, respectively, of the observed mortality occurred at spans that crossed natural drainageways. Flight lanes of birds at concentration areas can often be predetermined according to topographic features. Thus, the location of topographic features in relation to movements of birds should be considered during power line planning, with preferred areas avoided.

Preliminary planning should include a thorough examination of topographic maps and aerial photographs to identify potential high-risk areas. Where power lines must cross natural flight lanes, such as drainageways, I recommend that towers be placed near the middle of the flight lane in order to increase the visibility of the power line. In 
instances where engineering feasibility requires that towers cannot be placed within a drainageway, I recommend that the towers be placed as near as possible to one side of the drainageway.

\section{Ground Wire Modification}

My data concur with findings of other studies, indicating that most avian mortality at power lines results from collisions with the overhead ground wire. Observations of birds flying at power lines in North Dakota suggest that the primary reason birds collide after flaring to avoid the conductor is their lowered observability of the ground wire. This appears to be especially critical for birds that flare within about $10 \mathrm{~m}$ of the conductor and then have a reduced amount of airspace to maneuver around the ground wire. The most effective methods of reducing avian mortality are to remove the ground wire or place markers on it. Beaulaurier (1981) reported that collisions of birds with power lines were reduced by 35 and $69 \%$ at two Oregon study sites after ground wire removal. Mortality at the Kunkel Lake site in North Dakota could probably be greatly reduced by removal of the ground wire at one span.

Ground wire removal, however, can diminish reliability of the power grid because lightning strike protection is reduced (Beaulaurier 1981). Lightning strikes are a potential threat to support towers and conductors in the northern Great Plains because power line towers are often the tallest objects in the surrounding areas and so are especially susceptible to lightning strikes. Central North Dakota experiences about 36 thunderstorm days annually, or about $17 \%$ of the days between 1 April and 31 October (U.S. National Weather Service, Bismarck, N.D., personal communication). Thunderstorm and lightning strike frequency should be carefully evaluated before ground wires are removed.

Marking ground wires to increase their visibility to birds in flight appears to be a feasible alternative to ground wire removal. Beaulaurier (1981) summarized the results from 17 studies that involved marking ground wires or conductors and found an average reduction in collisions of $45 \%$ compared to unmarked lines. Among the most successful methods used to increase visibility of the lines were black-and-white ribbons and orange aviation marker balls. The Bonneville Power Administration recently installed $23-\mathrm{cm}$ orange marker balls on the ground wire of a $500-\mathrm{kV}$ line crossing the Missouri River in Montana to reduce the incidence of bird strikes (J. M. Lee, personal communication).

Another promising technique to increase observability of the ground wire is to place Spiral Vibration Dampers (Preformed Line Products Company, Cleveland, Ohio) on the wire. Spiral Vibration Dampers are one-piece helically-shaped rods made of polyvinyl chloride. Dampers were developed for placement on conductors and ground wires to control vibration and reduce line wear. This material is available in diameters of $0.8-1.2 \mathrm{~cm}$ with a maximum height of about $3.8 \mathrm{~cm}$. Installation of Spiral Vibration Dampers should be made across entire spans of ground wire so that maximum observability is provided.

In high-use areas, observability would be enhanced by installing both orange aviation marker balls and the dampers. Where it is not feasible to sleeve the entire span, priority consideration should be given to marking the mid-span region of the ground wire because of its high degree of bird use. Whereas certain difficulties are inherent in adding markers to existing power lines, because of added stress to the towers, new power lines should be designed to accommodate the stress from various marking techniques.

\section{Acknowledgments}

This research was accomplished through a cooperative agreement between the U.S. Fish and Wildlife Service and the Avian Mortality Study Group, a consortium of electric power companies made up of Basin Electric Power Cooperative, Cooperative Power Association, Minnesota Power and Light Company, Minnkota Power Cooperative, Montana-Dakota Utilities Company, Nebraska Public Power District, Northern States Power Company, Otter Tail Power Company, United Power Association, and the Western Area Power Administration of the U.S. Department of Energy. James K. Miller of the Basin Electric Power Cooperation served as Chairman of the study group.

Field work was accomplished with the assistance of Jonathan Andrew, Greg Johnson, Chris Lackney, Annette Mehlhoff, Wayne Norling, Charles Shaiffer, and Donald TeRonde. The manuscript 
benefitted from careful reviews provided by Jonathan Andrew, Eric Bauman, William Bicknell, Robert Blohm, Edward Brigham, Barry Curn, Mark Czaplewski, Richard Doherty, Harold Duebbert, Sara Jacobson, Douglas Johnson, Gary Krapu, Jack Lee, Jr., John Lokemoen, Dan McConnon, Mike McKenna, and Paul Springer. Leonard Cernohaus and C. Stanley Zschomler assisted in various ways.

\section{References}

Able, K. P. 1970. A radar study of the altitude of nocturnal passerine migration. Bird-Banding 41:282-290.

American Ornithologists' Union. 1983. Check-list of North American birds, 6th edition. Allen Press, Lawrence, Kans. 877 pp.

Avery, M., P. F. Springer, and J. F. Cassel. 1976. The effects of a tall tower on nocturnal bird migration-a portable ceilometer study. Auk 93:281-291.

Beaulaurier, D. L. 1981. Mitigation of bird collisions with transmission lines. Bonneville Power Administration, Portland, Oreg. 83 pp.

Boyd, H. 1961. Reported casualties to ringed ducks in the spring and summer. Wildfowl 12:144-146.

Cornwell, G., and H. A. Hochbaum. 1971. Collisions with wires-a source of anatid mortality. Wilson Bull. 83:305-306.

Drewien, R. C. 1973. Ecology of Rocky Mountain greater sandhill cranes. Ph.D. thesis, University of Idaho, Moscow. $152 \mathrm{pp}$.

Faanes, C. A. 1976. Winter ecology of bald eagles in southeastern Minnesota. Loon 48:61-69.

Gilmer, D. S., and J. M. Wiehe. 1977. Nesting by ferruginous hawks and other raptors on high voltage powerline towers. Prairie Nat. 9:1-10.

Goddard, S. V. 1975. Number and composition of birds killed by striking the transmission lines from the Prairie Island Nuclear Generating Plant. North. States Power Co. Annu. Rep. 2:2.7.3.2:1-6.

Jackson, P., L. Oftedahl, D. Bartz, D. L. Beaularier, and M. Jennings. 1982. Impact of the Ashe-Slatte $500 \mathrm{kV}$ transmission line on birds at Crow Butte Island: postconstruction final report. Bonneville Power Administration, Portland, Oreg. $155 \mathrm{pp}$.

James, B. W., and B. A. Haak. 1979. Factors affecting avian flight behavior and collision mortality at transmission lines. Bonneville Power Administration, Portland, Oreg. $109 \mathrm{pp}$.

Krapu, G. L. 1974. Avian mortality from collisions with overhead wires in North Dakota. Prairie Nat. 6:1-6.

Kroodsma, R. L. 1978. Evaluation of a proposed transmission line's impacts on waterfowl and eagles. Pages
69-76 in M. L. Avery, ed. Impacts of transmission lines on birds in flight. U.S. Fish and Wildlife Service, Washington, D.C.

Lee, J. M., Jr. 1978. Effects of transmission lines on bird flights: studies of Bonneville Power Administration lines. Pages 53-68 in M. L. Avery, ed. Impacts of transmission lines on birds in flight. U.S. Fish and Wildlife Service, Washington, D.C.

Lewis, J. C. 1974. Ecology of the sandhill crane in the southeastern Central Flyway. Ph.D. thesis, Oklahoma State University, Stillwater. $213 \mathrm{pp}$.

Malcolm, J. M. 1982. Bird collisions with a power transmission line and their relation to botulism at a Montana wetland. Wildl. Soc. Bull. 10:297-304.

Meyer, J. R. 1978. Effects of transmission lines on bird flight behavior and collision mortality. Bonneville Power Administration, Portland, Oreg. 200 pp.

Meyer, J. R. 1980. A study of wintering bald eagles to assess potential impacts from a proposed $230-\mathrm{kV}$ transmission line. Pages 87-103 in R. P. Howard and J. F. Gore, eds. Workshop on raptors and energy development. National Technical Information Service, Springfield, Va.

Nagel, T. J. 1978. Operating a major electrical utility today. Science 201:985-993.

Owen, M., and C. J. Cadbury. 1975. The ecology and mortality of swans at the Ouse Washes, England. Wildfowl 26:31-42.

Stewart, R. E. 1975. Breeding birds of North Dakota. Tri-College Center for Environmental Studies, Fargo, N.Dak. 295 pp.

Stewart, R. E., and H. A. Kantrud. 1971. Classification of natural ponds and lakes in the glaciated prairie region. U.S. Fish Wildl. Serv., Resour. Publ. 92. 57 pp.

Stout, I. J., and G. W. Cornwell. 1976. Nonhunting mortality of fledged North American waterfowl. J. Wildl. Manage. 40: 681-693.

Swanson, G. A., G. L. Krapu, and J. R. Serie. 1979. Foods of laying female dabbling ducks on the breeding grounds. Pages 47-57 in T. A. Bookhout, ed. Waterfowl and wetlands-an integrated review. North Central Section, Wildlife Society, Madison, Wis. $152 \mathrm{pp}$.

Tacha, T. C., D. C. Martin, and C. G. Endicott. 1979. Mortality of sandhill cranes associated with utility highlines in Texas. Pages 175-176 in J. C. Lewis, ed. Proceedings of the 1978 crane workshop. Colorado State University, Fort Collins.

Thompson, L. S. 1978. Transmission line wire strikes: mitigation through engineering design and habitat modification. Pages 27-52 in M. L. Avery, ed. Impacts of transmission lines on birds in flight. U.S. Fish and Wildlife Service, Washington, D.C.

Welty, J. C. 1962. The life of birds. W. B. Saunders Co., Philadelphia, Pa. 546 pp.

Wheeler, R. H. 1966. Sandhill crane casualties in the blizzard of March 22, 1966. Nebr. Bird Rev. 34:69-70. 

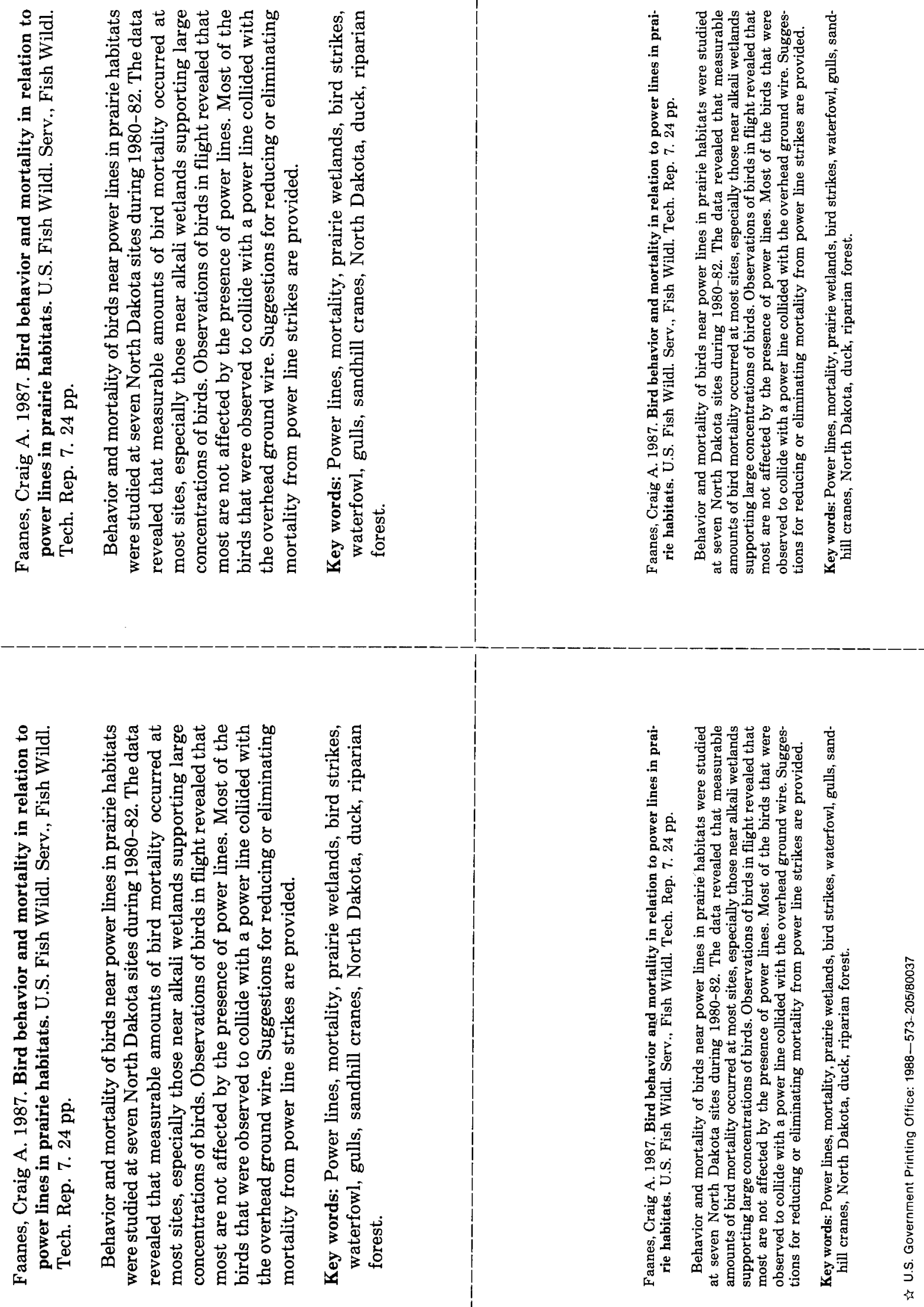
A list of current Fish and Wildlife Technical Reports follows.

1. Effects of Weather on Breeding Ducks in North Dakota, by Merrill C. Hammond and Douglas H. Johnson. 1984. $17 \mathrm{pp}$.

2. Lethal Dietary Toxicities of Environmental Contaminants and Pesticides to Coturnix, by Elwood F. Hill and Michael B. Camardese. 1986. 147 pp.

3. Effects of Vegetation Manipulation on Breeding Waterfowl in Prairie Wetlands-A Literature Review, by Harold A. Kantrud. 1986. 15 pp.

4. XYLOG: A Computer Program for Field Processing Locations of Radio-Tagged Wildlife, by Wendell E. Dodge and Alan J. Steiner. 1986. 22 pp.

5. Response to Lake Trout and Rainbow Trout to Dietary Cellulose, by H. A. Poston. 1986. 6 pp.

6. DDE, DDT + Dieldrin: Residues in American Kestrels and Relations to Reproduction, by Stanley N.

Wiemeyer, Richard D. Poster, Gary L. Hensler, and John R. Maestrelli. 1986, 33 pp.

NOTE: Use of trade names or commercial products in this publication is solely for the purpose of providing specific information and does not imply recommendation by the U.S. Government. 
As the Nation's principal conservation agency, the Department of the Interior has responsibility for most of our nationally owned public lands and natural resources. This includes fostering the wisest use of our land and water resources, protecting our fish and wildife, preserving the environmental and cultural values of our national parks and historical places, and providing for the enjoyment of life through outdoor recreation. The Department assesses our energy and mineral resources and works to assure that their development is in the best interests of all our people. The Department also has a major responsibility for American Indian reservation communities and for people who live in island territories under U.S. administration.

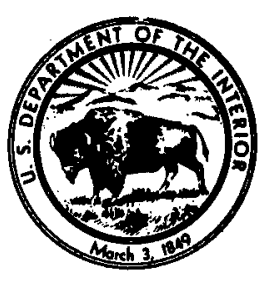

\section{UNITED STATES}

\section{DEPARTMENT OF THE INTERIOR} FISH AND WILDLIFE SERVICE

Office of Information Transfer 1025 Pennock Place, Suite 212

Fort Collins, Colorado 80524
THIRD-CLASS MAIL

POSTAGE AND FEES PAID

U.S. DEPARTMENT OF THE INTERIOR

PERMIT NO. G-77

NOTE: Mailing lists are computerized. Please return address label with change of address. 


\section{CORONA TESTING OF DEVICES USED TO MITIGATE BIRD COLLISIONS}

Prepared For:

California Energy Commission

Public Interest Energy Research Program

and

The U.C. Santa Cruz Predatory Bird Research Group

Prepared By:

EDM International, Inc.

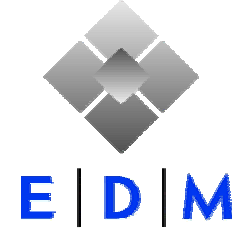

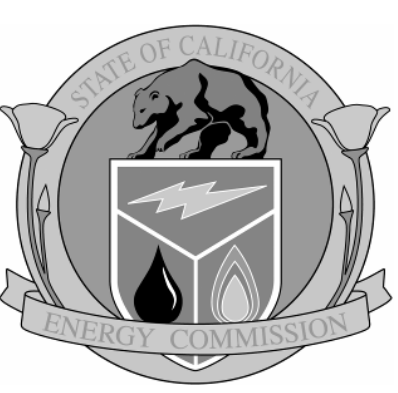

Arnold Schwarzenegger Governor

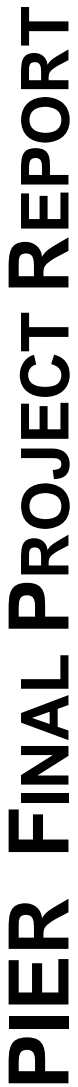




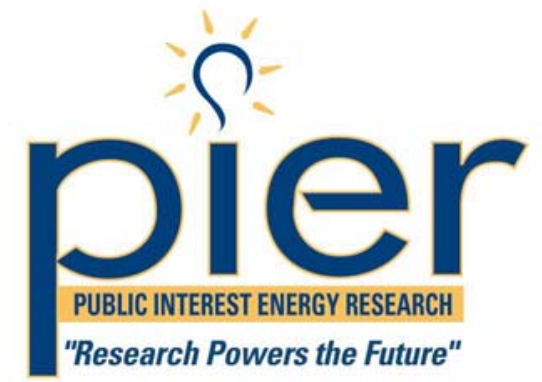

"Research Powers the Future"
Prepared By:

EDM International, Inc.

Neil Hurst, Primary Author

4001 Automation Way

Fort Collins, Colorado 80525

Contract No. 500-01-032

Prepared For:

California Energy Commission

Public Interest Energy Research (PIER) Program

Linda Spiegel,

Contract Manager

Kelly Birkinshaw,

Program Area Team Lead

Energy-Related Environmental Research

Ron Kukulka,

\section{Acting Deputy Director} ENERGY RESEARCH AND DEVELOPMENT DIVISION

Robert L. Therkelsen

Executive Director

\section{DISCLAIMER}

This report was prepared as the result of work sponsored by the California Energy Commission. It does not necessarily represent the views of the Energy Commission, its employees or the State of California. The Energy Commission, the State of California, its employees, contractors and subcontractors make no warrant, express or implied, and assume no legal liability for the information in this report; nor does any party represent that the uses of this information will not infringe upon privately owned rights. This report has not been approved or disapproved by the California Energy Commission nor has the California Energy Commission passed upon the accuracy or adequacy of the information in this report. 


\section{Acknowledgements}

- Bernard Clairmont, EPRISolutions

- John Bridges, Terrestrial Biologist, Western Area Power Administration

- Steve Rock, Western Area Power Administration

- Dawn Gable, Janet Linthicum, and Brian Walton, Santa Cruz Predatory Research Group, Santa Cruz, California

- Linda Spiegel, PIER Environmental Area, California Energy Commission

- Mark Wilson, technical editor

Please cite this report as follows:

Hurst, Neil. 2004. Corona Testing of Devices Used to Mitigate Bird Collisions. EDM International, Inc. California Energy Commission, PIER Energy-Related Environmental Research. 500-04-086F. 


\section{Preface}

The Public Interest Energy Research (PIER) Program supports public interest energy research and development that will help improve the quality of life in California by bringing environmentally safe, affordable, and reliable energy services and products to the marketplace.

The PIER Program, managed by the California Energy Commission (Energy Commission), annually awards up to $\$ 62$ million to conduct the most promising public interest energy research by partnering with Research, Development, and Demonstration (RD\&D) organizations, including individuals, businesses, utilities, and public or private research institutions.

PIER funding efforts are focused on the following six RD\&D program areas:

- Buildings End-Use Energy Efficiency

- Energy-Related Environmental Research

- Environmentally Preferred Advanced Generation

- Industrial/Agricultural/Water End-Use Energy Efficiency

- Renewable Energy

- Energy Systems Integration

What follows is the final report for Corona Testing Devices Used to Mitigate Bird Collisions, contract number 500-01-032, conducted by EDM International, Inc. The report is entitled Corona Testing Devices Used to Mitigate Bird Collisions. This project contributes to the PIER EnergyRelated Environmental Research program.

For more information on the PIER Program, please visit the Energy Commission's website www.energy.ca.gov/pier/ or contract the Energy Commission at (916) 654-4628. 


\section{Contents}

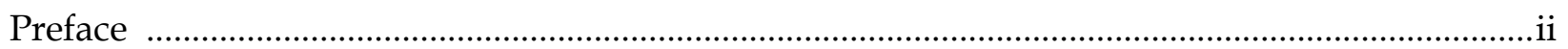

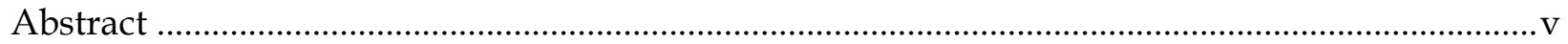

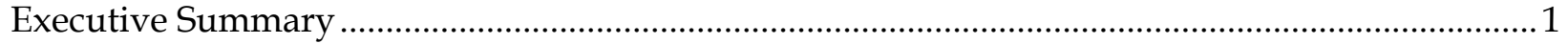

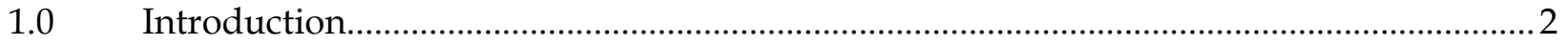

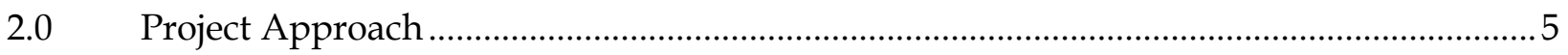

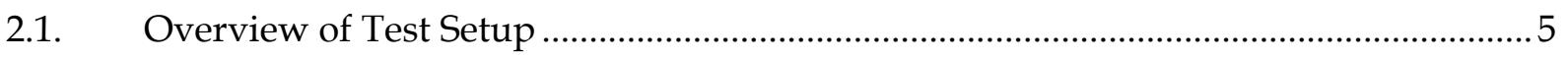

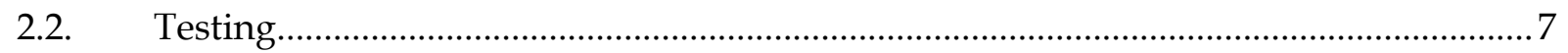

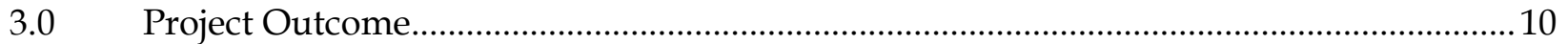

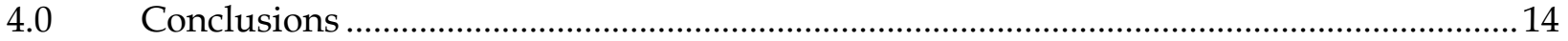




\section{List of Figures}

Figure 1. Flight diverters tested as part of the project ............................................................

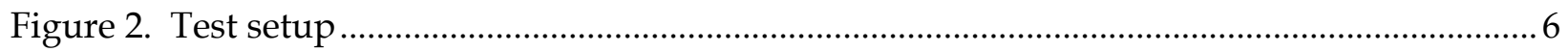

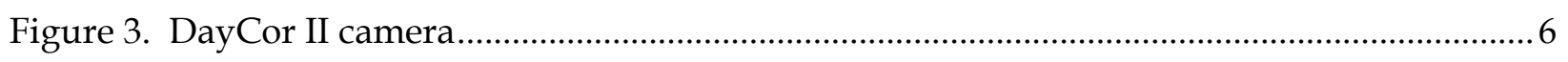

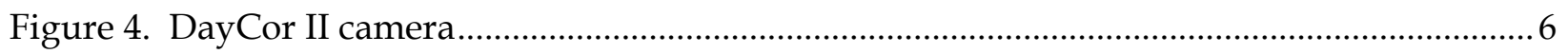

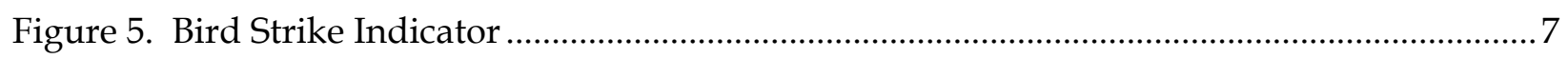

Figure 6. Bird Flight Diverter, Tyco Electronics (BFD2460) …...................................................

Figure 7. Swan Flight diverter, Tyco Electronics (SFD1960) ....................................................... 7

Figure 8. Bird Flapper, Mission Environmental ..........................................................................

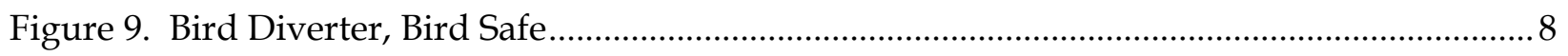

Figure 10. Bird Flapper - Prototype, Mission Environmental....................................................... 8

Figure 11. Bird Flapper, Preformed Line Products (LSFB0416) ................................................... 8

Figure 12. Bird Flapper, Preformed Line Products (FB0515) …................................................... 8

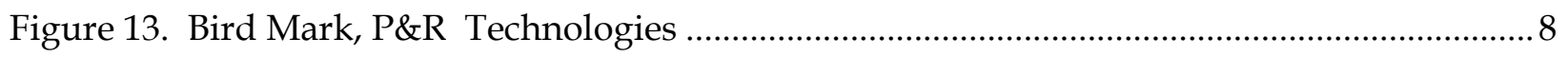

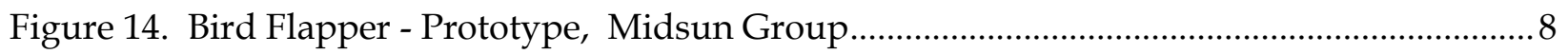

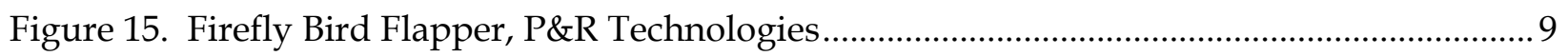

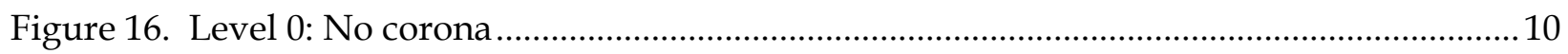

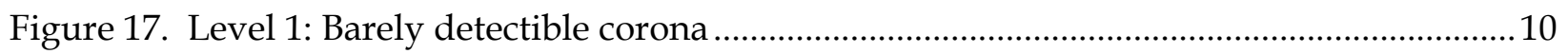

Figure 18. Level 2: Definitely detectable corona (at bottom of cable clamp) .............................11

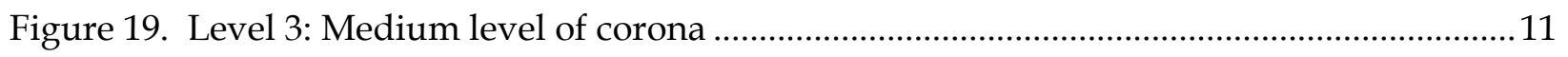

Figure 20. Level 4: High level of corona ….............................................................................. 11

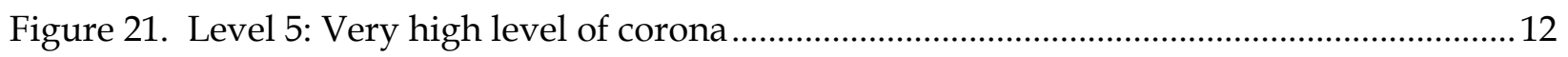

Figure 22. Corona-induced damage on diverter \#5 ….............................................................. 13

\section{List of Tables}

Table 1. List of flight diverter manufacturers and models tested ................................................ 3

Table 2. System voltages and corresponding test voltages ...................................................... 5

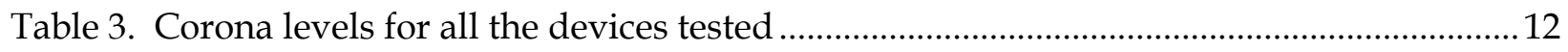




\begin{abstract}
Bird deaths resulting from power line collisions are a violation of the Migratory Bird Treaty Act and can result in federal fines. Accordingly, utilities often mark wires with various devices in bird concentration areas to prevent such collisions.

Placing such devices on energized power lines can reduce avian collisions with those lines; however, one of the issues associated with marking devices is corona discharge. Corona activity on power lines can result in audio noise (AN) or radio interference (RI) complaints. Because corona may result in customer complaints, it is important to know how marking wires might influence corona. This information will give biologists and engineers the information they need to determine the voltage of wires they can mark without creating unacceptable levels of AN or RI.

Below 115 kilovolts $(\mathrm{kV})$, all of the devices are suitable from an AN and RI perspective. The best-performing devices at $115 \mathrm{kV}$ were the Bird Flight Diverter and the Swan Flight Diverter, neither of which had any detectable corona discharge. At $230 \mathrm{kV}$, the Swan Flight Diverter and the Bird Flight Diverter had a medium level of corona, but still outperformed the flapper-type diverters. At $345 \mathrm{kV}$, all the devices had very high levels of corona.
\end{abstract}




\section{Executive Summary}

\section{Introduction}

One of the most effective ways to reduce avian collisions with power lines is to mark wires, making them more visible. Although several products are available to mark lines, there can be engineering/maintenance issues associated with placing these devices on energized wires. Corona discharge is one of the issues associated with using the marking devices. These discharges occur when surface electric field intensity surrounding an energized electrode exceeds a critical value, resulting in a localized ionization of the surrounding gas - in most cases, air. Corona activity generates light (mainly in the UV spectrum), sound waves, electromagnetic radiation, ozone, and other by-products that can result in unacceptable audio noise (AN) and/or radio interference (RI). Corona activity may occur from sharp edges on energized hardware, broken conductor strands, or defective insulators.

\section{Purpose}

The purpose of this project was to determine whether various marking products could be used on energized wires (at different voltages) without creating significant corona discharge.

\section{Project Objective}

The objective of this project was to test a variety of flight diverter devices at simulated $115-\mathrm{kV}$, $230-\mathrm{kV}$, and $345 \mathrm{kV}$ phase-to-phase line voltages, to measure the corona produced by each device.

\section{Project Outcomes}

The best-performing devices at 115 kilovolts $(\mathrm{kV})$ were the Bird Flight Diverter and the Swan Flight Diverter, neither of which had any detectable corona discharge. At $230 \mathrm{kV}$, the Swan Flight Diverter and the Bird Flight Diverter had a medium level of corona, but still outperformed the flapper-type diverters. At $345 \mathrm{kV}$, all the devices had very high levels of corona.

\section{Conclusions}

Below $115 \mathrm{kV}$, all of the devices are suitable from an AN and RI perspective.

\section{Recommendations}

The levels of AN and RI generated by the devices above voltages of $115 \mathrm{kV}$ do not invalidate their use at these voltages. Rather, device installations should be in areas that will not elicit complaints of the resulting AN and RI. Material degradation may occur at $115 \mathrm{kV}$ and higher, resulting in premature failure. Utilities should have sufficient test data to know if the proposed device can withstand the long-term effects of corona at $115 \mathrm{kV}$ and higher.

\section{Benefits to California}

This results of this research will enable biologists and engineers to determine on which voltages they can install flight diverters without creating excessive AN or RI. As a result, flight diversion efforts can proceed without concerns about these impacts, thereby removing a potential barrier to the use of these devices. 


\subsection{Introduction}

Electric corona occurs when the voltage of an overhead conductor, typically 115 kilovolts $(\mathrm{kV})$ or greater, is raised to such a value that the surrounding air is ionized and becomes a conductor. Corona manifests itself by bluish tufts or streamers appearing around the conductor, being more or less concentrated at irregularities on the conductor surface. This discharge is accompanied by a hissing sound, the odor of ozone and local radio interference. Corona forms at the sharp corners of energized parts so the radii on the corners of such parts are typically engineered large enough to avoid corona formation. However, voids, bubbles and other nonhomogenous compositions within solid materials can promote the formation of corona. Over time, corona can degrade certain materials such as organic insulation.

Along with audible and radio noise, corona emissions produce ultraviolet light in proportion to the strength of the corona emissions. Thus, the amount of ultraviolet light produced creates a relative measure of the amount of corona emission. The ultraviolet light cannot be seen with the naked eye during daylight conditions but can be observed in dark nighttime conditions. However, recently developed cameras can detect the level and location of ultraviolet light in the field of view during the day. These cameras superimpose the detected ultraviolet light as white pixels or small squares on a video image. The DayCor ${ }^{\circledR}$ II camera used in this test performs that function.

Bird deaths resulting from power line collisions are a violation of the Migratory Bird Treaty Act and can result in federal fines. One of the most effective ways to reduce avian collisions with power lines is to mark wires, making them more visible. Although several products are available to mark lines, there can be engineering and/or maintenance issues associated with placing devices on energized wires. Some these devices have many uneven surfaces and sharp corners that project or hang from the conductor, so it is likely they can be a source of corona emission. The goal of this research project was to determine the relative extent of corona emission caused by ten commercially available flight diverters at typical transmission voltages. Table 1 identifies the flight diverters tested, and Figure 1 displays them.

In addition to testing bird flight diverters, the Bird Strike Indicator (BSI) was tested for corona. The BSI is an impulse-based sensor being developed to remotely detect and record bird strikes. The BSI is being developed under a separate research project supported by the California Energy Commission and Western Area Power Administration. The testing of the bird flight diverters created an opportunity to test the BSI at no additional cost. 
Table 1. List of flight diverter manufacturers and models tested

\begin{tabular}{|c|l|l|}
\hline Device \# & Manufacturer & Model \\
\hline 2 & Tyco Electronics & Bird Flight Diverter, BFD2460 \\
\hline 3 & Tyco Electronics & Swan Flight Diverter, SFD1960 \\
\hline 4 & Mission Environmental & Bird Flapper \\
\hline 5 & Bird Safe Inc. & Bird Diverter ${ }^{\mathrm{TM}}$ \\
\hline 6 & Mission Environmental & Bird Flapper - Prototype \\
\hline 7 & Preformed Line Products & Bird Flapper LSFB 0416 \\
\hline 8 & Preformed Line Products & Bird Flapper FB0515 \\
\hline 9 & P\&R Technologies & BirdMark \\
\hline 10 & Midsun Group & Bird Flapper - Prototype \\
\hline 11 & P\&R Technologies & Firefly Bird Flapper \\
\hline
\end{tabular}

Note: The Bird Strike Indicator (BSI) was device \#1, and is not considered a diverter.

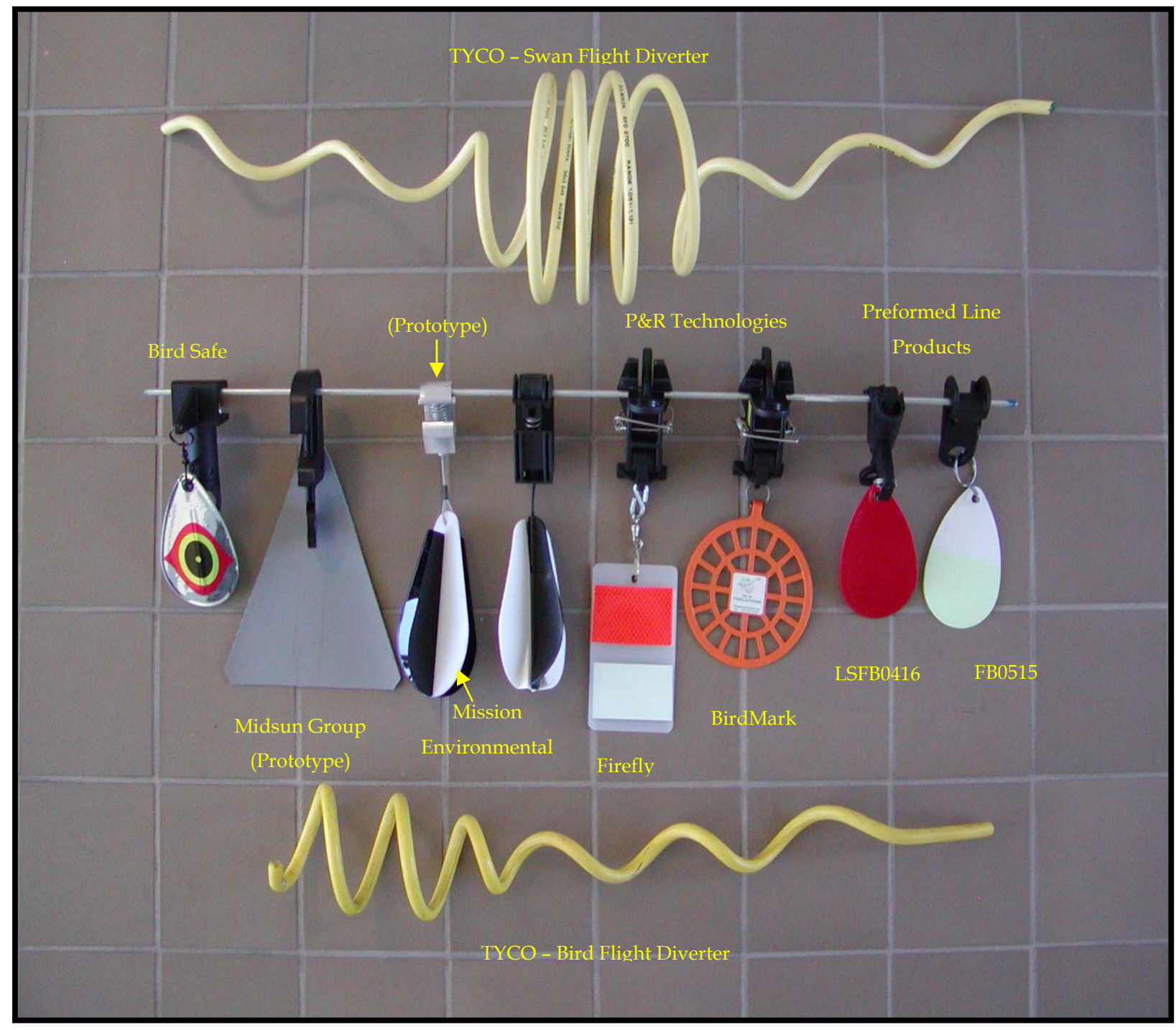

Figure 1. Flight diverters tested as part of the project 
Each of the devices was mounted to an overhead conductor, which was energized to simulate a real overhead transmission line with system voltages of $115 \mathrm{kV}, 230 \mathrm{kV}$, and $345 \mathrm{kV}$. Corona observations with a DayCor II corona camera were made on each device at all three voltages. Levels of corona on the devices were recorded on a 0 to 5 scale representing a range from no corona to very high corona. 


\subsection{Project Approach}

\subsection{Overview of Test Setup}

- The devices were attached to an existing 550-ft test line at the EPRISolutions laboratory in Lenox, Massachusetts (Figure 2).

- The devices were attached 10 feet apart so as not to influence the corona performance of adjacent samples.

- The conductor was 1.1 inches in diameter. Note that the diameter of a conductor has a significant effect on the surface gradient (and, therefore, the corona inception voltage) of the conductor; however, the surface gradient of an attached object does not depend significantly on the diameter of the conductor. Therefore, the results obtained will apply to any size single-conductor configuration.

- The height above ground was set at approximately 40 feet. Surface gradients of overhead conductors (including small attached objects) are only affected by changes in ground clearance when that clearance is very small. The results obtained in these tests will apply to any ground clearance that is practical for the voltage classes considered.

- Perceptible amounts of corona rarely occur below system voltages of $115 \mathrm{kV}$. Thus the voltages chosen for this test were $115 \mathrm{kV}, 230 \mathrm{kV}$, and $345 \mathrm{kV}$ - the three main transmission voltages used in North America. Transmission systems divide the power across three phases, with each phase having its own wire. Such voltages are called lineto-line voltages, where the voltage is measured between any two phases. For a threephase system, the magnitude of voltage surface gradient on each wire is determined by both the voltage on the wire and the influence of the electric fields from adjacent phase wires.

However, in this test, only the conductor bearing the devices was energized, creating a single-phase system instead. This difference in number of phases is not a problem so long as the voltage surface gradient of the single phase system matches that of the equivalent three-phase system. In a single phase system, the voltage is defined in terms of line-to-ground, where the voltage is measured between one phase conductor and ground potential. Three-phase system voltages can be alternatively defined in terms of line-to-ground voltages, through dividing the line-to-line voltages by the square root of three. Thus, a $115-\mathrm{kV}$, three-phase system has a line-to-ground voltage of $66.7 \mathrm{kV}$. However this line-to-ground voltage must be increased to raise the voltage surface gradient to a level equivalent to the three-phase, $115-\mathrm{kV}$ system, which is $78 \mathrm{kV}$. Table 2 shows this relationship for the three system voltages used during testing.

Table 2. System voltages and corresponding test voltages

\begin{tabular}{|c|c|c|}
\hline $\begin{array}{c}\text { Three-phase line-to-line } \\
\text { voltage }(\mathrm{kV})\end{array}$ & $\begin{array}{c}\text { Equivalent line-to-ground } \\
\text { voltage }(\mathrm{kV})\end{array}$ & Test Voltage $(\mathrm{kV})$ \\
\hline 115 & 66 & 78 \\
230 & 133 & 157 \\
345 & 199 & 234 \\
\hline
\end{tabular}


- The DayCor II camera was placed on the ground adjacent to the test line. Starting at the lowest voltage - and then increasing the voltage to the other two levels - observations of each sample were made and photographed with the DayCor II camera to determine corona activity. Figures 3 and 4 show the DayCor II camera during field use.

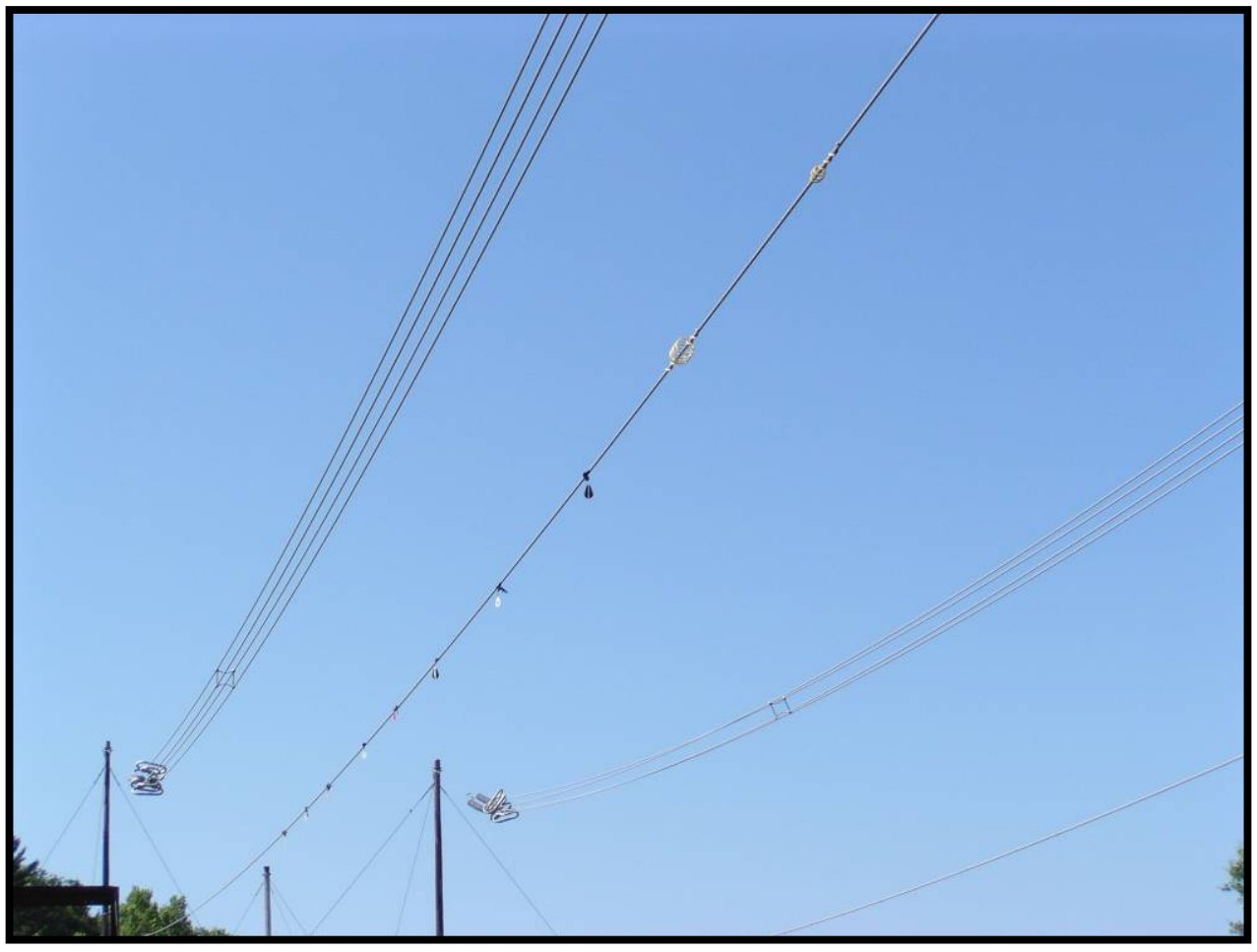

Figure 2. Test setup

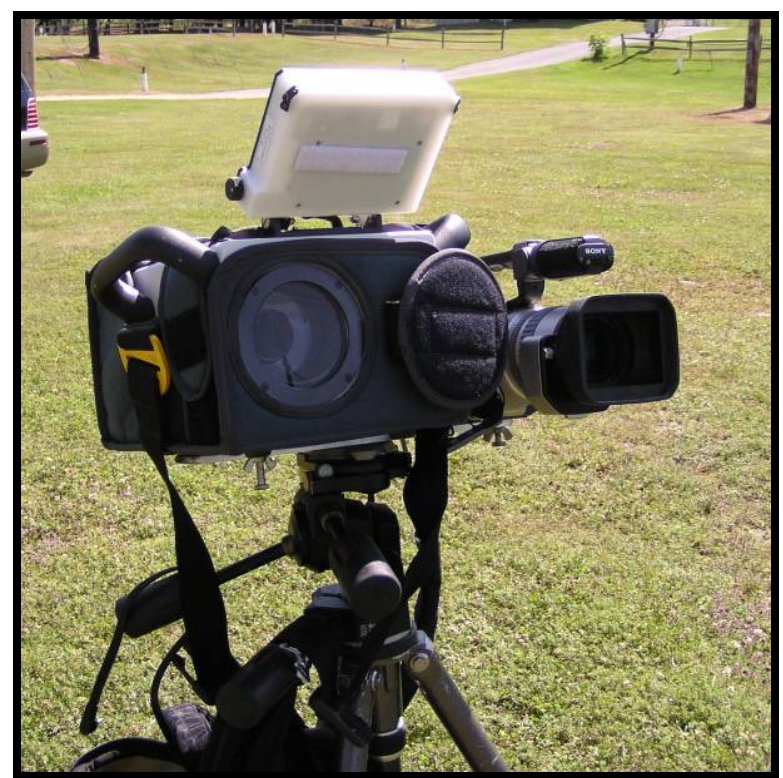

Figure 3. DayCor II camera

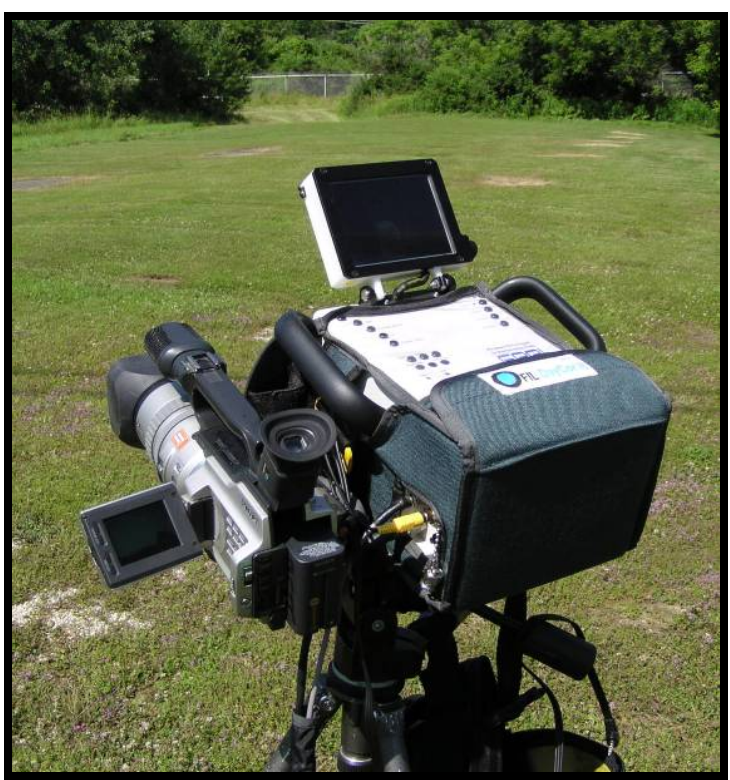

Figure 4. DayCor II camera 


\subsection{Testing}

The Bird Strike Indicator was tested and labeled as Device \#1. Ten separate flight diverters were tested and labeled 2 through 11. Below are photos (numbered accordingly) of all the installed flight diverters. Both Mission Environmental and Midsun Group supplied a prototype unit for testing. Mission Environmental also submitted their final design.

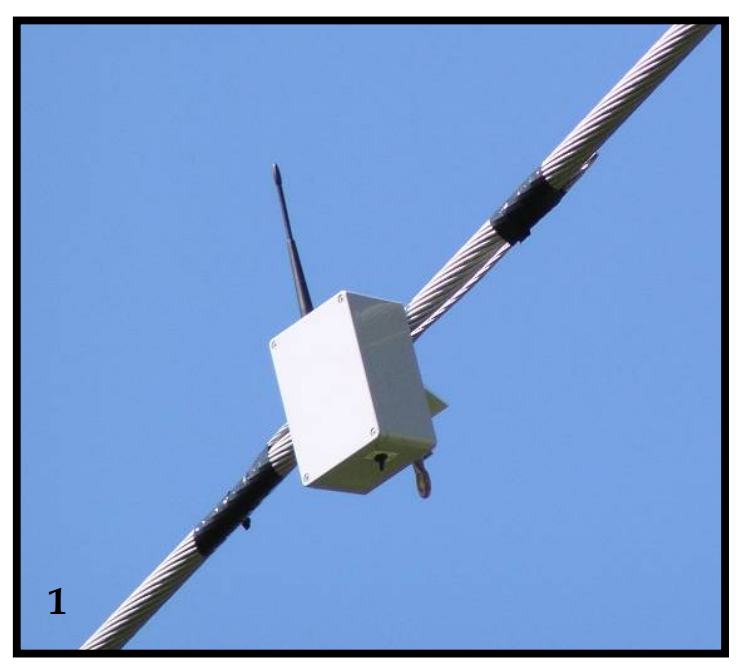

Figure 5. Bird Strike Indicator

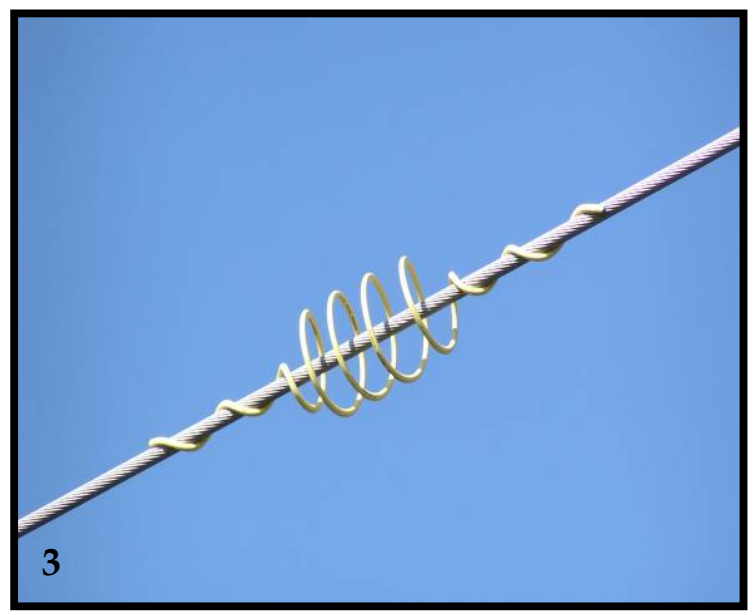

Figure 7. Swan Flight diverter, Tyco Electronics (SFD1960)

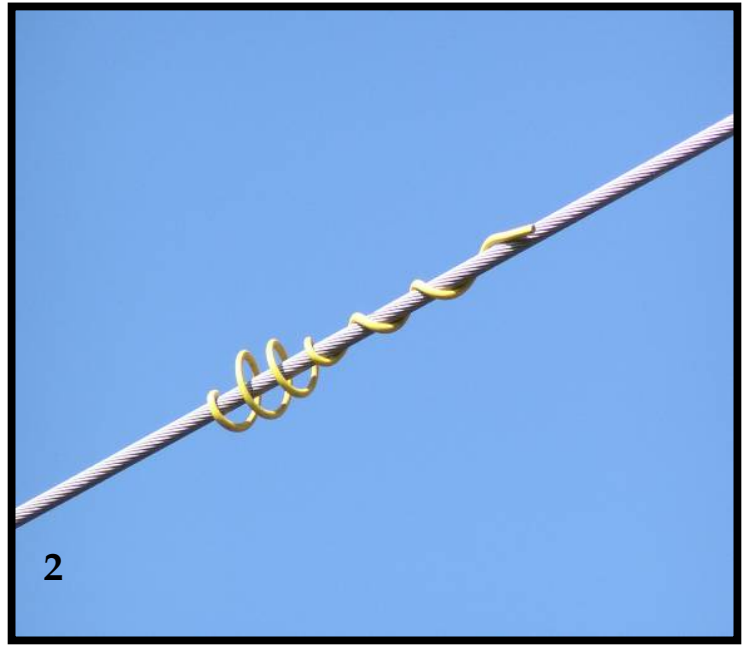

Figure 6. Bird Flight Diverter, Tyco Electronics (BFD2460)

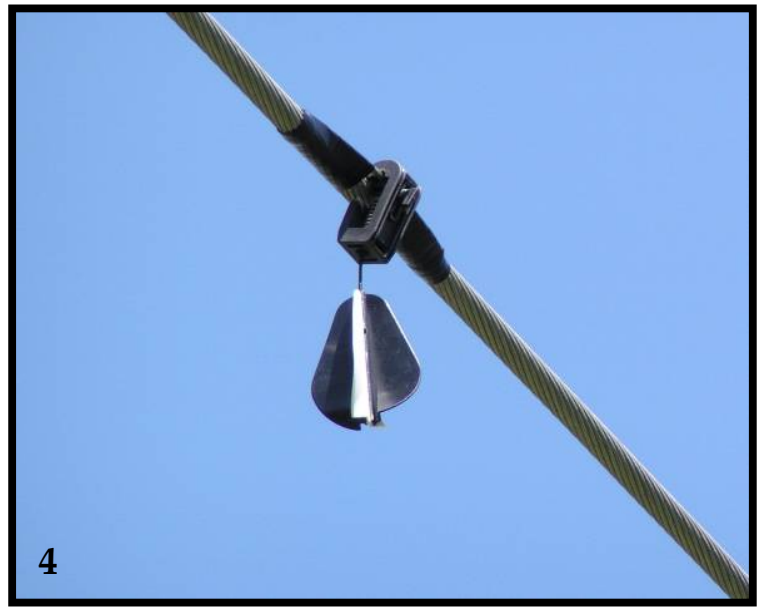

Figure 8. Bird Flapper, Mission Environmental 


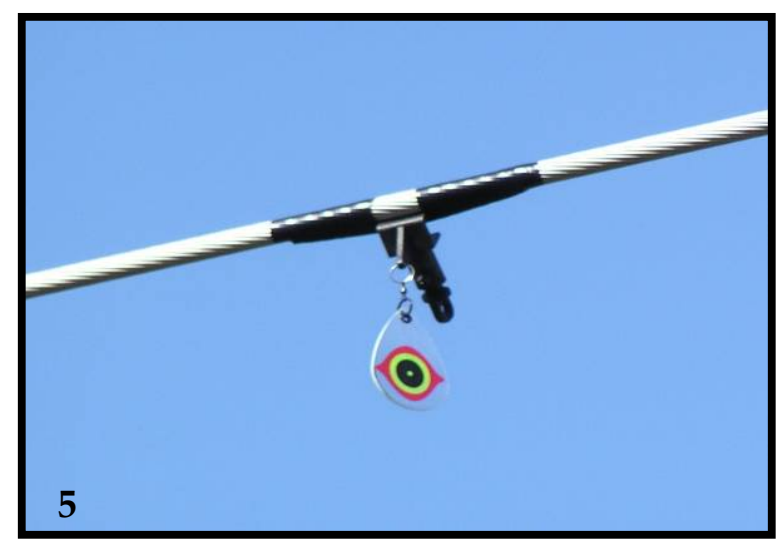

Figure 9. Bird Diverter, Bird Safe

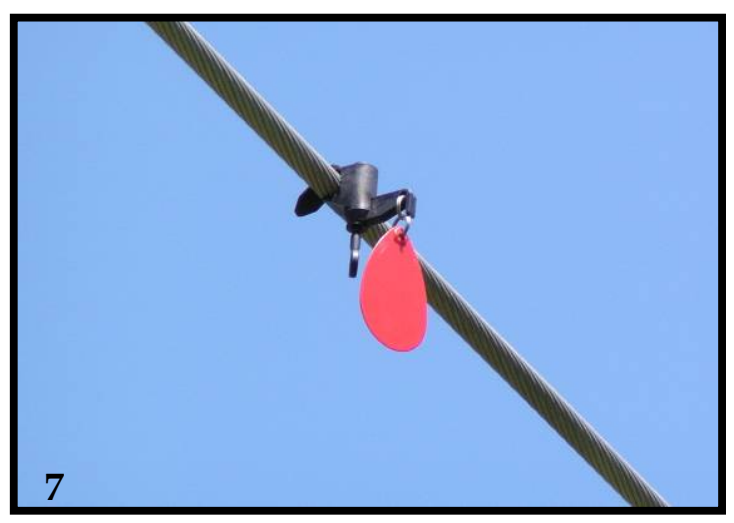

Figure 11. Bird Flapper, Preformed Line Products (LSFB0416)

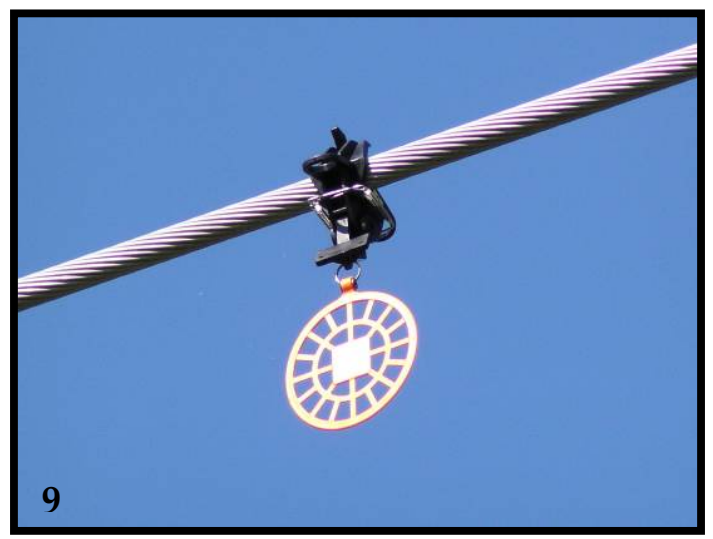

Figure 13. Bird Mark, P\&R Technologies

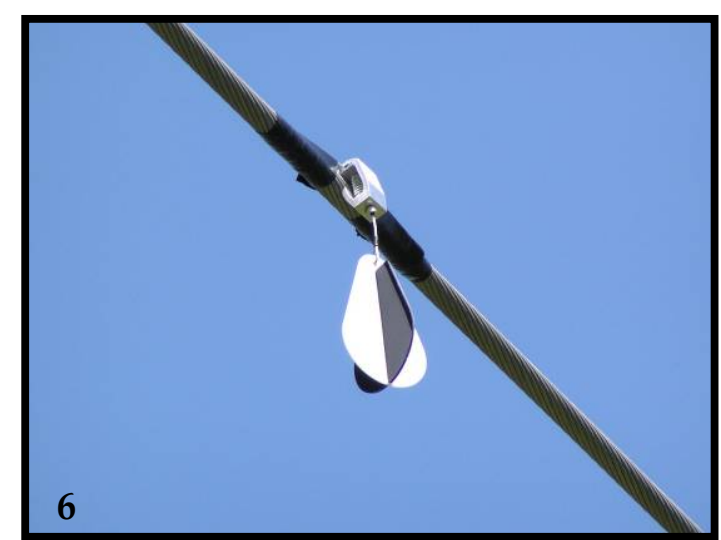

Figure 10. Bird Flapper - Prototype, Mission Environmental

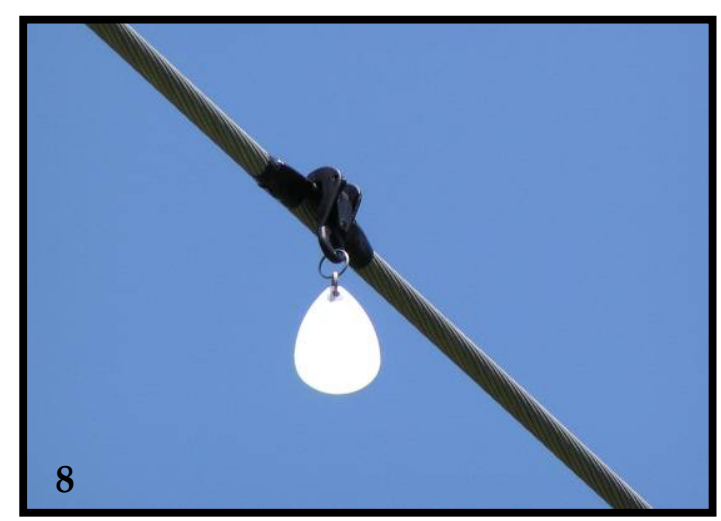

Figure 12. Bird Flapper, Preformed Line Products (FB0515)

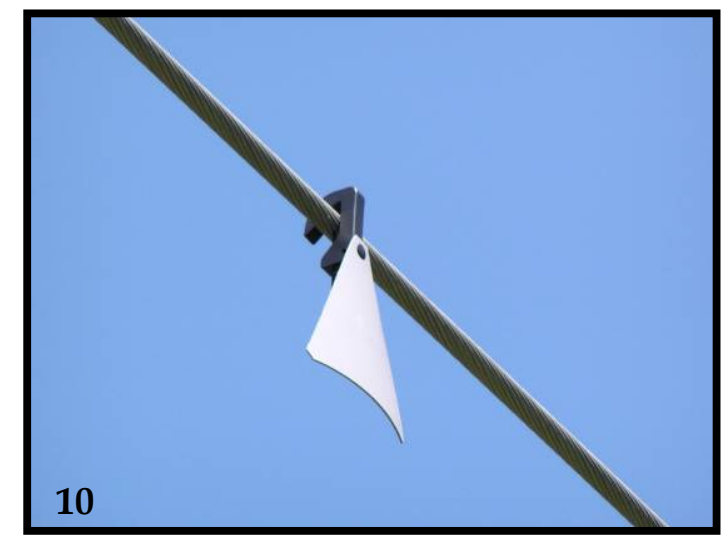

Figure 14. Bird Flapper - Prototype, Midsun Group 


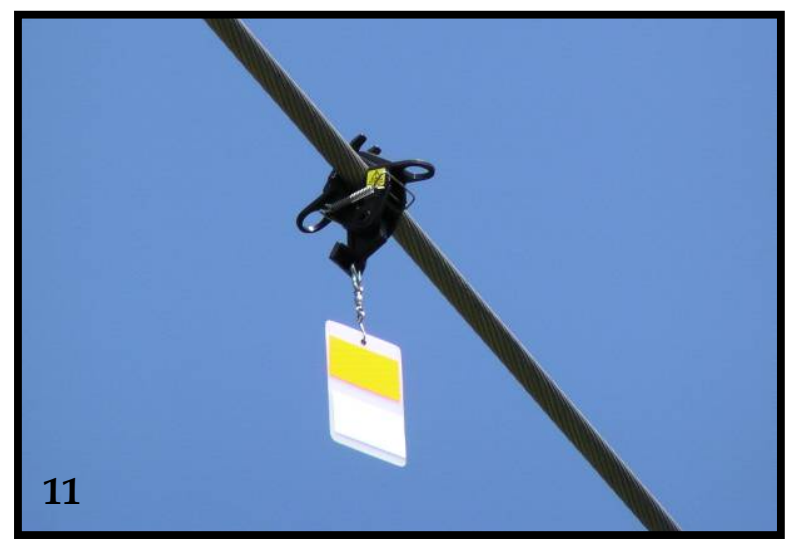

Figure 15. Firefly Bird Flapper, P\&R Technologies 


\subsection{Project Outcome}

The DayCor II camera does not provide a quantitative measurement of corona activity, but instead displays the intensity of corona by the presence of white pixels superimposed on the video image where the sources of corona exist. The user must then determine the relative amount of corona present through visual observation of the video image. Thus, for each voltage level and each device, the testing team observed the video display of the DayCor camera and judged the level of corona on each device on a scale of 0 to 5 , as follows:

$$
\begin{aligned}
& 0=\text { No corona } \\
& 1=\text { Barely detectable corona } \\
& 2=\text { Definitely detectable corona } \\
& 3=\text { Medium level of corona } \\
& 4=\text { High level of corona } \\
& 5=\text { Very high level of corona }
\end{aligned}
$$

Figures 16 through 21 are images captured from the video stream and illustrate the relative levels of the scales described above.

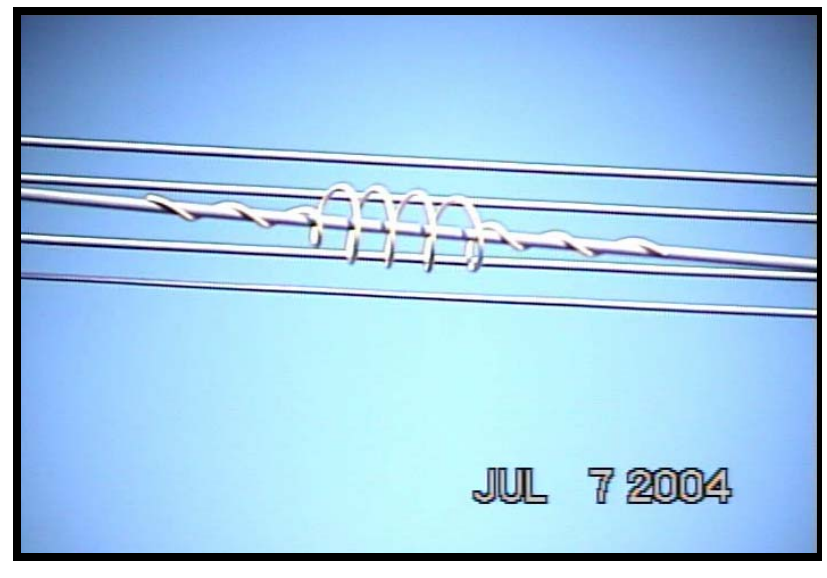

Figure 16. Level 0: No corona

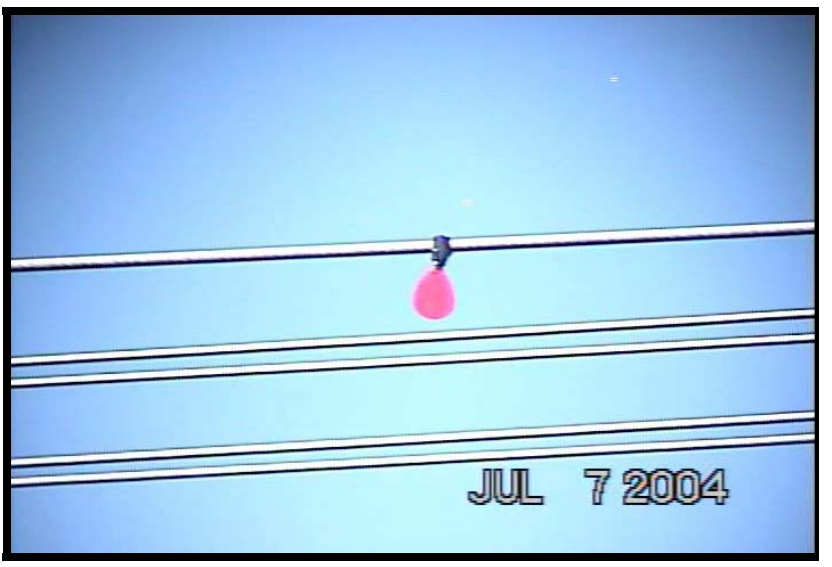

Figure 17. Level 1: Barely detectible corona 


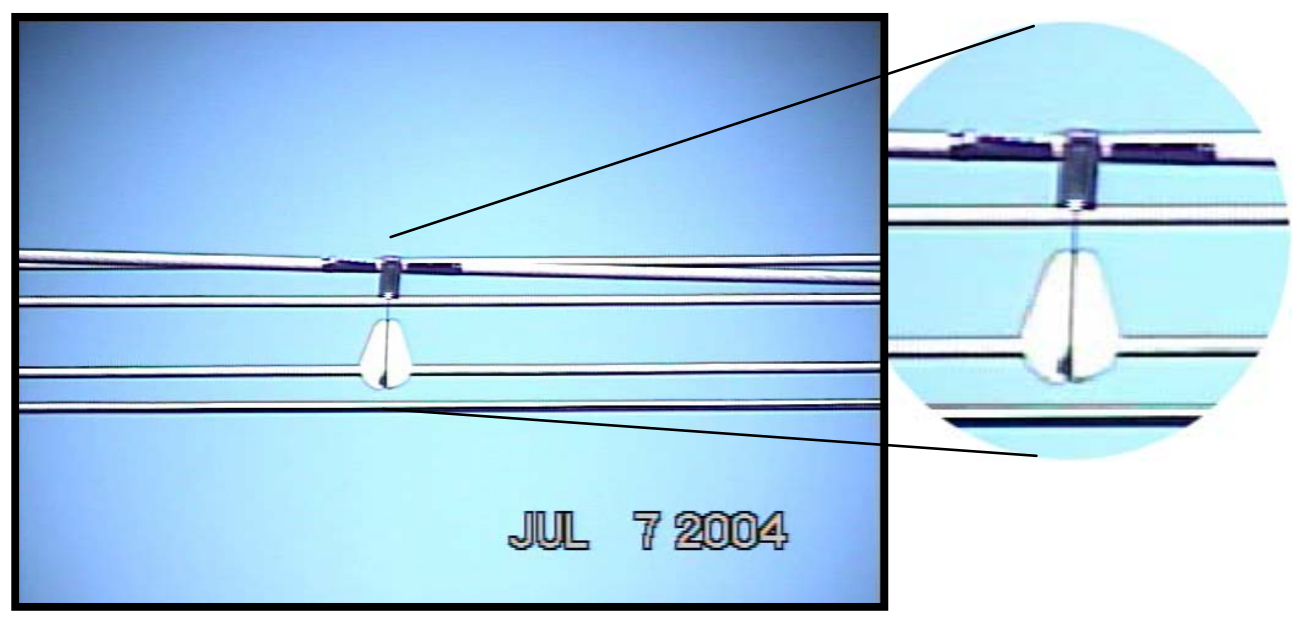

Figure 18. Level 2: Definitely detectable corona (at bottom of cable clamp)

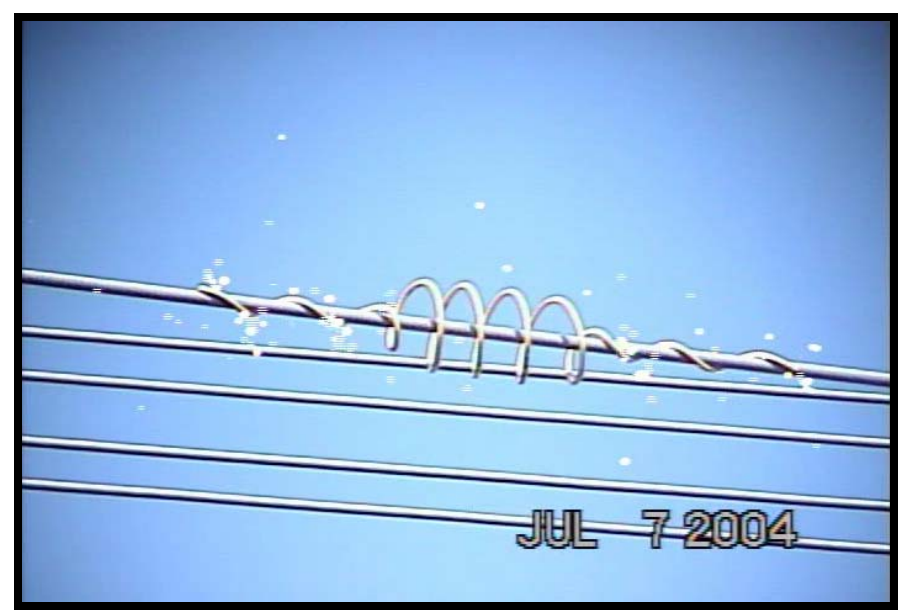

Figure 19. Level 3: Medium level of corona

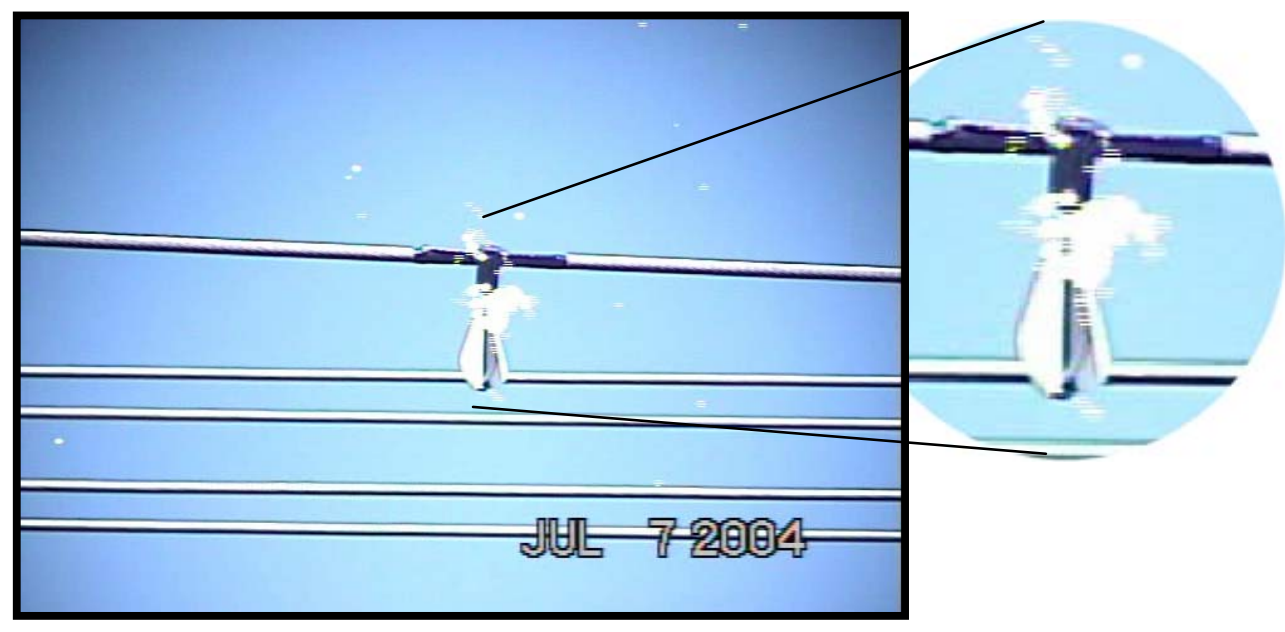

Figure 20. Level 4: High level of corona 


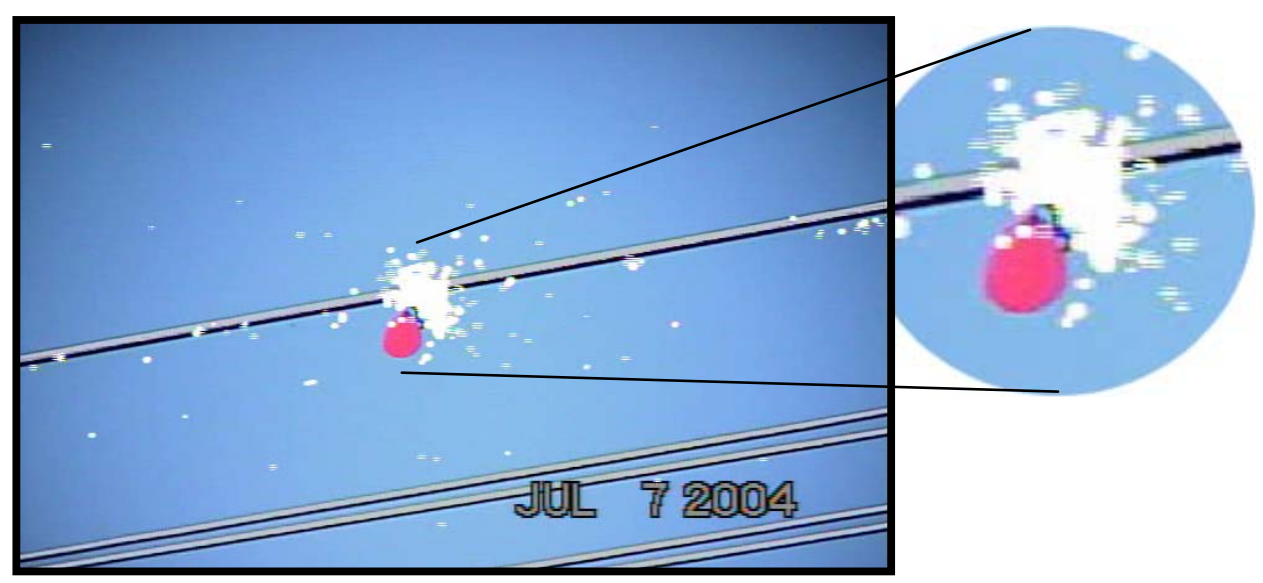

Figure 21. Level 5: Very high level of corona

Table 3 summarizes the results and is shown below.

Table 3. Corona levels for all the devices tested

\begin{tabular}{|c|l|c|c|c|}
\hline \multirow{2}{*}{$\begin{array}{c}\text { Device } \\
\text { Number }\end{array}$} & \multicolumn{1}{|c|}{ Model } & \multicolumn{3}{|c|}{ Corona Level } \\
\cline { 3 - 5 } & $\begin{array}{c}78 \mathrm{kV} \\
(\text { simulating a } \\
115-\mathrm{kV} \text { line })\end{array}$ & $\begin{array}{c}157 \mathrm{kV} \\
\text { (simulating a } \\
230-\mathrm{kV} \text { line) }\end{array}$ & $\begin{array}{c}234 \mathrm{kV} \\
(\text { simulating a } \\
345-\mathrm{kV} \text { line }\end{array}$ \\
\hline 1 & Bird Strike Indicator & 2 & 4 & 5 \\
\hline 2 & Bird Flight Diverter, BFD2460 & 0 & 3 & 5 \\
\hline 3 & Swan Flight Diverter, SFD1960 & 0 & 3 & 5 \\
\hline 4 & $\begin{array}{l}\text { Bird Flapper-Mission } \\
\text { Environmental }\end{array}$ & 2 & 4 & 5 \\
\hline 5 & Bird Diverter-Bird Safe & 1 & 4 & 5 \\
\hline 6 & $\begin{array}{l}\text { Bird Flapper-Prototype- } \\
\text { Mission Environmental }\end{array}$ & 4 & 4 & 5 \\
\hline 7 & Bird Flapper-LSFB0416 & 1 & 4 & 5 \\
\hline 8 & Bird Flapper-FB0515 & 1 & 4 & 5 \\
\hline 9 & BirdMark & 0 & 4 & 5 \\
\hline 10 & Bird Flapper-Prototype- & 1 & 4 & 5 \\
\hline 11 & Midsun & & & 5 \\
\hline
\end{tabular}

The most receptive sites for corona are on flapper-type devices (e.g., devices 4-11). The flappertype diverters are susceptible on the top of the flapper and at the point of attachment to the conductor.

After testing was completed, the flight diverters were visually inspected for any signs of physical damage due to corona discharge. No damage was observed, save for device \#5, where the mylar label on the flapper had disintegrated around the attachment grommet (Figure 22). 
During testing this was the only flapper where the entire flapper was engulfed in corona at 345 $\mathrm{kV}$.

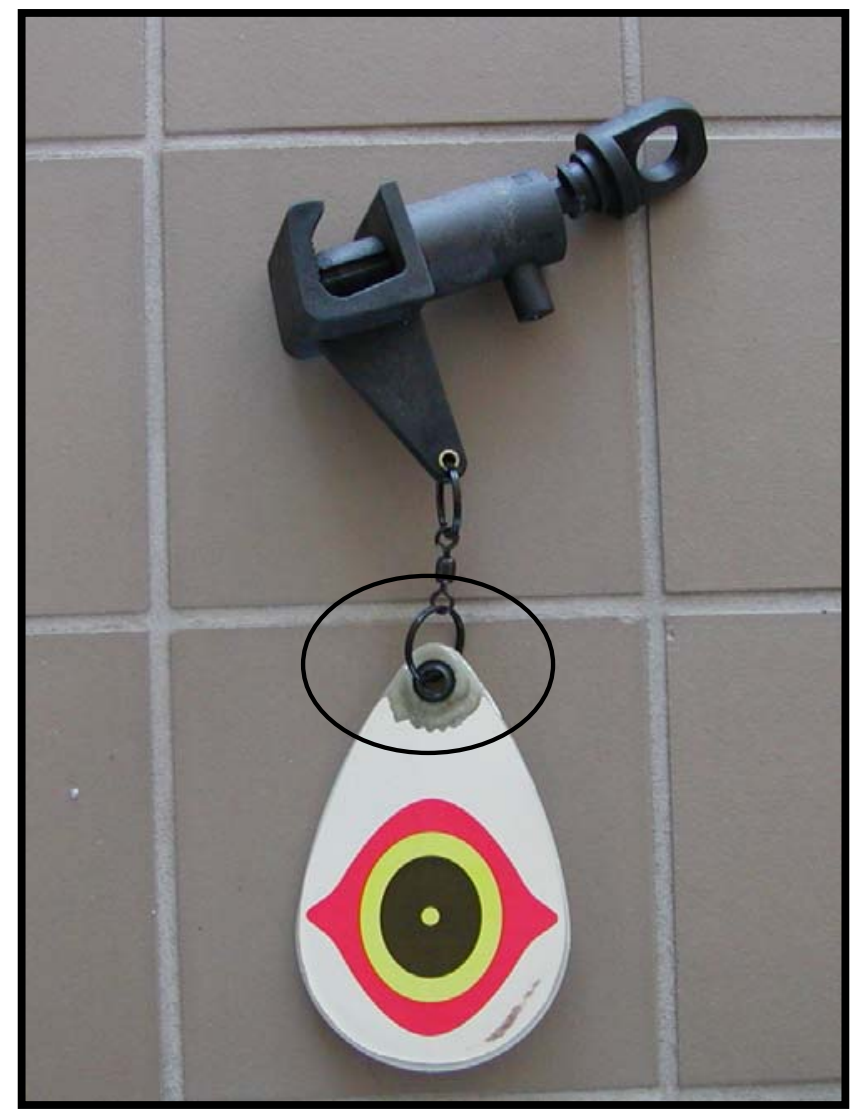

Figure 22. Corona-induced damage on diverter \#5 


\subsection{Conclusions}

At the 115-kV voltage, all the devices had very little or no corona, except for device \#6, which had a high level of corona at $115 \mathrm{kV}$ and a high and very high level at $230 \mathrm{kV}$ and $345 \mathrm{kV}$, respectively. This device is the prototype to device \#4, which had a reduced amount of corona at $115 \mathrm{kV}$.

At the 230-kV voltage, all the flapper type devices (devices $4-11$ ) had a high level of corona, and this corona increased on the $345-\mathrm{kV}$ line. The corona generally occurred at the point of attachment to the conductor and at the top of the flappers.

Given the small amount of corona emission found on the devices at $115 \mathrm{kV}$, all devices will not emit any significant amounts of corona. Based on the observed performance at $115 \mathrm{kV}$ and $230 \mathrm{kV}$, corona emission at the intermediate transmission voltages of $138 \mathrm{kV}$ and $161 \mathrm{kV}$ also used in the industry should be slightly higher than that at $115 \mathrm{kV}$.

The extent or rate of decay the flapper materials experience due to the corona discharge is unknown and was not ascertained from the test results. The only visibly detectable decay was found on device 5, where a portion of the mylar film on the flapper disintegrated around the mounting grommet.

Although similar materials have been known to withstand the effects of corona for some time, further testing is required to confidently determine the ability of the device materials to withstand ongoing corona emissions.

Corona also emits audible noise and radio interference. These emissions are not a problem unless people sufficiently frequent the immediate area to be annoyed by the emissions. The magnitude of both audible noise and radio interference decreases quickly over distance, typically limiting the effective range to hundreds of feet. Further reducing the range is the height of the wires above the ground. Such heights above the ground begin at 25 feet and may often rise up to 100 feet. Complaints of $\mathrm{AN}$ and RI are rarer in a rural environment. In urban environments, RI may cause more complaints than AN, which can be reduced in effectiveness due to ambient noise conditions.

However, the audible noise and ultraviolet light emitted by corona may provide a positive effect. One or both emissions might be sufficiently detected by certain species of birds, thus providing a further aid for avoiding a collision with the line.

The selection of the appropriate bird collision device depends on a variety of factors, including the effects on ice and wind loading, cost of the product and installation costs, product effectiveness for a particular bird species, aesthetics, and product durability. Devices also must adhere to safety requirements. In addition to these factors, corona discharge can occur resulting in audio noise, radio interference, and material degradation. The two commercially available products that performed the best at $115 \mathrm{kV}$ were the TYCO Bird Flight Diverter and the Swan Flight Diverter, with no detected corona. These devices also were the best-performing devices at $115 \mathrm{kV}$ with a medium level of corona discharge. Although flapper type devices may be more effective to deter collisions because of the movement of the swinging plates, they will generate greater corona at $115 \mathrm{kV}$ and higher. 


\title{
LEG PROBLEMS AND POWER LINE INTERACTIONS IN THE FLORIDA RESIDENT FLOCK OF WHOOPING CRANES
}

JAIMIE L. MILLER, Department of Infectious Diseases and Pathology, College of Veterinary Medicine, University of Florida, Box 110880, Gainesville, FL 32610, USA

MARILYN G. SPALDING, Department of Infectious Diseases and Pathology, College of Veterinary Medicine, University of Florida, Box 110880, Gainesville, FL 32610, USA

MARTIN J. FOLK, Florida Fish and Wildlife Conservation Commission, 1475 Regal Court, Kissimmee, FL, 34744, USA

\begin{abstract}
We retrospectively reviewed a database with over 1,800 health entries from 296 captive-reared whooping cranes (Grus americana) released in central Florida and 10 wild-fledged chicks from 1992 to 2007. Fifty percent of the study population $(n=306)$ had 1 or more leg problems that were placed into 4 broad categories: power line interactions $(n=39)$, other trauma $(n=94)$, deformities $(n=43)$, and miscellaneous conditions $(n=106)$. More males $(n=26,67 \%)$ had power line interactions than females $(n=13,33 \%)$. The majority of these 39 birds died $(57 \%)$, while the rest recovered from an injury $(20 \%)$, went missing (7\%), or survived with no apparent injury (16\%). Twenty-two of the $44(50 \%)$ recorded power line strikes involved the leg-mounted transmitter. Most minor leg problems in the other trauma category were observed at arrival or quarantine examinations; no major injuries occurred as a result of $>800$ handling or capture events. Birds arriving in Florida with toe deformities, short legs, or a leg rotation had no difference in survival or reproductive value when compared to the general population. All categories except for deformities contained birds with injuries associated with mortality. The most mortality related injuries were a result of power line interactions. Among the 149 birds with leg problems, 44 cranes $(29 \%$, $14 \%$ of all birds) had injuries sufficient enough to be associated with mortality. Birds that survived leg injuries lived longer than birds with no previous injury prior to death.
\end{abstract}

PROCEEDINGS OF THE NORTH AMERICAN CRANE WORKSHOP 11:156-165

Key words: deformities, Florida, Grus americana, leg injuries, monofilament line, power lines, radio transmitters, whooping cranes.

The reintroduced resident flock of whooping cranes (Grus americana) in Florida was established in an attempt to satisfy a goal of the species recovery plan (CWS and USFWS 2007). Four breeding centers were involved with captive rearing cranes for release into this flock (Nesbitt et al. 1997). Problems involving the legs are a continual concern for captive-reared cranes (Wellington et al. 1996), but their importance following release is not known. Kelley and Hartup (2008) identified potential risk factors for leg and toe deformities, including rearing method, egg source, egg laying order, and relative weight change during the first and second weeks of age. Here we analyzed a database of health records from 306 wild-fledged and captive-reared whooping cranes to determine the prevalence of leg problems and power line interactions, and their significance to health and survival in the wild. We also evaluated the survival and reproduction of birds released with pre-existing leg and toe deformities.

\section{METHODS}

Our study population consisted of 306 whooping cranes: 296 birds reared in captivity and released into the wild at 6 to 10 months of age (155 males and 141 females) and 10 wild-fledged birds ( 2 males and 8 females) from 1992 to 2007. Cranes were reared in captivity at Patuxent Wildlife Research Center (PWRC), Laurel, Maryland; International Crane Foundation (ICF), Baraboo, Wisconsin; the Calgary Zoo, Calgary, Alberta; and the San Antonio Zoo, San Antonio, Texas. Captive-reared birds were examined upon arrival in Florida and a leg-mounted transmitter was attached to either the left or right leg to track the birds for further monitoring. After a pre-release examination 2 weeks after arrival, birds were softreleased (Nesbitt et al. 1997) in 3 central Florida counties (Lake, Osceola, and Polk). The birds were frequently monitored to obtain location, health status, breeding status, and to observe behavior. We captured birds by 10 methods in order to replace transmitters and gather health data (Folk et al. 2005). All relevant health data were stored in a database which contained over 1,800 records of field observations, captures, and necropsy reports.

We searched the database for key words indicating 
possible leg problems or power line interactions. All conditions noted at the arrival examination and thereafter were considered. Birds $<1$ year of age were considered chicks, while birds 1 to $<3$ years of age were subadults and those $\geq 3$ years of age were adults. Conditions were placed into 4 broad categories: power line interactions, other traumatic injuries, deformities, and miscellaneous conditions. Birds could be placed in multiple categories based on the problems diagnosed and were included in each category total but were only counted once for the total injured population. Percentages refer to the percent of total population unless stated otherwise.

We defined a power line interaction as either direct evidence that a bird hit the power line, such as finding a dead or injured bird or its transmitter under a power line, or when a bird died from other causes such as predation, but was believed to have been previously injured from striking a power line in the area. For example, a bird with a broken wing within sight of a power line that was killed by a bobcat several days later was considered as a power line interaction.

Other traumatic injuries included leg dangle (leg is dropped from normal flight position), hip dislocation, leg fracture, fence and vehicular collision, lameness, monofilament line entanglement, and/or wounds. Wounds included abrasions, lacerations, and sores. Injuries sustained during capture or handling were also included in this category.

Deformities included toe deformities, short legs, rotated tarsometatarsus, or any combination of the 3 that were present upon arrival in Florida. An ANOVA test was used to determine the effects of developmental deformities on survival and reproduction for birds $\geq 3$ years of age using age at death or age in 2007 for surviving birds and the reproductive value of the bird. The reproductive value was calculated as per Spalding et al. (2010).

Miscellaneous conditions included birds with defects of the integument (calluses, cracked skin, crusts, dermatitis, dry skin, hyperemia, scabs, scars, sloughing skin, and avulsed skin), swelling (arthritis, bruises, cellulitis, edema, hemorrhage, and myositis, as well as generalized swelling), and miscellaneous toe problems (lost or missing toes or toenail injuries, pododermatitis, chondroma, and undiagnosed nodules).

An injury was considered related to death if it directly led to mortality or if it predisposed the bird to predation. If the injury did not meet these criteria, it was considered to be unrelated to mortality. A KaplanMeier survival analysis was used to gauge the survival of birds with injuries to birds with no recorded injury. An ANOVA test was used to evaluate leg problems and the source (PWRC, ICF, other, or wild) and rearing method among birds reared in isolation, by surrogate parents, as a combination of the 2 , or by wild parents (Nagendran et al. 1996).

\section{RESULTS}

We determined 50\% (154/306 birds; 78 males, 76 females) of the flock had 1 or more leg problems. We categorized these as power line interactions (39/306, $13 \%$ of total population), other trauma $(94 / 306,31 \%)$, deformities $(43 / 306,14 \%)$, and miscellaneous conditions $(106 / 306,35 \%)$.

\section{Power Line Interactions}

Thirty-nine whooping cranes had 44 power line interactions (Table 1). More males $(n=26,67 \%)$ than females $(n=13,33 \%)$ collided with power lines. The majority of these 39 birds died (57\%), while the rest recovered from an injury (20\%), went missing (7\%), or survived with no apparent injury (16\%). Four birds had multiple ( 2 to 3 ) power line interactions. Two males and 1 female died as a result of their second interaction and another female was still alive in 2007 after 3 interactions. The transmitter or the transmittered leg was involved in $22(50 \%)$ of the 44 individual power line interactions. Seventeen cases involved the transmitter being separated from the leg. The transmitter was involved twice for 1 bird, the first encounter causing a wound on the tarsometatarsus of the transmittered leg and the second causing lameness of the transmittered leg. All 8 instances of electrocution involved male birds; 3 were chicks, 3 were subadults, and 2 were adults (Fig. 1). Most of the female power line mortality was among subadult birds; in fact, no adult females died as a result of power line interaction. Five birds remained alive in 2007 following interactions with power lines. These birds include 2 males with no injuries, 2 females with temporary wing injuries, and a female with 3 power line interactions (1 wound on the tarsometatarsus of the transmittered leg, short-term lameness of the non-transmittered leg, and 
Table 1. Summary of whooping crane power line interactions in central Florida, 1992-2007.

\begin{tabular}{|c|c|c|c|c|c|c|c|c|}
\hline \multirow{2}{*}{ Power line interaction } & \multirow{2}{*}{ Total birds } & \multirow{2}{*}{$\%$ of total population } & \multicolumn{2}{|c|}{ Sex } & \multicolumn{3}{|c|}{ Age } & \multirow{2}{*}{ Total instances } \\
\hline & & & $\mathrm{M}$ & $\mathrm{F}$ & Chick & Subadult & Adult & \\
\hline Collision trauma & 14 & 5 & 9 & 5 & $3^{\mathrm{t} 1}$ & $8^{\mathrm{t} 3}$ & $3^{\mathrm{t} 1}$ & 14 \\
\hline Electrocution & 8 & 3 & 8 & 0 & 3 & 3 & $2^{\mathrm{t} 1}$ & 8 \\
\hline Survived uninjured & 7 & 2 & 5 & 2 & 0 & $3^{\mathrm{t} 3}$ & $4^{t 4}$ & 7 \\
\hline Lameness & 6 & 2 & 3 & 3 & $2^{\mathrm{t} 1}$ & $1^{\mathrm{t} 1}$ & $3^{\mathrm{t} 2}$ & 6 \\
\hline Missing & 3 & 1 & 2 & 1 & $1^{\mathrm{t} 1}$ & $2^{\mathrm{t} 2}$ & 0 & 3 \\
\hline Wing injury & 3 & 1 & 1 & 2 & 0 & 2 & 1 & 3 \\
\hline Leg fracture & 2 & 1 & 1 & 1 & 0 & 1 & $1^{\mathrm{t} 1}$ & 2 \\
\hline Leg wound & 1 & $<1$ & 0 & 1 & 0 & 0 & $1^{t 1}$ & 1 \\
\hline TOTAL & $39^{a}$ & 13 & 26 & 13 & 9 & 20 & 15 & 44 \\
\hline
\end{tabular}

a Birds with multiple conditions were only counted once.

tn Number of birds with injuries involving the transmitter.

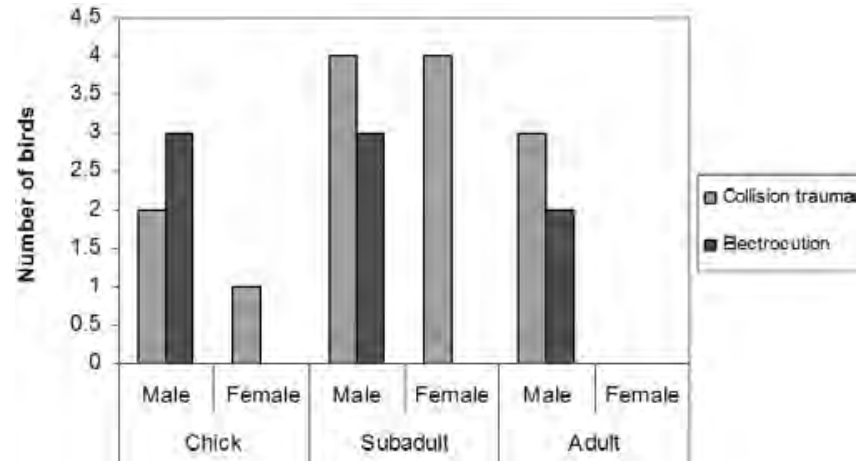

Figure 1. Gender and age of whooping cranes that died from trauma or electrocution when colliding with power lines in central Florida, 1992-2007.

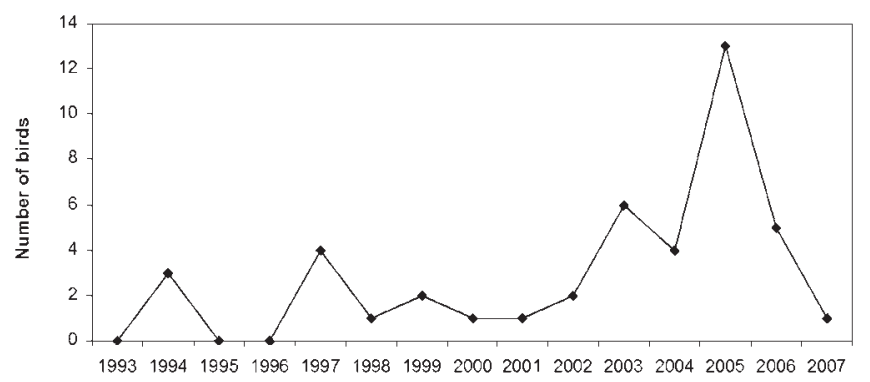

Figure 2. Number of whooping crane power line interactions in central Florida, 1993-2007.

short-term lameness of the transmittered leg).

An increase in the number of power line strikes occurred from 2003 to 2005 (Fig. 2). There were 23 interactions during those 3 years; 14 interactions were recorded the previous 10 years (1993-2002). There were 13 interactions in Lake and Sumter counties from the same power line, resulting in 6 dead or missing birds from 2003 to 2005 . These all involved transmission lines $(>115 \mathrm{kV})$ located between roosting and foraging sites. The increase was attributed to birds roosting and foraging on opposite sides of power lines based upon observations of sites used and flight patterns.

\section{Other Trauma}

Seventy-two whooping cranes had other traumatic injuries (Table 2). Two female birds observed dangling a leg while in flight (Fig. 3) were still alive in 2007, while the others either died from bobcat predation or went missing within a few months after injury. No cause for these leg deviations where found at post mortem examination. One of the surviving birds no longer had a leg dangle but did have a recurring limp in the opposite leg. The other bird's condition remained unchanged.

One (1\%) female bird suffered a hip dislocation after getting caught in a fence as a subadult. The hip displacement resolved in transit to the University of Florida Veterinary Medical Center (VMC) and this bird was released after a short period of treatment while a laceration healed. This bird sustained no other injuries until 10, 12, and 13 years of age, when a right digit 2 curl, lameness, and left digit 3 swelling, respectively, were observed. This bird was alive in 2007 and fledged 2 chicks.

Nine (3\%) whooping cranes were recorded with leg fractures (Table 3). Five of the $6(83 \%)$ single leg fractures involved the transmittered leg. Of 5 birds with leg fractures, 3 that were hospitalized and 1 left alone in the 
Table 2. Summary of whooping cranes with other (non-power line) traumas in central Florida, 1992-2007.

\begin{tabular}{|c|c|c|c|c|c|c|c|c|}
\hline \multirow{2}{*}{ Other trauma } & \multirow{2}{*}{ Total birds } & \multirow{2}{*}{$\%$ of total population } & \multicolumn{2}{|c|}{ Sex } & \multicolumn{3}{|c|}{ Age } & \multirow{2}{*}{ Total instances } \\
\hline & & & $\mathrm{M}$ & $\bar{F}$ & Chick & Subadult & Adult & \\
\hline Wounds & 50 & 16 & 21 & 29 & 40 & 7 & 6 & 53 \\
\hline Lacerations & 29 & 9 & 13 & 16 & $20^{\mathrm{t} 1}$ & 5 & $5^{\mathrm{c} 1, \mathrm{t} 2}$ & 30 \\
\hline Abrasions & 20 & 7 & 8 & 12 & 20 & 2 & $1^{\mathrm{t} 1}$ & 23 \\
\hline Lameness & 21 & 7 & 10 & 11 & $4^{t 4}$ & $9^{t 4}$ & $10^{t 4}$ & 23 \\
\hline Leg fracture & 9 & 3 & 6 & 3 & $1^{\mathrm{t} 1}$ & $4^{\mathrm{t} 2}$ & $4^{\mathrm{t} 2}$ & 9 \\
\hline \multicolumn{9}{|l|}{ Fence and vehicular } \\
\hline collisions & 7 & 2 & 2 & 5 & 0 & 3 & $4^{\mathrm{t} 1}$ & 7 \\
\hline Fence collision & 5 & 2 & 0 & 5 & 0 & 2 & 3 & 5 \\
\hline Vehicular collision & 2 & 1 & 2 & 0 & 0 & 1 & 1 & 2 \\
\hline Leg dangle & 6 & 2 & 2 & 4 & $3^{\mathrm{t} 2}$ & 1 & 2 & 6 \\
\hline \multicolumn{9}{|l|}{ Monofilament line } \\
\hline entanglement & 5 & 2 & 0 & 5 & $1^{\mathrm{t} 1}$ & 3 & 2 & 6 \\
\hline Hip dislocation & 1 & $<1$ & 0 & 1 & 0 & 1 & 0 & 1 \\
\hline TOTAL & $70^{\mathrm{a}}$ & 23 & 31 & 39 & 50 & 28 & 27 & 105 \\
\hline
\end{tabular}

\footnotetext{
a Birds with multiple conditions were only counted once.

cn Number of birds with a capture-related injury.

tn Number of birds with an injury involving the transmitter.
}

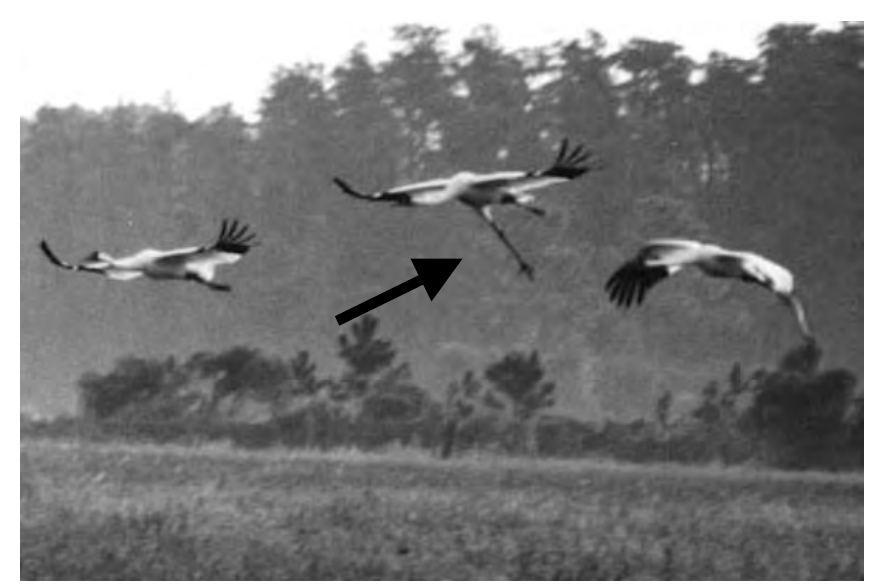

Figure 3. A whooping crane with a leg deviating from normal flight position. wild died, while 1 that remained in the wild without intervention survived and reproduced. Seven (2\%) whooping cranes have collided with either a vehicle or a fence (Table 4). In addition there were other cases of fence collision or entanglement that did not involve injury to the legs. Twenty-one (7\%) whooping cranes were observed in the field with lameness (Table 5). All 5 (2\%) whooping cranes reported with monofilament line entanglement were females (Fig. 4). Aside from the injuries listed in Table 6, all 5 birds recovered from the monofilament line entanglement.

Most of the wounds observed were in chicks (10 at the arrival examination and 27 at pre-release examination); remaining wounds occurred in 6 subadults and 6 adults.

Table 3. Details of whooping crane leg fractures in central Florida, 1992-2007.

\begin{tabular}{|c|c|c|c|c|}
\hline Sex & Age & Fracture location & Fracture cause & Outcome \\
\hline Female & Subadult & Bilateral tarsometatarsus ${ }^{\mathrm{t}}$ & Power line & Euthanized \\
\hline Female & Subadult & Left tibiotarsus $^{\mathrm{t}}$ & Power line & Died-corn aspiration in captivity for fracture repair \\
\hline Female & Adult & Bilateral femurs ${ }^{t}$ & Struck by golf ball & Died-anesthesia complications \\
\hline Male & Chick & Right tarsometatarsus ${ }^{t}$ & Unknown & Found dead \\
\hline Male & Subadult & Right tarsometatarsus ${ }^{t}$ & Entangled in cow feeder & Died-anesthesia complications \\
\hline Male & Subadult & Bilateral tarsometatarsus ${ }^{t}$ & Vehicular collision & Euthanized \\
\hline Male & Adult & Left tibiotarsus ${ }^{t}$ & Unknown & Bobcat predation 21 days later \\
\hline Male & Adult & Left tarsometatarsus & Unknown & Healed with bones overriding and fledged 1 chick \\
\hline Male & Adult & Bilateral femurs ${ }^{t}$ & Unknown & Found dead \\
\hline
\end{tabular}

${ }^{\mathrm{t}}$ Transmitter leg involved. 
Table 4. Details of whooping crane fence and vehicle collisions in central Florida, 1992-2007.

\begin{tabular}{cccl}
\hline Sex & Age & Object of collision & \multicolumn{1}{c}{ Outcome } \\
\hline Female & Subadult & Fence & Hip dislocation (resolved), fledged 2 chicks \\
Female & Subadult & Fence & Found dead near fence \\
Female & Adult & Fence & Bird uninjured, transmitter found near fence \\
Female & Adult & Fence & Found dead near fence \\
Female & Adult & Fence & Found dead near fence \\
Male & Subadult & Vehicle & Euthanized due to bilateral leg fractures \\
Male & Adult & Vehicle & Found dead in middle of highway with multiple fractures \\
\hline
\end{tabular}

Table 5. Details of whooping crane lameness in central Florida, 1992-2007.

\begin{tabular}{|c|c|c|c|c|}
\hline Sex & Age & Leg & Lameness cause & Outcome \\
\hline Female & Chick & Right $^{t}$ & Power line interaction & Died 1 year later from power line collision \\
\hline Female & Chick & Right $^{t}$ & Unknown & Still alive \\
\hline Female & Subadult & Right $^{t}$ & Monofilament line entanglement & Lameness resolved \\
\hline Female & Subadult & Right ${ }^{t}$ & Unknown & Bobcat predation 2 days later \\
\hline Female & Subadult & Left ${ }^{t}$ & Monofilament line entanglement & Lameness resolved \\
\hline Female & Subadult & Left $t^{t}$ & Unknown & Found dead \\
\hline Female & Subadult & Left & Unknown & Bobcat predation $>5$ years later \\
\hline Female $^{\mathrm{a}}$ & Adult & Left $t^{t}$ & Monofilament line entanglement & Lameness resolved \\
\hline Female & Adult & Left ${ }^{t}$ & Unknown & Lost transmitter, still lame (2007) \\
\hline Female & Adult & Left ${ }^{t}$ & Power line interaction & Died-corn aspiration in captivity for leg fracture repair \\
\hline Female ${ }^{a}$ & Adult & Left ${ }^{t}$ & Power line interaction & Still alive \\
\hline Female & Adult & Left & Unknown & Still alive \\
\hline Female $^{\mathrm{a}}$ & Adult & Right & Power line interaction & Still alive \\
\hline Male & Chick & Left ${ }^{t}$ & Unknown & Lameness resolved \\
\hline Male & Chick & Left $t$ & Power line interaction & Lameness resolved \\
\hline Male & Subadult & Right $^{t}$ & Unknown & Bobcat predation 20 days later \\
\hline Male & Subadult & Left ${ }^{t}$ & Power line interaction & Went missing $>4$ years later \\
\hline Male & Subadult & Right & Unknown & Lameness resolved \\
\hline Male & Subadult & Left ${ }^{t}$ & Unknown & Still alive \\
\hline Male & Adult & Left ${ }^{t}$ & Power line interaction & Bobcat predation 21 days later \\
\hline Male & Adult & Left & Re-injured healed fractured leg & Lameness resolved, fledged 1 chick \\
\hline Male & Adult & Left $^{t}$ & Unknown - chip out of transmitter band & Died $\sim 2.5$ years later from EEE \\
\hline Male & Adult & Right & Unknown & Went missing 3 months later \\
\hline
\end{tabular}

a Same bird with 3 separate instances of lameness.

$\mathrm{t}$ Transmitter leg involved.

The location of these wounds varied and some birds had multiple wounds noted. One adult female sustained a laceration on a toe during capture. The transmitter was responsible for 4 instances of minor leg wounds.

There were 9 capture or handling related injuries. One male bird and 2 wild-fledged female chicks had an avulsed toenail during hand captures. Another adult female had a laceration on a toe from the netting used in a clap trap capture. Five chicks ( 3 males and 2 females) had torn toenails due to handling prior to release. Three birds were still alive in 2007 including a wild-fledged chick.
The remaining birds died due to causes not associated with either their capture or handling injury.

\section{Deformities}

The deformities category included 43 (14\%) chicks with toe deformities $(n=28)$, short legs $(n=11)$, and/or rotated tarsometatarsus $(n=12)$ found at either the arrival or pre-release examinations (Table 7). Although whooping cranes with toe deformities tended to have a lower index of reproductive value than the general 

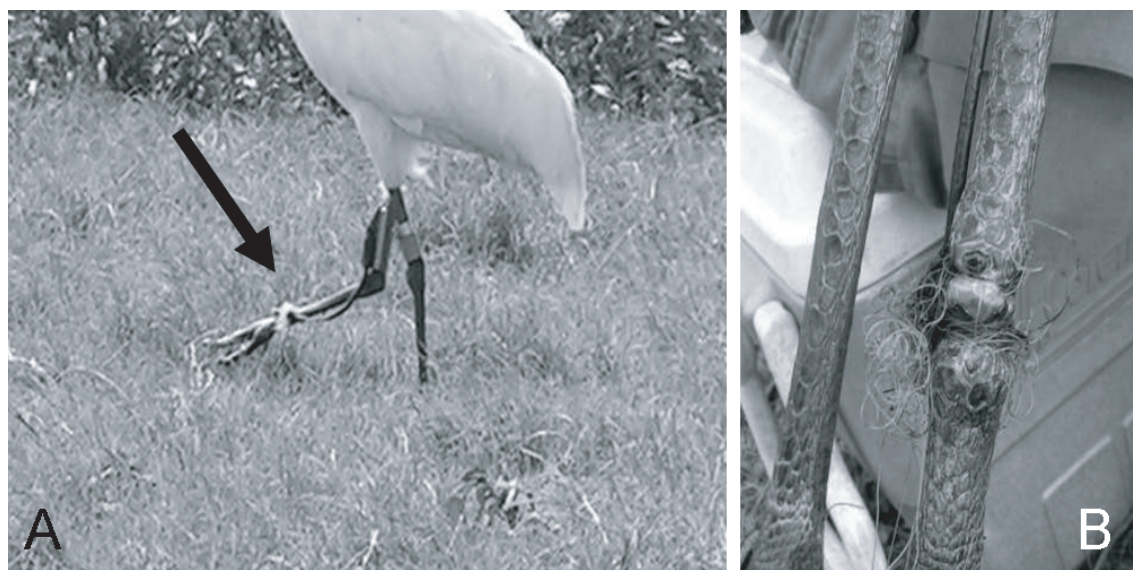

Figure 4. A wild-fledged whooping crane with monofilament line entanglement that included the antenna of the transmitter and caused swelling of the foot $(A)$; close up of entanglement $(B)$.

Table 6. Details of whooping crane monofilament line entanglement in central Florida, 1992-2007.

\begin{tabular}{llll}
\hline Sex & Age & Entanglement location & \multicolumn{1}{c}{ Outcome } \\
\hline Female & Chick & Left legt and foot & Swelling and lameness (both resolved) \\
Female & Subadult & Right tarsometatarsus ${ }^{\mathrm{t}}$ & Swelling and lameness (both resolved) \\
Female & Subadult & Left tarsometatarsus & Swelling and lameness (both resolved), lost 2/3 left hallux \\
Female & Subadult & Left tarsometatarsus & Swelling (resolved) \\
Female & Adult & Left legt & Swelling (resolved), scarring on leg \\
Female & Adult & Left tibiotarsus & Swelling (resolved) \\
\hline
\end{tabular}

a Same bird with 2 separate instances of monofilament line entanglement.

${ }^{\mathrm{t}}$ Transmitter leg involved.

Table 7. Summary of whooping crane deformities in central Florida, 1992-2007.

\begin{tabular}{|c|c|c|c|c|c|c|c|c|}
\hline \multirow{2}{*}{ Condition } & \multirow{2}{*}{ Total birds } & \multirow{2}{*}{$\%$ of total population } & \multicolumn{2}{|c|}{ Sex } & \multicolumn{3}{|c|}{ Age } & \multirow{2}{*}{ Total } \\
\hline & & & M & $\mathrm{F}$ & Chick & Subadult & Adult & \\
\hline Toe deformities & 36 & 12 & 17 & 19 & 31 & 3 & 2 & 36 \\
\hline Rotated tarsometatarsus & 12 & 4 & 3 & 9 & 9 & 1 & 0 & 12 \\
\hline Short legs & 10 & 3 & 2 & 8 & 12 & 0 & 0 & 10 \\
\hline TOTAL & $50^{\mathrm{a}}$ & 16 & 20 & 30 & 52 & 4 & 2 & 58 \\
\hline
\end{tabular}

a Birds with multiple conditions were only counted once.

population, there was no statistical difference $(P>0.05)$. Those with short legs or leg rotations also did not differ from the reproductive value of the general population $(P$ $>0.05)$. Overall, birds with leg deformities had no statistical difference of survival rate than the general population $(P>0.05)$.

\section{Miscellaneous Conditions}

Eighty-five (28\%) whooping cranes were observed with miscellaneous conditions (Table 8). Calluses, scabs, and scars were the most reported defect in the integument and were most often a minor injury due to the transmitter wearing on the skin of the hock. Pododermatitis was found in $4(1 \%)$ chicks, prior to their release. Two (1\%) male whooping cranes have been seen with chondromas (cartilage tumors). One wild-fledged chick with an 8mm-round chondroma on the tarsus was partially biopsied and the remaining mass regressed to a small scar within 2 years. The other chondroma was a $1 \times 1 \times 1 \mathrm{~cm}$ 
Table 8. Summary of whooping crane miscellaneous conditions in central Florida, 1992-2007.

\begin{tabular}{|c|c|c|c|c|c|c|c|c|}
\hline \multirow{2}{*}{ Condition } & \multirow{2}{*}{ Total birds } & \multirow{2}{*}{$\%$ of total population } & \multicolumn{2}{|c|}{ Sex } & \multicolumn{3}{|c|}{ Age } & \multirow{2}{*}{ Total instances } \\
\hline & & & $\mathrm{M}$ & $\mathrm{F}$ & Chick & Subadult & Adult & \\
\hline Swelling & 40 & 13 & 16 & 24 & 31 & 6 & 13 & 50 \\
\hline Generalized swelling & 33 & 11 & 13 & 20 & $23^{\mathrm{b} 1, \mathrm{~m} 1, \mathrm{t} 3}$ & $5^{\mathrm{m} 1, \mathrm{t} 3}$ & $12^{\mathrm{b} 1, \mathrm{~m} 3, \mathrm{t} 2}$ & 40 \\
\hline Bruises & 3 & 1 & 2 & 1 & 3 & 0 & 0 & 3 \\
\hline Cellulitis & 3 & 1 & 2 & 1 & $2^{\mathrm{t} 1}$ & 0 & 1 & 3 \\
\hline Edema & 2 & 1 & 1 & 1 & $1^{\mathrm{b} 1}$ & $1^{\mathrm{m} 1}$ & 0 & 2 \\
\hline Arthritis & 1 & $<1$ & 0 & 1 & 1 & 0 & 0 & 1 \\
\hline Myositis & 1 & $<1$ & 0 & 1 & 1 & 0 & 0 & 1 \\
\hline Defects of integument & 44 & 14 & 23 & 21 & 30 & 4 & 18 & 52 \\
\hline Calluses & 15 & 5 & 10 & 15 & $1^{\mathrm{b} 1}$ & $1^{\mathrm{t} 1}$ & $13^{\mathrm{t} 13}$ & 15 \\
\hline Scabs & 9 & 3 & 3 & 6 & 8 & 0 & 1 & 9 \\
\hline Scars & 9 & 3 & 3 & 6 & 6 & 0 & 3 & 9 \\
\hline Hyperemia & $8^{a}$ & 3 & 4 & 4 & 8 & 0 & 0 & 8 \\
\hline Crusts & 3 & 1 & 2 & 1 & 3 & 0 & 0 & 3 \\
\hline Dermatitis & 3 & 1 & 1 & 2 & 1 & 2 & 0 & 3 \\
\hline Sloughing skin & 2 & 1 & 2 & 0 & 2 & 0 & 0 & 2 \\
\hline Avulsed skin & 1 & $<1$ & 0 & 1 & 0 & 0 & 1 & 1 \\
\hline Cracked skin & 1 & $<1$ & 0 & 1 & 1 & 0 & 0 & 1 \\
\hline Dry skin & 1 & $<1$ & 1 & 0 & 0 & 1 & 0 & 1 \\
\hline Miscellaneous toe problems & ns 17 & 6 & 9 & 8 & 13 & 1 & 3 & 17 \\
\hline Toenail injuries & 14 & 5 & 7 & 7 & $13^{\mathrm{c} 7}$ & 0 & $1^{\mathrm{c} 1}$ & 14 \\
\hline Lost/missing toes & 3 & 1 & 2 & 1 & 0 & 1 & 2 & 3 \\
\hline Pododermatitis & 4 & 1 & 2 & 2 & 4 & 0 & 0 & 4 \\
\hline Chondroma & 2 & 1 & 2 & 0 & 1 & 1 & 0 & 2 \\
\hline Undiagnosed nodules & 2 & 1 & 1 & 1 & 1 & 0 & 2 & 3 \\
\hline TOTAL & $84^{\mathrm{d}}$ & 27 & 41 & 43 & 80 & 12 & 36 & 128 \\
\hline
\end{tabular}

\footnotetext{
a Six instances of hyperemia found on hips and associated with copulatory mounting.

bn Number of birds with an injury from the aluminum identification band.

cn Number of birds with a capture related injury.

d Birds with multiple conditions were only counted once.

$\mathrm{mn}$ Number of birds with an injury from monofilament line entanglement.

tn Number of birds with an injury involving the transmitter.
}

raised white nodule with a crusted center found on the tarsus of a subadult male that had been killed by a bobcat. Two (1\%) whooping cranes had undiagnosed nodules. A male chick had a proliferative epithelial lesion that resembled avian pox on the right digit 2 at the time of release. A female adult had 2 similar occurrences, 1 lesion on the foot that resolved, and 1 lesion near the hock 4 months later that also resolved.

\section{Injury Relation to Mortality, Source, and Rearing Method}

Of the 149 whooping cranes with leg problems and power line interactions, $118(79 \%)$ have died. Forty-four (29\%, $14 \%$ of total population) had injuries severe enough to be associated with mortality (Fig. 5). These birds were in the following categories: power line interactions $(n=28)$, other trauma $(n=15)$, and miscellaneous conditions $(n=1)$. Birds in the other trauma category included 2 birds with a leg dangle, 4 leg fractures, 6 fence and vehicle collisions, and 3 instances of lameness. The bird from the miscellaneous conditions category lost its foot below the tarsal joint and subsequently went missing shortly thereafter. No mortalities were associated with deformities; however, such an association would be unlikely to be observed. Birds were only released with deformities considered unlikely to influence survival. Except for captures to repair fractured legs, no serious capture or handling injuries occurred. Three birds died during hospitalization to repair or treat leg fractures. Two died from complications of anesthesia and 1 suffocated from aspiration of corn. The remaining birds either had injuries not considered related with mortality $(n=73$, 


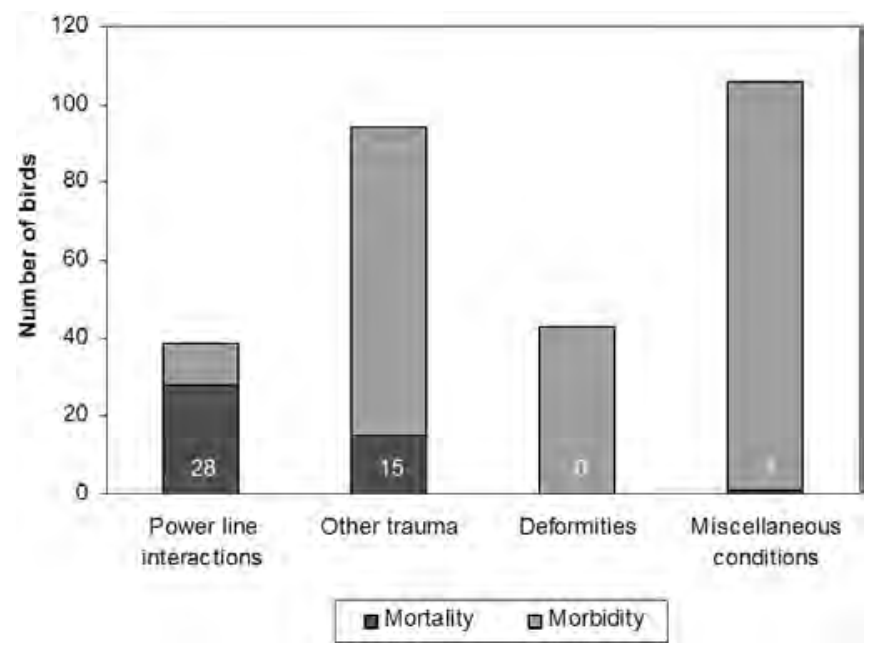

Figure 5. Injury-related morbidity and mortality in whooping cranes in central Florida, 1992-2007.

$50 \%$ of injured birds, $24 \%$ of total population) or were still alive in $2007(n=31,21 \%$ of injured birds, $10 \%$ of total population). Birds with injury were found to survive longer (mean $=47.2$ months) than birds with no previously recorded injury (mean $=30.7$ months $)(P<$ $0.001)$. We found no indication that source $(P>0.05)$ or rearing method $(P>0.05)$ predisposed birds to leg problems or power line interactions.

\section{DISCUSSION}

Although leg problems were common in the Florida resident population, only a few types of problems appeared to be significant to the health and survival of the birds. Forty-four birds were believed to die from legassociated problems or power line interactions. Power lines were the most common cause for these deaths. Other manmade hazards associated with whooping crane mortality included fences, monofilament line, vehicles, cow feeders and golf balls. Many of these hazards are associated with birds living in or close to urban areas. Power lines injure and kill other crane species and other large birds (Crivelli et al. 1988, Cochrane et al. 1991, Janss and Ferrer 2000, Sundar and Choudhury 2005) as well as whooping cranes in other wild flocks (Stehn and Wassenich 2008).

The greater mortality of males, especially older males, from power line collision may be due to a male flying ahead of the female and hitting the line first, alerting the female, or cushioning the blow; however, there have been 2 cases were 2 and 3 birds died in a single event.

Frequent mortality from particular power lines appears to occur when a line is located between foraging and roosting sites. Low light and fog conditions between these sites may contribute to the reasons that the lines are struck. Poor weather conditions affect the bird's ability to see and react to an imminent power line collision (Crivelli et al. 1988, Cochrane et al. 1991, Savereno et al. 1996, Stehn and Wassenich 2008). The consideration of power line presence when choosing release sites is made difficult by the rarity of power line-free areas, the rapid increase in new power lines, and the inability to predict which roosting and foraging areas will be used by the birds after release since birds frequently moved large distances from release sites.

To combat the problem of power line interactions, the Florida Fish and Wildlife Conservation Commission worked with a local power company to place markers (Firefly Bird Flappers ${ }^{\circledR}$, PR Technologies, Portland, OR) on $8 \mathrm{~km}$ of the power lines most frequently encountered. Other studies concur that marking power lines reduce the number of mortalities (Morkill and Anderson 1991, Alonso et al. 1994, Stehn and Wassenich 2008). Because we found $50 \%$ of power line interactions involved the transmitter, we began deploying a new style of transmitter in September 2006. The new transmitter has an angled leading edge, unlike the blunt edge of the old transmitter. The purpose of the new design was to allow a transmitter to glance off the power line as the bird flies over instead of catching on the line. By the end of 2007, 13 whooping cranes had been fitted with the modified transmitters. During the 15 months since using the new transmitter design, 3 power line interactions have been recorded, all in birds that had not yet been fitted with a new streamlined transmitter.

Contrary to expectation, whooping cranes with injuries survived longer than birds with no injuries. Since most mortalities were caused by trauma it does seem reasonable that birds surviving less severe traumatic events might survive longer on average than birds that die from more severe traumatic events with no prior observed leg problem. The source and rearing method of a bird have no bearing on whether or not a bird will become injured.

We found no clear evidence that a specific type of leg deformity influenced survival or reproductive success. Limb deformities have been noted in husbandry of 
captive cranes in general (Olsen and Langenberg 1996) and for whooping cranes specifically (Kelley and Hartup 2008), and are thought to be the result of dietary or exercise problems. Changes in diet and increased exercise appear to have resolved some of these problems (Kelley and Hartup 2008). Although we never recorded the death of a crane due to leg or foot malformation, the documentation of such an occurrence would be difficult.

Capture and handling injury was limited to minor wounds and toenail loss in a few out of $>800$ handling events. By avoiding the handling of young, growing, birds, which seem much more susceptible to leg injury, leg injuries were kept to a minimum in this study. Wildhatched chicks were not captured or handled until they were strong fliers ( $>4$ months of age). In our study it was not clear that intervention by hospitalizing a bird with a fractured leg resulted in the best outcome. Intervention for birds with fractured legs never resulted in a releasable bird, whereas one left in the wild went on to successfully reproduce. Because the chances for a hospitalized bird to be released back in the wild are low, we recommend careful consideration for leaving a bird with a fractured leg in the field if the conditions warrant any chance for recovery on its own.

Naturally acquired injuries by wild birds were rare and less likely to be discovered, whereas interactions with human-made objects were common enough to have population level impacts. These findings corroborate those found earlier for Florida cranes (Folk et al. 2001).

Chondromas, possibly due to a virus, have occasionally been seen in sandhill cranes (Grus canadensis) in Florida and can be severe enough to be life threatening (Forrester and Spalding 2003). Both of the lesions on whooping cranes were small and 1 regressed with time.

A problem requiring management is the entanglement of legs by monofilament line and bill entrapment by artificial objects. Although the second is not a leg problem, both require that the bird be captured to prevent death or, in the case of monofilament line entanglement, the loss of a foot. Monofilament line reclamation and education projects at popular recreation sites, close observation of birds, and capture and removal can all help to prevent mortality or limb loss.

In summary, we found that leg problems in wild whooping cranes were common, and generally those of significance involved man-made objects such as power lines, fences, vehicles, and monofilament line. Birds that were able to survive an injury went on to live longer than birds with no previously observed injury. Power line interactions were the most common cause of mortality and injury for birds with leg injuries and power line interactions. Line markers and transmitter design changes were instituted and further observations will be necessary to determine if mortality is reduced. Intervention to remove monofilament line was always successful; however, intervention to resolve a fractured leg was not. Capture or handling injuries were minimal and no deaths were associated with those injuries except when birds were hospitalized for fractured legs. Leg deformities noted at the arrival or pre-release examinations did not significantly influence survival or reproduction. Where and how the birds were reared also did not significantly affect incurring any future injuries.

\section{ACKNOWLEDGMENTS}

We thank J. Schmidt, T. Miller, K. Sullivan, J. Parker, S. Schwikert, J. Rodgers, S. Nesbitt, K. Candelora, S. Hatcher, and S. Baynes for their expert assistance with captures. We thank the many landowners for access to their properties. Funding for this work was supported in part by the U.S. Fish and Wildlife Service via Cooperative Agreement No. 401814-J-035.

\section{LITERATURE CITED}

Alonso, J. C., J. A. Alonso, R. Mufioz-Pulido. 1994. Mitigation of bird collisions with transmission lines through groundwire marking. Biological Conservation 67:129-134.

Canadian Wildlife Service [CWS] and U.S. Fish and Wildlife Service [USFWS]. 2007. International recovery plan for the whooping crane. Recovery of Nationally Endangered Wildlife (RENEW), Ottawa, Ontario, Canada, and U.S. Fish and Wildlife Service, Albuquerque, New Mexico, USA.

Cochrane, K. L., R. J. M. Crawford, and F. Kriel. 1991. Tern mortality caused by collision with a cable at Table Bay, Cape Town, South Africa in 1989. Colonial Waterbirds 14:63-65.

Crivelli, A. J., H. Jerrentrup, and T. Mitchey. 1988. Electric power lines: a cause of mortality in Pelecanus crispus Bruch, a world endangered bird species, in Porto-Lago, Greece. Colonial Waterbirds 11:301-305.

Folk, M. J., S. A. Nesbitt, and M. G. Spalding. 2001. Interactions of sandhill cranes and whooping cranes with foreign objects in Florida. Proceedings of the North American Crane Workshop 8:195-197. 
Folk, M. J., S. A. Nesbitt, S. T. Schwikert, K. A. Sullivan, T. M. Miller, S. B. Baynes, and J. M. Parker. 2005. Techniques employed to capture whooping cranes in central Florida. Proceedings of the North American Crane Workshop 9:141144.

Forrester, D. J., and M. G. Spalding. 2003. Cranes. Pages 702740 in Parasites and diseases of wild birds in Florida. University Press of Florida, Gainesville, Florida, USA.

Janss, G. F. E. and M. Ferrer. 2000. Common crane and great bustard collision with power lines: collision rate and risk exposure. Wildlife Society Bulletin 28:675-680.

Kelley, C., and B. K. Hartup. 2008. Risk factors associated with developmental limb abnormalities in captive whooping cranes. Proceedings of the North American Crane Workshop 10:119-124.

Morkill, A. E., and S. H. Anderson. 1991. Effectiveness of marking powerlines to reduce sandhill crane collisions. Wildlife Society Bulletin 19: 442-449.

Nagendran, M., R. P. Urbanek, and D. H. Ellis. 1996. Special techniques, part D: reintroduction techniques. Pages 231240 in D. H. Ellis, G. F. Gee, and C. M. Mirande, editors. Cranes: their biology, husbandry, and conservation. National Biological Service, Washington D.C., and International Crane Foundation, Baraboo, Wisconsin, USA.

Nesbitt, S. A., M. J. Folk, M. G. Spalding, J. A. Schmidt, S. T. Schwikert, J. M. Nicolich, M. Wellington, and J. C. Lewis. 1997. An experimental release of whooping cranes in
Florida-the first three years. Proceedings of the North American Crane Workshop 7:79-85.

Olsen, G. H., and J. A. Langenberg. 1996. Veterinary techniques for rearing crane chicks. Pages 100-103 in D. H. Ellis, G. F. Gee, and C. M. Mirande, editors. Cranes: their biology, husbandry, and conservation. National Biological Service, Washington D.C., and International Crane Foundation, Baraboo, Wisconsin, USA.

Savereno, A. J., L. A. Savereno, R. Boettcher, and S. M. Haig. 1996. Avian behavior and mortality at power lines in coastal South Carolina. Wildlife Society Bulletin 24:636-648.

Spalding, M. G., M. J. Folk, S. A. Nesbitt, and R. Kiltie. 2010. Reproductive health of the Florida flock of introduced whooping cranes. Proceedings of the North American Crane Workshop 11:142-155.

Stehn, T. V., and T. Wassenich. 2008. Whooping crane collisions with power lines: an issue paper. Proceedings of the North American Crane Workshop 10:25-36.

Sundar, K. S. G., and B. C. Choudhury. 2005. Mortality of sarus cranes (Grus antigone) due to electricity wires in Uttar Pradesh, India. Environmental Conservation 32:260-269.

Wellington, M., A. Burke, J. M. Nicolich, and K. O'Malley. 1996. Chick rearing. Pages 77-104 in D. H. Ellis, G. F. Gee, and C. M. Mirande, editors. Cranes: their biology, husbandry, and conservation. National Biological Service, Washington D.C., and International Crane Foundation, Baraboo, Wisconsin, USA. 


\title{
EFFECTIVENESS OF AVIAN COLlision AVERTERs IN PREVENTING MIGRATORY BIRD MORTALITY FROM POWERLINE STRIKES IN THE Central Platte River, Nebraska
}

\author{
2008 - 2009 Final Report \\ 30 September 2009 \\ Robert K. Murphy, * Shelly M. McPherron, Gregory D. Wright, \\ and Kimberly L. Serbousek
}

Department of Biology, University of Nebraska-Kearney, Kearney, NE 68849

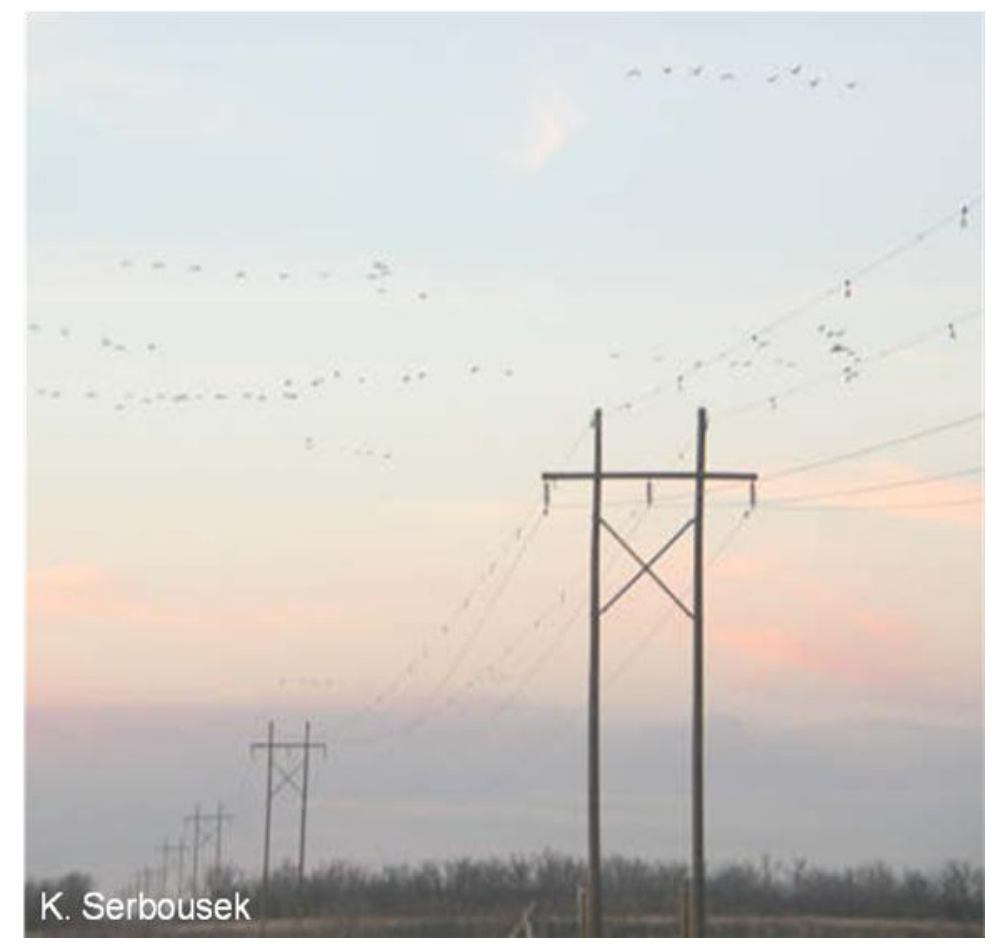

* Current address: Division of Migratory Birds, U.S. Fish and Wildlife Service, Albuquerque, NM 87103; E-mail: robert_murphy@fws.gov 


\section{EXECUTIVE SUMMARY}

Collisions with powerlines cause substantial mortality among many species of birds, but such losses may be reduced by installing devices that make powerline wires conspicuous. During 5 March-18 April 2008 and 3 March-13 April 2009, we investigated mortality of sandhill cranes (Grus canadensis) stemming from collisions with two 69-kilovolt $(\mathrm{kV})$ powerline arrays at a major night roost of the species on the Platte River in Buffalo County, south central Nebraska. Static wires of each powerline were equipped with FireFly ${ }^{\mathrm{TM}}$ bird diverters (FireFly Diverters LLC, Grantsville, Utah). We searched for carcasses of cranes at sandbars, islands, and shallow water areas between riverbanks below each powerline three times weekly and attempted to account for detectability biases. An estimated 50-93 sandhill cranes were killed by the two powerlines in 2008 and 37-70 were killed in 2009. These estimates were one-half to onethird of that reported in a previous study at the site, before FireFlys were installed. Using binoculars and night-vision scopes, we observed 101 and 117 collisions by sandhill cranes at one of the powerlines in 2008 and 2009, as the cranes returned to their roost from about 0.5 hours before sunset until about 2 hours after sunset. Most collisions occurred when flocks of more than 1000 cranes suddenly flushed from their roost within $0.5 \mathrm{~km}$ of the powerline after dusk. There appeared to be no relationship between collision incidence and weather or light conditions. About one-half of cranes that collided fell immediately to the ground, either dead or crippled. Another $29 \%$ continued to fly after striking wires, but their flight was hampered. About $65 \%$ of observed collisions involved static wires. We also observed reactions of 474 flocks of sandhill cranes to the powerline in 2009. Cranes reacted more quickly to avoid the powerline than they did to powerlines not equipped with diverters or to powerlines equipped with $30-\mathrm{cm}$ yellow aviation balls as diverters in a previous study in south central Nebraska, and did so mainly by gradually climbing in flight. Individual wires on the powerline we observed also were instrumented in 2009 with bird strike indicators (BSIs), a new electronic technology to detect bird collisions. Collision incidents we observed and those indicated by BSIs were highly correlated. Diel records from BSIs indicated one-half of collisions by birds occurred during evening; nearly all the rest were distributed across remaining night hours. Our results might suggest FireFlys reduce the likelihood that a sandhill crane will collide with powerlines at Rowe, but more rigorous experimental design incorporating replication is needed to reliably assess and provide broader inferences on effectiveness of FireFlys in decreasing mortality of cranes and other bird species at powerlines. BSIs should be further evaluated and incorporated into such assessments. 


\section{INTRODUCTION}

Many species of birds experience substantial mortality through collision and electrocution at powerlines (Bevanger 1994, Morkill and Anderson 1991, Avian Power Line Interaction Committee 1994, Lehman 2001). In North America, sandhill cranes (Grus canadensis) and whooping cranes (G. americana) seem particularly vulnerable to collisions with powerlines due to their large size and poor maneuverability in flight (Stehn and Wassenich 2008). The broad valley of the Platte River in central Nebraska poses great risk for such collisions (Ward et al. 1987). Roughly 500,000 sandhill cranes stage in the area for about 6 weeks during their spring migration, roosting at night on the river's sandbars and shallow waters. During spring 2006, Wright et al. (2009) recorded 61 carcasses of sandhill cranes during twice weekly searches below two $69-\mathrm{kV}$ powerline arrays, where the powerlines cross the river at the National Audubon Society's Lillian Rowe Sanctuary (hereafter, "Rowe”). In 2007, they searched more intensively and accounted for several potential detectability biases; an estimated 165 to 219 sandhill cranes were killed by colliding with the powerlines (Wright et al. 2009).

During spring 2008 and spring 2009, we expanded the work at Rowe by Wright et al. (2009) after FireFly ${ }^{\mathrm{TM}}$ devices (FireFly Diverters LLC, Grantsville, Utah) had been placed on the powerlines to avert birds. Our objectives were: 1) quantify mortality of sandhill cranes, whooping cranes, and other species of birds at the two powerlines after FireFly diverters had been installed; 2) describe the nature and context of collisions by sandhill cranes with one of the FireFly-equipped powerlines at Rowe as the cranes returned to their night roost during evenings; and 3) document behavioral reactions of flocks of sandhill cranes to a powerline equipped with FireFlys and compare the reactions to those of cranes to powerlines equipped and to powerlines not equipped with diverter devices in a previous study in the Platte River valley. During spring 2008, we also sought to document evidence of bird mortality at two other powerlines over the Platte River in south-central Nebraska, one of which was equipped with FireFlys.

\section{STUDY AREA AND METHODS}

Physical features of the study site and powerlines at Rowe are detailed in Wright et al. (2009) and summarized here. Rowe is in Buffalo and Kearney counties in south central 
Nebraska. A major roost site for spring migrant cranes, the sanctuary follows the Platte River's south channel. The 250- to 500-m (about 275 to 600 yards) wide channel is braided with sandbars and islands and bordered by grassy meadows and cropland. Water flows vary daily on the river in spring; most water is less than $0.5 \mathrm{~m}$ (20 inches) deep. Sandhill cranes and whooping cranes roost in the area mainly during late February through mid-April and mid-March through late April, respectively. The cranes usually leave night roosts on the river 1 to 2 hours after sunrise to feed in the surrounding landscape and return to roosts mainly during the last hour of daylight.

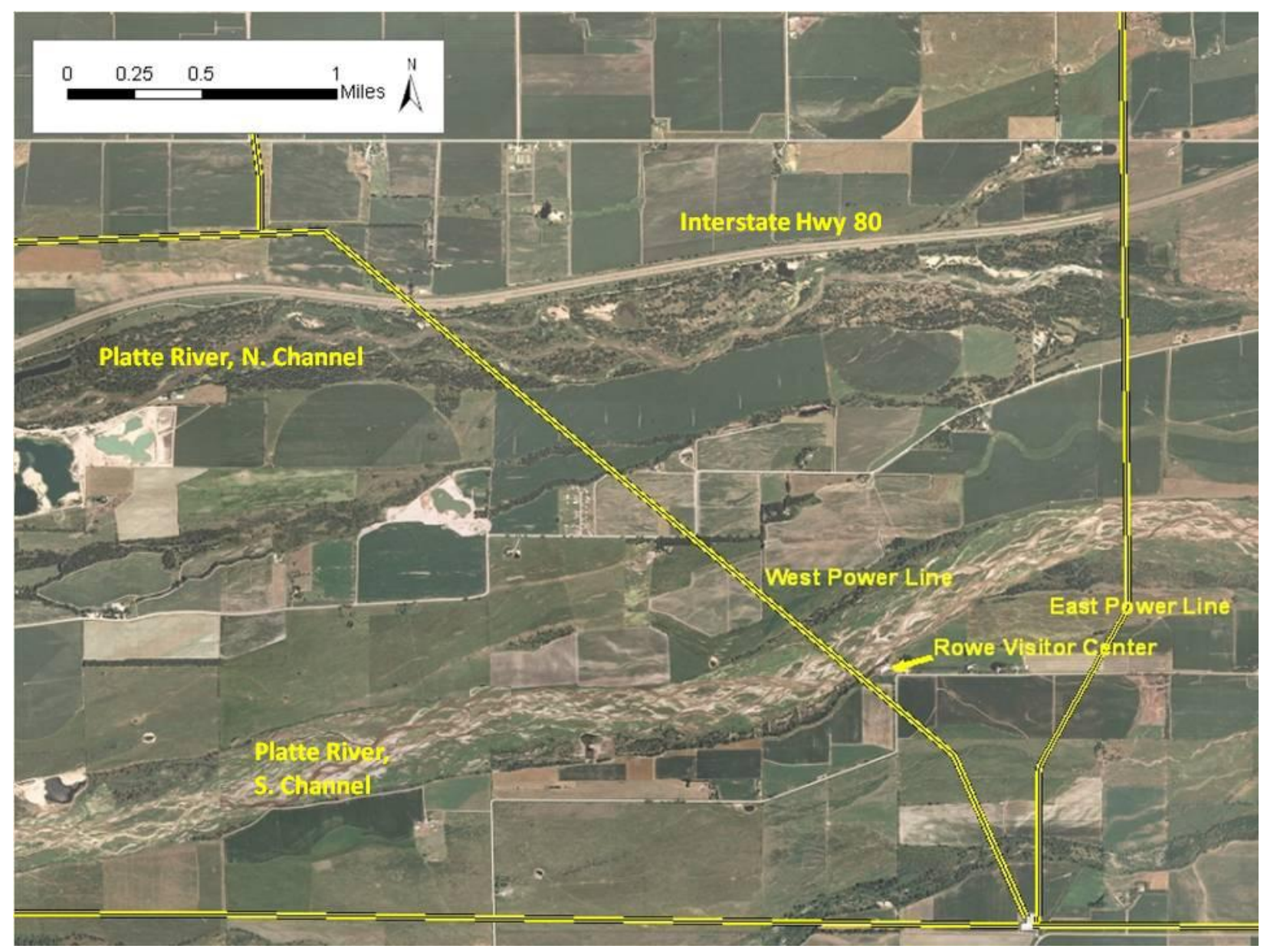

Two 69-kV powerlines cross the Platte River at the National Audubon Society's Lillian Rowe Sanctuary in Buffalo County, south central Nebraska. During spring 2008 and 2009, over-river spans of each were the focus of intensive study of powerline collisions by sandhill cranes that roost on the river. The area also is used by whooping cranes. 
Two 69-kV powerline arrays stretch across the Platte River within the sanctuary, one about $0.1 \mathrm{~km}$ (about 100 yards) west of Rowe's visitor center and the other about $1.8 \mathrm{~km}$ (about 1.1 miles) east. Each array has two nonelectrified "static" wires suspended about $15 \mathrm{~m}$ (50 feet) above the ground and three transmission "conductor" wires about $5 \mathrm{~m}$ (17 feet) below these, all supported by wood, H-frame pole structures (powerlines of $69 \mathrm{kV}$ or greater commonly are called transmission lines, while smaller arrays commonly are called distribution lines). The western powerline includes a support structure amid the river channel. The eastern powerline has a support structure on either river bank, but none in the river channel. Bank-to-bank spans of the western and eastern powerlines are $301 \mathrm{~m}$ (about $1000 \mathrm{feet}$ ) and $283 \mathrm{~m}$ (about 935 feet), respectively.

The over-river span of each powerline was equipped with a spinning model of the FireFly on its static wires in September 2007. The FireFly's main component is an acrylic plastic tag that measures $9 \times 15 \mathrm{~cm}(3.5 \times 6$ inches $)$, is $3 \mathrm{~mm}$ (0.13 inches) thick, and is covered with yellow and orange reflective tape and photo-reactive coatings that luminesce up to 8 to 10 hours after sunset. FireFlys were attached at 12-m (40-foot) intervals on each static wire by means of

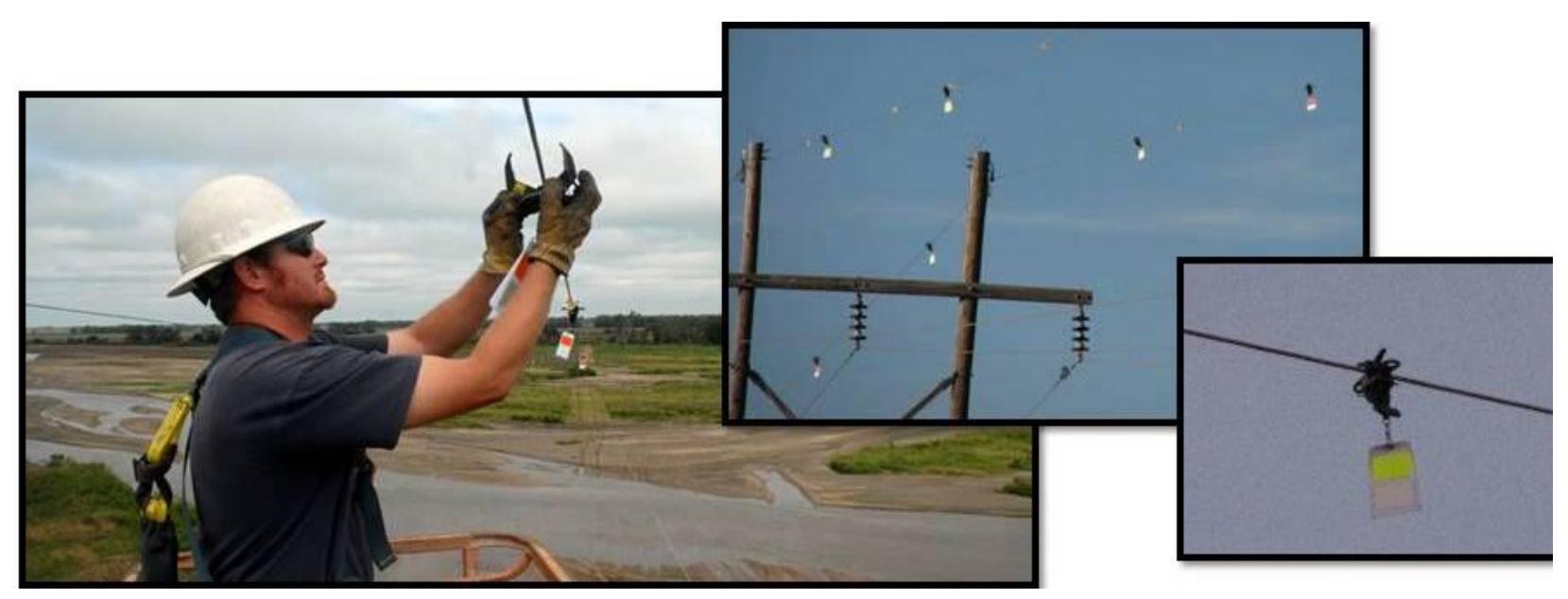

During spring 2008 and 2009, static wires of both powerlines at Rowe were marked with "FireFly"devices (FireFly Diverters LLC, Grantsville, Utah) in an attempt to make powerlines more conspicuous to birds and thus reduce collisions by birds with the wires. 
spring-loaded clamps. Attachment points alternated between wires such that a FireFly occurred on one or the other line every $6 \mathrm{~m}$ (20 feet). FireFlys were suspended by swivels so they would spin in any wind. By winter 2009, about one-third of the FireFlys broke, typically at the swivel, and fell from the powerlines; these were replaced by a non-spinning model just before migrant cranes began to arrive in the area in February 2009.

\section{Estimate of Mortality Based on Carcasses Below Powerlines}

We searched for carcasses on foot within $60 \mathrm{~m}$ (200 feet) of the powerlines between riverbanks every Monday, Wednesday, and Friday, using techniques described for 2007 surveys in Wright et al. (2009). All bird remains were removed from quadrats just before initial surveys were conducted each year. To locate crane carcasses in a quadrat, one searcher walked slowly (3-4 km/hour [about $2 \mathrm{mph}$ ]) in a zig-zag pattern down one-half of the quadrat then back on the other half. Searches lasted 0.5-1.5 hour/powerline. During each search, carcass type and description (i.e., extent scavenged) were recorded. We marked legs and distal wings of each carcass with orange paint to avoid recounting the carcass on subsequent surveys. Legs and wings were marked because they persisted longer than other body parts.

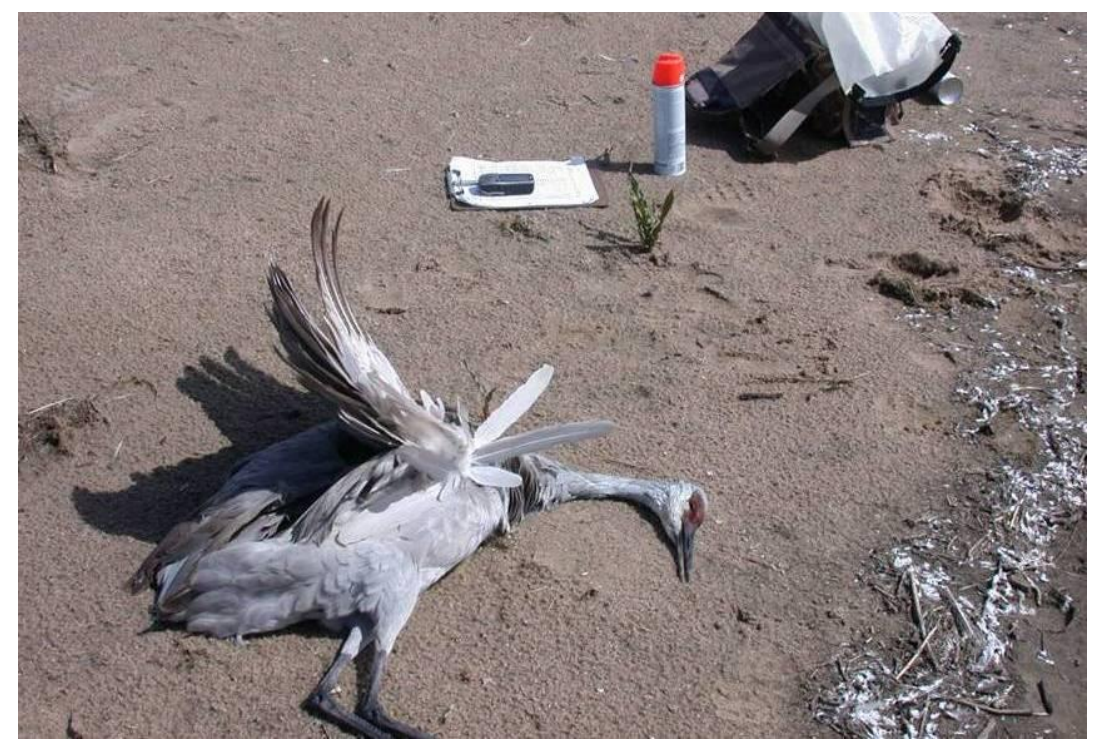

When a crane carcass was discovered, its distal legs and wings were painted orange to avoid 
recounting on subsequent surveys.

We estimated carcass detection rates by attempting to account for carcasses removed by scavengers, overlooked by observers, or swept downstream by water (Wright et al. 2009; Table 1). We used a blind assessment approach in which one of us placed one to three complete, intact sandhill crane carcasses within each quadrat 1.5-4 hours after a search on randomly selected days. Placed carcasses were uniquely but inconspicuously marked by a combination of broken or removed remiges and broken phalanges or tarsi. We recorded the location of each placed carcass via Geographic Positioning System receiver (GPS; Garmin eTrex, Garmin International, Olathe, Kansas; accuracy \pm 5 m, North American Datum 1983). We also noted distance and direction from natural markers. Carcasses were placed subjectively to simulate a typical pattern of distribution based on observations in 2006 and 2007 (Wright et al. 2009), and observers had no knowledge of carcass placements. Within 1.5-4 hours after each carcass search, GDW (2008) or SMM (2009) made a verification visit to placed carcasses. If remains of a given carcass persisted, it was noted whether signs of scavenging were evident and whether it had been marked with paint (i.e., discovered by the observer that day).

To estimate the number of carcasses swept downstream prior to detection, we calculated the proportion of the width of the channel at each powerline array covered by deep water, i.e., the mean depth needed to float complete carcasses of sandhill cranes downstream $(12.5 \mathrm{~cm}$ [5 inches]; Wright et al. 2009). We used a laser level and a GPS to determine widths of channel segments that equaled or exceeded this depth at the highest and lowest flow levels observed during our survey period. We multiplied the inverse of the proportion of channel covered by deep water by the number of estimated mortalities corrected for both carcass detection rates and scavenger removal rates (Wright et al. 2009; see Table 1 in RESULTS, page 12). We used measurements from 2008 for both years because maximum and minimum widths of deep water were similar.

\section{Direct Observation of Collisions and Behavioral Reactions of Cranes}

During 5 March-14 April 2008 and 3 March-13 April 2009, we observed the eastern powerline at Rowe from a blind placed on the south bank of the river about $60 \mathrm{~m}$ (200 feet) to the side (west) of the powerline. We observed the powerline each evening, defined as about 0.5 hours before until 2 hours after sunset (i.e., roughly 1800-2100 hrs). In 2008 we also observed 


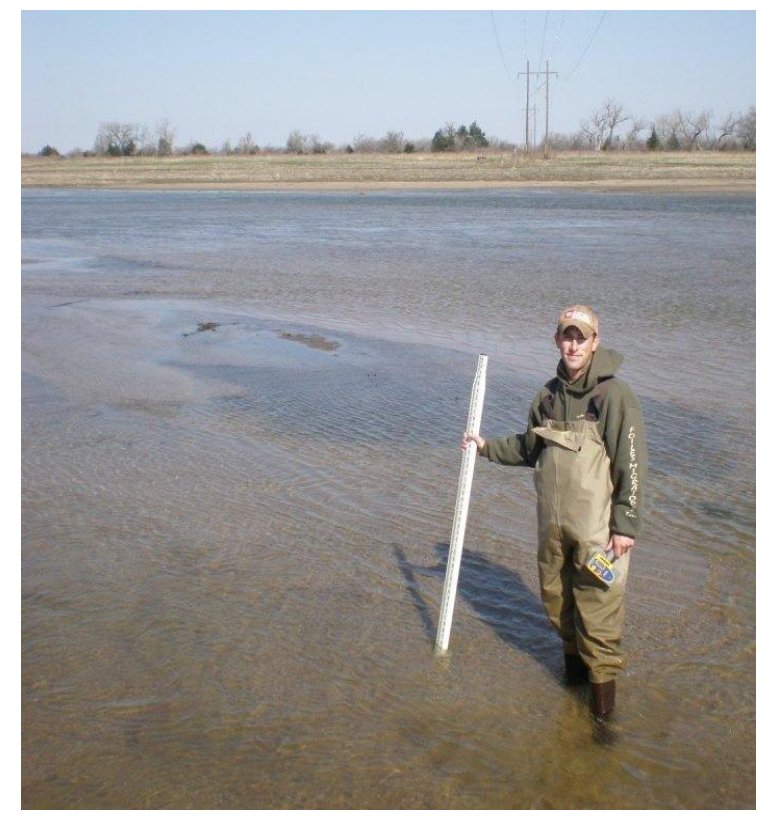

Some crane carcasses likely were swept downstream, away from powerlines, before being detected by investigators. Following methods in a recent study at Rowe (Wright et al. 2009), this potential bias was estimated by measuring the proportion of the river channel with water deep enough for carcasses to float, both at maximum and minimum flows for the season.

the powerline from about 1 hour before until 2 hours after sunrise, but discontinued these observations after noting cranes left the roost after sunrise and readily detected and avoided powerlines. Similarly, on seven nights in March 2008 we monitored crane flight activity at the powerline between evening and dawn. Noting no major activity by cranes during this sample of night-long periods, we focused on evenings.

Observations were of birds flying upstream or downstream, between riverbanks, below to just above the level of the powerline. We used 10 x $50 \mathrm{X}$ binoculars to observe cranes until 
darkness limited visibility, then switched to using 3x or 5x, Generation III night-vision scopes. We recorded time of collisions, flock size, and weather and light conditions. We categorized fate of each bird that collided with the powerline as either 1) collision or other contact evident but subsequent flight unaltered i.e., normal; 2) collision followed by obviously hampered flight (such birds often were losing height as they left our field of view); 3) collision followed immediately by loss of flight although alive while falling, typically evidenced by wing flapping; or 4) collision followed immediately by a motionless fall to the ground, i.e., appearing dead. When uncertain whether a collision occurred, we recorded "possible strike" but did not include such records in data summaries. In 2009, we also tried to identify which wire was struck.

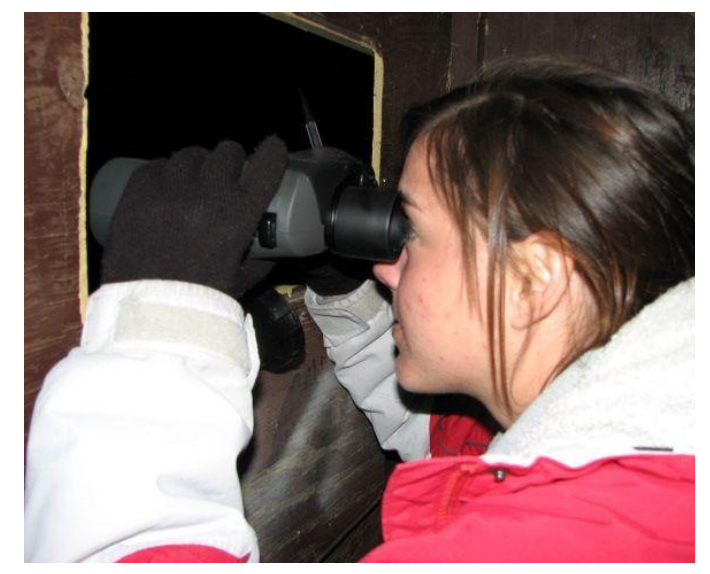

Sandhill cranes at Rowe's eastern powerline were observed from blinds each evening from early March through mid-April in 2008 and 2009.

Bird strike indicators (BSIs; EDM International, Fort Collins, Colorado) were attached to wires of the eastern powerline at Rowe in 2009. A relatively new technology, the BSI is an impulse-based, vibration sensing tool that, when mounted on a powerline wire, records bird collisions as unique signatures. A BSI was attached to each static and each transmission wire, roughly: 1) 90-95 m north, 2) 180-185 m north, and 3) $90 \mathrm{~m}$ south of the H-frame support 
structure on the south bank of the river. Thus, a total of 15 BSIs were used. BSIs were distributed at intervals of about one-third of the powerline span to maximize their sensitivity to vibrations caused by bird collisions. Records of collisions were transmitted to a computer base station at Rowe headquarters. To validate BSI records of collisions, we compared the timing and total number of collisions of birds that we observed directly to those recorded by BSIs during each evening observation period. We used correlation to assess the strength of the relationship between the two sources of data then used BSI records to explore the incidence of collisions by birds during each 24-hour diel period.

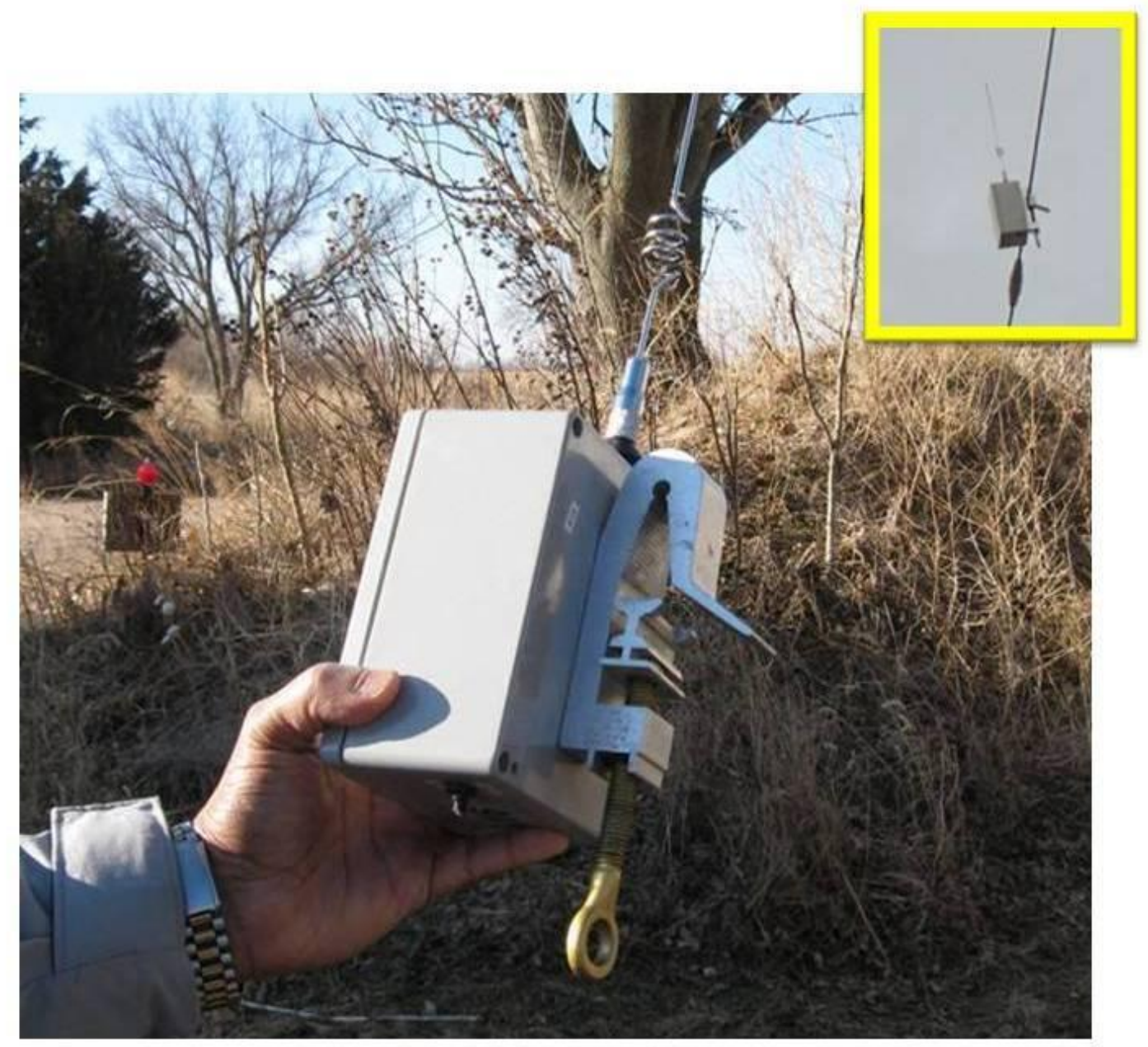

Bird Strike Indicators (EDM International, Inc., Ft. Collins, Colorado) were mounted on wires of the eastern powerline at Rowe during spring 2009 to record collisions by birds especially during hours when the powerline was not being directly observed. 
We categorized behavioral reactions of flocks of sandhill cranes to the eastern powerline at Rowe during 2009, using the same approach as Morkill and Anderson (1991): 1) no reaction, 2) gradual climb, 3) flare i.e., suddenly increased altitude as cranes flapped quickly to rise above the powerline, and 4) reverse path. Using a focal sampling approach (Altmann 1974), we selected the first flock approaching less than $10 \mathrm{~m}$ above the powerline in each 5 -minute interval every evening. A flock was defined as one or more cranes physically independent (more than roughly $30 \mathrm{~m}$ [100 feet]) from other cranes. We categorized flocks as either small (groups of 1-3 individuals) or large (4-20 individuals), similar to Morkill and Anderson (1991). We divided the evening data into two temporal subsets: 1) early evening (i.e., about 15 minutes before until 45 minutes after sunset) and 2) late evening (more than 45 minutes after sunset). Reactions of cranes by flock size and time were compared by using chi-square tests of independence. We also used chi-square tests to compare proportions of reaction categories in our study to those of sandhill cranes reported by Morkill and Anderson (1991), who measured reactions to powerlines not equipped with diverter devices and to powerlines marked with 30-cm (12-inch) diameter, yellow aviation balls as diverter devices. However, our late evening data were not used for the comparisons because Morkill and Anderson (1991) observed cranes only during daylight. Comparison to data in Morkill and Anderson (1991) was one of few, limited options to gauge the influence of FireFlys, because we were unable to directly compare effects of FireFlys by simultaneously assessing crane behavior at unmarked but otherwise equivalent (i.e., "control”) powerlines during our study.

We used similar methods between 2008 and 2009 except we added a second blind and observer on the north bank of the river in 2009 to try to discern which wire a given bird collided with. In 2009 we also sampled the level of local abundance of cranes in relation to time of evening by counting the number of cranes passing through the bank-to-bank river corridor during a 30-second interval every 5 minutes.

Simple correlation was used to assess relationships in 2009 between 1) local abundance of sandhill cranes and the number of collisions we directly observed, and 2) the number of collisions by birds recorded by BSIs and the number of collisions by sandhill cranes we directly observed during the same time each evening. We considered $\mathrm{P}<0.05$ to indicate statistical significance for chi-square tests and correlation results. 


\section{Evidence of Bird Mortality at Other Roost Sites}

During spring 2008, we also searched for carcasses of birds beneath spans of two other powerlines that crossed the Platte River in south-central Nebraska. The Speidel powerline was a $35-\mathrm{kV}$ distribution line that crossed the river's south channel about $8 \mathrm{~km}$ (5 miles) east-southeast of Kearney in Buffalo County. To restore open roosting habitat for cranes and other species of birds, roughly 20 ha (about 50 acres) of trees and other vegetation had been removed from the area during late winter 2008. The powerline lacked devices to alert birds and minimize collisions. The Shelton powerline was a $35-\mathrm{kV}$ distribution line about $5 \mathrm{~km}$ (3 miles) west of the Shelton interchange on U.S. Interstate highway 80 in Kearney County. FireFlys had been placed on its static wires in late winter 2008. Together with collaborators, we used methods outlined in Wright et al. (2009) to search three times weekly for bird carcasses beneath the Speidel and Shelton powerlines within respective river channels ( $\mathrm{n}=20$ search visits at each). We did not, however, attempt to correct for biases in detectability of carcasses at the two powerlines.

\section{RESULTS}

\section{Mortality Based on Carcasses}

We found 47 carcasses of sandhill cranes and none of whooping cranes beneath powerlines at Rowe (Table 2). Forty-two (89.4\%) carcasses were beneath the eastern powerline. We also found 13 carcasses of seven other species of birds beneath powerlines at Rowe, all but one of which were waterfowl (Anseriformes). Based on crane carcasses detected during searches and corrections for related biases, we estimate 50-93 and 37-70 sandhill cranes were killed by colliding with powerlines at Rowe in spring 2008 and 2009 (Table 1). 
Table 1. Assessment of detection bias and estimate of total mortality of sandhill cranes at two 69-kVpowerlines over a night roost of the cranes on the Platte River at the Lillian Rowe Sanctuary in south central Nebraska, based on carcasses found below the powerlines, 17 March-14 April 2008 and 3 March-13 April 2009 (follows Wright et al. 2009).

Carcass origin $\quad 2008 \quad 2009$ Source $^{\mathrm{a}}$

Assessment of detection bias on area of channel not covered by deep water ${ }^{b}$

Placed carcasses

Removed by scavengers before observer's search

Present for observer's search

Present for search but undetected by observer subtotal: removed plus present-undetected

Proportion detected ([A-B]/A)

Detected by observer, death attributed to collision

Estimate: killed by collision but not falling into deep water (D / C)

Percentage of bank-to-bank channel covered by deep water ${ }^{c}$

Minimum

Maximum

Estimate: total mortality attributed to powerlines

Minimum (E/[1.00-F] )

$49.8 \quad 37.4$

Maximum (E/[1.00-G])
20

1

19

6

7

$0.65 \quad 0.76$

$25 \quad 22$

$38.5 \quad 28.9$

E

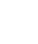


appeared similar in 2009 . 
Table 2. Number and identity of carcasses of birds detected beneath two 69-kVpowerlines ${ }^{\mathrm{a}}$ over the Platte River at the National Audubon Society's Lillian Rowe Sanctuary in Buffalo County, south central Nebraska, during 5 March to 18 April 2008 and 3 March to 13 April 2009.

\begin{tabular}{|c|c|c|c|c|c|c|c|c|}
\hline \multirow[b]{2}{*}{ Powerline } & \multicolumn{2}{|c|}{ Sandhill crane } & \multicolumn{2}{|c|}{ Duck $^{\mathrm{b}}$} & \multicolumn{2}{|c|}{ Goose $^{c}$} & \multicolumn{2}{|c|}{ Passerine species ${ }^{\mathrm{d}}$} \\
\hline & 2008 & 2009 & 2008 & 2009 & 2008 & 2009 & 2008 & 2009 \\
\hline Western & 0 & 5 & 1 & 0 & 2 & 2 & 0 & 0 \\
\hline Eastern & 25 & 17 & 2 & 3 & 1 & 1 & 0 & 1 \\
\hline
\end{tabular}

${ }^{a}$ Three searches were conducted on foot weekly on the ground within $60 \mathrm{~m}$ of each powerline, from riverbank to riverbank.

${ }^{\mathrm{b}}$ Mallard (Anas platyrhynchos), gadwall, (A. strepera), northern pintail (A. discors), greenwinged teal (A. crecca).

${ }^{\mathrm{c}}$ Snow goose (Chen caerulescens) and Canada goose (Branta canadensis).

${ }^{\mathrm{d}}$ Song sparrow (Melospiza melodia). 
No bird carcasses were detected beneath the Speidel powerline and 13 carcasses of nine species of birds were found under the Shelton powerline, including three sandhill cranes (2008 only; Table 3). Lack of bird tracks on sandbars within 100-150 m (about 325-500 feet) of the powerline at Speidel indicated cranes and other flocking species of birds were not roosting in the area. Based on tracks, cranes at Shelton probably roosted at least $140 \mathrm{~m}$ (> 460 feet) east of the powerline in early spring, but roosted closer later in spring as their abundance in the area increased. In all, 74 carcasses of at least 12 species of birds were recorded at the four powerlines surveyed in this study, including a common merganser (Mergus merganser) that, while in flight, wedged its bill into a spiral vibration damper on the eastern powerline at Rowe in late February 2009.

Table 3. Carcasses of birds detected beneath two 35-kV powerline spans over the Platte River in Buffalo and Kearney Counties, south central Nebraska, during 5 March to 18 April 2008. ${ }^{\text {a }}$

Powerline Sandhill crane $\quad$ Duck $^{\mathrm{b}} \quad$ Goose $^{\mathrm{c}} \quad$ Passerine species $^{\mathrm{d}}$

\begin{tabular}{llccc} 
Speidel & 0 & 0 & 0 & 0 \\
& & & & \\
Shelton & 3 & 1 & 3 & 6 \\
\hline
\end{tabular}

\footnotetext{
${ }^{a}$ Three searches were conducted on foot weekly on the ground within $60 \mathrm{~m}$ of each powerline, from riverbank to riverbank.

${ }^{\mathrm{b}}$ Green-winged teal.

${ }^{\mathrm{c}}$ Snow goose and Canada goose.
} 
${ }^{\mathrm{d}}$ Cedar waxwing (Bombycilla cedrorum), Lincoln's sparrow (Melospiza lincolnii), song sparrow, darkeyed junco (Junco hyemalis), unidentified sparrow (Emberizidae), and red-winged blackbird (Agelaius phoeniceus).

\section{Direct Observations of Birds at Rowe's Eastern Powerline}

In 2008, we did not witness collisions by birds with the eastern powerline at Rowe through 16 March, during which time observations were restricted to daylight hours. Thereafter, we used night-vision equipment and observed collisions by 101 individual sandhill cranes with the powerline during late evening (Table 4). Two-thirds of these collisions resulted in individual cranes falling to the ground within $60 \mathrm{~m}$ of the powerline. Nearly half of those that fell to the ground appeared to be killed instantly when they collided with wires of the powerline. Most other cranes that collided with the powerline exhibited hampered flight after collision. In 2009, we observed 117 collisions by sandhill cranes (Table 4). Outcomes of collisions differed markedly from $2008\left(X^{2}=1247, \mathrm{df}=3, \mathrm{P}<0.001\right)$. For example, the percentage of collisions resulting in unaltered flight was nearly four times greater in 2009 than in 2008 . We observed no collisions by other species of birds, except an unknown species from a mixed-species flock of sandhill cranes and Canada geese collided with the powerline in 2008.

We could identify which wires - static or transmission - were struck by cranes in 71 $(60.7 \%)$ of 117 collisions observed in 2009. Static wires were struck in $46(64.8 \%)$ of the 71 collisions. We often were unable to identify wires involved in collisions when large flocks (> 100 individuals) of cranes passed through the powerline array, obscuring our view of specific wires. Nearly all sandhill cranes that approached the powerline at or below line height flew up and over the static wires, although some (probably < 1\%) flew between static and transmission wires and, on rare occasions, one to several cranes flew below the transmission wires.

Collisions we observed by sandhill cranes with the eastern powerline at Rowe during evening occurred 24-105 minutes after sunset (i.e., from dusk into nightfall) in 2008 and 29-155 minutes after sunset in 2009. Illumination by moonlight or extent of cloud cover did not seem to markedly affect the birds' abilities to detect and avoid the powerline. For example, in 2008 the percentage of collisions that occurred on bright, moonlit nights (14.8\%) approached the 
percentage of such nights of observation $(25.0 \%)$; in $2009,53.8 \%$ of collisions were recorded on cloudless nights. There also was no obvious relationship between collision incidence and 
Table 4. Outcome of physical contact by flighted sandhill cranes with the eastern powerline over a night roosting area for the cranes on the Platte River at Audubon's Lillian Rowe Sanctuary in south central Nebraska, as determined by direct observation from about 0.5 hours before sunset until 2 hours after sunset, 17 March to 14 April 2008 and 3 March to 13 April 2009.

\begin{tabular}{|c|c|c|c|}
\hline & 2008 & 2009 & Total \\
\hline Collision category & $\mathrm{n}(\%)$ & $\mathrm{n}(\%)$ & $\mathrm{n}(\%)$ \\
\hline Flight unaltered & $8(7.9)$ & $34(29.1)$ & $42(19.3)$ \\
\hline Flight hampered & $22(21.8)$ & $42(35.9)$ & $64(29.4)$ \\
\hline Immediate loss of flight, alive & $41(40.6)$ & $37(31.6)$ & $78(35.8)$ \\
\hline Fell to ground dead & $29(28.7)$ & $4(3.4)$ & $33(15.1)$ \\
\hline Outcome unknown & $1(0.9)$ & 0 & $1(0.4)$ \\
\hline $\mathrm{n}$ total & $101^{\mathrm{a}}$ & 117 & 218 \\
\hline
\end{tabular}

${ }^{a}$ Excludes one large bird of unknown species that struck the powerline, amidst a flock of Canada geese and sandhill cranes.

strong wind or otherwise inclement weather, e.g., $58.1 \%$ of collisions in 2009 occurred when winds were less than $20 \mathrm{~km} /$ hour $(<12 \mathrm{mph})$. Instead, collisions occurred mainly when large flocks of cranes suddenly flushed upward, towards the powerline, after settling on their roost within $0.5 \mathrm{~km}$. Nearly two-thirds $(64.4 \%$ and $64.1 \%)$ of collisions in each of 2008 and 2009 occurred this way. Those in 2008 involved flocks of more than 1000 cranes, while most in 2009 
involved smaller flocks (100-1000 cranes, $35.1 \%$ of all collisions; > 1000 cranes, $29.0 \%$ of all collisions). The most dramatic example of this occurred on 4 April 2008, when 53 sandhill cranes from two flocks of more than 1,000 cranes each collided with the powerline, 71 and 105 minutes after sunset, respectively. The collisions occurred as cranes flew upwards from their roost on sandbars and shallows within roughly $300 \mathrm{~m}$ east of the powerline. We could not identify what disturbed the cranes. Coyotes (Canis latrans) may have, as we had noted tracks of medium-sized canids and observed a coyote on sandbars during carcass searches. Great horned owls (Bubo virginiana), probably the same individual, sometimes perched atop the powerline's support structure and flew out over roosting cranes, but the cranes did not seem to react. Regardless, cranes typically were unsettled as they arrived at the river to roost and often moved from one roost to another during 0.5-1.5 hours after sunset. Cranes mostly flew from east to west in 2008, but the converse was true in 2009 .

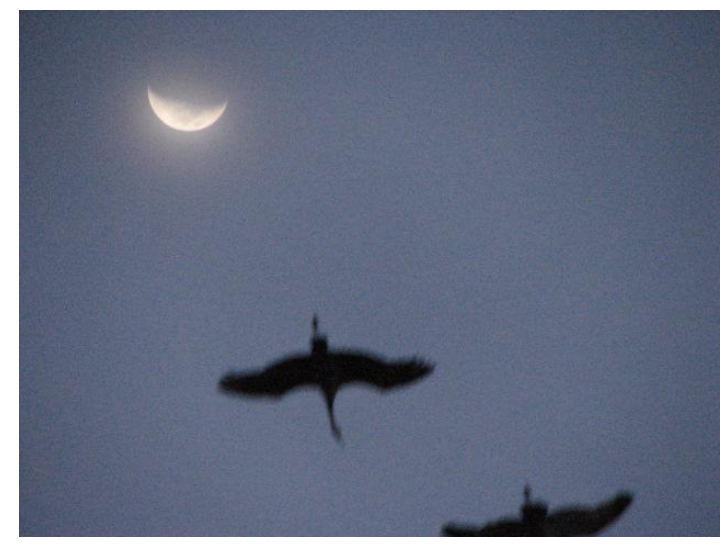

Illumination by moonlight or extent of cloud cover did not seem to influence the ability of cranes to detect and avoid the powerline marked with FireFlys. Instead, collisions occurred mainly when large flocks of cranes suddenly flushed upward towards the powerline, after settling on their roost within about 600 yards. 
At the peak of staging by sandhill cranes in the area in mid-March, we typically observed an average of about 500 cranes/minute pass through the over-river span of the eastern powerline (2009 data, Fig. 1). However, we detected no relationship between local abundance of cranes and number of collisions by cranes through spring $(\mathrm{r}=0.13, \mathrm{P}=0.41)$. After a week of almost no collisions at the end of each migration season in April, we noted an abrupt increase in collisions (e.g., 9 to 10 April 2009, in Fig. 1).

\section{Reactions by Cranes to Powerlines}

We recorded 474 reactions of sandhill crane flocks to the eastern powerline at Rowe in 2009. The proportion of reaction types differed with time (early versus late evening, flock sizes combined: $\left.X^{2}=70.9,3 \mathrm{df}, \mathrm{P}<0.001\right)$. During early evening, cranes typically avoided the powerline by climbing gradually as they approached (Fig. 2). In late evening, however, cranes were less likely to climb gradually. This was especially true for small flocks, which in late evening were almost equally likely to flare or reverse direction as they were to climb gradually. Cranes that did not react (7.8\% of large flocks during day, $6.4 \%$ of small flocks during late evening) generally were in flocks that passed 5-10 m above the static wires, although during late evening, some small flocks passed between static and transmission wires or beneath transmission wires without appearing to react to the wires.

Sandhill cranes we observed reacted more often to the powerline marked with FireFlys and did so more by gradually climbing as they approached, compared to reactions of cranes to powerlines marked with yellow aviation balls or to unmarked powerlines in Morkill and Anderson (1991; $X^{2}=230$ and 384; both, df = 3, P < 0.001; Fig. 3). Last, the cranes we observed reacted sooner to the powerline with FireFlys than they did to powerlines with aviation balls or to unmarked powerlines $\left(X^{2}=230\right.$ and 384 ; both, $\mathrm{df}=3, \mathrm{P}<0.001$; Fig. 4). 


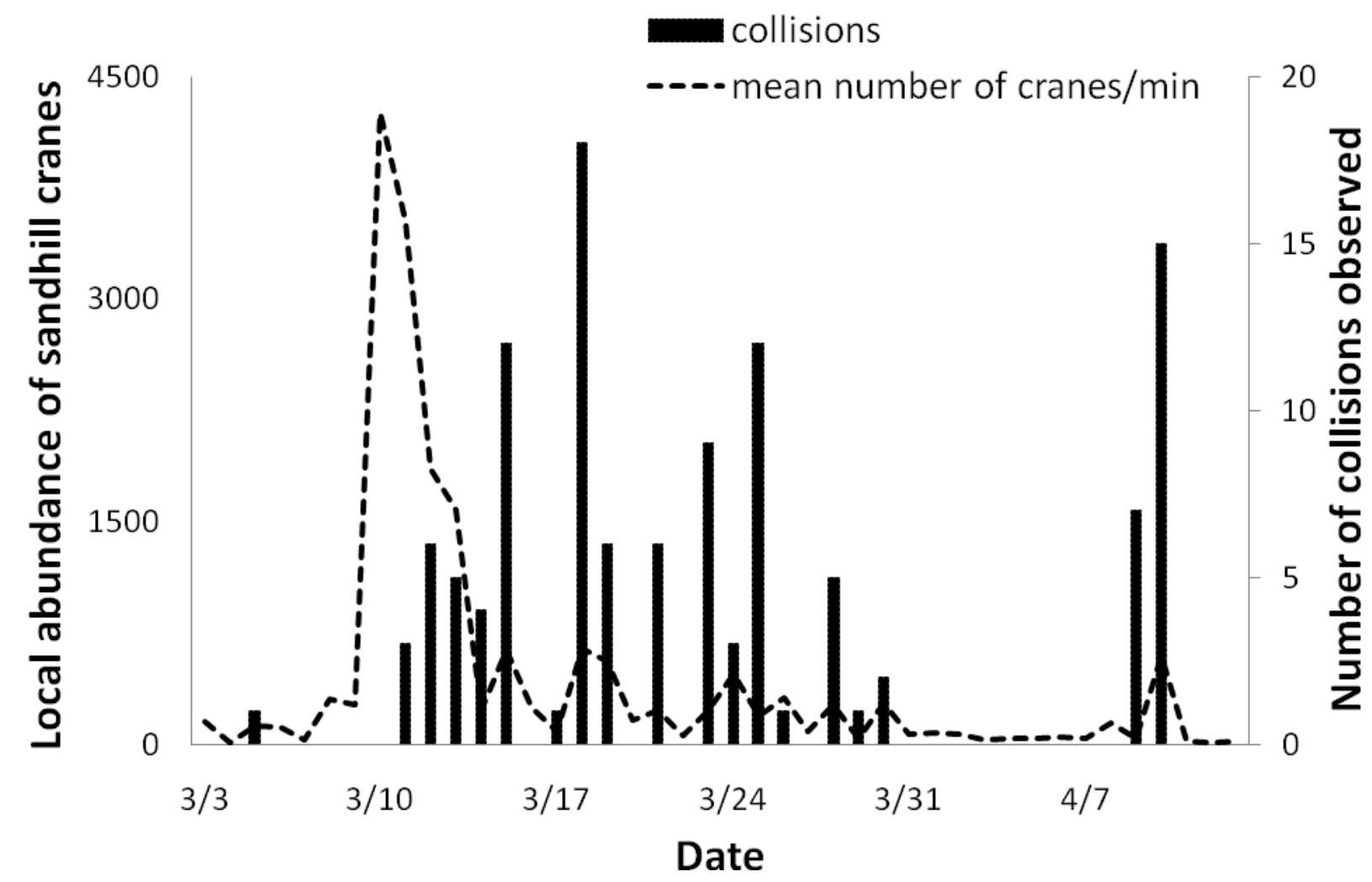

Figure 1. Relationship between the observed number of collisions by sandhill cranes with the eastern powerline over the Platte River at Rowe Sanctuary in Buffalo County, Nebraska, and local abundance of cranes defined as the mean number observed flying past the powerline per minute during evenings (i.e., about 0.5 hours before sunset until 2 hours after sunset), 3 March to 13 April 2009. Data were based on 30-second counts every 5 minutes. 


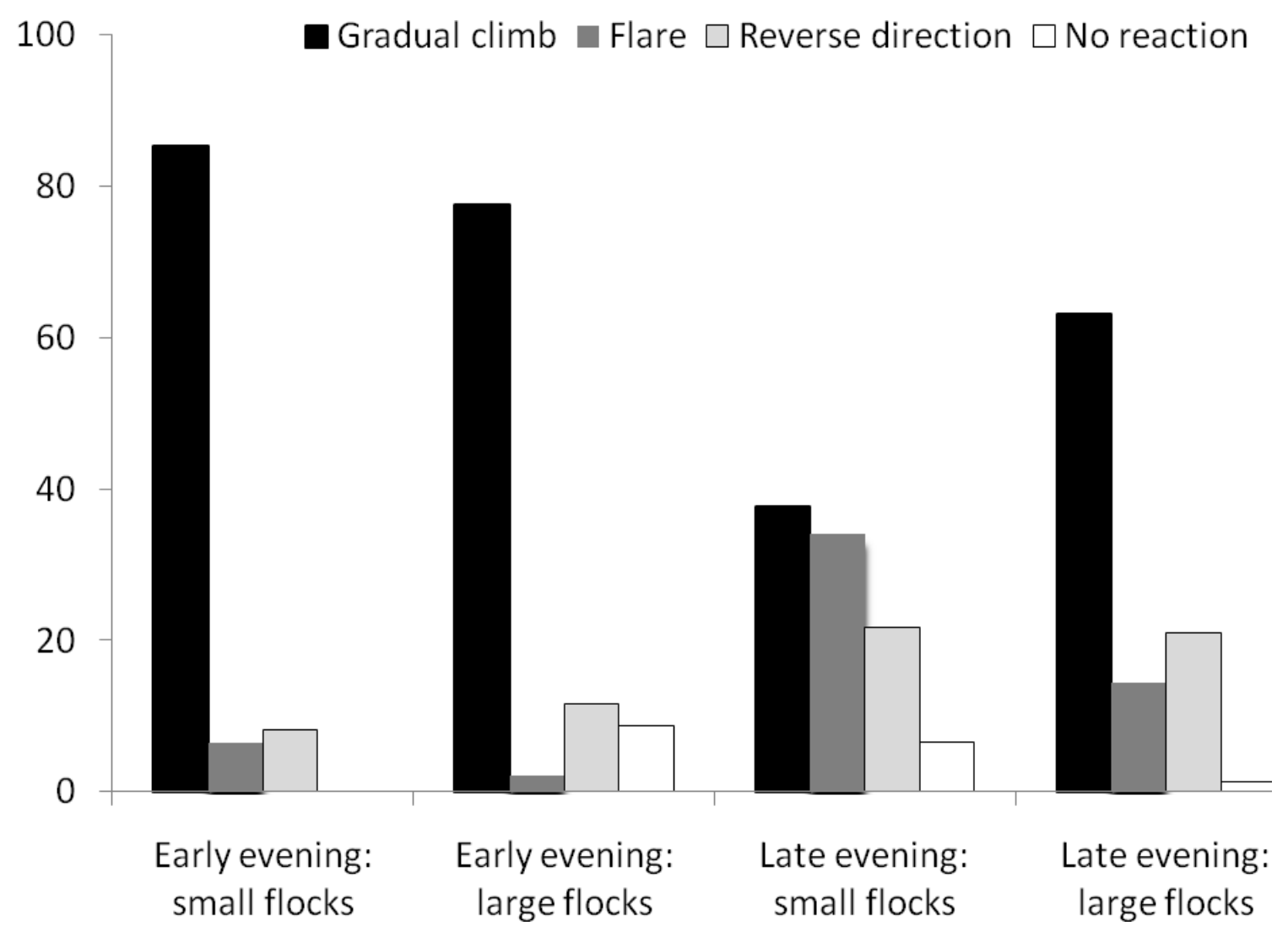

Figure 2. Behavioral reactions of flighted sandhill cranes to a $69-\mathrm{kV}$ powerline over a night roosting area for the cranes on the Platte River at Audubon's Lillian Rowe Sanctuary in south central Nebraska, as determined by direct observation, 3 March to 13 April 2009. Small flocks included one to three individuals and large flocks included more than three individuals. The first flock in each 5-minute interval was included in the sample. Numbers of reaction observations are in parentheses. Data were collected from about 0.5 hours before sunset until 2 hours after sunset; early evening was up to 45 minutes after sunset and late evening was more than 45 minutes after sunset. Flare was defined as a sudden increase in altitude as cranes flapped quickly to rise above the powerline. 


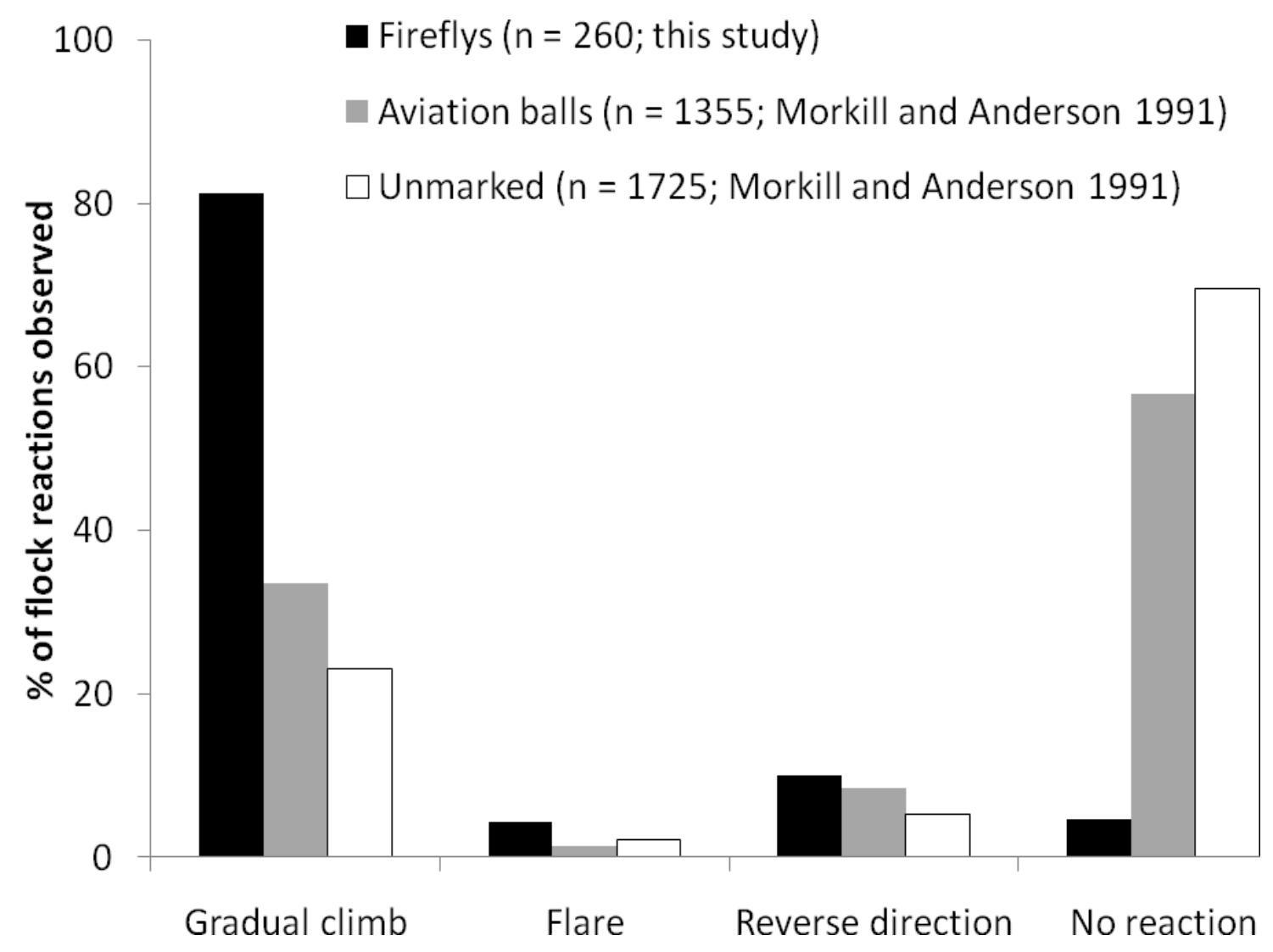

Figure 3. Behavioral responses of flighted sandhill cranes to a $69-\mathrm{kV}$ powerline marked with Firefly avian flight diverters over the Platte River in south-central Nebraska during spring 2009, and of reactions of sandhill cranes to unmarked powerline spans and powerline spans marked with $30-\mathrm{cm}$ diameter aviation marker balls over croplands in south-central Nebraska during spring 1988-1990, based on data in Morkill and Anderson (1991). Sample sizes (i.e., number of flock reactions observed) are in parentheses. 


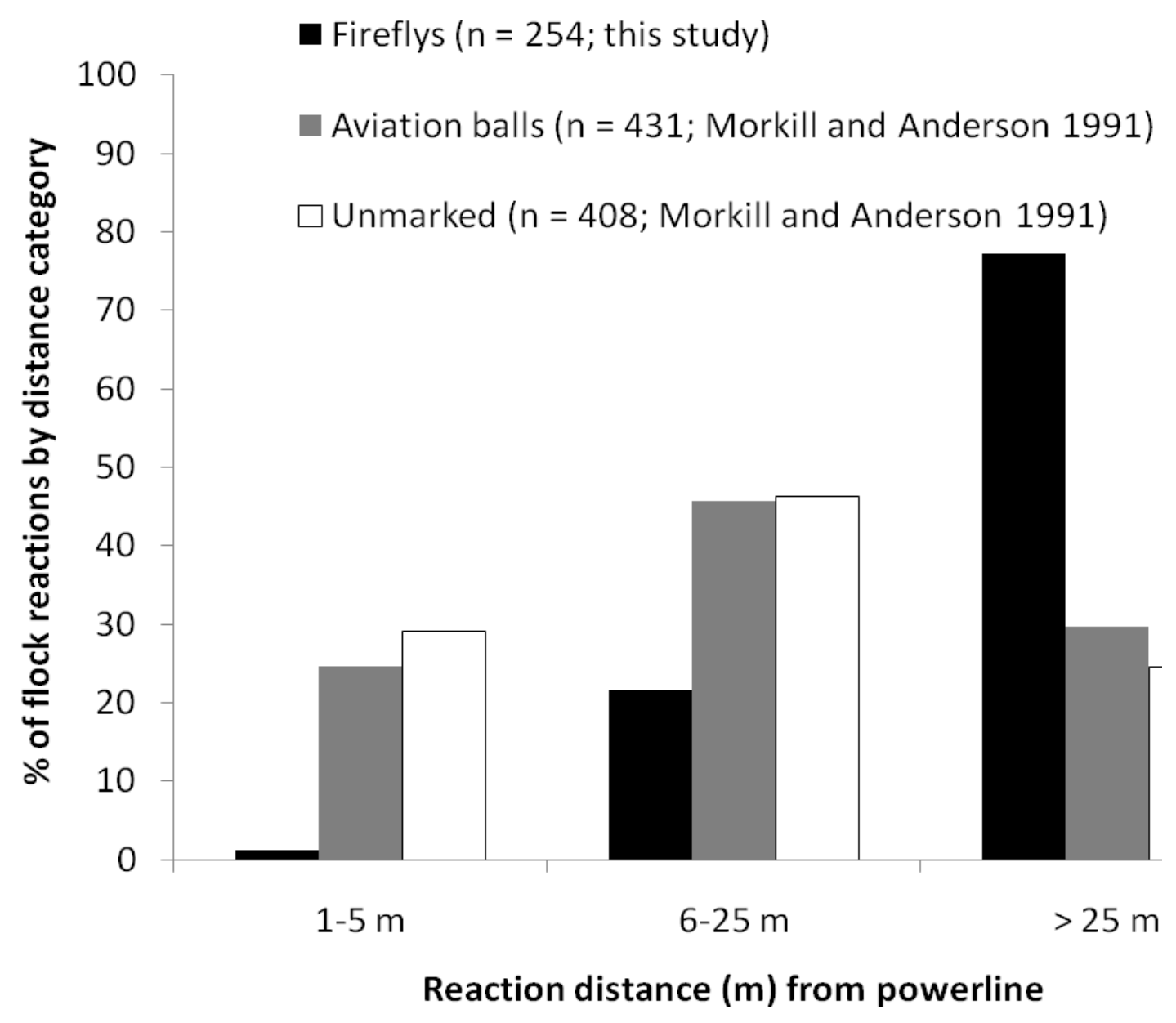

Figure 4. Frequency distribution of distances of initial reactions of flighted sandhill cranes to a 69-kV powerline marked with Firefly avian flight diverters over the Platte River in south-central Nebraska during spring 2009, and of reactions of sandhill cranes to powerline spans marked with $30-\mathrm{cm}$ diameter aviation marker balls and to unmarked spans over croplands in south-central Nebraska during spring 1988-1990, based on data in Morkill and Anderson (1991). Sample sizes (i.e., number of flock reactions observed) are in parentheses. 


\section{Collision Incidence based on BSIs}

The number of collisions by birds recorded by BSIs each evening correlated closely with the number of collisions by sandhill cranes we directly observed during the same time $(\mathrm{r}=0.86$, $\mathrm{P}<0.001$; Fig. 5). Several BSI records suggested double collisions (i.e., two birds striking a wire simultaneously), while several others suggested collisions that involved two wires (i.e., a bird striking one wire then immediately another). Stemming from this validation of reliability of BSIs, there were 358 collisions, presumably all by birds, with the eastern powerline on 55 days between 11 February and 15 April 2009. Collision incidence indicated by BSIs was distributed unevenly through night and day $\left(X^{2}=463 ; \mathrm{df}=7, \mathrm{P}<0.001\right)$, with about one-half occurring during evening and nearly all others during the remaining night hours (Fig. 6).

\section{DISCUSSION}

Our estimates of 50-93 and 37-70 sandhill cranes killed by the two powerlines at Rowe in 2008 and 2009, based on searches for carcasses, are one-third to one-half of an estimate of 153 to 229 sandhill cranes by Wright et al. (2009) at Rowe for spring 2007, before FireFly diverters were installed. Wright et al. also believed that the level of crane mortality in 2006, based on a more cursory search for carcasses, probably was similar to that in 2007. Previous assessments based on carcass searches have indicated that sandhill crane mortality due to collision with powerlines is roughly halved when the powerlines are marked with diverters (Morkill and Anderson 1991, Brown and Driewen 1995). However, differences in methods especially correction for potential bias in carcass detection cloud close comparison of studies.

A greater proportion of flocks of sandhill cranes we observed reacted to the powerline marked with FireFlys than did flocks of cranes to powerlines not equipped with diverter devices and to powerlines marked with aviation balls as diverter devices in Morkill and Anderson (1991). Also, a greater percentage of crane flocks in our study reacted by gradually climbing. However, our observations were derived from a single powerline over a river roost in southcentral Nebraska. Morkill and Anderson (1991) studied behavior of flighted cranes at alternately marked and unmarked spans of nine powerlines over cornfields and meadows in the same area. 


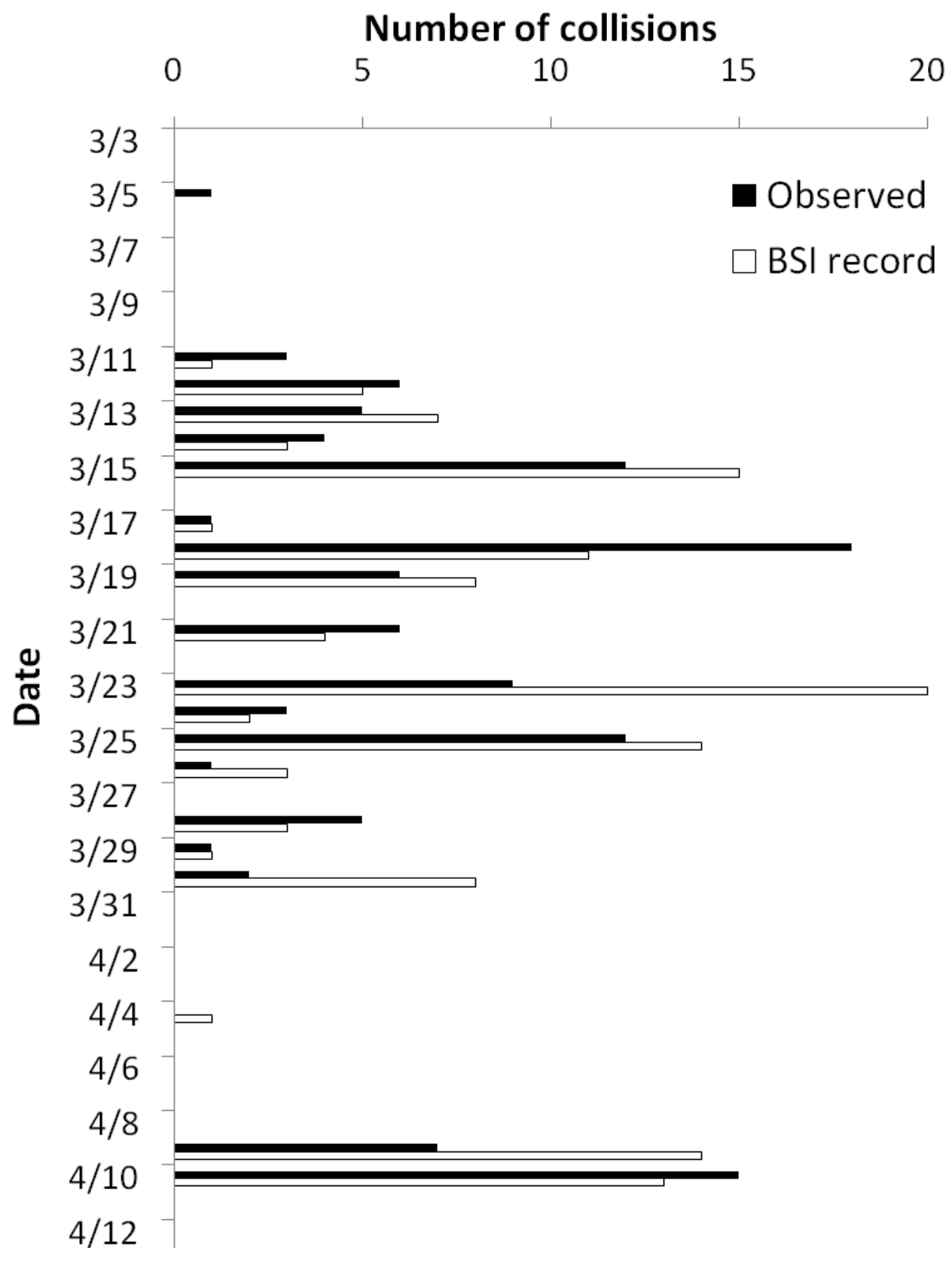

Figure 5. Number of collisions by birds with the eastern powerline over the Platte River at National Audubon Society's Lillian Rowe Sanctuary in south central Nebraska, as recorded by direct observation and by electronic bird strike indicators (BSIs; EDM International, Fort Collins, Colorado) during evenings, 3 March to13 April 2009. All collisions directly observed were of sandhill cranes, while those recorded by BSIs were of relatively large birds of unknown species. No BSI data were collected on 3 March. 


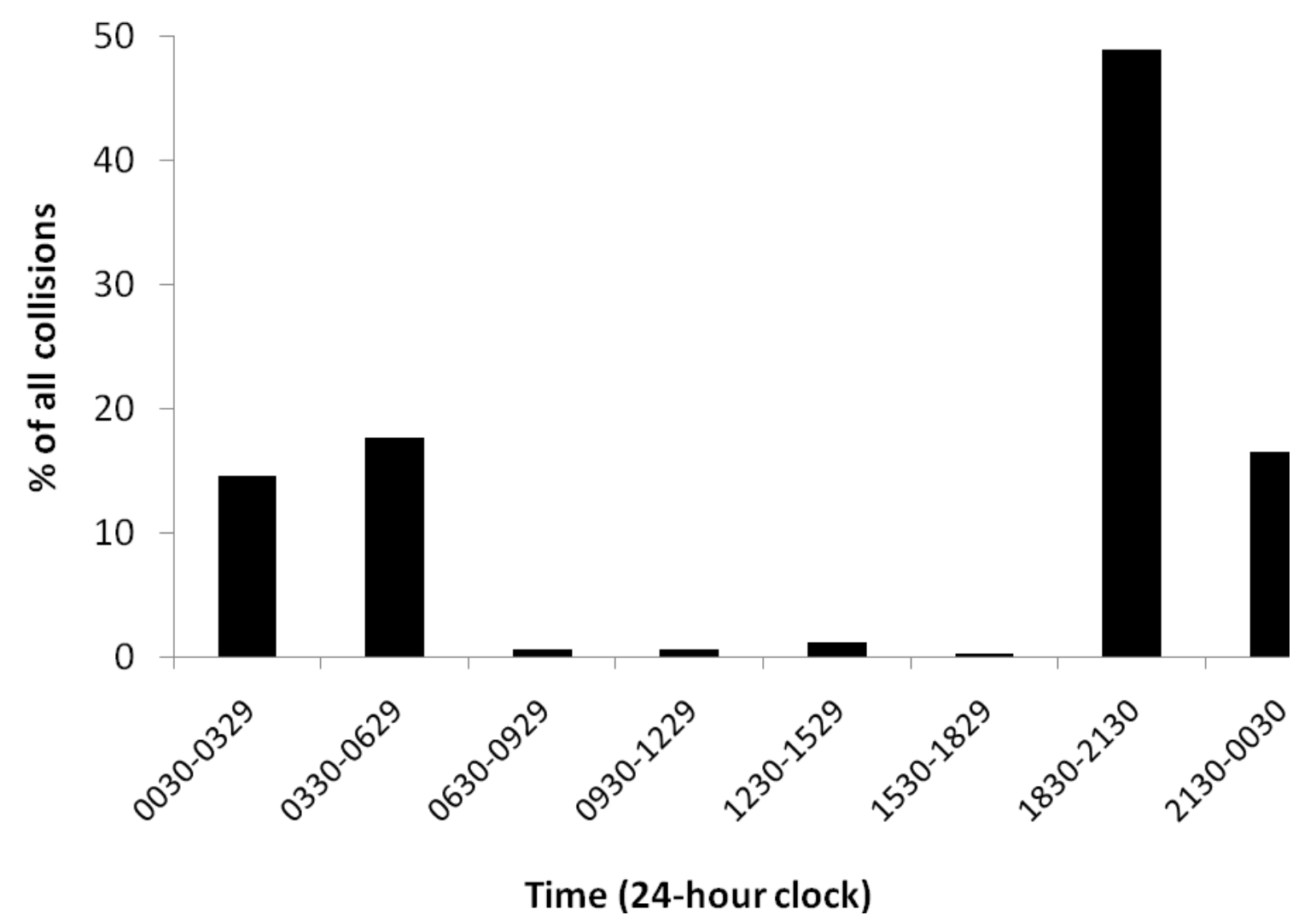

Figure 6. Diel timing of collisions by birds with the eastern powerline at National Audubon Society's Lillian Rowe Sanctuary in south central Nebraska, as detected by electronic bird strike indicators (EDM International, Fort Collins, Colorado) during 11 February to 15 April 2009. Data are presented as percentage of total collisions recorded $(n=358)$.

We are unsure whether or how differences in study sites influence comparisons. Regardless, our observations suggest FireFlys may alert sandhill cranes to powerlines earlier than aviation balls, giving the cranes more time to react and avoid wires. Finally, small flocks of cranes we observed approaching the eastern powerline at Rowe in late evening were more likely to flare and less likely to gradually climb than large flocks. This observation and similar findings by Morkill and Anderson (1991) suggest an interaction between flock size and diverter type. Clearly, additional studies incorporating at least modestly rigorous experimental design are 
needed to reliably assess effectiveness of FireFlys for reducing powerline collisions by cranes. Unfortunately, due to legal and logistical constraints, we were unable to implement such a design. Lack of design in our study, i.e., random treatment assignment, controls, and replication, preclude definitive conclusions about effectiveness of FireFlys in decreasing mortality of sandhill cranes, at least in terms of statistical significance.

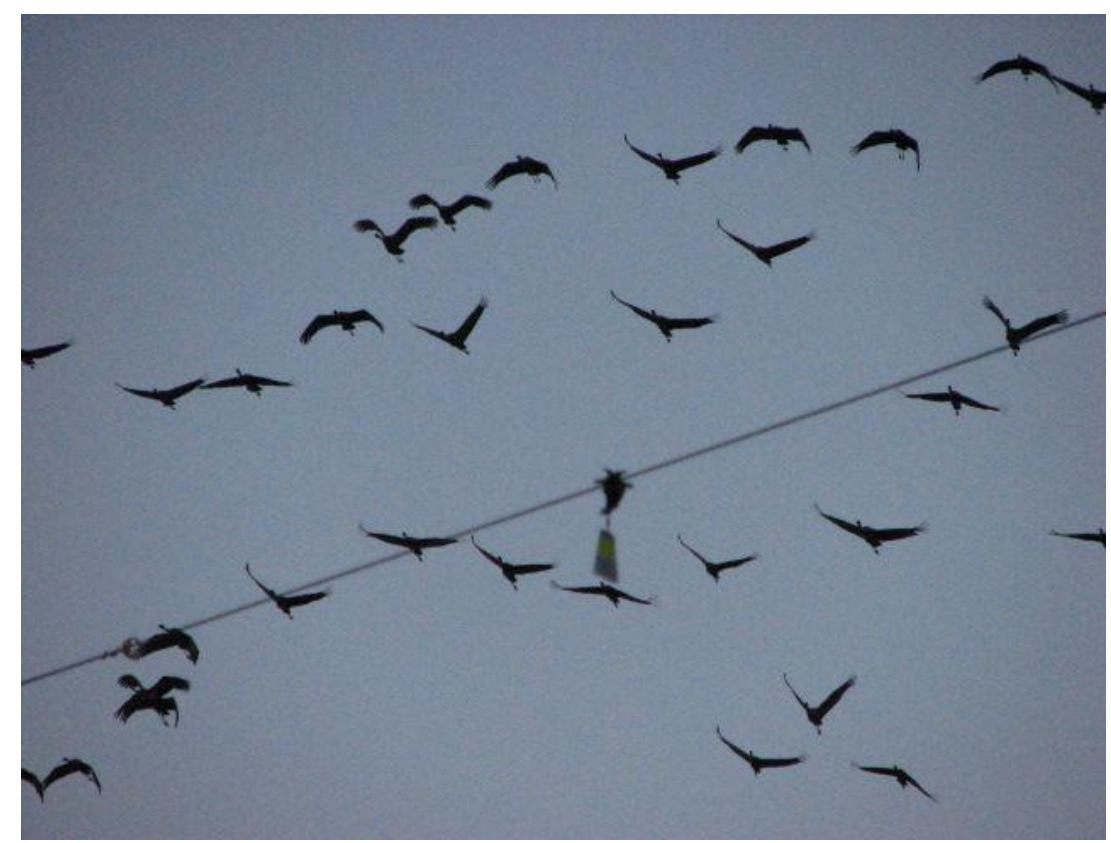

Flocks of sandhill cranes reacted more often and reacted earlier to Rowe's eastern powerline, marked with FireFly bird diverters, than they did to powerlines not equipped with diverter devices and to powerlines marked with aviation balls as diverter devices in another study in south central Nebraska.

Based on our direct observations, extent of crane mortality due to collisions with powerlines likely is underestimated by regular searches for carcasses beneath the wires, even after accounting for obvious sources of bias especially observer oversight and removal of carcasses by scavengers. Our estimate of the total number of sandhill cranes killed by colliding with the eastern powerline at Rowe, based on carcass searches and correction for several biases, roughly equalled the total number of cranes we observed colliding with the powerline and falling 
to the ground (2008 and 2009 data combined: 87 to 163 individuals estimated via carcass search versus 111 individuals directly observed falling to the ground). However, a significant source of bias not accounted for in carcass searches was posed by cranes injured by colliding with powerlines but managing to fly or glide beyond our search quadrat. Indeed, nearly one-third of collisions we directly observed were in this "crippling bias" category; such cranes typically were losing height as they left our field of view. We suspect most sandhill cranes that suffer hampered flight from striking powerlines do not complete their spring migration and ultimately are lost from the breeding population. Crippling bias is difficult to assess and often not included in estimates of avian mortality due to collisions with powerlines and other structures, yet the bias could be substantial (Avian Power Line Interaction Committee 1994). Last, in 2009 we observed a greater proportion of cranes that collided with powerlines subsequently glided or continued to fly, obviously hampered by injury, compared to 2008. This difference may be associated with light conditions. Most cranes in 2008 flew along the river from east to west, but most moved west to east in 2009. Perhaps cranes moving westward in 2008 tended to detect and react less quickly to the powerline because FireFlys were backlit by the western sky's glow after sunset. Such subtle differences in reaction time could influence the severity of collisions.

Based on direct observation, we believe most mortality of cranes at the eastern powerline at Rowe occurs when the birds are settling on night roosts close to the powerline during nightfall then are disturbed and suddenly flush upwards in large flocks. We could not qualitatively discern any relationship between incidence of mortality and ambient light or weather conditions during evening observation periods. Nor could we find a correlation between mortality incidence and local abundance of cranes, although no collisions were noted in early April when relatively few cranes remained in the area. A small increase in collisions at the end of the migration period in both years of our study probably was associated with arrival by what we believe were new migrant cranes, less familiar with the area. 


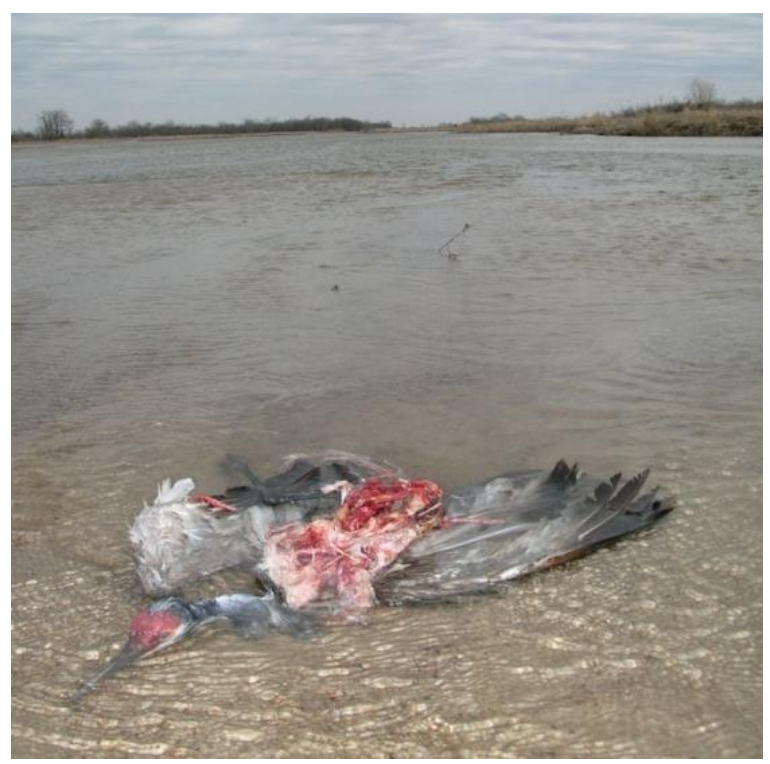

Direct observation of the eastern powerline at Rowe indicated many cranes suffer hampered flight after colliding with wires and likely land away from the powerline area, while many others fall close to the powerline, crippled, and may subsequently walk from the area. Either way, most such birds likely die before continuing to migrate. This mortality typically is overlooked in assessments of collision impacts.

Data recorded by BSIs suggest carcass searches and direct observation did not account for a substantial number of collisions by birds with the eastern powerline at Rowe. Specifically, we seldom observed the powerline after evening until dawn, during which time BSIs indicated as many collisions as we observed during the shorter evening observation period. Some, if not most, of these post-evening collisions recorded by BSIs likely were by sandhill cranes, based on two lines of support. First, all collisions we directly observed during evenings were by sandhill cranes (except for one large bird of unknown species). Second, during carcass searches we noted a high ratio of sandhill cranes to other bird species (25:3 in 2008, 17:5 in 2009), although detection rates vary among species, with smaller species likely more sensitive to biases we attempted to account for. Regardless, BSI records suggest our estimates of crane mortality based 
on carcass searches are ever more biased low. Conversely, we did not directly observe collisions by six other species of birds that were represented in carcass searches at Rowe, indicating that collisions recorded by BSIs after evening included those of bird species other than sandhill cranes. BSI records cannot be relied on to distinguish among bird species or species groups because signatures produced when small birds forcibly strike a wire may resemble those created when large birds, such as cranes or geese, lightly contact a wire (personal communication, A. Pandey and R. Harness, EDM International, Inc., Ft. Collins, Colorado). Also, collisions with wires near support structures produce different signatures than collisions occurring farther away. We used BSIs mainly to assess our notion that relatively few collisions by birds occur during post-evening through dawn and to document collisions during periods of low visibility, e.g., snowstorms, fog. Although we were unable to discern exactly which species or species groups

of birds collided with the eastern powerline during post-evening through dawn, close correlation between direct observations and BSI records of collisions by cranes in evenings indicate the technology holds promise for many applications of impact assessment.

\section{MANAGEMENT IMPLICATIONS}

Our results might suggest FireFlys reduce the likelihood that a sandhill crane will collide with powerlines at Rowe, but more rigorous experimental design incorporating replication is needed to reliably assess and provide broader inferences on effectiveness of FireFlys in decreasing mortality of cranes and other bird species at powerlines. Compared with other mitigation options (e.g., line burial or rerouting), initial installation of FireFlys is relatively inexpensive but long term costs may be high if diverters must be replaced every 1-2 years. Durability of the spinning model of the FireFly, many of which broke during this study, recently has been improved by changing to a heavy-duty, stainless steel swivel and a heavier metal ring to attach the reflective, plastic tag to the swivel (T. Chervick, FireFly Diverters LCC, personal communication). Other diverter devices could be considered. Spiral vibration dampers that are much longer than those currently on powerlines at Rowe have reduced collision mortality of cranes and other birds elsewhere (Brown and Drewien 1994), but might increase ice loading on wires at Rowe. Continued improvement of diverter devices is critical to bird conservation as powerlines and other structures (e.g., wind turbines) rapidly increase on the landscape. 
Regardless, diverter devices cannot be relied on solely. Effective mitigation of collisions by birds with a given powerline or other structure must be tailored to the site's unique physical features and should integrate multiple tools.

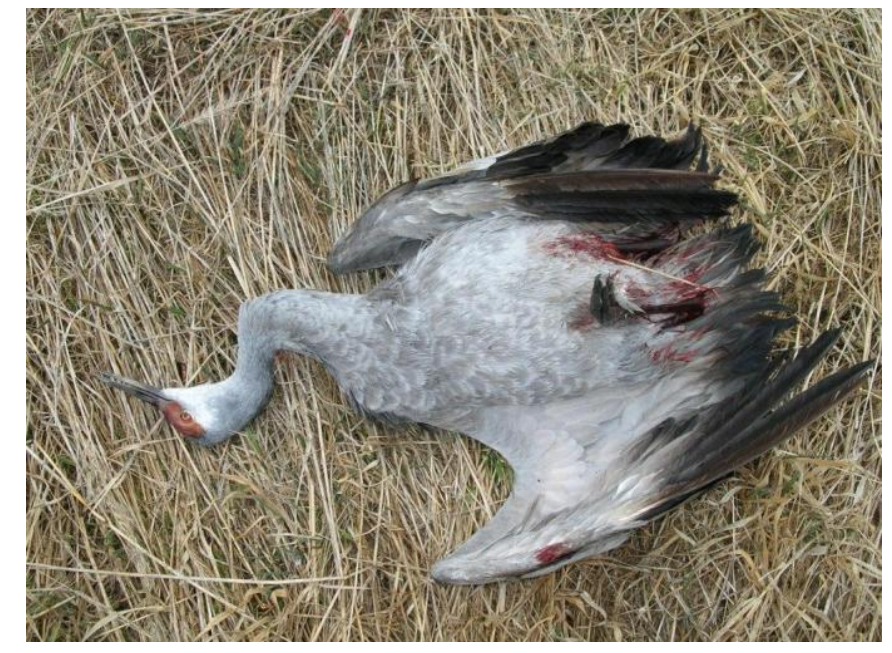

Fresh carcass of sandhill crane beneath the western powerline at Rowe in March 2008, with evidence of blunt trauma to the legs, abdomen, and right wing.

\section{ACKNOWLEDGMENTS}

This work was supported mainly by a grant from Nebraska Game and Parks Commission (NGPC) via the U.S. Fish and Wildlife Service's (FWS) Section 6 program. Dawson Public Power District installed FireFlys on powerlines at Rowe. NGPC, Nebraska Rural Electric Association, National Audubon Society's Lillian Rowe Sanctuary, and FWS supported this work in many ways. University of Nebraska-Kearney students C. Fickel and M. Morten were key field assistants. M. Fritz (NGPC) facilitated study implementation. J. Runge and R. Harms (FWS) conducted most searches for bird carcasses at the Shelton powerline and, together with M. Fritz, lent excellent technical support. B. Taddicken (Rowe) helped with local logistics. We thank A. Pandey and R. Harness, EDM International, Inc., for collecting and interpreting BSI data, and J. Goodrich-Mahoney, Electric Power Research Institute, for helping support BSI 
instrumentation. J. Kuebler and J. Falconer, University of Nebraska-Kearney, graciously administered funding for this work.

\section{LITERATURE CITED}

Altmann, J. 1974. Observational study of behavior: sampling methods. Behaviour 49:227-265.

Avian Power Line Interaction Committee. 1994. Mitigating bird collisions with power lines: the state of the art in 1994. Edison Electric Institute, Washington, D.C.

Bevanger, K. 1994. Bird interactions with utility structures: collision and electrocution, causes and mitigating measures. Ibis 136:412-425.

Brown, W. M., and R. C. Drewien. 1995. Evaluation of two power wire markers to reduce crane and waterfowl collision mortality. Wildlife Society Bulletin 23:217-227.

Lehman, R. N. 2001. Raptor electrocution on powerlines: current issues and outlook. Wildlife Society Bulletin 29:804-813.

Morkill, A. E., and S. H. Anderson. 1991. Effectiveness of marking powerlines to reduce sandhill crane collisions. Wildlife Society Bulletin 19:442-449.

Stehn, T. V., and T. Wassenich. 2008. Whooping crane collisions with powerlines: an issue paper. Proceedings North American Crane Workshop 10:25-36.

Ward, J. P., J. J. Jenniges, and S. H. Anderson. 1987. Evaluation of the Platte River as a site to study powerline modification to reduce sandhill crane collisions: second annual report. Wyoming Cooperative Wildlife Research Unit, University of Wyoming, Laramie, Wyoming.

Wright, G. D., T. J. Smith, R. K. Murphy, J. T. Runge, and R. R. Harms. 2009. Mortality of cranes (Gruidae) associated with powerlines over a major roost on the Platte River, Nebraska. Prairie Naturalist 41: In Press. 


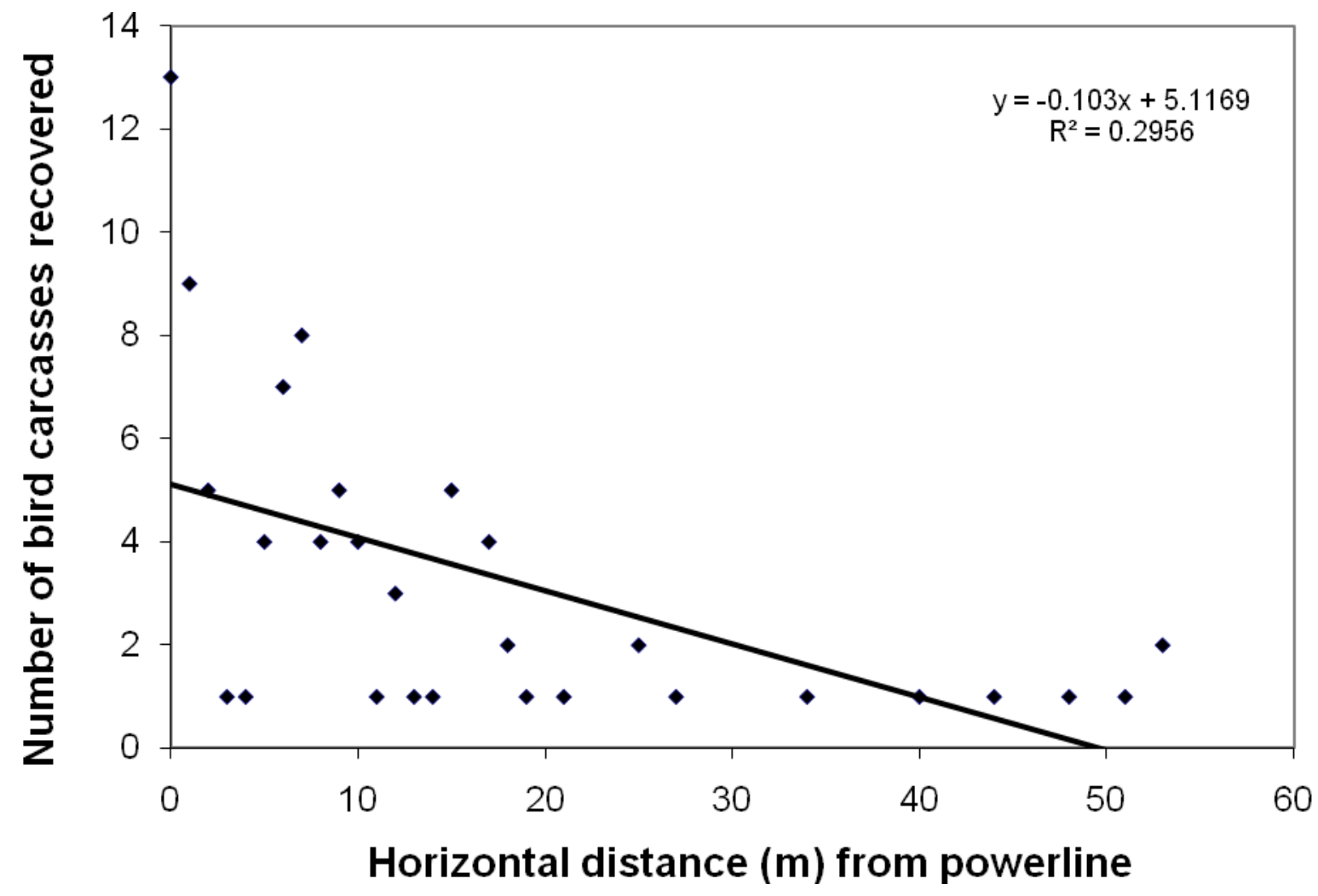

Appendix A. Distribution of distances at which bird carcasses were discovered from powerlines at Rowe, spring 2007 (R. Murphy and T. Smith, University of NebraskaKearney, unpublished data). 


\title{
University of Nebraska - Lincoln DigitalCommons@University of Nebraska - Lincoln
}

2008

\section{Survival and Sources of Mortality in Florida Sandhill Crane Chicks - Hatching to Fledging}

\author{
Stephen A. Nesbitt \\ Florida Fish and Wildlife Conservation Commission, Wildlife Research Laboratory \\ Stephen T. Schwikert \\ Florida Fish and Wildlife Conservation Commission, Wildlife Research Laboratory \\ Marilyn G. Spalding \\ University of Florida
}

Follow this and additional works at: http://digitalcommons.unl.edu/nacwgproc

Part of the Behavior and Ethology Commons, Biodiversity Commons, Ornithology Commons, Population Biology Commons, and the Terrestrial and Aquatic Ecology Commons

Nesbitt, Stephen A.; Schwikert, Stephen T.; and Spalding, Marilyn G., "Survival and Sources of Mortality in Florida Sandhill Crane Chicks - Hatching to Fledging" (2008). North American Crane Workshop Proceedings. Paper 190.

http://digitalcommons.unl.edu/nacwgproc/190

This Article is brought to you for free and open access by the North American Crane Working Group at DigitalCommons@University of Nebraska -

Lincoln. It has been accepted for inclusion in North American Crane Workshop Proceedings by an authorized administrator of

DigitalCommons@University of Nebraska - Lincoln. 


\section{SURVIVAL AND SOURCES OF MORTALITY IN FLORIDA SANDHILL CRANE CHICKS - HATCHING TO FLEDGING}

STEPHEN A. NESBITT, Florida Fish and Wildlife Conservation Commission, Wildlife Research Laboratory, 1105 S.W. Williston Road, Gainesville, FL 32601, USA

STEPHEN T. SCHWIKERT, Florida Fish and Wildlife Conservation Commission, Wildlife Research Laboratory, 1105 S.W. Williston Road, Gainesville, FL 32601, USA

MARILYN G. SPALDING, Department of Pathobiology, Box 110880, College of Veterinary Medicine, University of Florida, Gainesville, FL 32611, USA

Abstract: Forty-five pairs of Florida sandhill cranes (Grus canadensis pratensis) were monitored during the nesting seasons from 1996 through 1999. Thirty-eight chicks were produced from 25 successful nests. Twenty-one of these survived to fledging age. Predation was the source of most $(81 \%)$ of the mortality for which a cause was determined. Mammals were the primary predator. Average age at time of mortality was 27.2 days for the 17 chicks lost.

PROCEEDINGS OF THE NORTH AMERICAN CRANE WORKSHOP 10:86-89

Key words: chick mortality, Florida, Florida sandhill cranes, Grus canadensis pratensis, Grus, predation, radio telemetry, survival.

Efforts to establish a population of nonmigratory whooping cranes (Grus americana) in Florida began in 1993 (Nesbitt et al. 2001). The overall goal for the Florida reintroduction project is to establish a population of 25 breeding pairs of whooping cranes that are reproducing at a rate consistent with normal (self-sustaining) populations. Past studies of the reproduction of Florida sandhill cranes ( $G$. canadensis pratensis) indicate that about half $(56.6 \%)$ of the chicks hatched survived to the age of natal dispersal (independent of their parents); an average of 295 days old (Nesbitt 1992). Nesbitt (1992) found that $36 \%$ of the chick mortality occurred between time of hatching and 10 days of age, but the causes of mortality in these chicks were not determined. Studies of greater sandhill cranes (G. c. tabida) in Oregon and California reported that predators were responsible for 58,77 , and $78 \%$ of identified cause chick mortality (Littlefield and Lindstedt 1992, Ivey and Scheuering 1997, Desroberts 1997, respectively). Similarly for Florida sandhill cranes Dusek et al. (2005) found that predation was the likely cause of death in $73 \%$ of identified causes of mortality of the chicks they studied.

The oldest of the whooping cranes experimentally introduced to Florida were approaching breeding age by the late 1990s, and the first nest with eggs was found in 1999 (Nesbitt et al. 2001). First time nesting efforts among the introduced whooping cranes were often unsuccessful (Folk et al. 2005) and this was also true for first-time-nesting Florida sandhill cranes (Nesbitt 1992).

The objectives of this study were to evaluate causes of death of Florida sandhill crane chicks and to compare those results with results of other studies of wild cranes and with the results we observed with the whooping cranes experimentally introduced to Florida. Also improved understanding of cause of mortality for Florida sandhill crane chicks would allow us to assess if and how chick survival in the introduced whooping cranes differed.

\section{METHODS}

We individually marked, and in some cases radio instrumented, members of 30 breeding pairs of sandhill cranes in the Gainesville, Alachua County, Florida region during past studies. These marked adult pairs were monitored during the early nesting season to determine their nest initiation date, as closely as possible. We began daily monitoring of the nest as the expected hatch date approached.

Newly hatched chicks were captured as soon after hatching as possible, when hand capture was comparatively easy. These young $(<10$-days-old) chicks were radio instrumented with miniature $(2 \mathrm{~g})$ transmitters (Advanced Telemetry Systems, Isanti, Minn.). These transmitters had an expected life of 10 days and an effective range of $0.5 \mathrm{~km}$. The transmitters were glued to the skin on the back between the wings with skinadhering epoxy glue (Titan Corp., Lynnwood, Wash.). After the first year of using these transmitters, we learned that gluing a piece of cotton fabric to the back of the transmitter before we glued it to the bird improved adhesion of the transmitter to the bird.

At 10 days of age, the birds were recaptured and a larger transmitter (about $5 \mathrm{~g}$ ) was surgically inserted under the skin on the back. This second transmitter was expected to last 60 days and had an effective range of $1 \mathrm{~km}$. The method of attachment was a modification of one used previously in Oregon and California (Ivey and Scheuering 1997, Desroberts 1997, Stern et al. 1986). The modifications were developed by M. Spalding in consultation with G. Olsen (Patuxent Wildlife Research Center, USGS) and are described by Spalding et al. (2001).

At 60 days of age the birds were recaptured and the inserted 
transmitter was removed and replaced with a traditional legband-mounted transmitter (Melvin et al. 1983). These latter two types of radio transmitter included a sensor that would switch into mortality mode (faster transmitter pulse rate) if the bird (radio) had not moved in the previous 6 hours. This signaled us that the bird had died or the transmitter had come off.

To replace radios that had failed or fallen off in older, more mobile chicks we used a different method of capture than the one we used for newly hatched chicks. The process involved stationing an observer in an inconspicuous position with a view of an area where, based on past behavior, the family was expected to be feeding. One or more other people served as a capture team. The observer and the capture team stayed in voice contact using walkie-talkies while the observer watched the family's movements through a telescope. Once the family had moved into an area where the chick's movements could easily be observed, the observer would signal the capture team to rush the family with the intention of causing the chick to hide. The observer would follow the chick and direct the capture team to the exact spot where the chick had hidden. This proved to be the most effective way of capturing highly mobile chicks, because we did not need to random search the chick's last known location and, in the process, run the risk of stepping on the hidden chick during the course of the search.

Captures were planned for morning or evening because this was the time of day when families are most active, and when temperatures would be coolest, so handling would be less stressful. We attempted to obtain a blood sample when chicks were handled for general health monitoring. Also a portion of each blood sample was used for gender determination (Goodpasture et al. 1992).

Chicks were monitored twice daily $(0700-1000 \mathrm{~h}$ and $1600-1900 \mathrm{~h}$ ) to determine if mortality occurred during the day or overnight. Twice-daily monitoring continued until the chicks could fly well (90 days of age). Monitoring was reduced after 90 days to once every 2 or 3 days because mortality after fledging was significantly reduced (Nesbitt 1992).

To test the effect of the transmitter or multiple captures on survival, we used 9 chicks from 5 pairs as controls. These chicks were never captured, but we were able to determine the outcome by monitoring their parents. We used a KaplanMeier procedure available in the software package JMP (SAS Institute Inc, Cary, North Carolina, USA) to analyze survival results.

\section{RESULTS}

We monitored 42 nests between 17 February 1996 and 22 May 1999. At least 1 chick hatched in 25 of these nests. Eggs in the other 17 nests did not hatch because of flooding (31\%), infertility (15\%), abandonment $(15 \%)$, predation $(8 \%)$, or unknown causes (31\%). Twenty-one of the 38 chicks that hatched survived to successfully fledge (Table 1).

Six of the 17 chicks that did not survive were lost to unknown causes. Of the other 11 chicks, predation was identified as the cause of death for $9(82 \%), 1$ died as a result of snakebite, and the other died after becoming entangled in a fence. Avian predators (hawks and owls would be the most likely in Florida) were more of a factor in the death of younger chicks, while mammalian predators (bobcats [Lynx rufus] and coyotes [Canis latrans]) were more likely to take older chicks. The median age at death was 17 days (mean age was $27.2 \pm$ 23.2 SD days, range 4-70 days).

The survival rate to 90 days of age for the 38 chicks that hatched was 0.553 . Survival rate for males was $0.50,0.80$ for females, and 0.45 for gender unknown. These rates did not differ significantly from random $(P>0.16)$. Survival rates to 90 days for the 29 radio instrumented chicks was 0.48 and 0.78 for the 9 non-instrumented chicks; these rates did not differ significantly from random $(P=0.137)$. We were particularly interested in evaluating any effects our capture, handling, and radio attachment might have had on mortality, so we compared the 2 survival curves for the radio instrumented and noninstrumented chicks using a nonparametric Log-Rank test. Again the difference in the 2 curves was not significant $(P=0.15)$.

\section{DISCUSSION}

The smaller, limited-life, glue-on transmitters were effective on the smaller birds, but only for a few days. Three transmitters fell off before 4 days, and 2 others fell off before the end of the 10-day period. Recapturing these birds to apply the inserted transmitters was more labor intensive than if the transmitters had remained attached. When the transmitters lasted for the required 10 days, recapture of the birds for health check and replacing the transmitter was a simple procedure. Premature transmitter failure was a source of frustration for us and put additional stress on the chicks that had to be recaptured.

The type of glue and the attachment method seems to be an important consideration in the life of the transmitter. Gluing the small piece of material to the transmitter before it is glued to the bird was beneficial. Being careful to glue the transmitter directly to the chick's skin also improved the longevity of the attachment. We saw no adverse effects associated with the inserted transmitters when the birds were recaptured and the transmitters removed at 60 days.

Predation was the most frequently identified source of mortality. This result is consistent with the conclusions of the other studies of sandhill crane chick survival. Both bobcats and coyotes occur in the study area and are known predators of young and adult cranes in Florida (Nesbitt and Badger 1995, Nesbitt et al. 2001). We had suspected that some of the chick deaths seen in the past had been the result of inattentive parents; 
Table 1. Fate of 38 Florida sandhill crane chicks monitored in Florida, 1996 through 1999 nesting season.

\begin{tabular}{|c|c|c|c|c|c|c|c|}
\hline $\begin{array}{c}\text { Adult } \\
\text { pair ID }\end{array}$ & $\begin{array}{l}\text { Clutch } \\
\text { size }\end{array}$ & $\begin{array}{c}\text { Chick } \\
\#\end{array}$ & $\begin{array}{l}\text { Exp. (E) or } \\
\text { control (C) }\end{array}$ & Hatch date & Gender & $\begin{array}{l}\text { Age at death } \\
\text { (days) }\end{array}$ & Cause \\
\hline BWB & 2 & 1 & $\mathrm{E}$ & $6 \operatorname{Mar} 96$ & Female & Fledged & \\
\hline 107 & 2 & 1 & $\mathrm{E}$ & 5 May 96 & Unknown & 4 & Unknown \\
\hline NEW & 2 & 1 & $\mathrm{E}$ & 25 Apr 96 & Female & 45 & Mammal predation \\
\hline 134 & 2 & 1 & $\mathrm{E}$ & 1 May 96 & Unknown & 8 & Unknown \\
\hline 126 & 2 & $\begin{array}{l}1 \\
2\end{array}$ & $\begin{array}{l}\mathrm{E} \\
\mathrm{E}\end{array}$ & $\begin{array}{l}5 \text { May } 96 \\
7 \text { May } 96\end{array}$ & $\begin{array}{l}\text { Female } \\
\text { Male }\end{array}$ & $\begin{array}{l}17 \\
17\end{array}$ & $\begin{array}{l}\text { Avian Predation } \\
\text { Avian Predation }\end{array}$ \\
\hline 096 & 2 & $\begin{array}{l}1 \\
2\end{array}$ & $\begin{array}{l}\mathrm{E} \\
\mathrm{E}\end{array}$ & $\begin{array}{l}22 \text { May } 96 \\
25 \text { May } 96\end{array}$ & $\begin{array}{l}\text { Unknown } \\
\text { Unknown }\end{array}$ & $\begin{array}{l}6 \\
6\end{array}$ & $\begin{array}{l}\text { Unknown } \\
\text { Unknown }\end{array}$ \\
\hline CUTTLER & 2 & $\begin{array}{l}1 \\
2\end{array}$ & $\begin{array}{l}\mathrm{E} \\
\mathrm{E}\end{array}$ & $\begin{array}{l}24 \text { May } 96 \\
26 \text { May } 96\end{array}$ & $\begin{array}{l}\text { Unknown } \\
\text { Unknown }\end{array}$ & $\begin{array}{l}20 \\
45\end{array}$ & $\begin{array}{l}\text { Mammal Predation } \\
\text { Fence Injury }\end{array}$ \\
\hline WAR & 2 & $\begin{array}{l}1 \\
2\end{array}$ & $\begin{array}{l}\mathrm{E} \\
\mathrm{E}\end{array}$ & $\begin{array}{l}5 \text { May } 96 \\
7 \text { May } 96\end{array}$ & $\begin{array}{l}\text { Unknown } \\
\text { Unknown }\end{array}$ & $\begin{array}{c}10 \\
8\end{array}$ & $\begin{array}{l}\text { Mammal Predation } \\
\text { Mammal Predation }\end{array}$ \\
\hline NEW & 2 & $\begin{array}{l}1 \\
2\end{array}$ & $\begin{array}{l}\mathrm{E} \\
\mathrm{E}\end{array}$ & $\begin{array}{l}16 \text { Mar } 97 \\
18 \text { Mar } 97\end{array}$ & $\begin{array}{c}\text { Male } \\
\text { Female }\end{array}$ & $\begin{array}{l}\text { Fledged } \\
\text { Fledged }\end{array}$ & \\
\hline CUTTLER & 2 & $\begin{array}{l}1 \\
2\end{array}$ & $\begin{array}{l}\mathrm{E} \\
\mathrm{E}\end{array}$ & $\begin{array}{c}9 \text { Mar } 97 \\
10 \text { Mar } 97\end{array}$ & $\begin{array}{c}\text { Male } \\
\text { Female }\end{array}$ & $\begin{array}{l}\text { Fledged } \\
\text { Fledged }\end{array}$ & \\
\hline 126 & 1 & 1 & $\mathrm{E}$ & 26 Mar 97 & Unknown & Fledged & \\
\hline 134 & 1 & 1 & $\mathrm{E}$ & 4 Apr 97 & Male & 37 & Mammal Predation \\
\hline BWB & 1 & 1 & $\mathrm{E}$ & 21 Apr 97 & Male & 70 & Mammal Predation \\
\hline 107 & 1 & 1 & $\mathrm{E}$ & 14 May 97 & Female & Fledged & \\
\hline 096 & 1 & 1 & $\mathrm{E}$ & 20 Apr 97 & Female & Fledged & \\
\hline CUTTLER & 2 & $\begin{array}{l}1 \\
2\end{array}$ & $\begin{array}{l}\mathrm{C} \\
\mathrm{C}\end{array}$ & $\begin{array}{l}10 \text { Apr } 98 \\
12 \text { Apr } 98\end{array}$ & $\begin{array}{l}\text { Unknown } \\
\text { Unknown }\end{array}$ & $\begin{array}{c}67 \\
\text { Fledged }\end{array}$ & Unknown \\
\hline BWB & $\mathrm{U}$ & 1 & $\mathrm{C}$ & 1 Apr 98 & Unknown & Fledged & \\
\hline BWB & 2 & $\begin{array}{l}1 \\
2\end{array}$ & $\begin{array}{l}\mathrm{C} \\
\mathrm{C}\end{array}$ & $\begin{array}{l}12 \text { Mar } 99 \\
15 \text { Mar } 99\end{array}$ & $\begin{array}{l}\text { Unknown } \\
\text { Unknown }\end{array}$ & $\begin{array}{c}4 \\
\text { Fledged }\end{array}$ & Unknown \\
\hline 107 & 2 & $\begin{array}{l}1 \\
2\end{array}$ & $\begin{array}{l}\mathrm{C} \\
\mathrm{C}\end{array}$ & $\begin{array}{l}18 \text { Mar } 99 \\
20 \text { Mar } 99\end{array}$ & $\begin{array}{l}\text { Unknown } \\
\text { Unknown }\end{array}$ & $\begin{array}{l}\text { Fledged } \\
\text { Fledged }\end{array}$ & \\
\hline CUTTLER & 2 & $\begin{array}{l}1 \\
2\end{array}$ & $\begin{array}{l}\mathrm{C} \\
\mathrm{C}\end{array}$ & $\begin{array}{l}21 \text { Mar } 99 \\
23 \text { Mar } 99\end{array}$ & $\begin{array}{l}\text { Unknown } \\
\text { Unknown }\end{array}$ & $\begin{array}{l}\text { Fledged } \\
\text { Fledged }\end{array}$ & \\
\hline CATO & 2 & $\begin{array}{l}1 \\
2\end{array}$ & $\begin{array}{l}\mathrm{E} \\
\mathrm{E}\end{array}$ & $\begin{array}{l}20 \text { Mar } 99 \\
22 \text { Mar } 99\end{array}$ & $\begin{array}{c}\text { Female } \\
\text { Male }\end{array}$ & $\begin{array}{l}\text { Fledged } \\
\text { Fledged }\end{array}$ & \\
\hline 126 & 1 & 1 & $\mathrm{E}$ & 21 Apr 99 & Female & Fledged & \\
\hline Red & 2 & 1 & $\mathrm{E}$ & 22 May 99 & Male & 60 & Snake Bite \\
\hline 134 & 2 & $\begin{array}{l}1 \\
2\end{array}$ & $\begin{array}{l}\mathrm{E} \\
\mathrm{E}\end{array}$ & $\begin{array}{l}3 \text { May } 99 \\
5 \text { May } 99\end{array}$ & $\begin{array}{c}\text { Male } \\
\text { Female }\end{array}$ & $\begin{array}{l}\text { Fledged } \\
\text { Fledged }\end{array}$ & \\
\hline 096 & 2 & $\begin{array}{l}1 \\
2\end{array}$ & $\begin{array}{l}\mathrm{E} \\
\mathrm{E}\end{array}$ & $\begin{array}{l}24 \text { Apr } 99 \\
26 \text { Apr } 99\end{array}$ & $\begin{array}{l}\text { Unknown } \\
\text { Unknown }\end{array}$ & $\begin{array}{c}38 \\
\text { Fledged }\end{array}$ & Unknown \\
\hline
\end{tabular}


however, desertion or parental neglect was not a factor in any of the deaths for which a cause could be identified. Disease or parasite infections also were not seen as an important cause of mortality among the 38 chicks we studied. Intraspecific aggression or sibling aggression was also not detected as causes of mortality.

We would not recommend using inserted transmitters for any crane chicks $<10$ days of age because of the size and weight of the radios. We would avoid using the full-sized legband transmitter on any crane chick $<55$ days. Though we did not find a significant difference in survival between the experimental and control group of chicks, one should not ignore the possibility of adverse effects whenever we are deciding if, when, or how to radio-instrument juvenile cranes.

Based on results from this and earlier studies, the first chicks produced by inexperienced pairs of the experimentally introduced whooping cranes will likely not survive to fledge. It may take a year or more of failure before a pair raises their first chick to fledging. We anticipate that the main source of mortality for these first chicks will be from predation. If disease, parasite infection, or parental neglect were found to be major ( $>30 \%$ ) cause of whooping crane chick mortality in Florida, then that would be a cause for concern.

\section{ACKNOWLEDGMENTS}

The Florida Fish and Wildlife Conservation Commission, Nongame Trust Fund and the United States Fish and Wildlife Service through Section 6 of the Endangered Species Act (PL 93-205) provided funding for this study. The Florida Department of Environmental Protection, C. L. Brice and Company, and Dr. W. Murphy kindly allowed access to their property. We wish to thank G. L. Ivey for his review and suggested improvements to this manuscript. Funding for this work was supported in part by the USFWS via Cooperative Agreement No. 401814-J-035.

\section{LITERATURE CITED}

DesRoberts, K. J. 1992. Survival and habitat use of greater sandhill crane colts on Modoc National Wildlife Refuge, California. Proceedings of the North American Crane Workshop 7:18-23.

Dusek, R. J., K. G. Spalding, D. J. Forrester, N. Komar, and J. F. Day.
2005. Morbidity and mortality factors in pre-fledged Florida sandhill cranes (Grus canadensis pratensis) chicks. Proceedings of the North American Crane Workshop 9:7-13.

Folk, M. J., S. A. Nesbitt, S. T. Schwikert, J. A. Schmidt, K. A. Sullivan, T. J. Miller, S. B. Baynes, and J. M. Parker. 2005. Breeding biology of re-introduced nonmigratory whooping cranes in Florida. Proceeding of the North American Crane Workshop 9:105-109.

Goodpasture, C., G. Seluja, and G. F. Gee. 1992. Karyotype and identification of sex in two endangered crane species. Pages 219-224 in D. A. Wood, editor. Proceedings of the 1988 North American Crane Workshop. Florida Game Freshwater Fish Commission, Nongame Wildlife Program Technical Report 12. Tallahassee, Florida, USA.

Ivey, G. L., and E. J. Scheuering. 1997. Mortality of radio-equipped sandhill crane colts at Malheur National Wildlife Refuge, Oregon. Proceedings of the North American Crane Workshop 7:14-17.

Littlefield, C. D., and S. M. Lindstedt. 1992. Survival of juvenile greater sandhill cranes at Malheur National Wildlife Refuge, Oregon. Pages 21-32 in D. A. Wood, editor. Proceedings of the 1988 North American Crane Workshop. Florida Game Freshwater Fish Commission, Nongame Wildlife Program Technical Report 12. Tallahassee, Florida, USA.

Melvin, S. M., R. C. Drewien, S. A. Temple, and E. G. Bizeau. 1983. Leg-band attachment of radio transmitters for large birds. Wildlife Society Bulletin 11:282-285.

Nesbitt, S. A. 1992. First reproductive success and individual productivity in sandhill cranes. Journal of Wildlife Management 56: 573-577.

Nesbitt, S. A., and L. C. Badger. 1995. Coyote preys on young Florida sandhill crane. Florida Field Naturalist 23:15-16.

Nesbitt, S. A., M. J. Folk, K.A. Sullivan, S. T. Schwikert, and M. G. Spalding. 2001. An update of the Florida whooping crane release project through June 2000. Proceedings of the North American Crane Workshop 8:62-73.

Spalding, M. G., S. A. Nesbitt, S. T. Schwikert, and R. J. Dusek. 2001 The use of radio transmitters to monitor survival of sandhill crane chicks. Proceedings of the North American Crane Workshop $8: 213-215$.

Stern, M. A., G. J. Pampush, K. Kristensen, and R. E. Delcarlo. 1986. Survivorship, habitat use and causes of mortality in juvenile Sandhill Cranes. Unpublished Report. The Nature Conservancy, Portland, Oregon, USA. 


\section{BIRD STRIKE INDICATOR FIELD DEPLOYMENT AT THE AUDUBON NATIONAL WILDLIFE REFUGE IN NORTH DAKOTA}

Prepared For:

$$
\text { PHASE TWO }
$$

California Energy Commission

Public Interest Energy Research Program

Prepared By:

EDM International Inc.

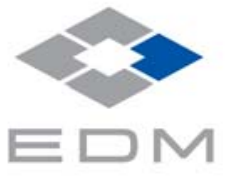

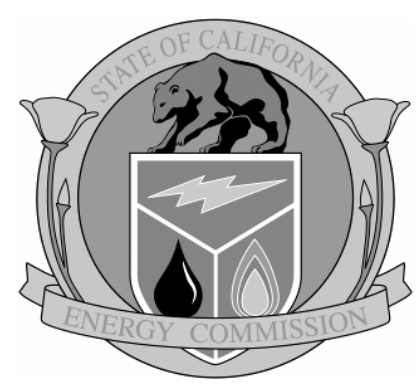

Arnold Schwarzenegger Governor

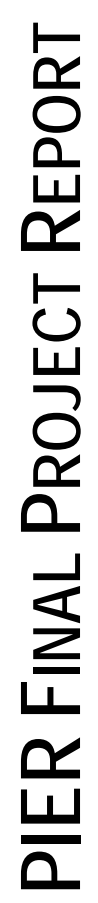

May 2008

CEC-500-2008-020 


\section{Prepared By:}

EDM International, Inc.

Dr. Arun Pandely, Richard Harness and Misti Kae Schriner

Fort Collins, Colorado 80525

Commission Contract No. 500-01-032

\section{Prepared For:}

Public Interest Energy Research (PIER)

\section{California Energy Commission}

Linda Spiegel

\section{Contract Manager}

Kelly Birkinshaw

Program Area Lead

Insert: Program Area Name

Mike Gravely

Office Manager

Insert: Office Name

Martha Krebs, Ph.D.

PIER Director

Thom Kelly, Ph.D.

Deputy Director

ENERGY RESEARCH \& DEVELOPMENT DIVISION

Melissa Jones

Executive Director

\section{DISCLAIMER}

This report was prepared as the result of work sponsored by the California Energy Commission. It does not necessarily represent the views of the Energy Commission, its employees or the State of California. The Energy Commission, the State of California, its employees, contractors and subcontractors make no warrant, express or implied, and assume no legal liability for the information in this report; nor does any party represent that the uses of this information will not infringe upon privately owned rights. This report has not been approved or disapproved by the California Energy Commission nor has the California Energy Commission passed upon the accuracy or adequacy of the information in this report. 


\section{Acknowledgments}

The authors wish to express their appreciation to the volunteers at the Audubon National Wildlife Refuge for their dedication and hard work. The following groups also provided valuable assistance in developing and completing this field trial:

- Otter Tail Power Company

- U.S. Fish and Wildlife Service

- Western Area Power Administration

- Avian Power Line Interaction Committee

The authors also thank the University of California, Santa Cruz, Predatory Bird Research Group for their support and oversight of this project.

Please cite this report as follows:

Pandey, Arun, Richard Harness, and Misti Kae Schriner. 2008. Bird Strike Indicator Field Deployment at the Audubon National Wildlife Refuge in North Dakota: Phase Two. California Energy Commission, PIER Energy-Related Environmental Research Program. CEC-500-2008-020. 


\section{Preface}

The Public Interest Energy Research (PIER) Program supports public interest energy research and development that will help improve the quality of life in California by bringing environmentally safe, affordable, and reliable energy services and products to the marketplace.

The PIER Program, managed by the California Energy Commission (Energy Commission), conducts public interest research, development, and demonstration (RD\&D) projects to benefit California.

The PIER Program strives to conduct the most promising public interest energy research by partnering with RD\&D entities, including individuals, businesses, utilities, and public or private research institutions.

PIER funding efforts are focused on the following RD\&D program areas:

- Buildings End-Use Energy Efficiency

- Energy Innovations Small Grants

- Energy-Related Environmental Research

- Energy Systems Integration

- Environmentally Preferred Advanced Generation

- Industrial/Agricultural/Water End-Use Energy Efficiency

- Renewable Energy Technologies

- Transportation

Bird Strike Indicator Field Deployment at the Audubon National Wildlife Refuge in North Dakota is the final report for the Monitoring System for Studying Avian and Wildlife Interactions with Power and Communication Facilities project (contract number 500-01-032) conducted by EDM International, Inc. (EDM). The information from this project contributes to PIER's Energy-Related Environmental Research Program.

For more information about the PIER Program, please visit the Energy Commission's website at www.energy.ca.gov/pier or contact the Energy Commission at 916-654-5164. 


\section{Table of Contents}

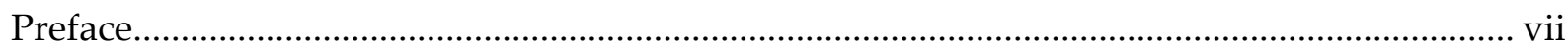

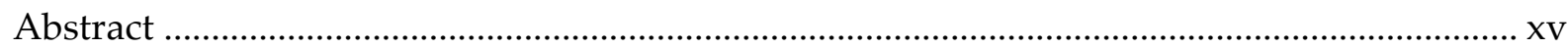

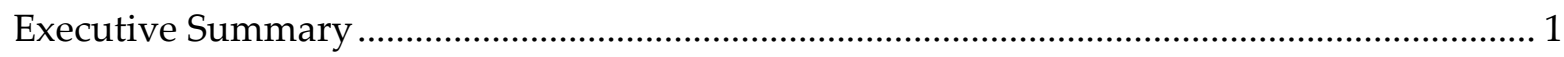

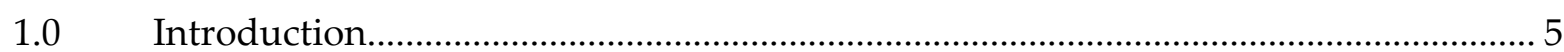

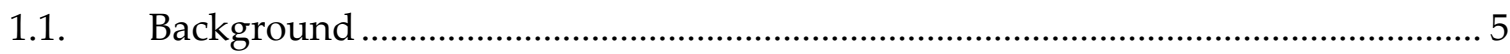

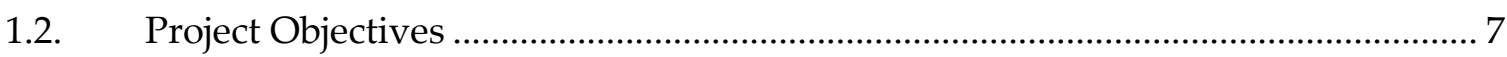

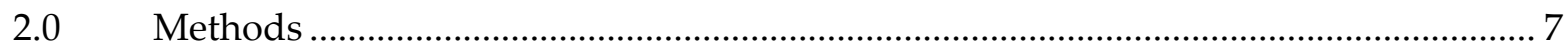

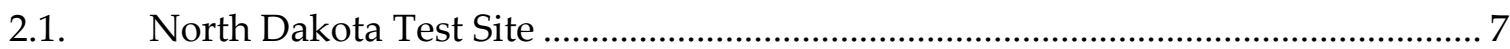

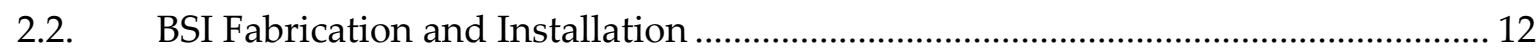

2006 BSI Field Testing at North Dakota ...................................................................... 13

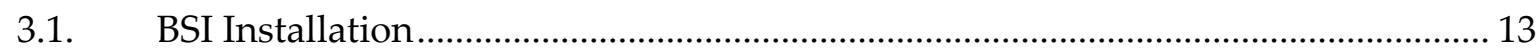

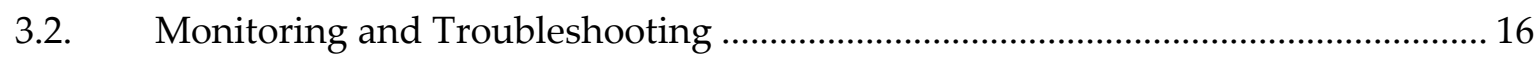

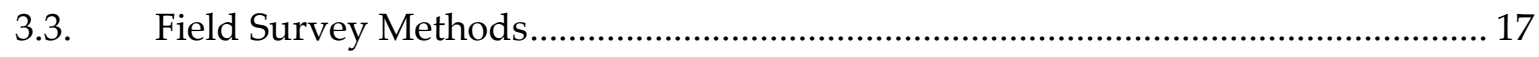

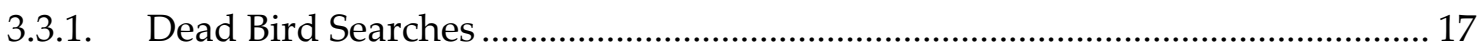

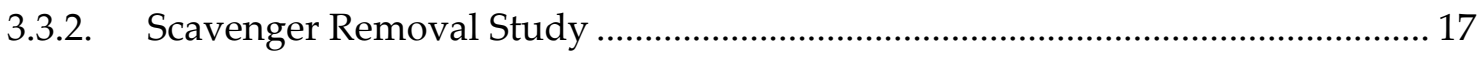

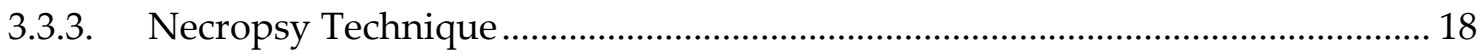

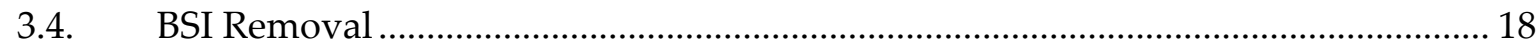

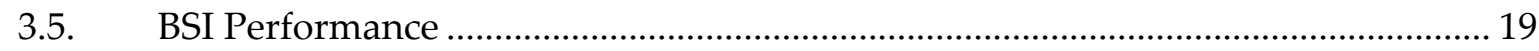

3.5.1. Installation/Removal Requirements ............................................................... 19

3.5.2. Physical Performance on Energized Wires ....................................................... 19

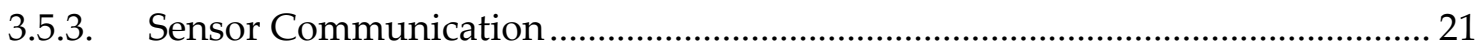

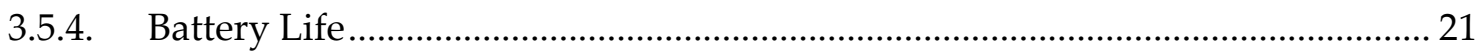

3.5.5. Summary of BSI Performance Affecting Strike Monitoring ............................. 22

3.6. BSI Sensor Collision Recording …....................................................................... 23

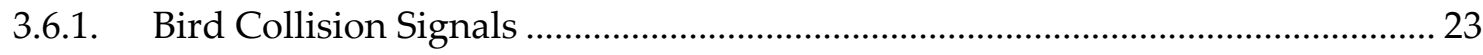

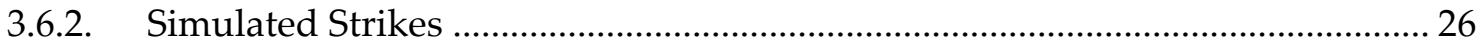

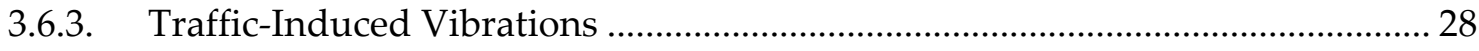

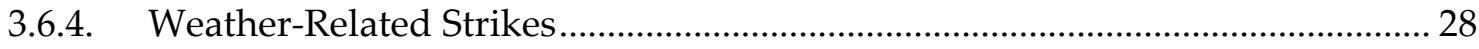

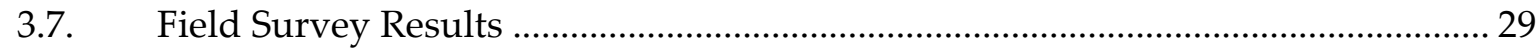

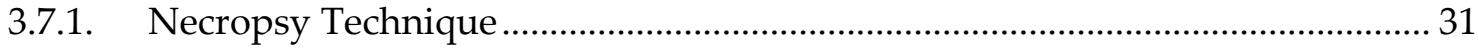

3.8. Strikes Correlation With Recovered Carcass........................................................... 32 


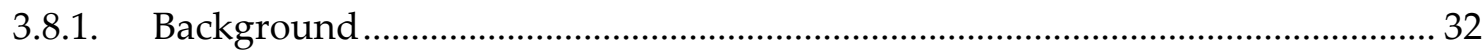

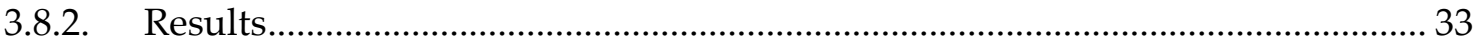

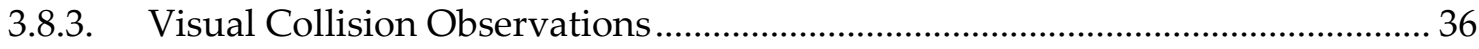

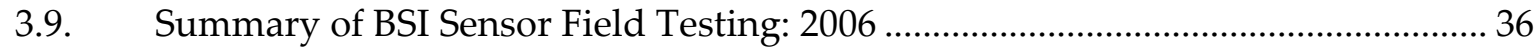

4.0 2007 BSI Field Testing at North Dakota …...................................................................... 39

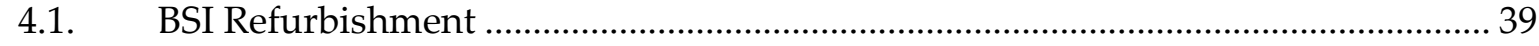

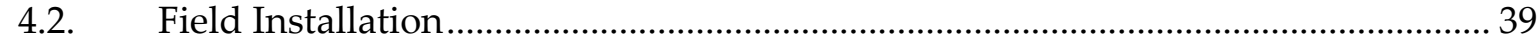

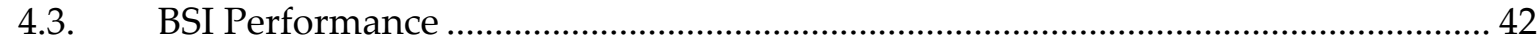

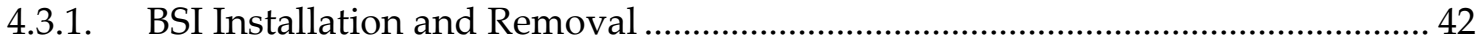

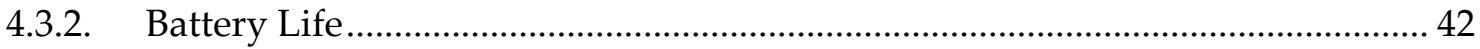

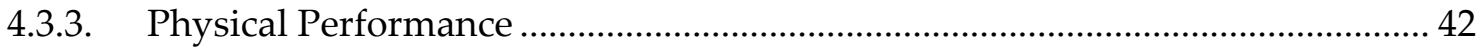

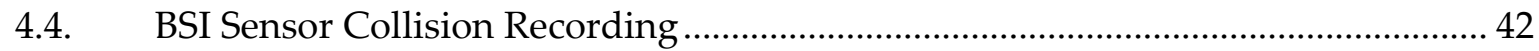

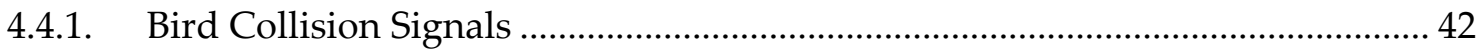

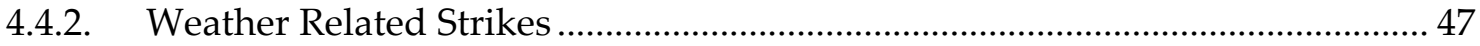

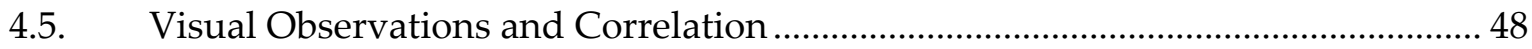

4.5.1. Visual Observation Correlation Summary …...................................................... 52

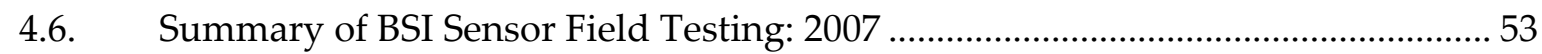

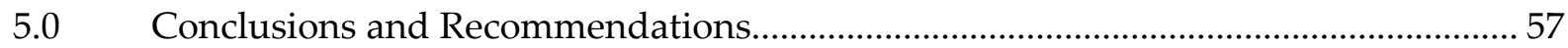

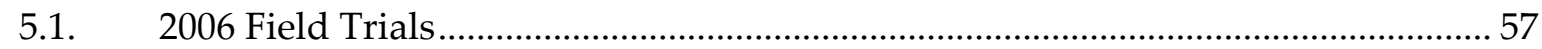

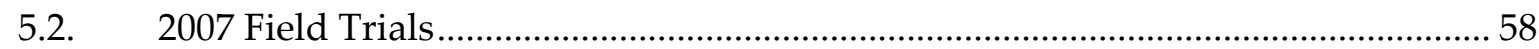

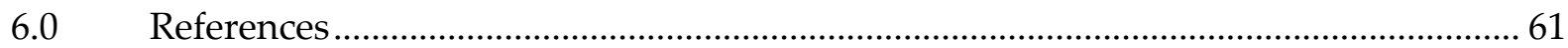

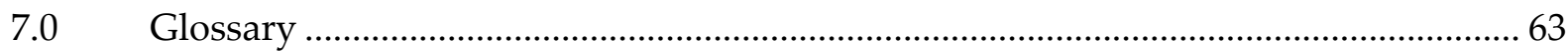




\section{List of Figures}

Figure 1. Schematic showing attachment locations for bird strike indicators and their associated

base station on a power line 6

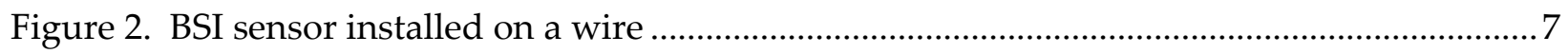

Figure 3. Study site location in western North Dakota ................................................................ 8

Figure 4. Photograph of the North Dakota test site, looking north .............................................. 9

Figure 5. Cross-sectional diagram of the transmission line looking north ................................... 10

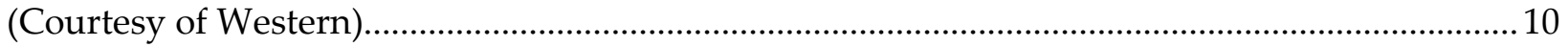

Figure 6. BSI sensor installation detail for the North Dakota field trials .................................... 11

Figure 7. Installation of BSI sensors using a bucket truck and hot stick ...................................... 13

Figure 8. Sensors installed on a typical span at the North Dakota test site .................................. 15

Figure 6. Communication shack housing the BSI base station ................................................... 16

Figure 7. Typical BSI sensor recording for a bird collision with a power line in the X-Axis (left

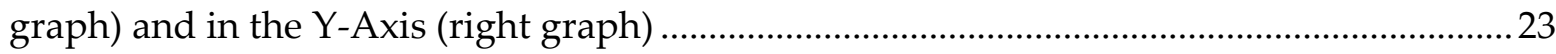

Figure 8. Two consecutive recordings by BSI sensor 27 ............................................................... 24

Figure 9. Representation of BSI sensors recorded strikes (number in parenthesis is the number of bird collisions recorded by that sensor). Stars represent units that failed at some point

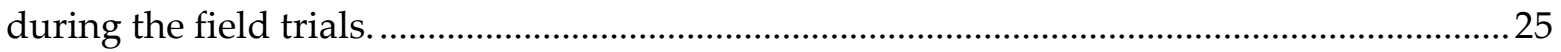

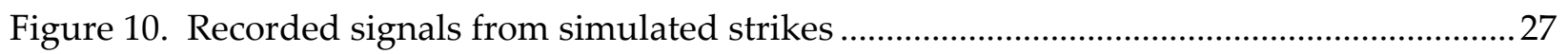

Figure 14. A typical train-induced vibration recording ................................................................2 28

Figure 15. Vibration signature likely produced by hail..............................................................2 29

Figure 16. Vibration signature produced by extreme wind gusts exceeding 30 to $40 \mathrm{mph}$.........29

Figure 17. Distribution pattern of dead birds based on distance from tower locations ............... 32

Figure 18. Redesigned BSI with metallic antenna and switch ..................................................... 40

Figure 19. Typical BSI sensor installed on a $115 \mathrm{kV}$ conductor during 2007 field tests ................ 40

Figure 20. BSI sensor installation details for the 2007 field tests ................................................. 41

Figure 21. Typical BSI sensor recordings for a bird collision with the power line with sensor

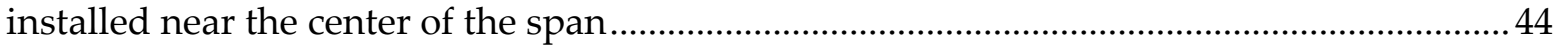


Figure 22. Vibration recording from a likely two-bird collision within a second.........................44

Figure 23. Summary of bird collision recordings in 2007 by wire location ................................. 46

Figure 24. Bird collisions recorded in 2007, by hour of day ......................................................... 46

Figure 25. Bird collision recording distribution by day on the three spans ................................ 47

Figure 26. Wind-induced vibration signal recorded by the BSI sensors in 2007........................ 48

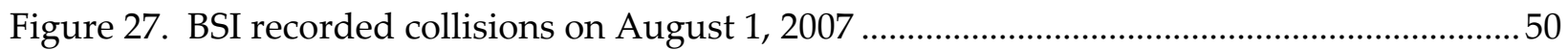

Figure 28. Observer's field of view from his sitting location at the south end of the span ..........51

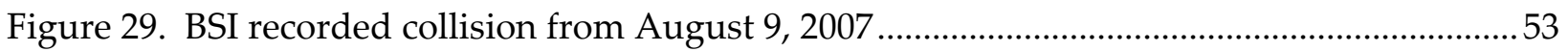




\section{List of Tables}

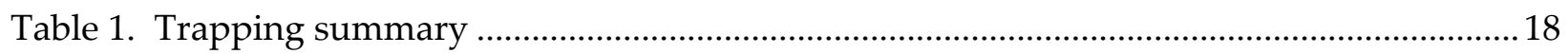

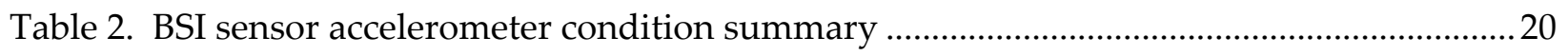

Table 3. Battery performance of the BSI sensors......................................................................... 22

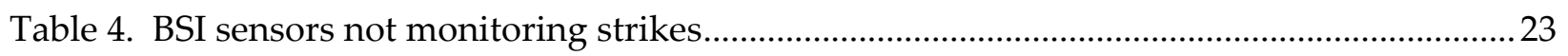

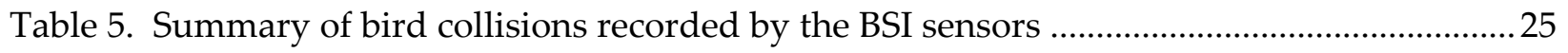

Table 6. Bird fatalities recorded during the 2006 field season ..................................................... 30

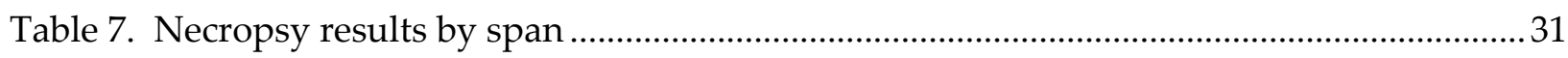

Table 8. BSI strikes correlated with bird carcasses recovered on the ground ............................... 35

Table 9. Summary of BSI sensor performance and vibration recordings during field monitoring

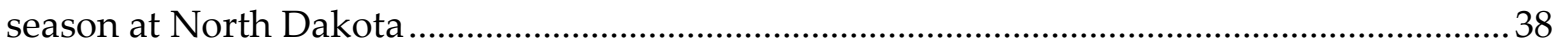

Table 10. Battery performance of the BSI sensors during 2007 tests.............................................43

Table 11. Summary of bird collision recordings in 2007 by span and sensors ............................. 45

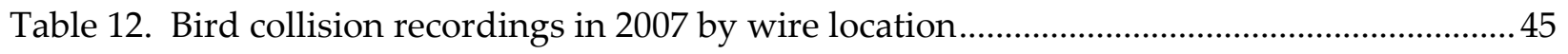

Table 13. Summary of necropsy results for the 2007 field survey season ......................................54 


\begin{abstract}
The bird strike indicator is an impulse-based vibration sensing and recording tool to detect bird strikes on aerial cables. This project was designed to perform the first field trial of the bird strike indicator on an energized power line. Three power line spans were instrumented with 30 bird strike indicators for parts of two successive years: 2006 and 2007. Ground searches were performed to relate detected carcasses with recorded strikes, and in 2007 visual observations were added to improve the likelihood of getting visual verification of bird collisions detected by the bird strike indicator. In 2006, 71 collisions were recorded and 35 were successfully correlated with ground searches. The bird strike indicators recorded additional collisions that could not be correlated with carcasses found by the surveyors, indicating that some of the carcasses might have fallen outside the search area. In 2006 some bird collisions were likely missed by malfunctioning sensors. During the 2007 field trials, improvements were made to the design of the bird strike indicator sensors based on the lessons learned from 2006. There were 154 detected bird collisions, and three were visually verified. Most collisions (68 percent) were recorded with the top wires (the overhead static wires). There were no false bird collision recordings by sensors during the visual observation period of 446 hours.
\end{abstract}

Keywords: Avian collisions, power lines, BSI, bird strike indicator, bird searches, accelerometers, vibration recorder 


\section{Executive Summary}

\section{Introduction}

The bird strike indicator is a vibration sensing and recording tool to detect bird strikes on aerial cables such as power lines. It works on the premise that a bird colliding with a wire will induce a stress wave/vibration into the wire that can be monitored and detected using accelerometers inside the bird strike indicator. The system consists of two main components: the bird strike indicator sensors and a base station. The sensors are installed on the wires to be monitored, and report any strike activity to the base station. The base station logs all the data from the sensors for future downloading and analysis. Before this project was conducted, the bird strike indicator was tested in laboratory and field settings, but not on energized lines. A previous Public Interest Energy Research Program project tested the corona effects ${ }^{1}$ of the bird strike indicator.

\section{Purpose and Benefits to California}

This project was designed to perform the first bird strike indicator field trial on an energized power line. The trials were conducted for portions of two years: 2006 and 2007. The testing period was chosen to coincide with highest incidences of bird use and collisions. The North Dakota study site was selected because it had a documented history of high ( $\sim 500$ per year) bird collision problems and many of the migratory bird species found in North Dakota also occur in California. The project site also offered a unique opportunity because it is located at a national wildlife refuge with staff willing to assist with the field work and with utility partners agreeing to allow installation of bird strike indicators on energized conductors.

Bird collisions with power lines are a growing concern in California and around the world. In the United States bird collisions are a violation of federal law under the Migratory Bird Treaty Act (MBTA). Bird collisions also can occasionally result in electrical outages. Although power line collisions historically have been a low level mortality factor for broad bird populations, power line collisions have been documented for critically endangered species such as the California condor. Successful development of bird strike indicator sensors will help researchers study the level of collision problems and determine the effectiveness of line marking devices in deterring collisions. These monitors can be cost-effectively used in remote locations to capture vital information necessary to minimize the impacts of utility structures on birds. This work is consistent with the PIER Program's mission to develop cost-effective approaches to evaluate and resolve the environmental effects of energy production, delivery, and use in California and to explore how new electricity applications and products can solve environmental problems.

${ }^{1}$ Corona effect occurs when electricity dischared from the power line passes through the bird strike indicator causing damage to the indicator and subsequently the power line on which it is mounted. 


\section{Project Objectives and Methods}

The project's objectives were to test the effectiveness of the bird strike indicator in detecting bird collisions with power lines and to evaluate its overall design and performance on energized lines.

The test site chosen for the bird strike indicator field trial is situated near the Audubon National Wildlife Refuge located approximately two miles north of Coleharbor, North Dakota. In 2006 three power line spans known to cause numerous bird collisions were equipped with bird strike indicators to remotely monitor bird strikes. Regular ground searches were performed under the lines to relate carcasses to recorded strikes. The lines were also monitored on site by field personnel at dawn and dusk to record any bird collisions observed during those survey periods. Field tests in 2006 indicated that some design improvements were necessary, so those improvements were made, and the bird strike indicators were re-installed in 2007. Ground searches were complemented with expanded visual observations to help verify strike recordings with actual bird collisions.

\section{Project Outcomes and Conclusions}

The field testing of the bird strike indicator sensors at the North Dakota test site has shown that they are able to successfully detect and record bird collisions with power lines. During the 2006 monitoring season, 71 collisions were recorded, and of those 35 were correlated with carcasses from ground searches. The bird strike indicators recorded some collisions that could not be correlated with carcasses found by the surveyors, suggesting that some of the carcasses might have fallen outside the search area, as indicated by some of the observed collisions. Some bird collisions were also missed by the bird strike indicators during the 2006 season. On three occasions they failed to log collisions visually observed by field technicians. In addition, 9 out of 30 sensors failed at some point during this initial field trial and missed recording any collisions after their failure.

Additionally, the 2006 field testing identified some design and fabrication issues affecting the sensors' field performance. The most significant design/fabrication flaw was that accelerometers became detached from the sensors due to glue failure, making them dysfunctional. The sensors installed on the 115 kilovolt $(\mathrm{kV})$ wires also had damaged antenna tips from corona (electrical ionic discharge) activity. However, this damage did not have any effect on the sensors' communication performance.

During the 2007 field trials, design changes were incorporated to solve the problems identified in the 2006 trials. New metallic antennas replaced the plastic antennas, a new switch was used to eliminate moisture intrusion, and accelerometers were allowed to cure for sufficient time before handling, ensuring they developed a strong bond. The 2007 bird strike indicators also 
had both accelerometers mounted to monitor in the horizontal plane, as opposed to the 2006 models, where both horizontal and vertical signals were recorded. These design changes significantly improved the performance of the sensors in 2007, resulting in no further problems. Lastly, the 2007 trials used a technician to visually monitor spans fitted with bird strike indicators.

Visual observations during the 2007 field trial showed correlation between observed strikes and the bird strike indicator recordings. During 2007, the bird strike indicators detected 154 recorded events versus 101 dead birds found during the field surveys under these same spans. As in 2006, this discrepancy suggests that dead birds are falling outside the search area or striking the wires and continuing to fly off since both scenarios were observed during visual monitoring. It is also important to note that there were no false collision recordings (false positives) by the sensors during the visual observation period of 446 hours over 79 days.

Data from the bird strike indicators suggest that many collisions occur during low visibility, making it impossible to visually observe them with the unaided eye. The maximum number of events occurred just around dusk, between 9 p.m. to 10 p.m. and again around 4 a.m. Very few collisions occurred during daylight hours.

The bird strike indicator results also demonstrate how events may change throughout a season. In the beginning of the monitoring season, bird collisions were being detected more often on Span 2, but later the intensity of bird collisions picked up on Span 6 and continued at the same pace until the end of the season. The sensors also recorded 68 percent of all events on the upper two shield wires.

The battery lasted throughout the six-month trial during both 2006 and 2007 and wireless communication between the sensors and base station was functional. It also was demonstrated that the installation and removal of the bird strike indicator required minimal effort by the Western Area Power Administration line crews.

The findings of the field testing are encouraging, especially results from the 2007 season, considering that this was the first installation of the bird strike indicator sensors on energized power lines at such a complicated test environment as encountered at the North Dakota test site.

\section{Recommendations}

The specific recommendations after the 2006 field trials were as follows:

1. Install the sensors closer to the middle of the span to improve the range and sensitivity of collision detection. This location could reduce the sensors' sensitivity to traffic induced vibrations by putting the sensors farther from the towers.

2. Install the accelerometers to ensure they are permanently attached, and investigate using accelerometers that can be mounted without glue.

3. Reinforce antenna tips or find an alternate metallic antenna with no sharp tips, to minimize corona effects. 
4. Use greater precaution during fabrication to ensure that the area around each switch is properly sealed to prevent moisture intrusion.

5. Increase the duration of visual observations to increase the chances of direct verification of bird collisions with bird strike indicator-detected collisions.

Items 1 through 5 were successfully incorporated into the 2007 field trials.

Additional testing is recommended to further prove the effectiveness and sensitivity of the bird strike indicator sensors to detect bird collisions. More on the sensitivity of detecting bird collisions is still needed. Detecting a collision includes several variables such as the bird size and flight speed, span length, size of the wire, mounting position, and accelerometer sensitivity setting. Controlled bird strike trials using simulated birds or bird carcasses projected at instrumented spans would provide useful information on the overall detection sensitivity. Finding another study site with less confounding factors but with high documented bird collisions would also be beneficial.

Another recommendation from both the 2006 and 2007 season is the need to develop and incorporate a digital filter in the firmware of the sensor to filter out wind-induced vibrations being recorded by the sensors. 


\subsection{Introduction}

\subsection{Background}

Bird collisions with power lines are a growing concern in California and around the world. In the United States bird collisions are a violation of federal law under the Migratory Bird Treaty Act (MBTA). The MBTA, (16 U.S.C. 703-712; Ch. 128; July 13, 1918; 40 Stat. 755 and Amendments) applies to the vast majority of birds in the United States (See 50 Code of Federal Regulations [CFR] $\S 10.13$ ) with the exception of a few species, such as the introduced house sparrow, European starling, rock pigeon, and monk parakeet. The MBTA states that, unless permitted by regulation, it is unlawful to "pursue, hunt, take, capture, kill, possess, sell, barter, purchase, ship, export, or import any migratory birds alive or dead, or any part, nests, eggs, or products thereof." Migratory bird collisions violate the misdemeanor provisions of the MBTA. For misdemeanors, the penalties include fines up to $\$ 15,000$ per organization and up to six months imprisonment. Bird collisions also can occasionally result in electrical outages.

The extent of bird collision throughout the world is unknown although some estimates have been developed by taking numbers from existing studies and extrapolating values to total miles of power lines. However these estimates are not reliable because the potential risk of birds colliding with lines depends on a complex set of site specific items, such as habitat type, line orientation to foraging flight patterns, number of migratory and resident bird species, species' composition and area familiarity, visibility and weather patterns, types of human-related disturbance, and line design. Although power line collisions historically have been a low level mortality factor for broad bird populations (Brown, 1993; Olendorff and Lehman, 1986), power line collisions have been documented for critically endangered species such as the California condor.

The bird strike indicator (BSI) is an impulse-based vibration sensing and recording tool to detect bird strikes on power lines. It is based in part on an earlier bird strike instrument developed by Pacific Gas and Electric Company (PG\&E) (CEC 2000), with the basic premise that a bird colliding with a wire will induce a stress wave/vibration into the wire that can be monitored and detected using accelerometers inside the BSI. The system consists of two main components: the BSI sensors and a base station. The sensors are installed on the wires to be monitored, and they report any strike activity to the base station. The base station logs all the data from the sensors for future downloading and analysis (Figure 1). Successful development of the BSI will help researchers study the level of collision problems and determine the effectiveness of line marking devices in deterring collisions. These monitors can be cost-effectively used in remote locations to capture vital information necessary to minimize the impacts of utility structures on birds. 


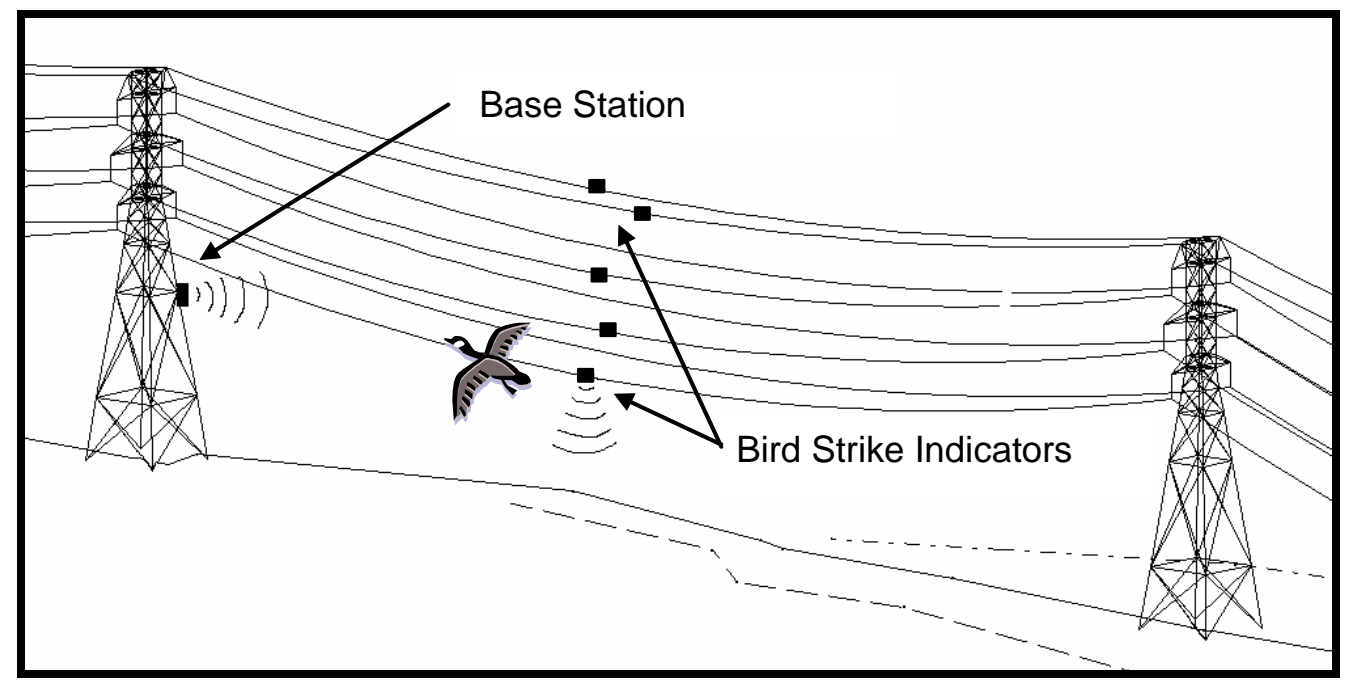

Figure 1. Schematic showing attachment locations for bird strike indicators and their associated base station on a power line

The BSI and base station were developed and lab tested as part of a previous project (CEC 2003). The BSI has been tested in Alaska on United States Coast Guard (USCG) Differential Global Positioning System (GPS) tower guy wires (EPRI 2006) and was shown to operate successfully in a harsh weather environment. Placing devices on power lines can result in corona discharge, resulting in radio interference. Initial testing on the possible impact of BSI corona discharge was conducted, and at 115 kilovolts $(\mathrm{kV})$ the BSI generated low corona levels (CEC 2004).

This study's purpose was to field test the BSI on energized lines and to evaluate the performance of the BSI at a site known to have numerous bird collisions (CEC 2003). This project was co-funded by the California Energy Commission's Public Interest Energy Research (PIER) Program, the Western Area Power Administration (Western), and the Avian Power Line Interaction Committee (APLIC). The BSI is patented by the Electric Power Research Institute (EPRI). The following organizations are past contributors to the BSI development:

- EPRI

- Bonneville Power Administration (BPA)

- NorthWestern Energy - Butte, Montana

- Otter Tail Power Company - Fergus Falls, Minnesota

- PG\&E - San Francisco, California

- Salt River Project (SRP) - Phoenix, Arizona

- Southern California Edison (SCE) - Rosemead, California

- Southwest Research Institute, Inc. (SwRI) - San Antonio, Texas

- Tri-State Generation \& Transmission Association (Tri-State G\&T) - Denver, Colorado

- United States Fish and Wildlife Service (USFWS) - Washington D.C. 


\subsection{Project Objectives}

This project was designed to perform the first BSI field trials on an energized power line. The objectives were to test the BSI effectiveness in detecting bird collisions with power lines and to evaluate the overall BSI design and performance on energized lines.

\subsection{Methods}

Three power line spans known to cause numerous bird collisions were instrumented with BSIs (Figure 2) to remotely monitor bird strikes. Daily ground searches were performed under the lines to relate detected carcasses with recorded strikes. The instrumented lines also were monitored on site by field personnel at dawn and dusk to record any bird collisions observed during those survey periods. Three spans of line were equipped in 2006 and 2007. The first year tested the technology and correlated the results with the daily field searches. The second year the BSIs were modified in response to lessons learned from 2006, and additional visual observations were emphasized. Section 3 provides a detailed description of the 2006 study; Section 4 provides the 2007 study results.

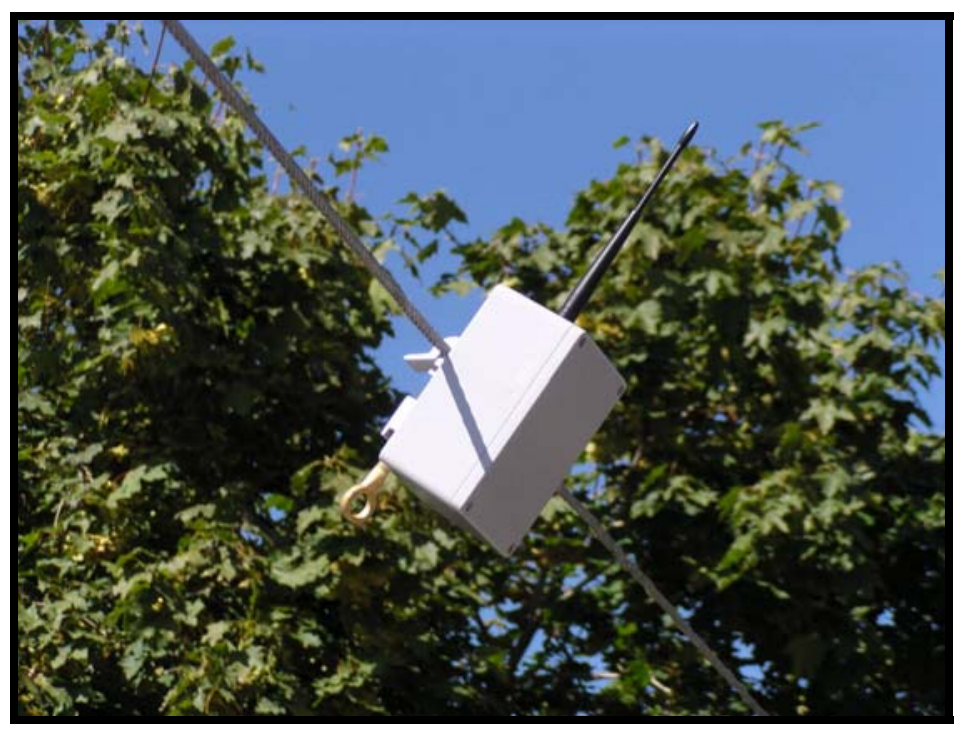

Figure 2. BSI sensor installed on a wire

\subsection{North Dakota Test Site}

The test site chosen for this research is situated near the Audubon National Wildlife Refuge, located approximately two miles north of Coleharbor, North Dakota (Figure 3). The triplecircuit line extends along the Audubon Causeway and parallels U.S. Highway 83 (Figures 3 and 4), which bisects Lake Sakakawea and Lake Audubon. This site was selected because it has a history of known bird collisions. Pedestrian surveys for avian fatalities along the causeway were conducted in 2001 and 2002, documenting 885 bird carcasses, representing over 90 species (CEC 2003). The unusual abundance of bird fatalities coupled with the diverse array of area 
species provide an opportunity to collect sample sizes adequate for data evaluations and comparisons. The North Dakota study site was selected because it had a documented history of bird collision problems and many of the migratory bird species found in North Dakota also occur in California. The project site also offered a unique opportunity because it is located at a national wildlife refuge with staff willing to assist with the field work and with utility partners agreeing to allow installation of bird strike indicators on energized conductors.

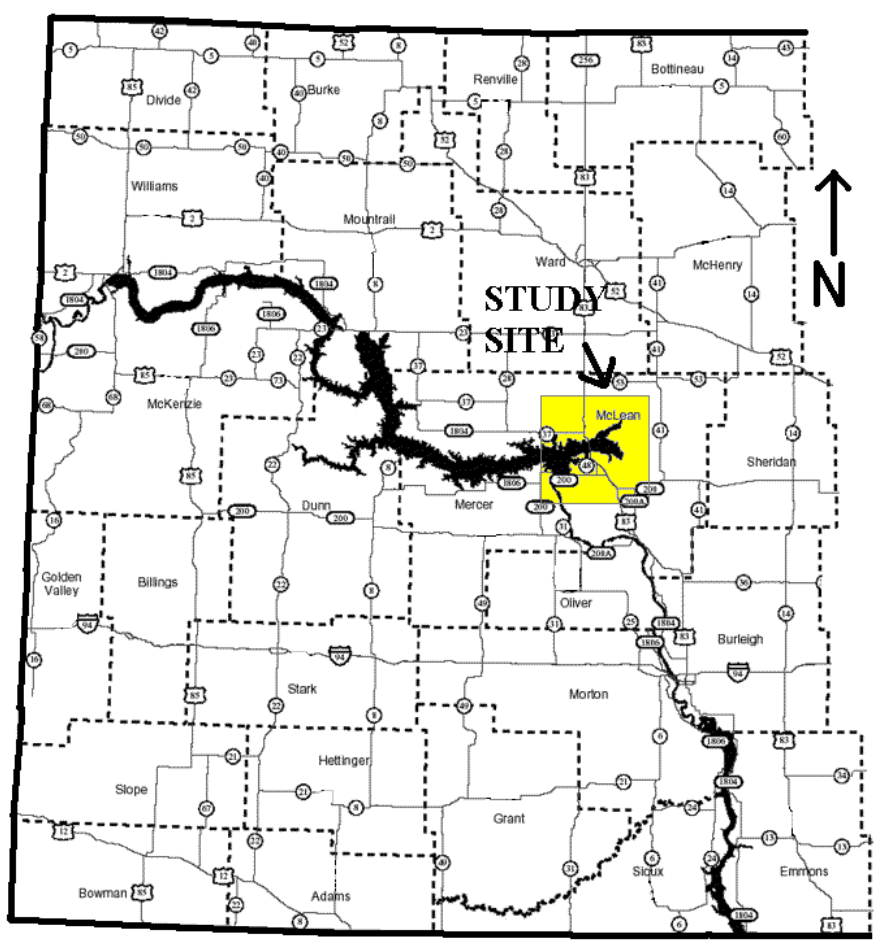

Figure 3. Study site location in western North Dakota 


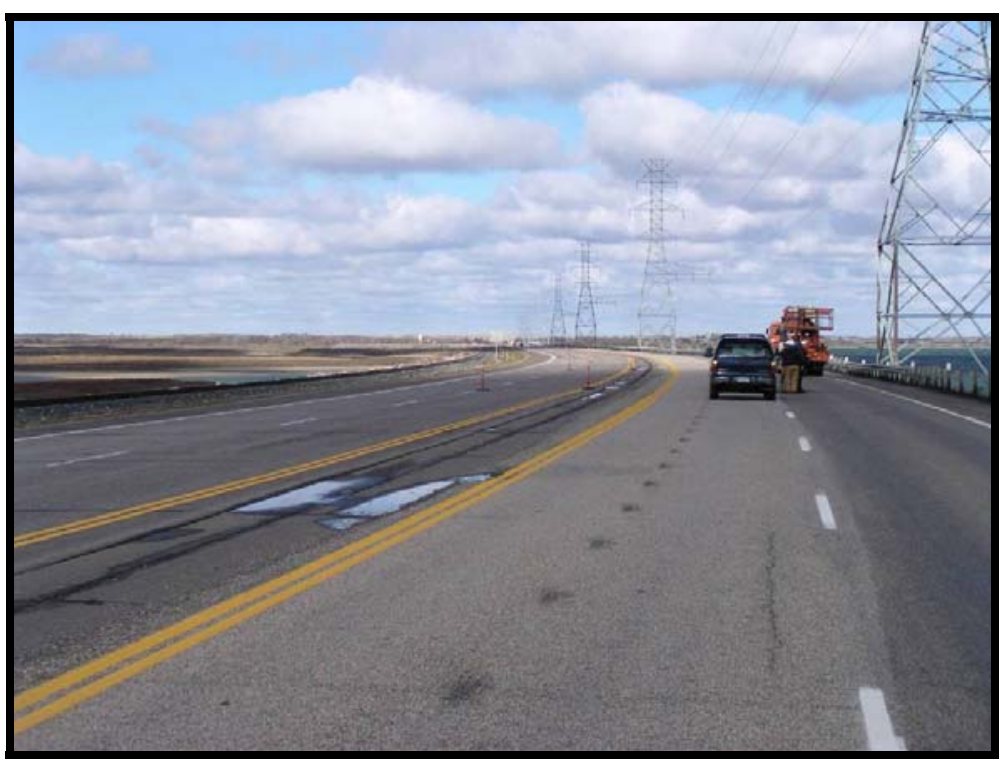

Figure 4. Photograph of the North Dakota test site, looking north

There are 13 transmission spans, each approximately 1000 feet in length, crossing the causeway. Each span consists of 11 wires, as shown in Figure 5. The top two wires are shield wires for lightning interception, the next two sets of three vertical wires are the double-circuit, $115 \mathrm{kV}$ transmission line. The bottom three horizontal wires are a $41.6 \mathrm{kV}$ circuit. In this report, the spans are numbered from 1 to 13, beginning at the south end of the causeway (Figure 6). The numbering begins with Western's structure 12/5, indicating this structure is the fifth structure in Mile 12. Western's numbering continues north to structure 14/6, the sixth structure in Mile 14. The causeway also supports a railroad line, paralleling the highway. 


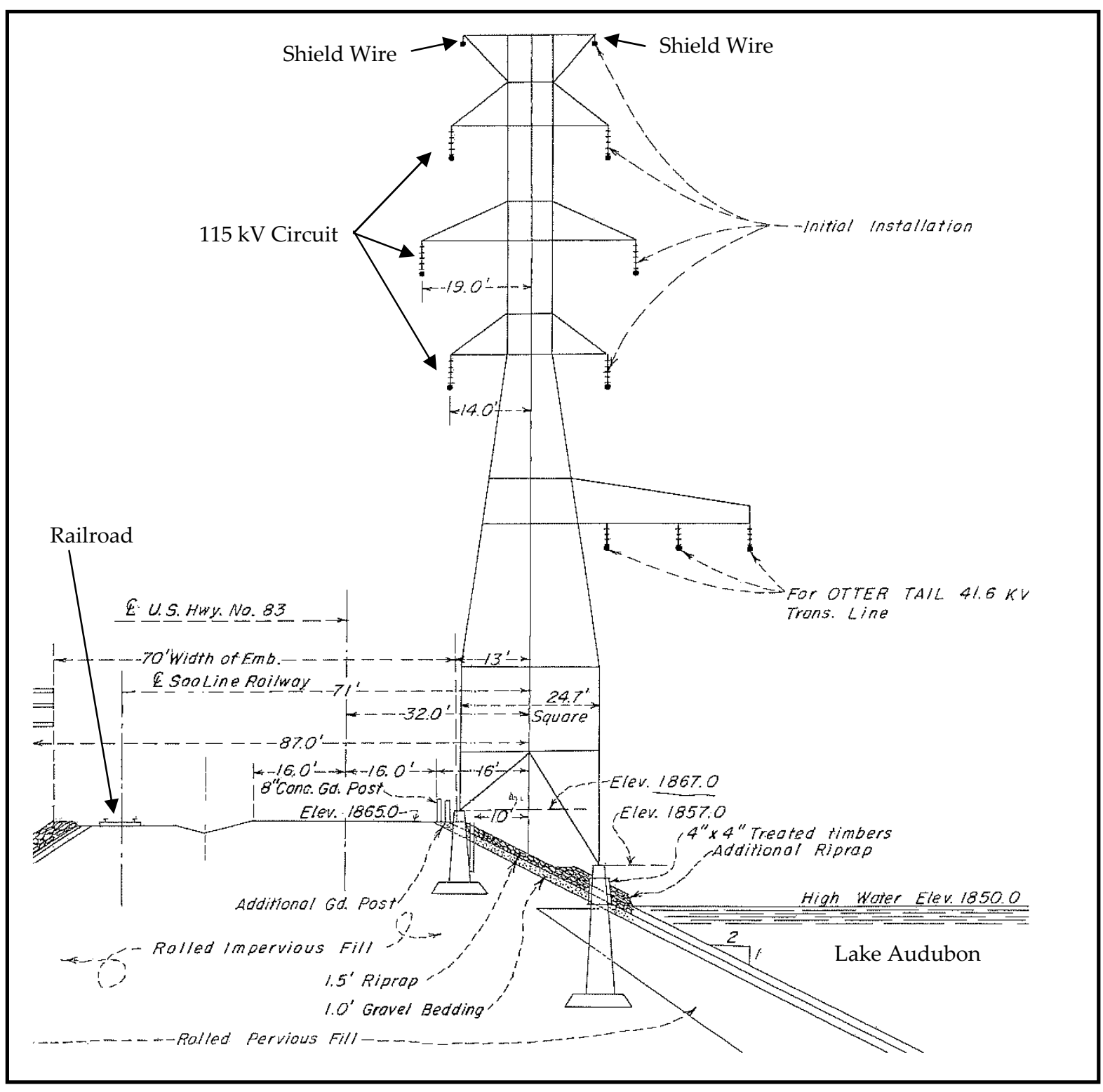

Figure 5. Cross-sectional diagram of the transmission line looking north

(Courtesy of Western) 


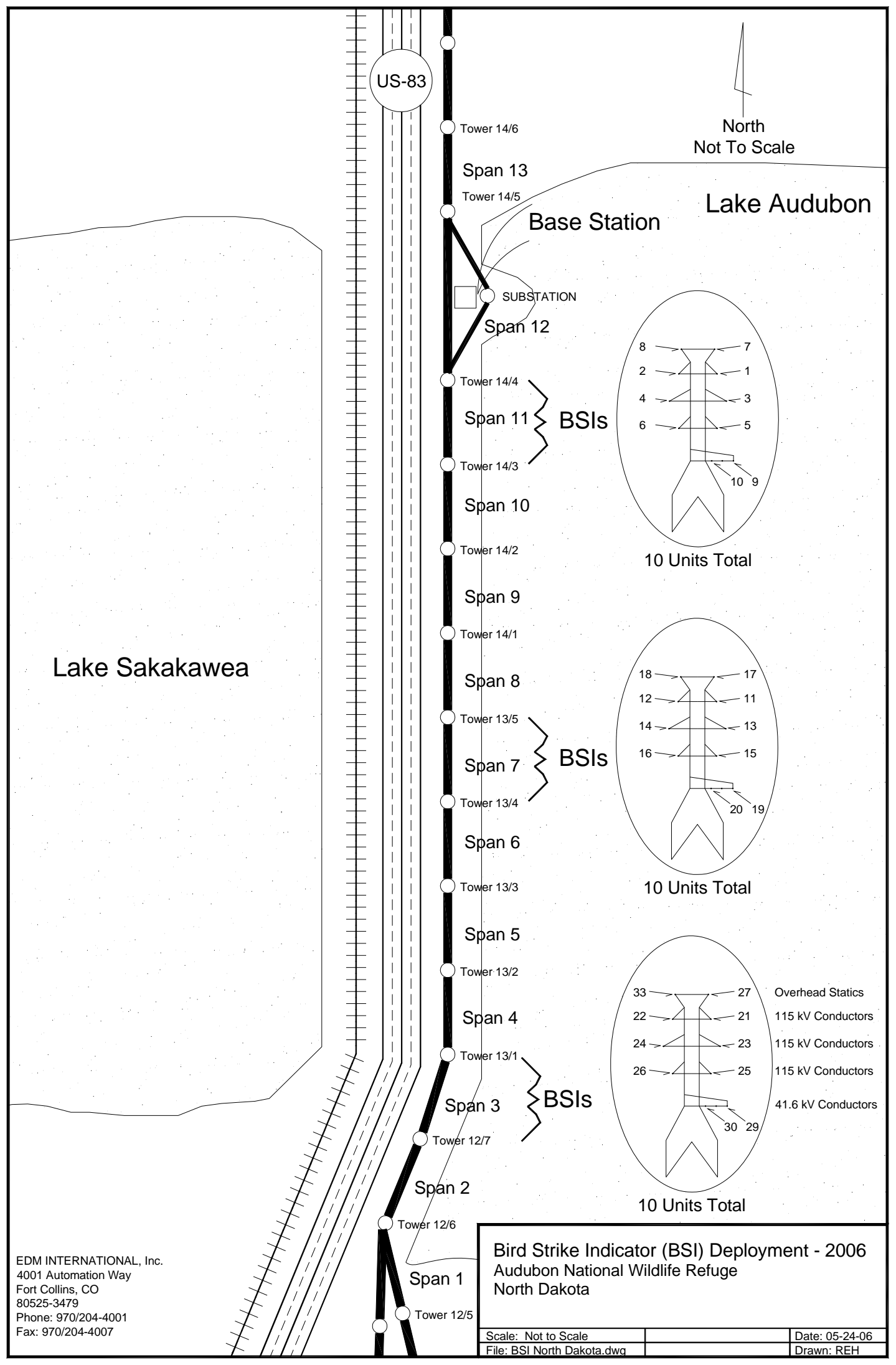

Figure 6. BSI sensor installation detail for the North Dakota field trials 


\subsection{BSI Fabrication and Installation}

Bird strike indicator prototypes were first developed and tested by PIER-sponsored projects with PG\&E and EPRI. EPRI later obtained a patent for the BSI. For this project EPRI licensed 30 BSI sensors and one base station to EDM International. EDM fabricated, calibrated, and tested the sensors and a base station from late 2005 to early 2006.

Each BSI sensor has two low power consuming accelerometers for monitoring vibration. These accelerometers are similar to ones used to trigger airbags in automobiles. Each of the BSI sensors also incorporates a small wireless radio to transmit the recorded vibration data to a base station. Bird strike indicator sensors are powered using four size-D primary lithium (nonrechargeable) batteries. There are two analog filters built into the sensor to filter $60 \mathrm{hertz}(\mathrm{Hz})$ noise and also to remove very low-frequency signals. In addition, BSI firmware filters certain weather related events, such as precipitation falling directly on the sensor, which produces a very unique signature. These events are filtered out and are not recorded or transmitted by the sensors to the base station. The units are fitted with proper hotline clamps based on the wire diameters. The sensors for the six $115 \mathrm{kV}$ transmission wires require a bigger clamp compared to the other wires because of their larger diameter.

A base station consists of a laptop computer with an uninterruptible power supply (UPS), wireless radio, and high gain Omni-directional antenna. A graphical user interface (GUI)-based application is used on the laptop to communicate with the BSI sensors and to log all the collected data. The primary function of the base station is to receive strike signals. If and when any vibration data exceeding a set threshold is detected by the sensors, the information is automatically transmitted to the base station and logged. Each vibration record is time stamped and logged by sensor ID and date on the computer. Additionally, the base station receives and logs daily health reports from each BSI sensor, indicating the sensor parameters and their battery health. The base station keeps the clock on each sensor synchronized so the units are never off by more than one minute. Greater detail on the hardware and firmware are provided in a previous report (CEC 2003). 


\subsection{BSI Field Testing at North Dakota}

This study started on April 4, 2006, and ended October 9, 2006. The North Dakota site was selected because of the high rate of bird collisions recorded during previous ground searches (CEC 2003).

\subsection{BSI Installation}

Thirty BSI sensors were installed on three spans of the transmission lines at the North Dakota study site. The BSI sensors were installed on the 10 wires from a bucket truck using a hot stick, as shown in Figure 7. The BSI sensor was designed to be installed using a hot stick, eliminating the need for initiating a power outage. However, because of the configuration of the wires and the limited access to all wires from only one side along the causeway road, it was necessary to take an outage to install these devices. In addition to the power outage, two road lanes had to be closed for the sensor installation.

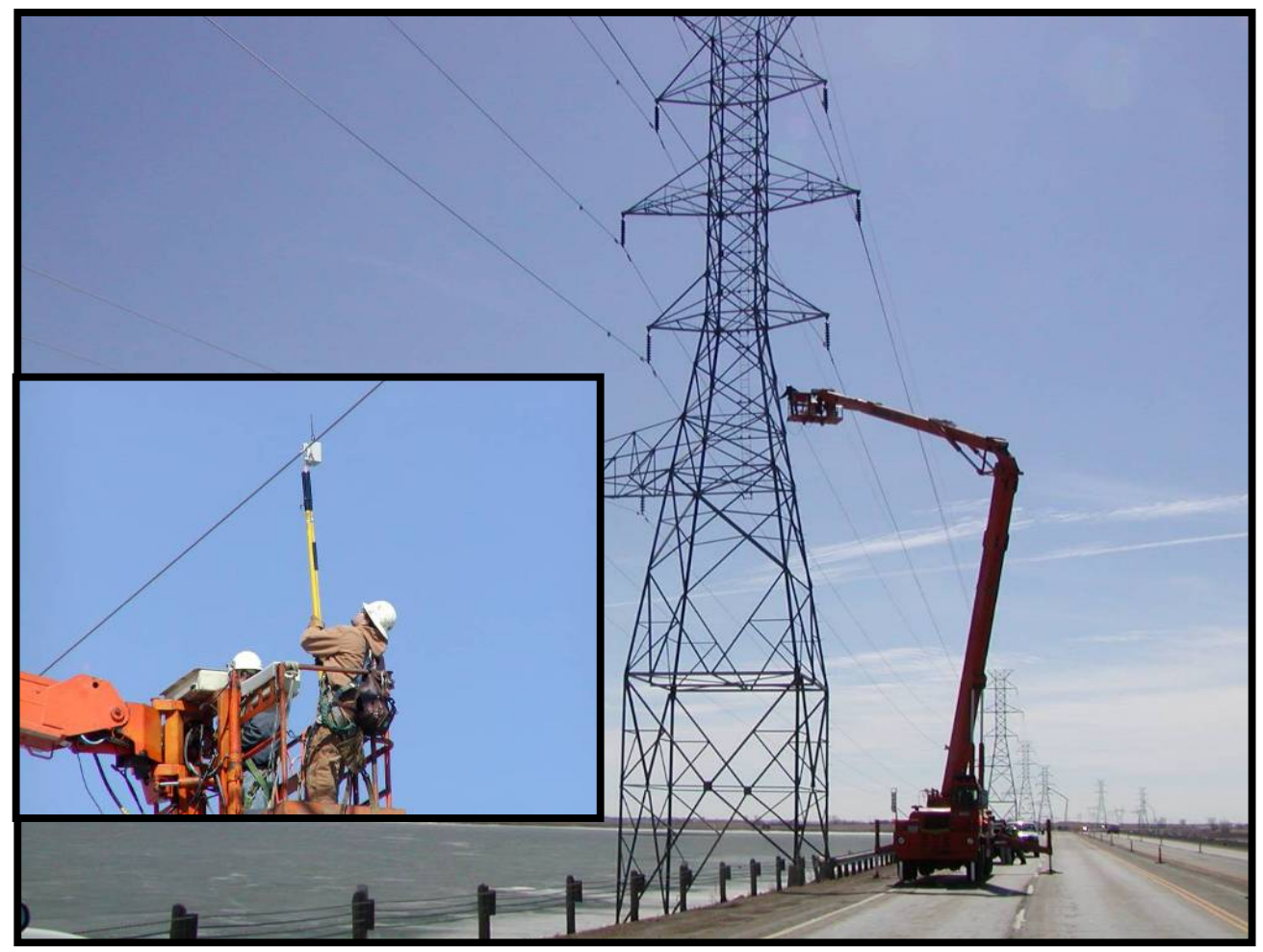

Figure 7. Installation of BSI sensors using a bucket truck and hot stick

The three spans selected for monitoring were the third, seventh, and eleventh span from the south end of the causeway (Figure 8). These three spans were selected so that the monitored spans were evenly dispersed on the causeway. The selected spans also had a high likelihood for bird collisions, based on the bird search data collected in the years 2001 and 2002 (CEC 2003), which showed a wide range of bird species previously affected. The three study spans were separated by line sections designed to be used as buffer spans for a future line marking study. 
A BSI sensor was installed on 10 of the 11 wires in each span. The only wire not instrumented was the middle wire on the bottom $41.6 \mathrm{kV}$ circuit, shown in Figure 5. This middle wire is parallel to the two outer conductors that were instrumented, and the middle conductor's position minimizes the likelihood of avian collisions. In 2006 all BSI sensors were installed approximately 15 feet north of the existing vibration dampers located on the north side of each structure. This location was selected because of concerns that a sensor mounted in the middle of a span might act as a marking device or bird deterrent, reducing the number of collisions.

Figure 8 shows a typical span with all the sensors installed. Installation of the 30 sensors went smoothly and was completed in less than three hours.

After installation, each sensor was turned on and checked to make sure each unit communicated with a mobile base station, as the permanent base station was not yet installed. Once the BSI sensor was turned on, it immediately initiated communication with the base station, received configuration parameters, and synchronized its clock. The strike monitoring command was turned on for each sensor by sending a command automatically from the base station. Although 30 sensors were installed, the sensor numbering is not sequential (Figure 6). Sensor number 28 was the only sensor that did not communicate properly after turning on, and a spare sensor (sensor number 33) was substituted. 


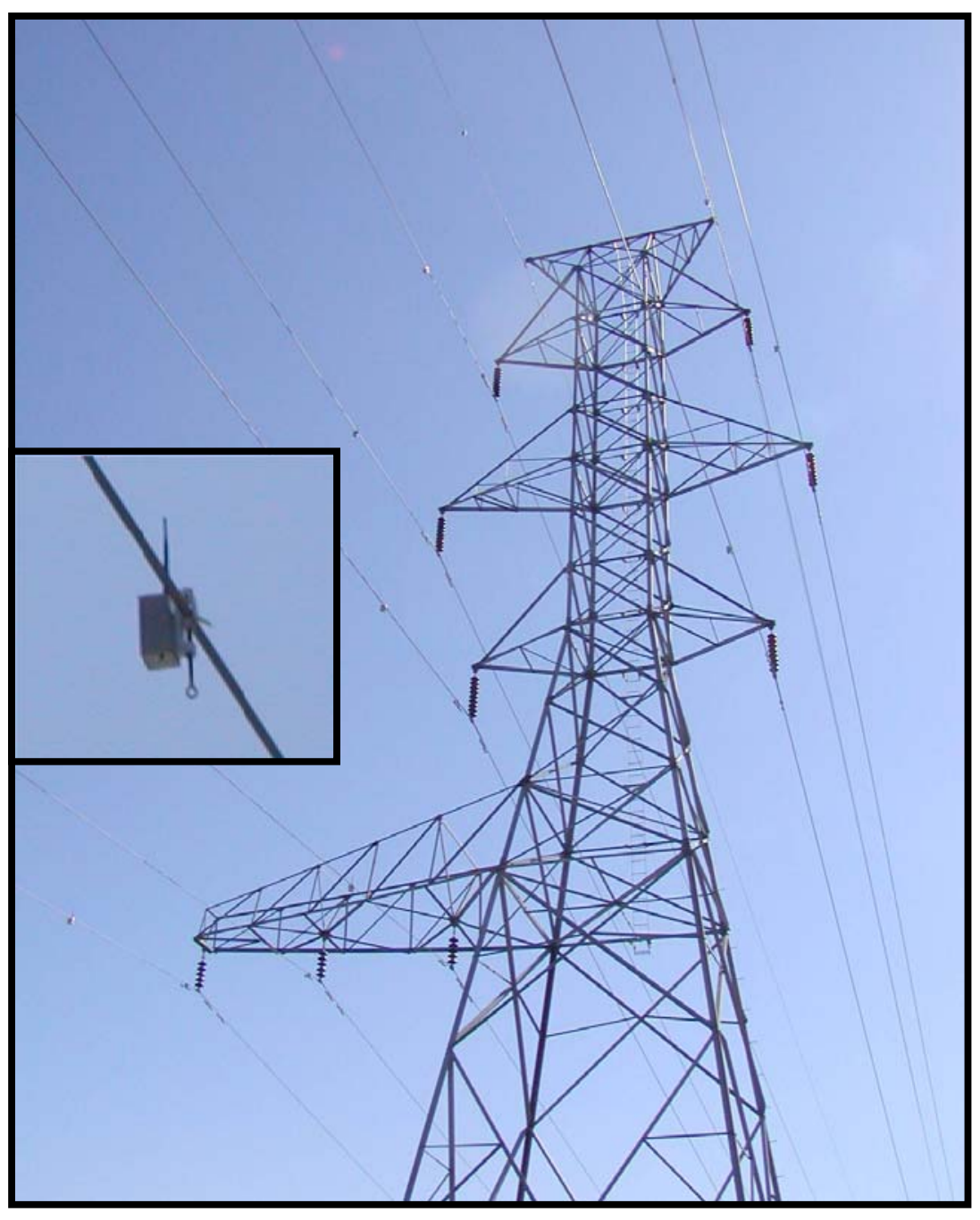

Figure 8. Sensors installed on a typical span at the North Dakota test site

The permanent base station was installed in an insulated communication shack located immediately north of the fenced perimeter of the Snake Creek Embankment Substation (Figure 9). The distance to the farthest sensor was approximately two miles from the base station. The laptop computer, along with the wireless radio and UPS, was placed inside the shack. The omnidirectional antenna was installed on a pipe attached to the nearby fence to increase the height. A dedicated phone line was connected to the laptop for remote access and data retrieval. Software was used to remotely access the base station via the phone line, allowing for complete remote control of the base station and retrieval of the logged data. 


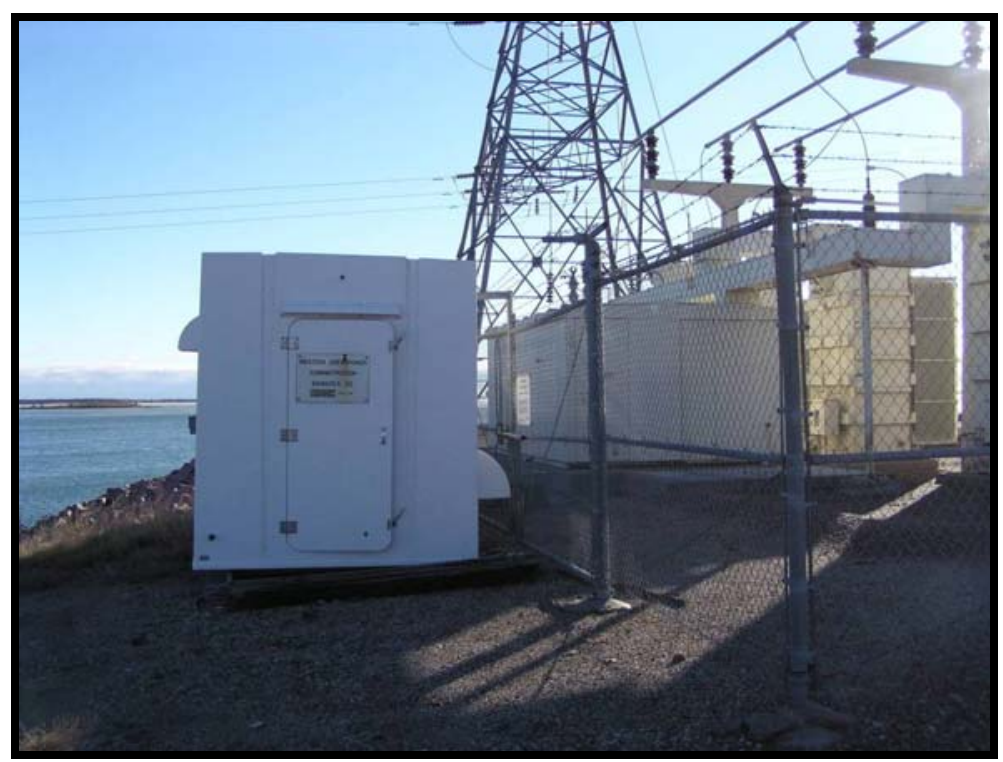

Figure 6. Communication shack housing the BSI base station

\subsection{Monitoring and Troubleshooting}

The BSI sensors are designed to continuously monitor vibrations of instrumented transmission line sections. They detect, record, and then transmit collision data to the base station when a vibration signal at the sensor location exceeds a set threshold. First, a summary of the detected collision information consisting of the date, time, sensor number, and the maximum signal on the two monitored axes is sent to the base station. Immediately following the strike summary data, the actual vibration data in both axes perpendicular to the wire also are transmitted. These vibration data are collected for a one-second duration and are ideal for troubleshooting and to determine if the signal actually represents a bird strike.

In addition to reporting detected collisions, each sensor reports its health to the base station daily at a preset time. The health report includes the parameters set for monitoring collision, the clock time, and battery voltages. The health report is used to ensure the sensors are operating properly, synchronizing their clock, and monitoring each sensor's battery life. As stated, each sensor's clock is kept synchronized to within one minute of the base station clock.

During this test, the base station was linked to a phone line to allow for remote access connection. This link was used to monitor and troubleshoot the BSIs at least weekly and frequently daily. The remote link was regularly used to download logged data for further analysis.

The remote link proved to be particularly useful immediately following BSI installation. During the first week, the BSI sensors detected numerous vibrations with a unique waveform signature not consistent with bird collisions. It was determined these signals were caused by heavy truck and train traffic along Highway 83. The BSIs have a built-in capability to reprogram the parameters for monitoring vibration remotely and the threshold for detecting collision was 
raised to $750,{ }^{1}$ from the normal threshold of 500 for a three-week period in an attempt to minimize traffic vibrations (the maximum possible amplitude for detecting a vibration is 2048, which corresponds to approximately $10 \mathrm{~g}$ of acceleration). It was subsequently determined that bird collisions were still detectable even with ambient traffic vibrations because of the bird collisions' unique signature; therefore, the threshold was dropped back down to 500, which also ensured the ability to detect smaller collision events.

\subsection{Field Survey Methods}

Dead bird searches and scavenger removal surveys were conducted in tandem with the remote BSI monitoring. Visual flight observations of bird flights were recorded at dusk and dawn to document any actual collisions occurring during these low-light periods. The protocols for the field surveys were similar to that used in the 2001 and 2002 study, as described in a previous report (CEC 2003).

\subsubsection{Dead Bird Searches}

During previous field surveys, all 13 spans were searched for bird carcasses. In the 2006 study described in this report, Spans 1 and 13 were not included. Access to the previously searched area beneath Span 13 was denied. Span 1 had not been mowed or grazed during the previous summer and there were no plans to remove the high vegetation located along the eastern side of this line span during the 2006 field season. Since the grass height would decrease searcher efficiency, Span 1 was not included in the study, as it would likely result in artificially low carcass observation and collision numbers. The elimination of these two terminal spans allowed for the field observations to be condensed into a three-day cycle (A, B, and C). Cycle A included Spans 2, 3, 4, and 5; Cycle B included Spans 6, 7, 8, and 9; Cycle C included Spans 10, 11, and 12.

\subsubsection{Scavenger Removal Study}

To estimate the effects of survey biases from both scavenger removal and searcher observations, bird carcasses retained for this purpose were marked and placed in areas beneath the transmission line typically surveyed by the field personnel. The planted birds were monitored by field personal to determine how many are removed by scavengers. The method for planting birds for the 2006 scavenger removal study season was originally designed to follow the protocols outlined in a previous report (CEC 2003). However, this protocol was altered because of two factors: high on-site scavenging rates and a lack of on-site staff.

The primary factor was directly linked to high on-site scavenging rates. After the initial carcasses were planted using random times and locations, the pedestrian surveyors failed to recover any planted birds. A concentrated effort was then initiated to recover the remaining planted birds using a Trimble global positioning system (GPS) unit. Despite these efforts, no planted carcasses were found or recovered. It was assumed the high rate of removal was from predator scavenging; therefore replanting birds would be of limited value. Additionally, a high

\footnotetext{
${ }^{1}$ These numbers are a relative amplitude of vibration.
} 
scavenging rate would affect carcass retrieval from birds colliding with the line during the 2006 field surveys.

The second factor was the lack of additional on-site staff to continue the steady rate of carcass planting. The time required to replant the carcasses using the same methods was too substantial to meet the project requirements with the given staff. Consequently, bird carcass planting was discontinued and methods to trap area scavengers were developed.

After obtaining authorization from the Audubon Refuge staff, trapping began on June 19, 2006, and ended October 9, 2006. Five raccoon and two mink traps were placed around areas with signs of scavenged birds and area predators (e.g., scat or tracks). Traps were placed along Spans $2,7,9,11,12$, and at an offsite location, Schaeffer Pond. Various types of baits were used, including sardines, jackal, fish oil, "Plum Crazy," and carp. On average, the traps were baited once every work cycle. Table 1 presents a trapping summary.

Table 1. Trapping summary

\begin{tabular}{|c|c|c|c|}
\hline Date & Trap Number & Species Caught & Bait used \\
\hline $6 / 21 / 06$ & 1 & Raccoon & Jackal \\
\hline $7 / 3 / 06$ & 2 & Raccoon & Sardines \\
\hline $7 / 8 / 06$ & 2 & Beaver & Sardines \\
\hline $7 / 15 / 06$ & 6 & Skunk & Carp \\
\hline $7 / 16 / 06$ & 5 & Skunk & Carp \\
\hline $8 / 8 / 06$ & 3 & Skunk & Carp \\
\hline $10 / 3 / 06$ & 2 & Raccoon & Carp \\
\hline $10 / 8 / 06$ & 1 & Feral cat & Carp \\
\hline
\end{tabular}

After scavenger trapping was initiated, all planted birds were recovered by the pedestrian surveyors. The trapping reduced the scavenging rate of bird carcasses along the causeway and allowed the pedestrian surveyors to search for and recover planted birds for the surveyor bias study. The placement of the planted birds followed the October 2003 Interim Report (CEC 2003) protocols, but the frequency of planting was altered, as well as the numbering system. Summer staff at the refuge was trained to plant birds according to a specific schedule. After the trapping, no carcasses were removed due to scavenging, reducing the bias to zero.

\subsubsection{Necropsy Technique}

Necropsies were performed on all recovered carcasses, excluding those carcasses that were uncollectible (i.e., flattened by vehicles, feather spots, or decayed beyond recovery). The techniques used to perform the necropsies were the same as those used in the 2003 Report (CEC 2003).

\subsection{BSI Removal}

The BSI sensors were removed prior to winter, after being operational for approximately six months. When the Western line crew was able to remove all sensors, the BSIs were shipped back to EDM for analysis. 


\subsection{BSI Performance}

There are several parameters used to determine the mechanical/electrical performance of the BSI sensor system. These parameters are classified into four categories: installation/removal requirements, physical performance on energized wires, sensor communications, and battery life.

\subsubsection{Installation/Removal Requirements}

This study of the BSI sensor system was the first to be completed on an energized power line. Prior to this project, the BSI sensors had been tested only on communication tower guy wires. The installation of 30 BSI sensors on the power line went very well and was accomplished in less than three hours by Western's line crew using a bucket truck and hot stick. An outage was taken to install the BSIs, because of the unique right-of-way (ROW) configuration limiting access along both sides of the lines. Normally an outage would not be necessary. EDM participated in the installation; however, Western's crews independently removed the sensors.

\subsubsection{Physical Performance on Energized Wires}

The sensors were on the North Dakota lines for approximately six months. Immediately after receiving the sensors back from the field, their physical condition was examined for any damage. The inside of each box also was examined for moisture, damage, or deterioration.

The overall physical condition of the sensors was very good, with no sign of external damage except for the tips of the plastic antennas. The antenna tips on the 18 sensors installed on the energized $115 \mathrm{kV}$ wires, as well as the tip on one other unit, were noticeably degraded. The degradation did not have any effect on the performance of the sensors in the field, as the sensors continued to communicate with the base station throughout the entire monitoring season. The cause of damage on 18 sensors was likely due to electrical corona activity on the energized conductors. The magnitude of corona increases with increasing voltage, which would explain the damage to the 18 sensors installed on the $115 \mathrm{kV}$ wires. This type of damage was not noted on units mounted on the shield wires or on the lower voltage $41.6 \mathrm{kV}$ wires. One sensor installed on the lower $41.6 \mathrm{kV}$ wire showed some damage, but it was different from the other antenna damage. Whereas the antennas on the $115 \mathrm{kV}$ wires showed significant fraying on the antenna tips, the unit on the $41.6 \mathrm{kV}$ wire had a small break at the tip. The cause of this break is unknown. Based on these results, any BSI unit to be installed on a line equal or greater than $115 \mathrm{kV}$ should have a metal antenna with no sharp tips, e.g., an antenna with a small spherical ball at the top. An alternative is to use a plastic antenna with a reinforced tip.

Four out of the 30 sensors showed some sign of condensation in the inside bottom of the box. Two of the four had very light condensation, consisting of a light fogging with no visible water droplets. The remaining two had moderate condensation consisting of a few small water droplets. Moisture may have entered around the switch mounted at the bottom of the sensor. Greater precaution during future fabrication should ensure the area around each switch is properly sealed.

After the sensors were removed they were subjected to a recalibration test to evaluate their sensitivity in detecting strikes after the six-month deployment. Ten sensors had low sensitivity 
in one or both axes. Although the accelerometers were attached to the box using specialized glue designed for very high temperatures, investigation showed that in some accelerometers the glue had failed. In four BSIs both accelerometers had become unglued. Six sensors had one of their two accelerometers unglued. Of these six units, four of the unglued accelerometers were units measuring vibration in the horizontal axes. This is a significant factor, because the primary axis for detecting bird collisions is the horizontal axis. Therefore, a total of eight out of the 30 sensors stopped monitoring collisions at some point after the accelerometers became detached. Table 2 provides a list of the sensors where the glue failed on the accelerometers.

Although the glue was designed for high temperatures, nine of the 10 units with detached accelerometers were mounted on the high voltage, $115 \mathrm{kV}$ wires. The remaining unit was on the $41.6 \mathrm{kV}$ circuit. None of the units on the static wires experienced glue failure.

Table 2. BSI sensor accelerometer condition summary

\begin{tabular}{|c|c|c|c|c|c|c|}
\hline \multirow[b]{2}{*}{$\begin{array}{c}\text { BSI } \\
\text { Sensor } \\
\text { No. }\end{array}$} & \multicolumn{2}{|c|}{ Accelerometer Condition } & \multirow[b]{2}{*}{$\begin{array}{c}\text { Total } \\
\text { Recorded } \\
\text { Strikes }\end{array}$} & \multicolumn{3}{|c|}{ Last Day of Strike Reporting } \\
\hline & $\begin{array}{l}\text { Horizontal } \\
\text { Axis }\end{array}$ & $\begin{array}{c}\text { Vertical } \\
\text { Axis }\end{array}$ & & $\begin{array}{c}\text { Sensor } \\
\text { Location }\end{array}$ & $\begin{array}{c}\text { No. Days } \\
\text { after } \\
\text { Installation }\end{array}$ & Date \\
\hline 3 & Unglued & & 0 & 115 kV Wire & & \\
\hline 5 & & Unglued & 0 & 115 kV Wire & & \\
\hline 10 & Unglued & Unglued & 3 & 41.6 kV Wire & 120 & $8 / 2 / 2006$ \\
\hline 12 & Unglued & Unglued & 0 & 115 kV Wire & & \\
\hline 13 & Unglued & & 0 & 115 kV Wire & & \\
\hline 15 & & Unglued & 0 & 115 kV Wire & 4 & $4 / 8 / 2006$ \\
\hline 21 & Unglued & Unglued & 0 & 115 kV Wire & & \\
\hline 22 & Unglued & & 7 & 115 kV Wire & 144 & $8 / 26 / 2006$ \\
\hline 23 & Unglued & & 0 & 115 kV Wire & & \\
\hline 24 & Unglued & Unglued & 0 & 115 kV Wire & & \\
\hline
\end{tabular}

The strike data log was searched to determine the last day any of the sensors listed in Table 2 reported a strike event. This was done because the accelerometers likely became detached either on or after this day. Of the three sensors that reported strikes, one sensor reported strikes only during the week of installation. Two sensors reported strikes as late as August. The remaining seven sensors never reported any strike events. However, this does not mean the sensors were defective from the beginning of the project, as other sensors with properly glued accelerometers similarly never reported strikes. Other than the two sensors that reported strikes in August, it is not possible to determine when the accelerometers might have become detached and thus stopped monitoring collisions.

There are several possibilities to explain why the accelerometers became detached where glued. The first involves the process of installing the accelerometers. Inadequate surface preparation and curing time prior to installation may have contributed to the failures. The second possibility is that aeolian vibration in the power line might have caused the failures. This line may also have experienced high thermal loading over the summer months. However, these causes cannot 
be confirmed. Nonetheless, future installations will need to be rigorously inspected to minimize the likelihood of this failure type. Using accelerometers that can be mounted without glue also should be investigated.

\subsubsection{Sensor Communication}

The BSI sensors are designed to communicate to the base station daily to report their health, synchronize their clocks, and communicate whenever they detect any strike signals. Bird strike indicator sensor communications worked very well throughout the monitoring season, with 28 sensors reporting their health daily, as programmed. Two sensors (BSIs 4 and 24, mounted on $115 \mathrm{kV}$ wires) unexpectedly stopped communicating with the base station 19 days after installation. At the end of the project the batteries for both these sensors tested positive. Additionally, they communicated properly after being taken down from the lines and rebooted. These two sensors likely experienced a firmware lockup and could not be remotely restarted by the firmware, as designed. These two sensors required a hard reset by turning the power off and then on, which is not typically feasible when installed on overhead lines without mobilizing line crews. It also should be noted that sensor 24 was one of the four units where both accelerometers became unglued for unknown reasons. Additionally, although both these units were on different towers, they were both located on the same $115 \mathrm{kV}$ circuit wire.

In addition to reporting their health, the sensors also transmitted strike signatures consisting of both horizontal and vertical axes vibration data. The sensor communications during strike reporting worked very well, especially considering the large amount of strike data that needed to be transmitted during these communications.

\subsubsection{Battery Life}

Each sensor contains two sets of batteries. One set powers the radio; the second set powers the other electronics, including the accelerometers. The BSI sensors were designed with a battery life of six months. All sensors' radio batteries exceeded the six-month design life and were still operational when the sensors were removed from the North Dakota site. The average battery life for the accelerometer batteries was 5.8 months, with 10 of the 30 sensors still showing battery capacity to continue working past the day of planned removal of the sensors from the site. Table 3 summarizes the battery performance for all the BSI sensors. Battery voltages highlighted in red in the table indicate low voltage. Sensor 4 and 24 had firmware lockup 19 days after installation and are also highlighted in red. 
Table 3. Battery performance of the BSI sensors

\begin{tabular}{|c|c|c|c|c|c|}
\hline \multirow{2}{*}{$\begin{array}{c}\text { BSI Sensor } \\
\text { No. }\end{array}$} & \multicolumn{2}{|c|}{ Last Day of Health Reporting } & \multirow{2}{*}{$\begin{array}{l}\text { Days since } \\
\text { installation }\end{array}$} & \multicolumn{2}{|c|}{ Reported Battery Voltage } \\
\hline & Day & Date & & Accelerometer & Radio \\
\hline 1 & 252 & $9 / 9 / 2006$ & 158 & 2.81 & 3.44 \\
\hline 2 & 283 & $10 / 10 / 2006$ & 189 & 3.54 & 3.58 \\
\hline 3 & 260 & $9 / 17 / 2006$ & 166 & 2.82 & 3.53 \\
\hline 4 & 113 & $4 / 23 / 2006$ & 19 & 3.47 & 3.54 \\
\hline 5 & 258 & $9 / 15 / 2006$ & 164 & 2.86 & 3.56 \\
\hline 6 & 283 & $10 / 10 / 2006$ & 189 & 3.53 & 3.56 \\
\hline 7 & 267 & $9 / 24 / 2006$ & 173 & 2.93 & 3.59 \\
\hline 8 & 266 & $9 / 23 / 2006$ & 172 & 2.92 & 3.53 \\
\hline 9 & 263 & $9 / 20 / 2006$ & 169 & 2.96 & 3.62 \\
\hline 10 & 235 & $8 / 23 / 2006$ & 141 & 2.82 & 3.23 \\
\hline 11 & 252 & $9 / 9 / 2006$ & 158 & 2.94 & 3.58 \\
\hline 12 & 257 & $9 / 14 / 2006$ & 163 & 2.97 & 3.59 \\
\hline 13 & 264 & $9 / 21 / 2006$ & 170 & 2.88 & 3.53 \\
\hline 14 & 257 & $9 / 14 / 2006$ & 163 & 2.98 & 3.63 \\
\hline 15 & 258 & $9 / 15 / 2006$ & 164 & 2.97 & 3.58 \\
\hline 16 & 265 & $9 / 22 / 2006$ & 171 & 2.93 & 3.60 \\
\hline 17 & 283 & $10 / 10 / 2006$ & 189 & 3.51 & 3.55 \\
\hline 18 & 283 & $10 / 10 / 2006$ & 189 & 3.51 & 3.55 \\
\hline 19 & 283 & $10 / 10 / 2006$ & 189 & 3.51 & 3.56 \\
\hline 20 & 283 & $10 / 10 / 2006$ & 189 & 3.54 & 3.58 \\
\hline 21 & 259 & $9 / 16 / 2006$ & 165 & 2.95 & 3.62 \\
\hline 22 & 283 & $10 / 10 / 2006$ & 189 & 3.53 & 3.58 \\
\hline 23 & 254 & $9 / 11 / 2006$ & 160 & 2.82 & 3.45 \\
\hline 24 & 113 & $4 / 23 / 2006$ & 19 & 3.56 & 3.60 \\
\hline 25 & 256 & $9 / 13 / 2006$ & 162 & 3.04 & 3.38 \\
\hline 26 & 283 & $10 / 10 / 2006$ & 189 & 3.51 & 3.54 \\
\hline 27 & 283 & $10 / 10 / 2006$ & 189 & 3.41 & 3.43 \\
\hline 29 & 262 & $9 / 19 / 2006$ & 168 & 2.95 & 3.55 \\
\hline 30 & 283 & $10 / 10 / 2006$ & 189 & 3.50 & 3.55 \\
\hline 33 & 259 & $9 / 16 / 2006$ & 165 & 2.80 & 3.54 \\
\hline
\end{tabular}

Note: Red indicates a low battery level or firmware lockup.

\subsubsection{Summary of BSI Performance Affecting Strike Monitoring}

In summary, nine out of the 30 BSI sensors, listed in Table 4, stopped monitoring strikes at some point during the monitoring season. The majority of these failures were a result of accelerometers coming unglued, thus rendering the sensors dysfunctional. Two sensors stopped functioning 19 days into the monitoring season as a result of a firmware lockup. All of the remaining sensors functioned properly until batteries became depleted on 11 units near the very end of the monitoring season. September 9 was the first date a functional BSI experienced a low 
battery level (158 days after installation). Sensor 10 had a low battery after 141 days but it was not properly functioning after 120 days due to an unglued accelerometer (Refer to Table 4). The damage to antenna tips of the sensors installed on the $115 \mathrm{kV}$ wires and condensation in a few of the sensors did not affect the field performance.

Table 4. BSI sensors not monitoring strikes

\begin{tabular}{|c|c|c|}
\hline BSI Sensor No. & $\begin{array}{c}\text { Estimate of No. of Days } \\
\text { Properly Functioning }\end{array}$ & Cause \\
\hline 3 & & Accelerometer Unglued \\
\hline 4 & 19 & Firmware Lockup \\
\hline 10 & 120 & Accelerometer Unglued \\
\hline 12 & & Accelerometer Unglued \\
\hline 13 & & Accelerometer Unglued \\
\hline 21 & 144 & Accelerometer Unglued \\
\hline 22 & & Accelerometer Unglued \\
\hline 23 & 19 & Accelerometer Unglued \\
\hline 24 & & Firmware Lockup, Accelerometer Unglued \\
\hline
\end{tabular}

\subsection{BSI Sensor Collision Recording}

The BSI sensors frequently recorded wire vibration data. These data included non-bird collision data such as vibrations induced from the railroad and truck traffic traveling along the causeway. There were also a few weather related events recorded. The BSI sensors also recorded 87 bird collisions. Bird collisions were determined by analyzing the vibration signal or signature recorded for each event.

\subsubsection{Bird Collision Signals}

Bird collisions produce signal signatures that allow a researcher to clearly distinguish a bird collision from other events. Bird collisions with power lines produce vibrations primarily in the horizontal axis (X-axis). As a bird collides with a power line it pushes the wire generating a slow back-and-forth motion into the wire, which quickly ends. This form is depicted by the transient nature of the vibration signal shown in Figure 10. After the initial strike, the wire recovers from the displaced position and slowly goes back to rest. The vibration signal then travels down the wire and disperses and spreads out, depending on the distance it has to travel to the sensor.

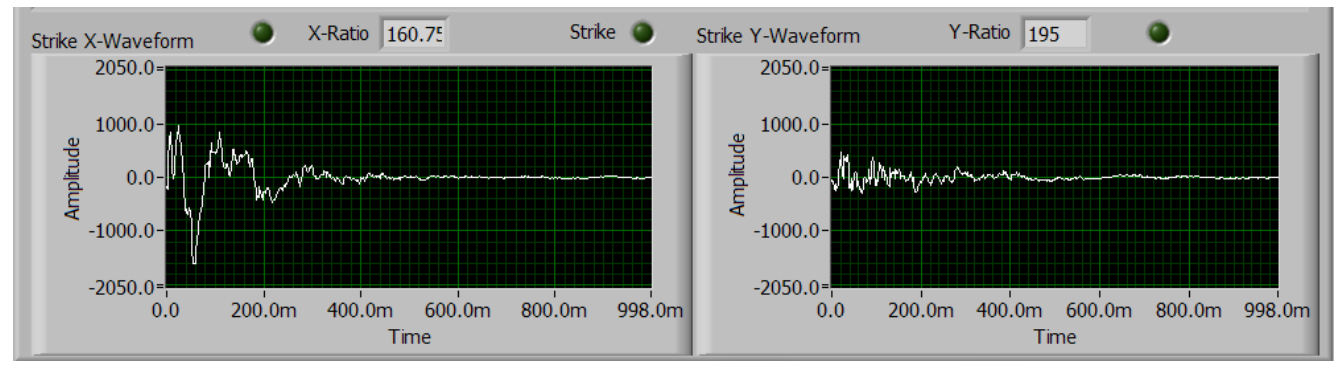

Figure 7. Typical BSI sensor recording for a bird collision with a power line in the X-Axis (left graph) and in the Y-Axis (right graph) 
Another example of bird collision recordings is shown in Figure 11, along with a second event recorded within one second of the first event, as shown by the time stamp. The beginning of the second event is initiated at the end of the horizontal (X-axis) vibration signal recording for the first event. The second event could be a second bird colliding with the power line in less than one second after the first collision. However, it is possible the second event was a reflection of the first event from the end of the wire span.

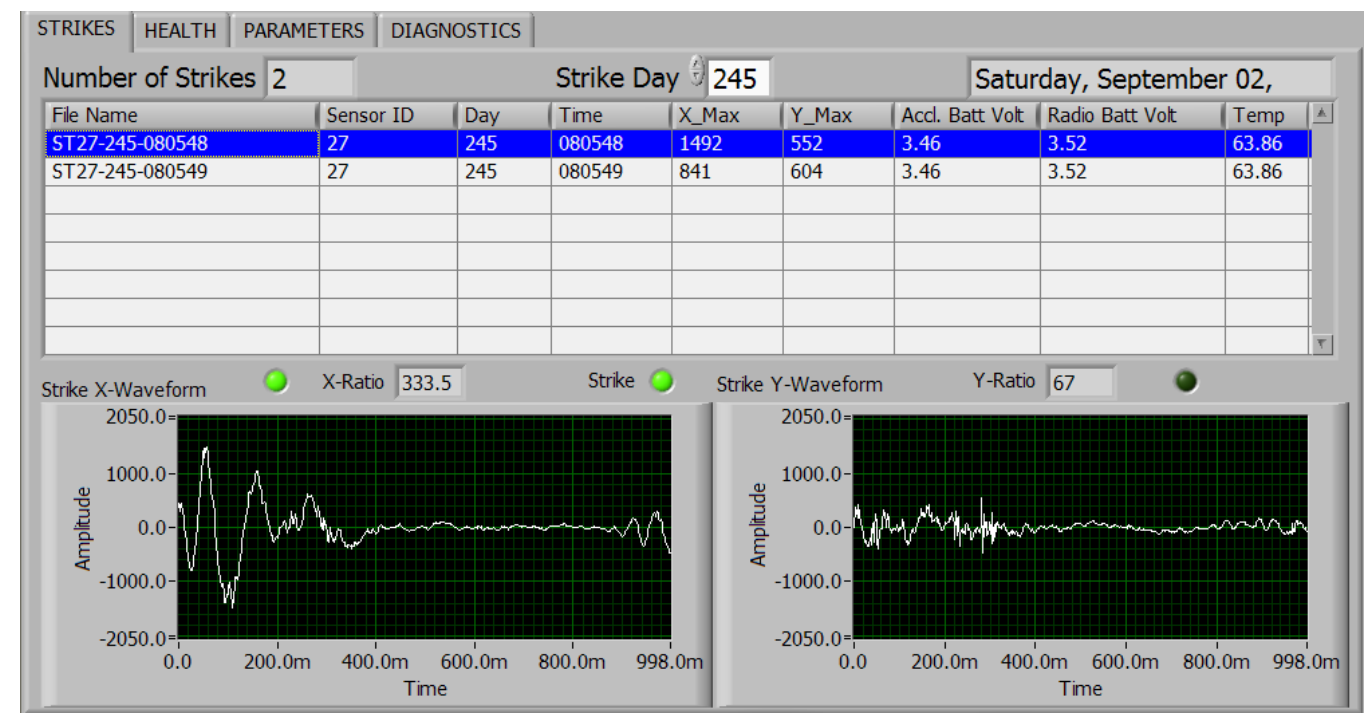

(a) Bird collision recording

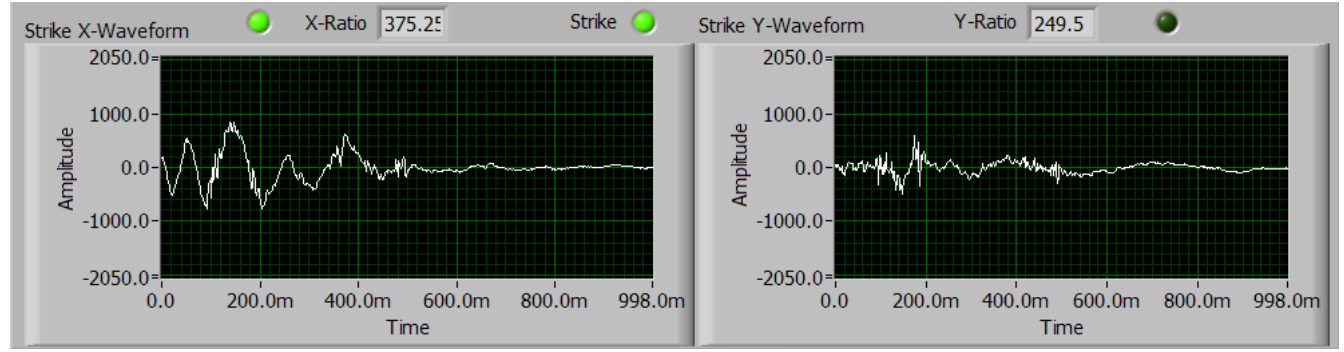

(b) Possible second collision within one second or reflection from end of span

Figure 8. Two consecutive recordings by BSI sensor 27

A review of all the collision data identified 87 possible bird collisions recorded by the BSI sensors on the three monitored spans during the six-month monitoring season. A summary of the bird collisions recorded by the sensors is provided in Table 5. Sixteen of the recorded bird collisions occurred within five seconds of a previous event recorded by the same sensor. These sixteen collision recordings could either be a second bird from a flock colliding with the same wire or a reflection from the original bird collision. 
Table 5. Summary of bird collisions recorded by the BSI sensors

\begin{tabular}{|c|c|c|c|c|}
\hline Span & BSI Sensor No. & Wire Type & No. of Collisions & $\begin{array}{l}\text { Possible Reflection } \\
\text { from Span End }\end{array}$ \\
\hline 11 & 8 & Shield Wire & 3 & 2 \\
\hline 11 & 10 & $41.6 \mathrm{kV}$ & 3 & 2 \\
\hline 7 & 17 & Shield Wire & 17 & 1 \\
\hline 7 & 18 & Shield Wire & 26 & 3 \\
\hline 7 & 20 & $41.6 \mathrm{kV}$ & 3 & 1 \\
\hline 3 & 22 & $115 \mathrm{kV}$ & 7 & 1 \\
\hline 3 & 27 & Shield Wire & 24 & 5 \\
\hline 3 & 30 & $41.6 \mathrm{kV}$ & 4 & 1 \\
\hline \multicolumn{2}{|r|}{ Total } & & 87 & 16 \\
\hline
\end{tabular}

Ninety-two percent of the bird collisions $(n=80)$ recorded by the BSIs were on the upper and lower wires (the overhead shield wires and the underbuild). Sensor 22, which is one of the top $115 \mathrm{kV}$ wires immediately below the overhead shield wire on Span 3 (see Figure 12), recorded the remaining seven events. Although detecting most strikes on the upper and lower wires is supported by the observational flight data, these results are confounded by BSI failures on the $115 \mathrm{kV}$ wires at some point of time during the field trials (BSIs 3, 4, 10, 12, 13, 21, 22, 23, and 24). Figure 12 is a graphical representation of the strike summary with the number of strikes in brackets. Units with stars indicated failures at some point in the field season.

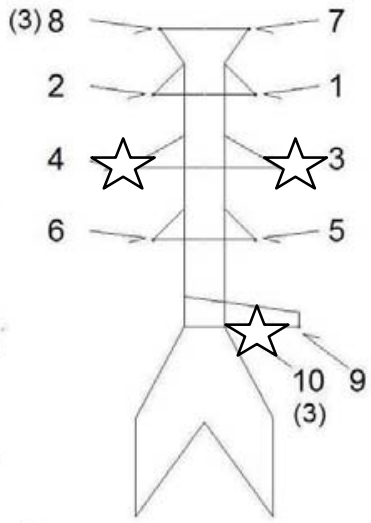

Span 11

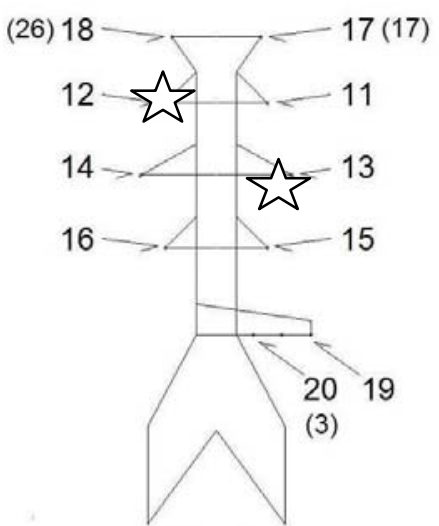

Span 7

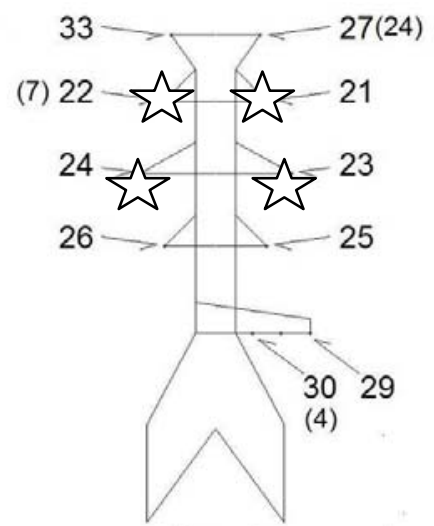

Span 3

Figure 9. Representation of BSI sensors recorded strikes (number in parenthesis is the number of bird collisions recorded by that sensor). Stars represent units that failed at some point during the field trials.

The pattern of recorded events supports the dawn and dusk line observations. The visual observations noted that birds often responded to the lines with one of two behaviors: (1) to fly over the wires, or (2) to fly under the wires. This response would put the birds at the highest 
risk as they begin their ascent or descent, and it relates well with collisions recorded by the BSI sensors.

\subsubsection{Simulated Strikes}

At the end of the project, artificial strikes were initiated to determine if the BSI sensors were capable of detecting collisions at the opposite end of a $1000 \mathrm{ft}$ span. These tests were performed in early October, just before the BSI sensors were removed. Different strike magnitudes were created by hitting the wires with a hot stick. These tests occurred on Span 3 with the wires instrumented with BSI sensor no. 27 (static wire) and BSI sensor no. 30 (41.6 kV wire). It should be noted hot stick strikes are similar but not exactly the same as bird collisions because hot sticks are much stiffer than birds.

Figure 13 illustrates the simulated strike signals propagated by two different strike levels. The strongest hot stick strike produced a very large vibration signal in magnitude, exceeding the upper scale value. The following two moderate strikes produced consistent results in both strength and vibration magnitude. The moderate strikes, which are closer to what might be expected from bird collisions, resulted in vibration at the sensor with a maximum magnitude of 667 and 638 in the horizontal (X-axis) direction. The threshold above which the sensors were set to detect collisions was 500. This indicates that sensors are capable of detecting events similar in magnitude to a moderate hot stick strike a full span apart from the impact. In contrast, a very light hot stick strike, barely touching the wire with the hot stick, was not detected by the BSI sensors located 1000 feet from the simulated strike, as was expected. 


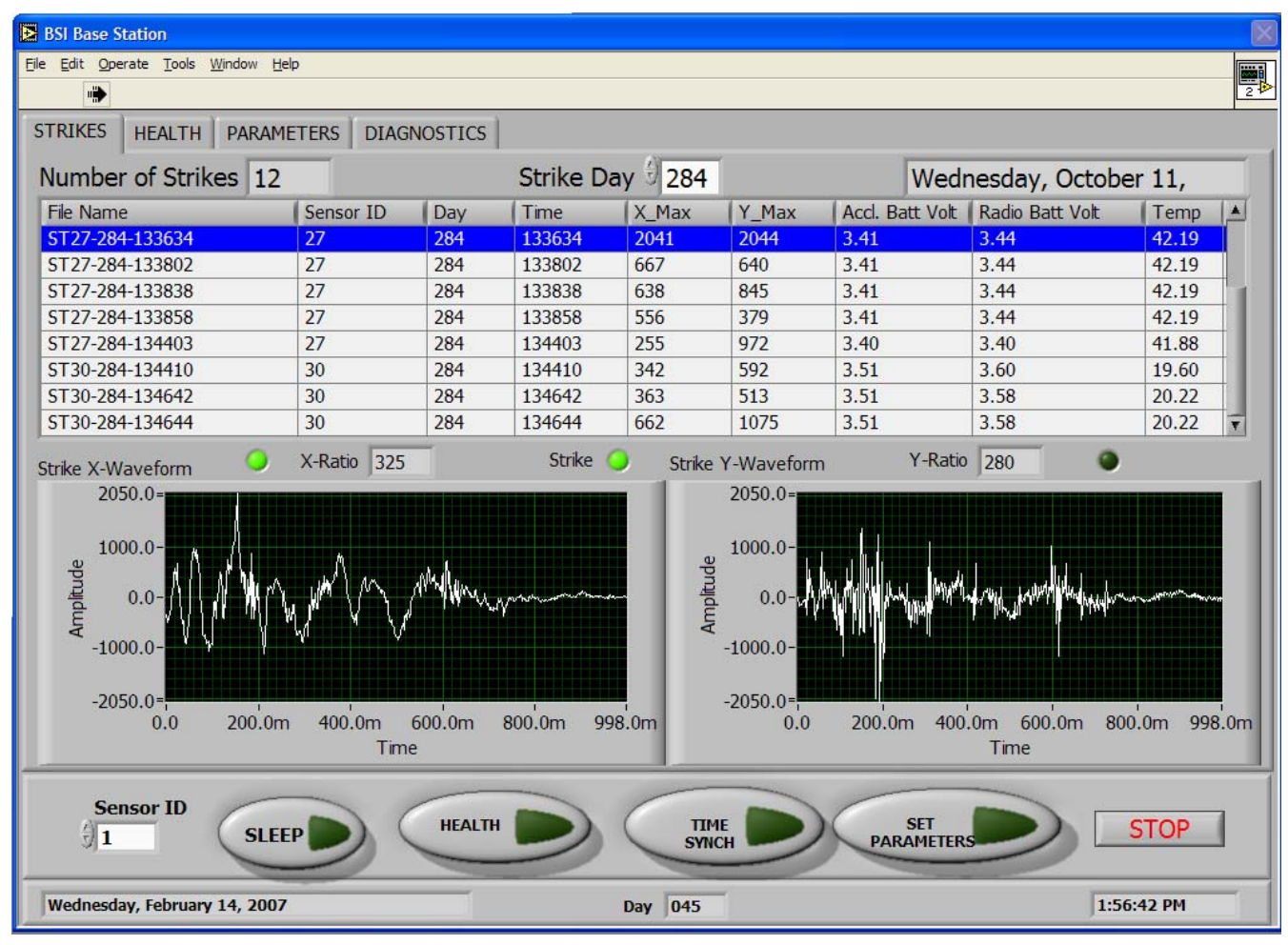

(a) Strong hot stick strike

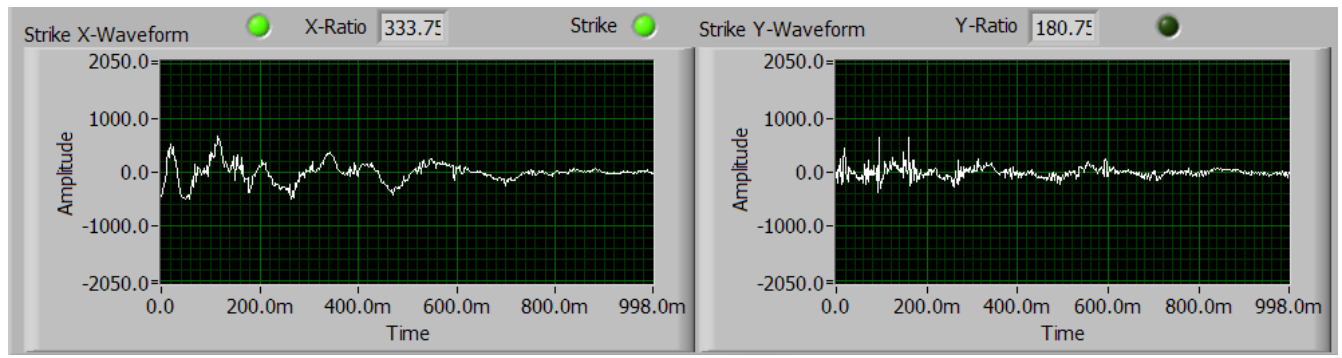

(b) Moderate hot stick strike

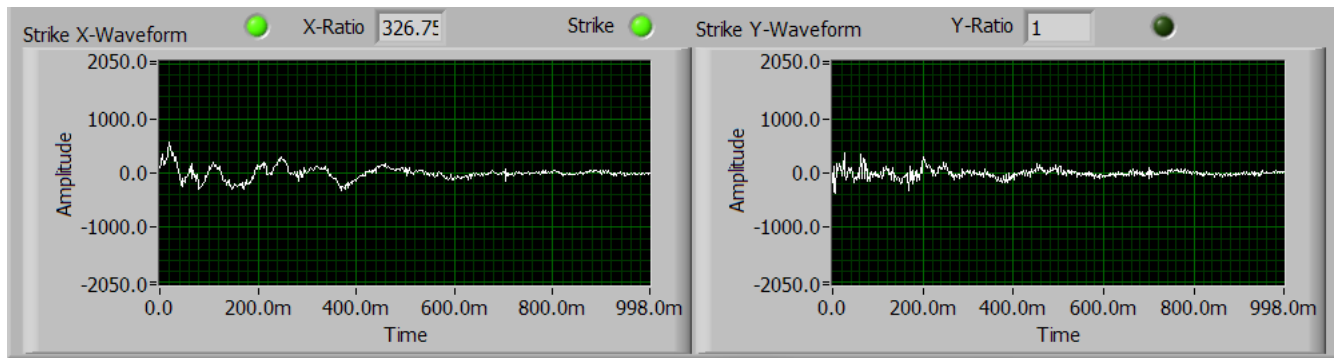

(c) Another moderate hot stick strike

Figure 10. Recorded signals from simulated strikes 


\subsubsection{Traffic-Induced Vibrations}

The North Dakota test site is located parallel to a four lane highway and a railroad track (Figure 6). As discussed in Section 3.2, soon after the BSI installation, traffic-induced vibrations produced numerous vibration recordings. Because the BSIs use batteries to transmit strike data, there was concern these traffic events could drain the batteries before the end of the six-month project period. Therefore it was decided to reset the strike threshold to minimize these events. Accordingly, the threshold for collision detection was increased from 500 to 750 . The higher threshold did significantly reduce the highway traffic-induced recordings but did not eliminate the infrequent railroad traffic-induced collision recordings. After three weeks of field examinations and comparisons, it was decided to reset the BSIs back to 500, which was used for the reminder of the monitoring season.

Train-induced vibrations were separated from bird collision events by analyzing the strike signatures. The signature of train traffic was continuous in nature, resulting in a back-and-forth movement of the wire throughout the one-second recording duration (Figure 14). In contrast to a bird strike, which tapers off after an initial impact, the train caused vibrations continued as long as the set threshold was exceeded.

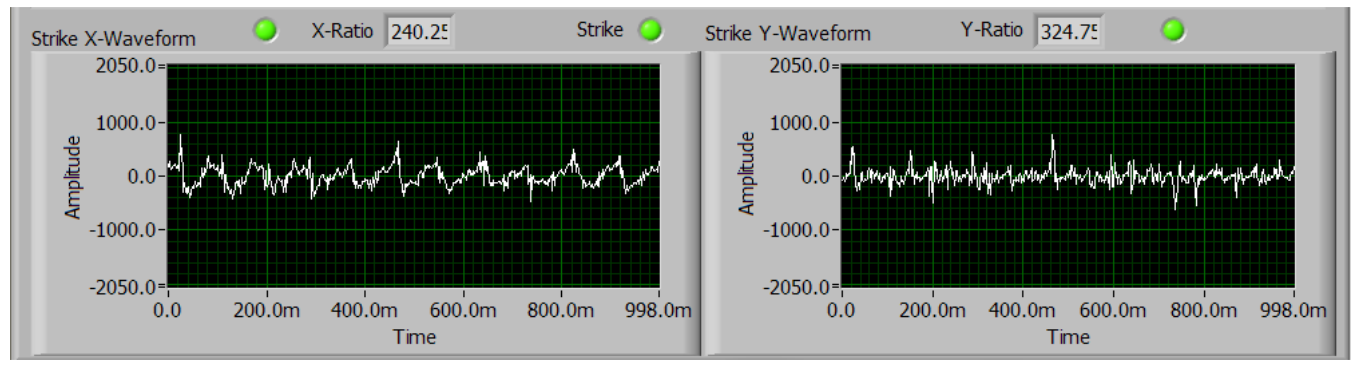

Figure 14. A typical train-induced vibration recording

Bird collisions with wires that were receiving traffic-induced vibrations could result in a difficult-to-interpret combined signature. Not all the BSIs at the study site were affected in the same way by passing traffic. Some sensors were positioned in such a way that they did not record the train-induced vibrations, and bird strikes were even detected during traffic periods. Although this traffic could mask bird collisions, the railroad traffic was limited in duration and on limited days.

Because of the unique nature of the traffic vibration signature, a digital filter could be designed and programmed into the firmware of the BSI sensor to eliminate or at least minimize these traffic-induced recordings. However, most monitoring sites may not have the same traffic problem found at the causeway.

\subsubsection{Weather-Related Strikes}

Severe weather events, such as hail and extreme high winds, also can produce "strikes" detected by the sensors. Hail hitting the wire or the sensor typically produces a signature primarily in the vertical (Y-axis) direction (Figure 15). These signals are very transient and may just produce a sharp blip. 


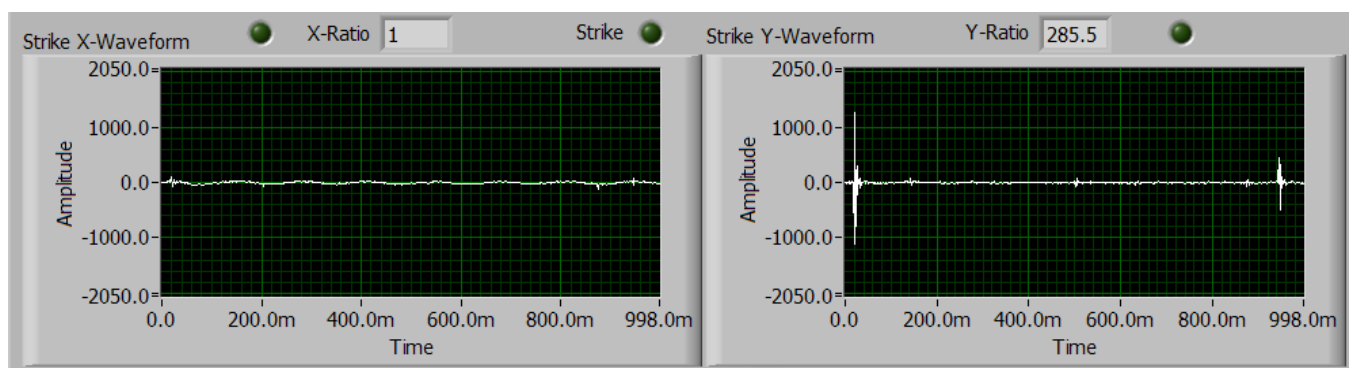

Figure 15. Vibration signature likely produced by hail

Light to moderate winds do not affect the BSI sensors and typically do not result in any vibration recordings. Light winds are 2 or less on the Beaufort Wind Scale (7 mph or less). Moderate winds are 3 to 4 on the Beaufort Wind Scale (8-18 mph). Higher winds can produce vibrations, but a wind-induced vibration signal is transient in nature with very different frequency content than those for bird collisions. As expected, high wind vibrations were noted on the North Dakota site. The day the BSI sensors were to be removed, the causeway was very windy, with wind gusts above 30 to 40 miles per hour ( $\mathrm{mph}$ ) (7 on the Beaufort Wind Scale). Only when wind gusts were extreme did the BSI sensors record any wire vibration (Figure 16). Wind-induced vibrations also have a very different signature, with a higher frequency content.

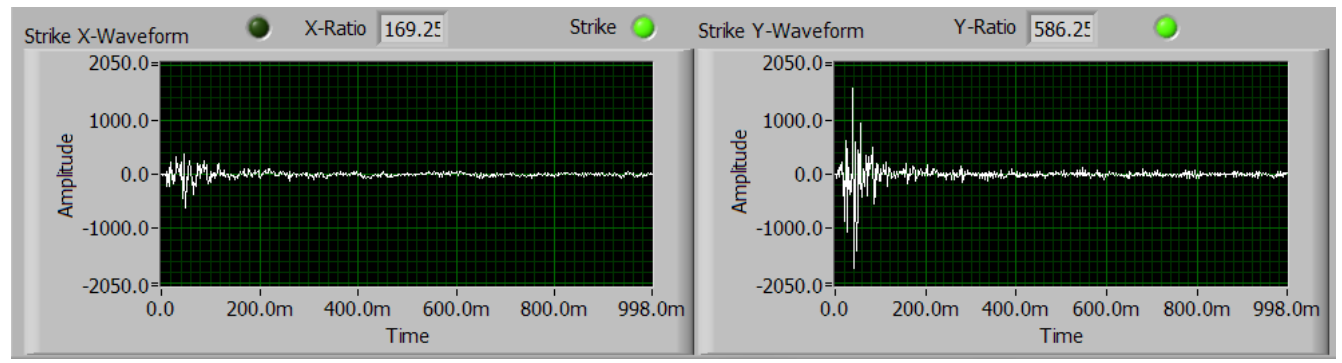

Figure 16. Vibration signature produced by extreme wind gusts exceeding $\mathbf{3 0}$ to $40 \mathrm{mph}$

\subsection{Field Survey Results}

The 2006 field season began with the installation of the BSIs on April 4, 2006, and ended with the last day of pedestrian survey data collected on October 9, 2006. The field season consisted of 135 days of pedestrian survey data and 180 days of BSI data. A total of 429 bird carcasses were recovered along the causeway during the 2006 field season.

The single species with the greatest number of individuals recovered was the American coot (Fulica americana), with a total of 76 carcasses recovered. Table 6 summarizes the 67 known birds species recovered in 2006. Overall, passerines represented the largest species diversity, while waterfowl and shorebirds accounted for the largest carcass sample. The nine most abundant species recovered are listed in bold in Table 6. 
Table 6. Bird fatalities recorded during the 2006 field season

\begin{tabular}{|c|c|c|c|c|c|}
\hline Species & $\begin{array}{c}\text { Wt. } \\
\text { Grams }\end{array}$ & $\begin{array}{c}\text { Number } \\
\text { Found }\end{array}$ & Species & $\begin{array}{c}\text { Wt. } \\
\text { Grams }\end{array}$ & $\begin{array}{c}\text { Number } \\
\text { Found }\end{array}$ \\
\hline American coot & 650 & 76 & Longspur sp. & - & 1 \\
\hline American white pelican & 7,500 & 6 & Mallard & 1,100 & 3 \\
\hline American wigeon & 720 & 1 & Marbled godwit & 370 & 2 \\
\hline Bank swallow & 13 & 11 & Mourning dove & 120 & 5 \\
\hline Black tern & 62 & 4 & Nelson's sharp-tailed sparrow & 17 & 1 \\
\hline Blackbird sp. & - & 2 & Northern flicker & 130 & 1 \\
\hline Blue-winged teal & 380 & 1 & Northern pintail & 800 & 1 \\
\hline Bobolink & 43 & 4 & Northern waterthrush & 18 & 1 \\
\hline Brown-headed cowbird & 44 & 6 & Orange-crowned warbler & 9 & 2 \\
\hline California gull & 610 & 8 & Pied-billed grebe & 450 & 2 \\
\hline Canada goose & 4,500 & 9 & Purple martin & 56 & 2 \\
\hline Canvasback & 1,220 & 1 & Rail sp. & - & 2 \\
\hline Cedar waxwing & 32 & 3 & Redhead & 1,050 & 3 \\
\hline Clay-colored sparrow & 12 & 4 & Red-winged blackbird & 52 & 4 \\
\hline Cliff swallow & 21 & 11 & Ring-billed gull & 520 & 31 \\
\hline Common grackle & 115 & 25 & Ring-necked pheasant & 1,150 & 4 \\
\hline Common loon & 4,100 & 1 & Sandpiper sp. & - & 1 \\
\hline Common tern & 120 & 19 & Savannah sparrow & 20 & 14 \\
\hline Common yellowthroat & 10 & 3 & Semipalmated sandpiper & 25 & 2 \\
\hline Double-crested cormorant & 1,700 & 18 & Sharp-tailed grouse & 880 & 1 \\
\hline Downy woodpecker & 27 & 1 & Song sparrow & 20 & 3 \\
\hline Duck sp. & - & 1 & Sora rail & 75 & 18 \\
\hline Eared grebe & 300 & 6 & Sparrow sp. & - & 7 \\
\hline Eastern kingbird & 40 & 2 & Swainson's thrush & 31 & 2 \\
\hline Forester's tern & 160 & 2 & Swallow sp. & - & 3 \\
\hline Franklin's gull & 280 & 4 & Swamp sparrow & 17 & 2 \\
\hline Gadwall & 910 & 6 & Tern sp. & - & 5 \\
\hline Grasshopper sparrow & 17 & 4 & unknown & - & 10 \\
\hline Grebe sp. & - & 1 & Vesper sparrow & 26 & 6 \\
\hline Green-winged teal & 350 & 1 & Warbling vireo & 12 & 1 \\
\hline Grey catbird & 37 & 1 & Western grebe & 1,500 & 4 \\
\hline Gull sp. & - & 3 & Western meadowlark & 97 & 1 \\
\hline Harris's sparrow & 36 & 1 & White-crowned sparrow & 29 & 2 \\
\hline House finch & 21 & 1 & Wilson's phalarope & 60 & 5 \\
\hline Killdeer & 95 & 6 & Yellow warbler & 9 & 6 \\
\hline Lapland longspur & 27 & 1 & Yellow-bellied flycatcher & 11 & 1 \\
\hline Least flycatcher & 10 & 3 & Yellow-headed blackbird & 65 & 7 \\
\hline Lesser scaup & 830 & 1 & Yellow-rumped warbler & 12 & 3 \\
\hline Lesser yellowlegs & 80 & 2 & & & \\
\hline
\end{tabular}


The 429 bird fatalities, encompassing 67 species, recorded during the 2006 field season was roughly the same number of fatalities as the 2001 season (451 dead birds, 63 species) and 2002 season (434 dead birds, 77 species). The species composition is roughly equivalent as well. This parallel may suggest that avian dynamics have remained approximately the same at the site during the four-year period from 2002 to 2006.

\subsubsection{Necropsy Technique}

The nature of the causeway makes it difficult to discern the cause of death for many of the retrieved birds. Secondary injuries sustained from vehicles may mask power line collision injuries. This uncertainty increases the complexity of correlating collision signatures recorded by the BSI sensors to carcasses on the ground. Whenever possible, necropsies were completed on carcasses collected in 2006. Table 7 presents necropsy results by span, along with numbers of bird collisions recorded by the BSI sensors.

Table 7. Necropsy results by span

\begin{tabular}{|c|c|c|c|c|c|c|}
\hline \multirow{2}{*}{ Span ID } & \multirow{2}{*}{$\begin{array}{l}\text { Spans } \\
\text { with } \\
\text { BSIs }\end{array}$} & \multirow{2}{*}{$\begin{array}{c}\text { No. of Strikes } \\
\text { Detected by } \\
\text { BSIs }\end{array}$} & \multirow{2}{*}{$\begin{array}{l}\text { Total Number } \\
\text { of Bird } \\
\text { Fatalities per } \\
\text { Span }\end{array}$} & \multicolumn{3}{|c|}{ Cause of Death } \\
\hline & & & & Power Line & Vehicle & Unknown \\
\hline 2 & & & 42 & 8 & 18 & 16 \\
\hline 3 & BSIs & 35 & 49 & 11 & 16 & 22 \\
\hline 4 & & & 39 & 9 & 17 & 13 \\
\hline 5 & & & 28 & 10 & 7 & 11 \\
\hline 6 & & & 55 & 17 & 16 & 22 \\
\hline 7 & BSIs & 46 & 40 & 9 & 14 & 17 \\
\hline 8 & & & 31 & 4 & 14 & 13 \\
\hline 9 & & & 31 & 6 & 13 & 11 \\
\hline 10 & & & 44 & 10 & 19 & 15 \\
\hline 11 & BSIs & 6 & 36 & 6 & 19 & 11 \\
\hline 12 & & & 34 & 8 & 14 & 12 \\
\hline Totals & & & 429 & 98 & 167 & 163 \\
\hline $\begin{array}{l}\text { Total } \\
\text { for BSI } \\
\text { Spans }\end{array}$ & BSIs & 87 & 125 & 26 & 49 & 50 \\
\hline
\end{tabular}

The distance bird carcasses were detected from each tower was recorded in this study to determine the spatial distribution of carcasses. These data indicate a reduced number of detected carcasses closer to towers (Figure 17) and show a general increase in detected carcasses occurring roughly 250 feet from south towers and roughly 100 to 250 feet from north towers. This general trend suggests birds are flying more frequently near the middle span section, perhaps due to the structure visibility. This trend also suggests that installing BSI sensors closer to the middle of the spans on future projects might increase the likelihood of detecting a greater 
number of bird collisions. It is not clear why the distribution of birds also increased at approximately 850 and 925 feet.

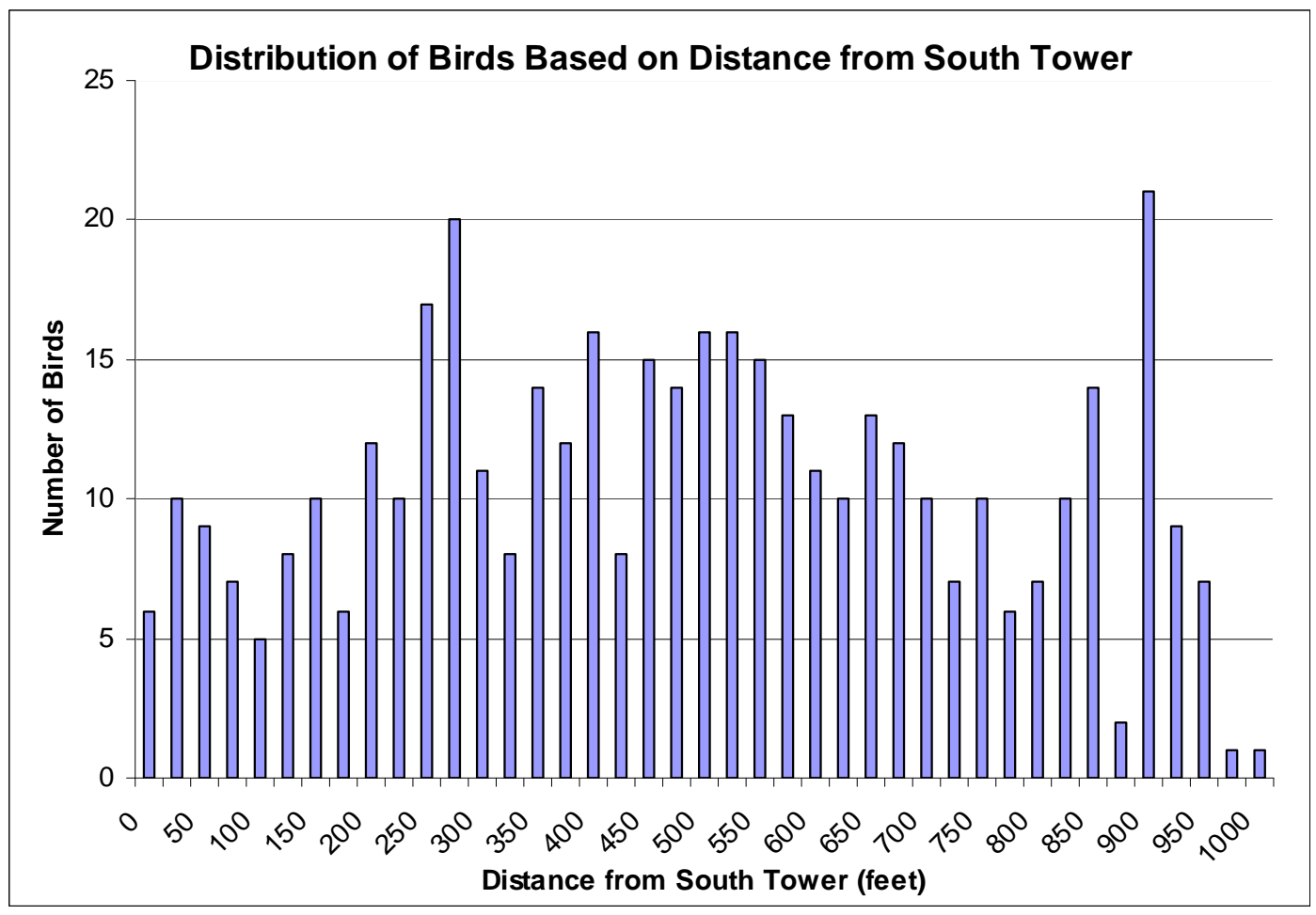

Figure 17. Distribution pattern of dead birds based on distance from tower locations

\subsection{Strikes Correlation With Recovered Carcass}

\subsubsection{Background}

The correlation between detected carcasses and BSI strikes are affected by the following factors:

1. Carcass detection biases (searcher bias, scavenger removal bias, habitat bias, crippling bias).

2. Correct diagnosis of cause of death.

3. BSI functionality and sensitivity.

The carcass detection biases were addressed by planting carcasses to determine searcher efficiency and scavenging rates. After it was determined that there was a high rate of scavenging, animals were trapped to reduce this bias. Although searcher and scavenger biases were taken into account, and floating bird carcasses were recovered when possible, bird fatalities were still observed beyond the project's search zone. When birds fall outside the survey area or fly away injured, they are not detected. This is called the crippling bias. The crippling bias at this site also may be a significant factor. In APLIC (1994), crippling rates from $73 \%$ to $75 \%$ were noted, and Crowder (2000) reported a rate of $81.8 \%$ at a $345 \mathrm{kV}$ transmission line located in a wetland complex in southern Indiana. These biases were supported by visual project observations, which consisted of four wire strikes where one bird glanced off the wire 
and flew away to the lake and another bird fell into the lake, but its carcass could not be retrieved.

Correlating BSI strikes successfully with detected carcasses requires a correct diagnosis of cause of death. The Audubon Causeway is a busy stretch of highway where birds collide with both vehicles and wires. In some cases birds may be striking wires and then getting hit by vehicles or run over on the pavement surfaces. Whenever possible, necropsies were done; however, it is possible that the cause of death in some of these cases may have been wrongly attributed and/or power line collisions might have been masked by secondary vehicle collisions.

Proper correlation also requires the sensors to detect collisions. As noted, the BSI sensors were able to detect bird strikes but also recorded train and vehicle traffic and weather throughout the season. Although each of these events have unique signatures to differentiate them, it is possible that traffic events masked some bird strikes. Additionally, the monitors were placed at the end of the spans to prevent them from acting like line markers (bird diverters) and increasing the visibility of the wire. The placement of the BSIs at the end of the spans makes it difficult to detect light collisions at the opposite end of the span. Placing the BSIs mid-span would be preferable from a detection perspective. Lastly, technical problems with some sensors may have precluded detection of some strikes.

\subsubsection{Results}

The BSI sensors recorded a total of 87 bird collisions in Spans 3, 7, and 11. Sixteen of these events were either dual bird strikes or strike reflections (the result of a wave generated by a strike reverberating back down the line). Eliminating these possible reflections leaves a total of 71 recorded bird collisions.

These numbers relate well with the overall number of carcasses recovered from the three instrumented spans. A total of 125 carcasses were recovered by the field crews at the three monitored spans, of which 76 were identified as either power line collisions $(n=26)$ or unknown collisions $(n=50)$. The remaining 49 carcasses were determined to be from vehicle collisions.

All strikes detected by the BSIs were compared to the carcasses found under the instrumented spans. Following a strike event, the bird carcass records were reviewed for all carcasses detected within two full search cycles. This method allowed nine days for the pedestrian surveyors to locate all birds. By increasing the search effort to two full search cycles, the opportunity for the surveyors to find carcasses was maximized.

Once the nine-day window was established, the carcass records were searched for dead birds found within the allotted time frame. A viable carcass was defined as one adhering to the following parameters:

1. The carcass was collected after the BSI strike time signature.

2. The necropsy determined the fatality was caused by a power line collision or from an unknown cause of death.

3. The carcass record was not already attributed to another strike event. 
Most BSI strike records had at least one or more associated carcasses; however, 13 strike records were eliminated, since they did not relate to carcass retrieval. These birds may have fallen outside the search area into the lake, been crippled and flown off, been scavenged, or avoided detection by the surveyors. In some other cases, more birds were found than recorded by the sensors. The maximum number of birds associated with a single strike event was six. It is possible that these birds hit one of the energized wires without a functioning BSI or hit wires and did not trigger a threshold value. It is possible that some birds may have been the victims of vehicle collisions and not the power lines.

Using this process, 35 collisions detected by field searchers were related to the 71 BSI collisions (Table 8). These associations are conservative because they excluded any carcasses identified as victims of vehicle collisions, some of which could be masking wire collisions.

The carcasses that related between the BSI and field searches included 16 birds where power lines were determined to be the confirmed cause of death or injury. These birds consisted of larger birds, such as coots $(n=7)$, gulls $(n=3)$, cormorants $(n=2)$, and a grebe. They ranged in size from approximately 10 ounces (oz) to 3.7 pounds (lbs). However, three small birds, a least flycatcher and two yellow-headed blackbirds, also were recorded.

The data in Table 8 also includes 19 birds where the cause of death was determined to be unknown. These 19 deaths consist of larger birds, such as coots $(n=3)$, gulls $(n=4)$, terns $(n=2)$, ducks (n=2), one loon, and one grebe. They range in size from approximately 4.2 oz to 9 lbs. However, five small birds consisting of two grackles, a bobolink, a clay-colored sparrow, and a common yellowthroat also were recorded. One unknown species also was recorded.

Because of the location of BSI sensors, it is possible that a bird collision at the very north end of an adjacent south span also could be detected and recorded by the sensors. For example, collisions occurring at the north end of Span 2 were very close to the sensors on Span 3. The transmission wires are continuous through each transmission suspension clamp, and it is possible for vibration signals to travel from one span to another, even though the spans are equipped with vibration dampers. This was observed during the installation of the BSI sensors as the sensors detected Western crews replacing vibration dampers on nearby spans. Including detected carcasses from the north end of the adjacent south span also would increase the association between the recorded bird collisions and recovered carcasses. 
Table 8. BSI strikes correlated with bird carcasses recovered on the ground

\begin{tabular}{|c|c|c|}
\hline Span & Sensor & Species \\
\hline 3 & 22 & Common loon \\
\hline 3 & 22 & Double-crested cormorant \\
\hline 3 & 22 & American coot \\
\hline 3 & 22 & American coot \\
\hline 3 & 27 & Yellow-headed blackbird \\
\hline 3 & 27 & Yellow-headed blackbird \\
\hline 3 & 27 & Ring-billed gull \\
\hline 3 & 27 & Lesser scaup \\
\hline 3 & 27 & American coot \\
\hline 3 & 27 & American coot \\
\hline 3 & 27 & American coot \\
\hline 3 & 30 & Common grackle \\
\hline 3 & 30 & Franklin's gull \\
\hline 3 & 30 & Double-crested cormorant \\
\hline 7 & 17 & American coot \\
\hline 7 & 17 & Ring-billed gull \\
\hline 7 & 17 & Common tern \\
\hline 7 & 17 & California gull \\
\hline 7 & 17 & Eared grebe \\
\hline 7 & 17 & American wigeon \\
\hline 7 & 17 & unknown \\
\hline 7 & 18 & Least flycatcher \\
\hline 7 & 18 & unknown gull \\
\hline 7 & 18 & Franklin's gull \\
\hline 7 & 18 & Common tern \\
\hline 7 & 18 & Common grackle \\
\hline 7 & 18 & unknown gull \\
\hline 7 & 18 & unknown grebe \\
\hline 7 & 18 & American coot \\
\hline 7 & 18 & Common yellowthroat \\
\hline 7 & 18 & American coot \\
\hline 7 & 18 & American coot \\
\hline
\end{tabular}




\subsubsection{Visual Collision Observations}

Visual monitoring was used as part of the field survey protocol to obtain visual confirmation of bird collisions with the wires. This approach was an attempt to relate strike recordings with the BSI sensors.

During the six-month field survey cycle, only three observed collisions were recorded on the test spans, one on each of the three monitored spans. Many collisions were probably not detected because they occurred in low light conditions or outside the observation periods. Thirty-two percent of the bird strikes recorded by the BSIs were between the hours of 22:00 and 04:45. The three observed collisions are described below:

1. Span 11 (BSI sensor 1): The strike occurred on June 13, 2006, at 21:40 on Span 11, approximately 500 feet from the sensor unit. A Canada goose was observed flying into the uppermost $115 \mathrm{kV}$ line on the east side. After hitting the wire the bird glided/flew to water by a distant island.

2. Span 3 (BSI sensor 21): The strike occurred on July 8, 2006, at 16:10 on Span 3, approximately 650 feet from the sensor unit. A Double-crested cormorant was observed flying into the uppermost $115 \mathrm{kV}$ line on the east side. This bird was part of a larger flock. After hitting the wire the cormorant fell into the water, 50 feet from the shoreline.

3. Span 7 (BSI sensor 16): The strike occurred on August 26, 2006, at 12:30 on Span 7, approximately 300 feet from the sensor unit. A California gull was observed flying into the lowermost $115 \mathrm{kV}$ line on the west side. After hitting the wire the gull fell into the rocks on the east side of the highway.

None of these strike events were recorded by the BSI sensors. Additionally, none of these three sensors recorded any vibrations throughout the field monitoring season (e.g., birds, traffic, and weather). According to the post-study review of the BSIs, sensors 1, 16, and 21 were all communicating properly with base station during the time of the observed collisions, indicating that their batteries were charged. However, both accelerometers in sensor 21 were detached at the end of the project, which could explain why the cormorant collision was not recorded. The collision on Span 11 may have not been recorded because of the great distance between the sensor and the bird (500 feet) and the nature of the collision (a glancing hit). For a collision to be detected by the sensors it needs to produce vibration at the sensor exceeding the set threshold for detection. The collision with sensor 16 should have been recorded by the sensor. In this case a large bird hit the wires and fell straight down approximately 300 feet from the sensor. This suggests that there was a problem with this sensor.

\subsection{Summary of BSI Sensor Field Testing: 2006}

Table 9 provides an overall summary of the BSI sensor testing at North Dakota. The monitoring season lasted 189 days from installation of the sensors on the line until the day they were taken down. Seventeen of the 30 BSI sensors recorded vibration events, and eight of those seventeen recorded bird collisions. Twenty-eight sensors were operational until close to the end of the monitoring season, with an average battery life of 5.8 months. Two sensors had firmware 
lockup very early on - 19 days after installation - and were not operational after that. X-axis accelerometers on eight sensors came unglued, making them unable to monitor bird collisions.

In addition, all the 18 sensors installed on the $115 \mathrm{kV}$ wires had their plastic antenna tip disintegrate as a result of corona activity. However, this did not affect their performance and the sensors continued to communicate with the base station. Four sensors had some condensation on the inside of the box resulting from moisture ingress through the switch at the bottom of the sensors. 
Table 9. Summary of BSI sensor performance and vibration recordings during field monitoring season at North Dakota

\begin{tabular}{|c|c|c|c|c|c|c|c|c|c|}
\hline \multirow{2}{*}{$\begin{array}{c}\text { BSI } \\
\text { Sensor }\end{array}$} & \multirow{2}{*}{$\begin{array}{c}\text { Wire } \\
\text { Voltage }\end{array}$} & \multirow[b]{2}{*}{ Antenna } & \multirow[b]{2}{*}{ Condensation } & \multicolumn{2}{|c|}{ Accelerometer } & \multicolumn{2}{|c|}{ Sensor Stopped Functioning } & \multicolumn{2}{|c|}{ Vibration Recordings } \\
\hline & & & & X-Axis & Y-Axis & $\begin{array}{l}\text { Days since } \\
\text { installation }\end{array}$ & Cause & $\begin{array}{c}\text { Bird } \\
\text { Collisions }\end{array}$ & Other \\
\hline 1 & $115 \mathrm{kV}$ & Tip Broken & Light & & & 158 & Low Voltage & & \\
\hline 2 & $115 \mathrm{kV}$ & Tip Broken & & & & 189 & & & Yes \\
\hline 3 & $115 \mathrm{kV}$ & Tip Broken & & Unglued & & 166 & Low Voltage & & \\
\hline 4 & $115 \mathrm{kV}$ & Tip Broken & Moderate & & & 19 & Firmware Lockup & & \\
\hline 5 & $115 \mathrm{kV}$ & Tip Broken & & & Unglued & 164 & Low Voltage & & \\
\hline 6 & $115 \mathrm{kV}$ & Tip Broken & & & & 189 & & & Yes \\
\hline 7 & $41.6 \mathrm{kV}$ & & & & & 173 & Low Voltage & & Yes \\
\hline 8 & $41.6 \mathrm{kV}$ & & & & & 172 & Low Voltage & 3 & Yes \\
\hline 9 & $41.6 \mathrm{kV}$ & & & & & 169 & Low Voltage & & \\
\hline 10 & $41.6 \mathrm{kV}$ & & Light & Unglued & Unglued & 141 & Low Voltage & 3 & Yes \\
\hline 11 & $115 \mathrm{kV}$ & Tip Broken & & & & 158 & Low Voltage & & \\
\hline 12 & $115 \mathrm{kV}$ & Tip Broken & & Unglued & Unglued & 163 & Low Voltage & & \\
\hline 13 & $115 \mathrm{kV}$ & Tip Broken & & Unglued & & 170 & Low Voltage & & \\
\hline 14 & $115 \mathrm{kV}$ & Tip Broken & & & & 163 & Low Voltage & & \\
\hline 15 & $115 \mathrm{kV}$ & Tip Broken & & & Unglued & 164 & Low Voltage & & Yes \\
\hline 16 & $115 \mathrm{kV}$ & Tip Broken & & & & 171 & Low Voltage & & \\
\hline 17 & $41.6 \mathrm{kV}$ & & & & & 189 & & 17 & Yes \\
\hline 18 & $41.6 \mathrm{kV}$ & & & & & 189 & & 26 & Yes \\
\hline 19 & $41.6 \mathrm{kV}$ & Tip Broken & & & & 189 & & & Yes \\
\hline 20 & $41.6 \mathrm{kV}$ & & & & & 189 & & 3 & Yes \\
\hline 21 & $115 \mathrm{kV}$ & Tip Broken & Moderate & Unglued & Unglued & 165 & Low Voltage & & \\
\hline 22 & $115 \mathrm{kV}$ & Tip Broken & & Unglued & unglued & 189 & & 7 & Yes \\
\hline 23 & $115 \mathrm{kV}$ & Tip Broken & & Unglued & & 160 & Low Voltage & & \\
\hline 24 & $115 \mathrm{kV}$ & Tip Broken & & Unglued & Unglued & 19 & Firmware Lockup & & \\
\hline 25 & $115 \mathrm{kV}$ & Tip Broken & & & & 162 & Low Voltage & & Yes \\
\hline 26 & $115 \mathrm{kV}$ & Tip Broken & & & & 189 & & & Yes \\
\hline 27 & $41.6 \mathrm{kV}$ & & & & & 189 & & 24 & Yes \\
\hline 29 & $41.6 \mathrm{kV}$ & & & & & 168 & Low Voltage & & Yes \\
\hline 30 & $41.6 \mathrm{kV}$ & & & & & 189 & & 4 & Yes \\
\hline 33 & $41.6 \mathrm{kV}$ & & & & & 165 & Low Voltage & & Yes \\
\hline
\end{tabular}




\subsection{BSI Field Testing at North Dakota}

It was decided to continue the BSI tests at the North Dakota causeway in 2007 in coordination with a Western Area Power Administration marking study to further evaluate the performance of the BSI sensors. Prior to this retesting, the design issues encountered in the 2006 season were addressed (CEC 2007). One of the main goals of the 2007 testing was to increase the amount of visual observations in the hope of getting direct correlation between observed bird collisions and BSI-detected collisions.

\subsection{BSI Refurbishment}

Changes were made to the BSI sensors to address the design issues encountered during the 2006 field trial prior to redeployment. New batteries were also installed in each of the sensors. The most signification changes to the sensor design were in the antenna and the on/off switch. Almost all of the antennas of the sensors installed on the $115 \mathrm{kV}$ lines had encountered failures at the tip because of high corona activity. In addition, there was some moisture ingress in a few of the sensors through the on/off switch at the bottom, and the switch was also a likely source of some corona activity. Figure 18 shows the redesigned 2007 BSI sensor with the new antenna and switch. The new antenna is all metallic, with a spherical tip that helps minimize corona. The switch is made of plastic, has a low profile, and is rounded.

Another major issue encountered with some of the BSI sensors in 2006 was accelerometers coming unglued because of glue failure. This was thought to be a result of improper application of the glue and limited cure time prior to installation. Extra precautions were taken in 2007 when installing the accelerometers, and sufficient time was allowed for the glue to cure.

It also was decided there was no need to monitor vibrations in the vertical direction as bird collisions with a transmission line will result in primarily horizontal vibrations. This was the case with all the bird collision recordings in 2006. Therefore, both the accelerometers were mounted such that they would be monitoring the horizontal, thus providing a backup for each other. This eliminated vibration monitoring in the vertical direction, which would likely eliminate some of the weather-related vibration recordings.

\subsection{Field Installation}

Thirty BSI sensors were installed on spans 2, 6, and 10 on April 13, 2007, with help of Western line crews. Just like the 2006 installation, the installation of the sensors in 2007 went very smoothly and all 30 sensors were installed quickly. Typical installation of ten sensors on one span took less than an hour. The base station was installed in the same shed as in 2006. An outage was taken on the line prior to installation. The base station became active on April 24, 2007.

Figure 19 shows a typical BSI sensor installed on the $115 \mathrm{kV}$ conductors during the 2007 field trials. The sensors were installed on three spans, as shown in Figure 20. For the 2007 field trials, it was decided to install the BSI sensors near mid-span. This was done because the towers might act as visual markers for the birds and thus, the likelihood of collisions might be greater near 
the middle section of the span. The installation near the mid-span also would improve collision detection range of the BSI sensors.

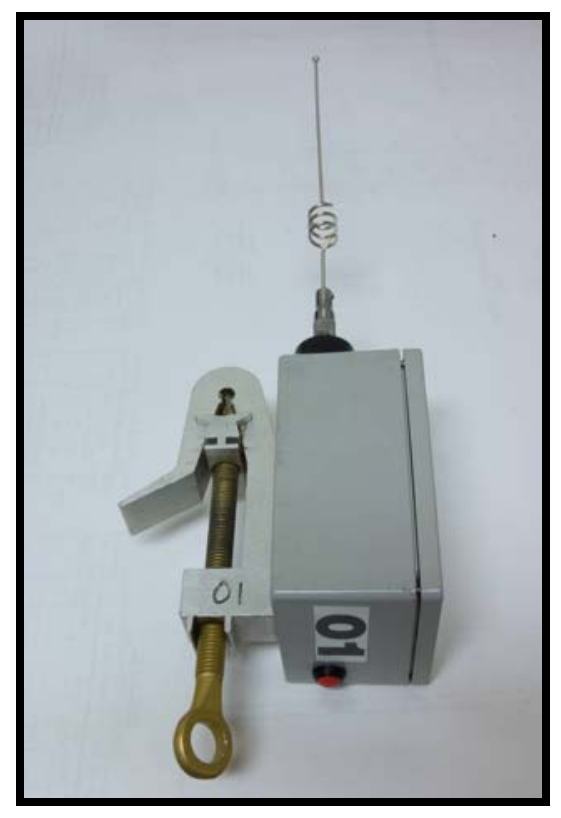

Figure 18. Redesigned BSI with metallic antenna and switch

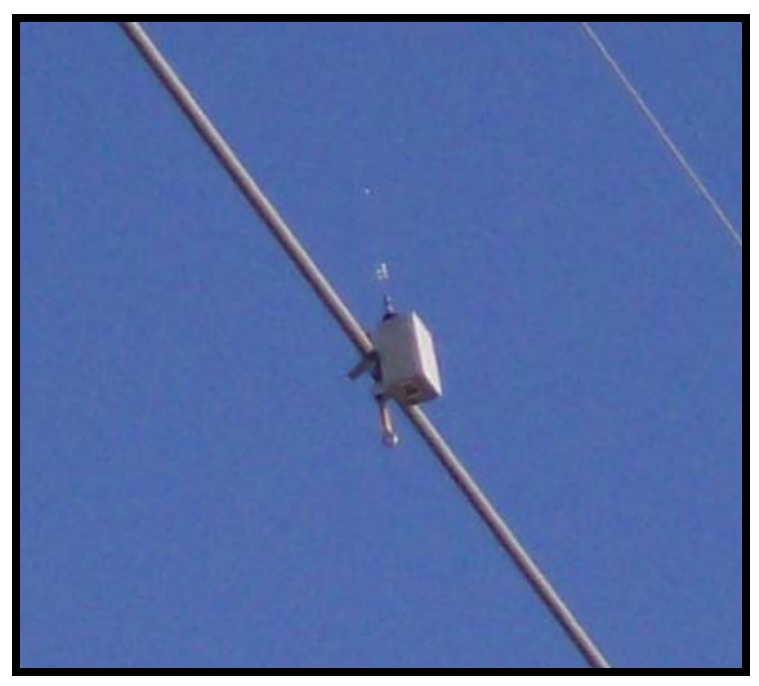

Figure 19. Typical BSI sensor installed on a $115 \mathrm{kV}$ conductor during 2007 field tests 


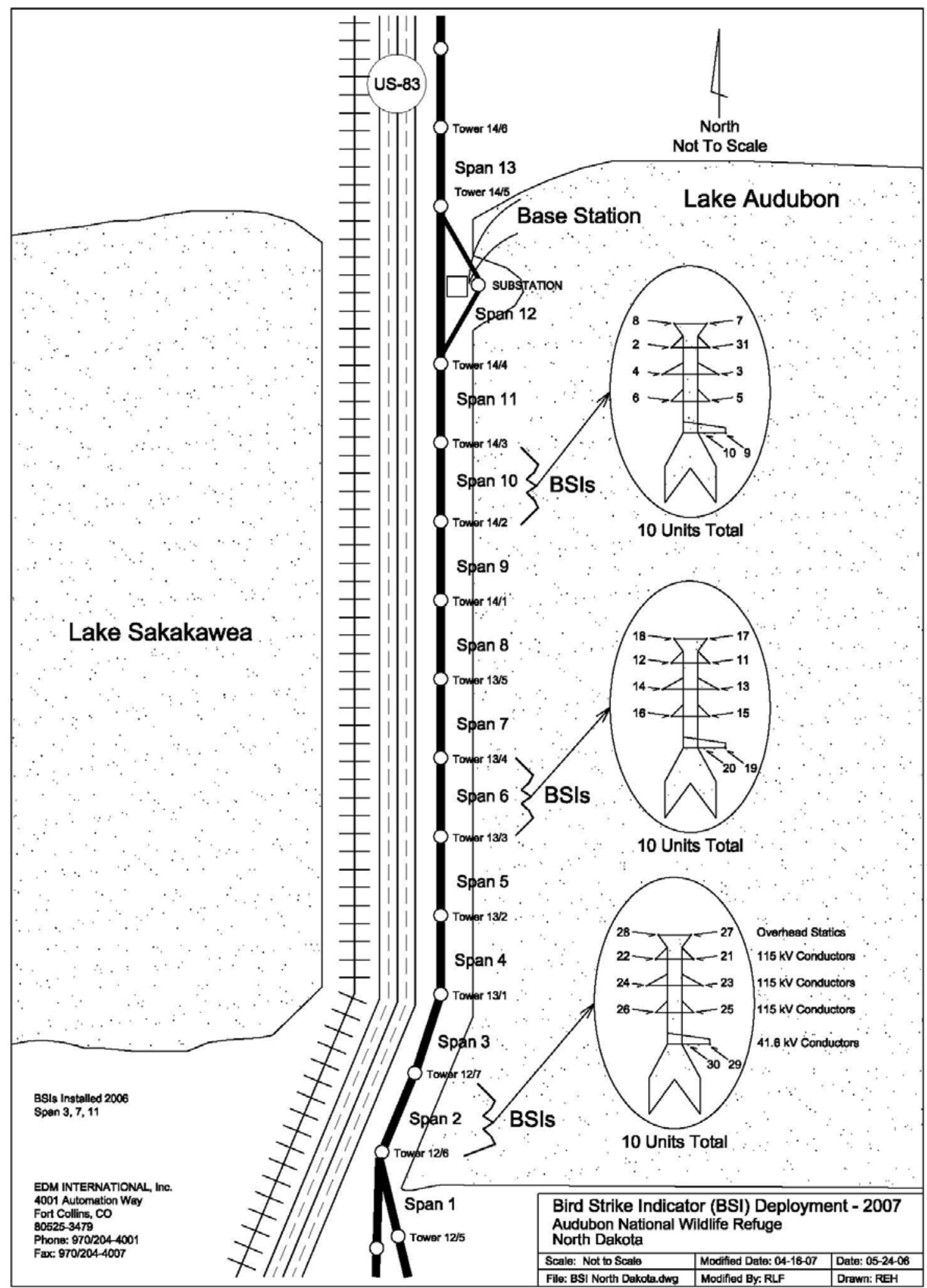

Figure 20. BSI sensor installation details for the 2007 field tests 


\subsection{BSI Performance}

\subsubsection{BSI Installation and Removal}

The BSI sensor installation and removal process met the design requirements of ease of installation using a hot stick. After removal of the BSI sensors, a visual observation of the wire surface underneath the BSI clamps did not show any sign of damage.

\subsubsection{Battery Life}

The battery life for most of the BSI sensors exceeded the overall design requirements of sixmonth battery life. All the sensors' radio batteries exceeded the six-month design life and were still operational when the sensors were removed from the North Dakota site. The average battery life for the accelerometers was 6.6 months, with only 3 of the 30 sensors, highlighted in red in the table below, quitting just a few days before the six month period. Twenty-two of the sensors had battery capacity and continued working past the day of planned removal. Table 10 summarizes the battery performance for all the BSI sensors. Battery voltages highlighted in red in the table indicate a low voltage.

\subsubsection{Physical Performance}

As the BSIs were taken off the wires, a review of the outside indicated no physical damage. The design changes incorporated in the sensors had completely eliminated the problems identified in the 2006 season due to corona activity at the antenna tips. Further, after opening the lid to evaluate the inside of the BSI sensors, there was no sign of any moisture ingress into any of the 30 BSI sensors. In addition, none of the accelerometers were unglued. Therefore, all the 30 sensors were functional throughout the entire 2007 field trials. Only 3 of the sensors' battery died just before the six month period.

\subsection{BSI Sensor Collision Recording}

The BSI sensors recorded wire vibration data that were either from bird collisions or weatherrelated events as a result of factors such as high wind or hail. These recordings included 154 bird collisions on the three spans being monitored. Bird collisions were determined by analyzing the vibration signal or signature recorded for each event.

\subsubsection{Bird Collision Signals}

Review of the vibration signal recordings identified bird collision signals which are unique and different from the weather-induced vibrations. As a bird collides with a power line it pushes the wire, generating a slow back-and-forth motion, which quickly dissipates, into the wire. This form is depicted by the transient nature of the vibration signal shown in Figure 21. After the initial strike, the wire recovers from the displaced position and slowly goes back to rest. The vibration signal then travels down the wire and disperses and spreads out depending on the distance it has to travel to the sensor. The signal might be strong enough to reflect back from the clamps at the span ends and get picked up again by the BSI sensor as shown in Figure 21 (b). Bird collision vibration recordings are slightly different than those from 2006, because the sensor is installed near mid-span. The 2007 BSIs also have both accelerometers mounted to 
monitor the horizontal plane, as opposed to the 2006 BSIs, where horizontal and vertical signals were recorded.

Table 10. Battery performance of the BSI sensors during 2007 tests

\begin{tabular}{|c|c|c|c|c|c|}
\hline \multirow{2}{*}{$\begin{array}{c}\text { BSI Sensor } \\
\text { No. }\end{array}$} & \multicolumn{2}{|c|}{ Last Day of Health Reporting } & \multirow{2}{*}{$\begin{array}{l}\text { Days since } \\
\text { installation }\end{array}$} & \multicolumn{2}{|c|}{ Reported Battery Voltage } \\
\hline & Day & Date & & Accelerometer & Radio \\
\hline 2 & 309 & $11 / 5 / 2007$ & 206 & 3.51 & 3.54 \\
\hline 3 & 297 & $10 / 24 / 2007$ & 194 & 3.21 & 3.46 \\
\hline 4 & 309 & $11 / 5 / 2007$ & 206 & 3.48 & 3.53 \\
\hline 5 & 266 & $9 / 23 / 2007$ & 163 & 3.01 & 3.58 \\
\hline 6 & 309 & $11 / 5 / 2007$ & 206 & 3.43 & 3.41 \\
\hline 7 & 309 & $11 / 5 / 2007$ & 206 & 3.47 & 3.55 \\
\hline 8 & 279 & $10 / 6 / 2007$ & 176 & 2.86 & 3.53 \\
\hline 9 & 309 & $11 / 5 / 2007$ & 206 & 3.52 & 3.57 \\
\hline 10 & 309 & $11 / 5 / 2007$ & 206 & 3.52 & 3.53 \\
\hline 11 & 309 & $11 / 5 / 2007$ & 206 & 3.49 & 3.55 \\
\hline 12 & 297 & $10 / 24 / 2007$ & 194 & 3.17 & 3.47 \\
\hline 13 & 288 & $10 / 15 / 2007$ & 185 & 2.85 & 3.52 \\
\hline 14 & 309 & $11 / 5 / 2007$ & 206 & 3.48 & 3.5 \\
\hline 15 & 284 & $10 / 11 / 2007$ & 181 & 2.85 & 3.5 \\
\hline 16 & 275 & $10 / 2 / 2007$ & 172 & 3.09 & 3.62 \\
\hline 17 & 309 & $11 / 5 / 2007$ & 206 & 3.51 & 3.55 \\
\hline 18 & 309 & $11 / 5 / 2007$ & 206 & 3.48 & 3.52 \\
\hline 19 & 309 & $11 / 5 / 2007$ & 206 & 3.48 & 3.51 \\
\hline 20 & 309 & $11 / 5 / 2007$ & 206 & 3.5 & 3.54 \\
\hline 21 & 309 & $11 / 5 / 2007$ & 206 & 3.5 & 3.55 \\
\hline 22 & 309 & $11 / 5 / 2007$ & 206 & 3.52 & 3.54 \\
\hline 23 & 302 & $10 / 29 / 2007$ & 199 & 2.82 & 3.41 \\
\hline 24 & 309 & $11 / 5 / 2007$ & 206 & 3.51 & 3.56 \\
\hline 25 & 309 & $11 / 5 / 2007$ & 206 & 3.47 & 3.51 \\
\hline 26 & 309 & $11 / 5 / 2007$ & 206 & 3.48 & 3.54 \\
\hline 27 & 309 & $11 / 5 / 2007$ & 206 & 3.45 & 3.49 \\
\hline 28 & 309 & $11 / 5 / 2007$ & 206 & 3.49 & 3.54 \\
\hline 29 & 309 & $11 / 5 / 2007$ & 206 & 3.51 & 3.53 \\
\hline 30 & 309 & $11 / 5 / 2007$ & 206 & 3.51 & 3.55 \\
\hline 31 & 309 & $11 / 5 / 2007$ & 206 & 3.5 & 3.52 \\
\hline
\end{tabular}

Note: Red indicates a low battery level. 


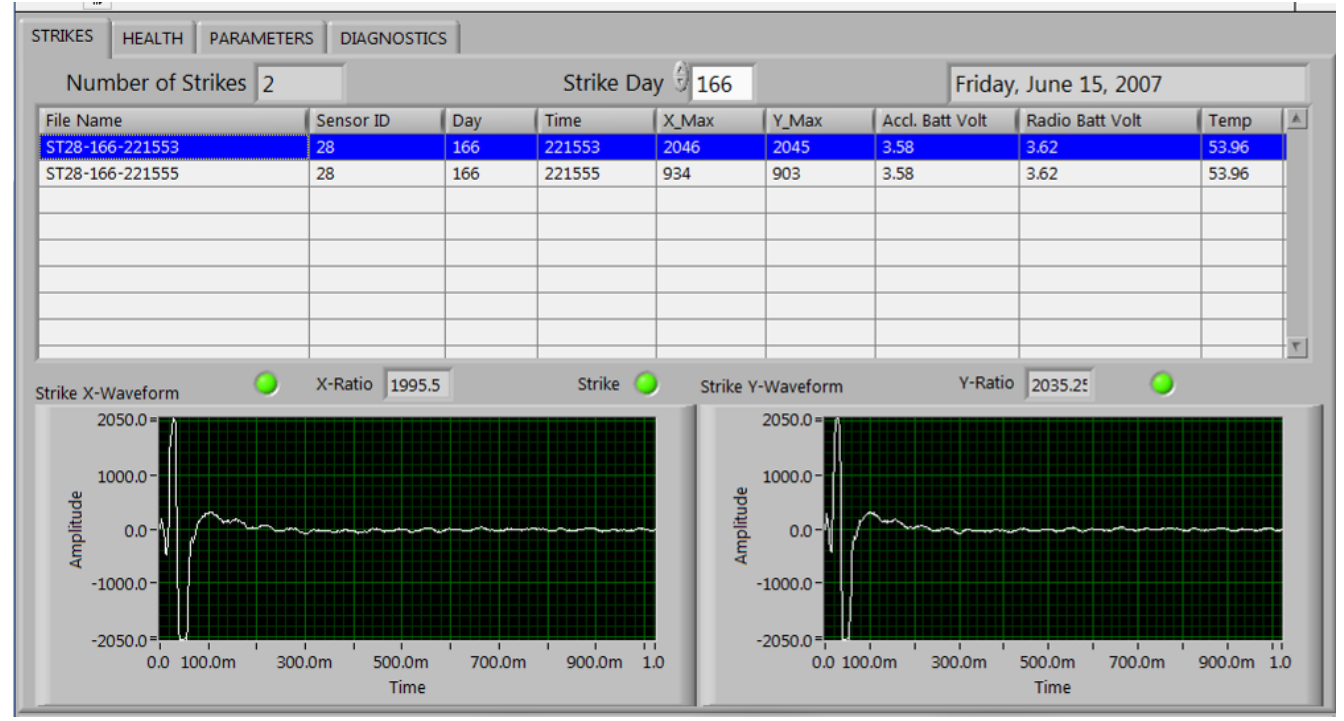

(a) Bird collision vibration signal

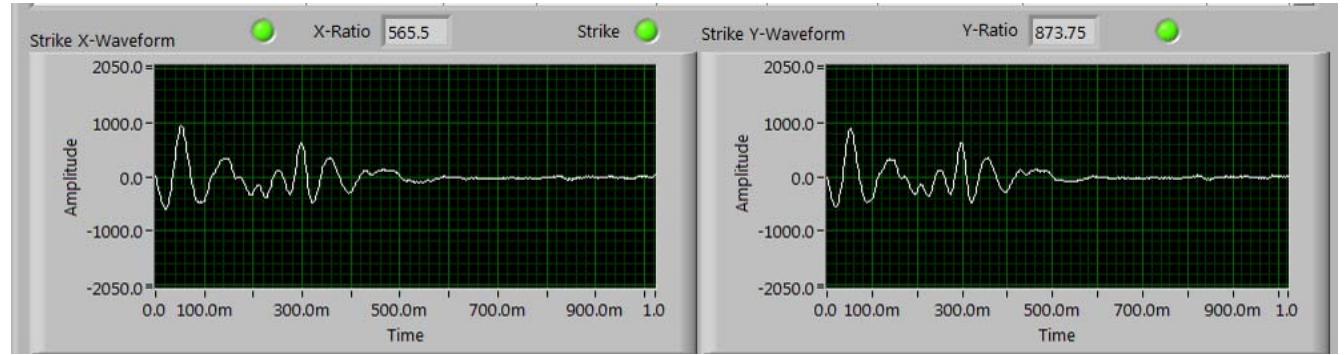

(b) Signal reflected from the end of the span

Figure 21. Typical BSI sensor recordings for a bird collision with the power line with sensor installed near the center of the span

Figure 22 shows a vibration recording consisting of two possible bird collisions. This could be two birds in a flock colliding with the same wire within a second.

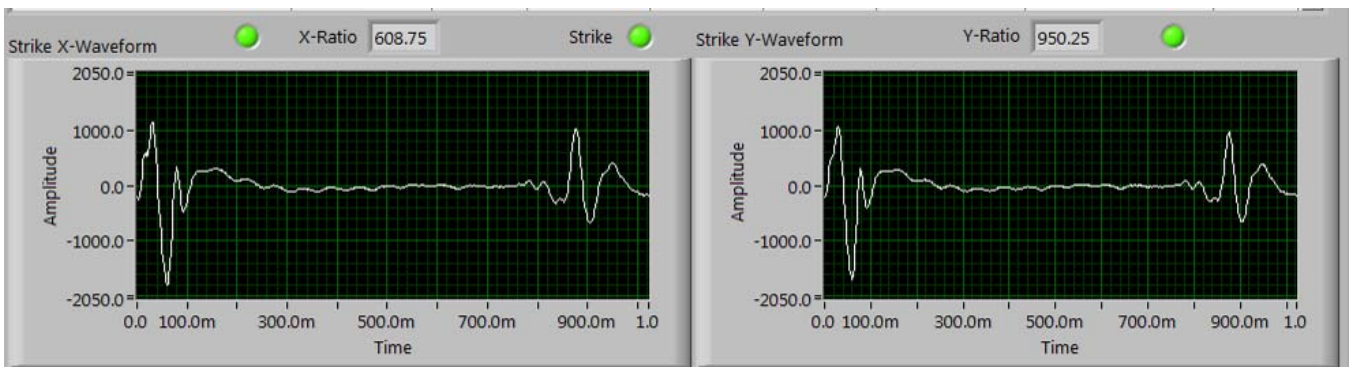

Figure 22. Vibration recording from a likely two-bird collision within a second

Table 11 provides a summary of bird collisions recorded by the BSI sensors broken down by sensor, span, and location. Overall 154 bird collisions were recorded during the 2007 season. The most collisions were recorded on Span $6(n=68)$. Span $10(n=44)$ and Span $2(n=42)$ recorded approximately the same number of collisions. For each of the three spans, most of the collisions were recorded by the top-most sensors, followed by the next two sensors. 
Table 11. Summary of bird collision recordings in 2007 by span and sensors

\begin{tabular}{|c|c|c|c|c|c|}
\hline Span & $\begin{array}{c}\text { West } \\
\text { Sensor No. }\end{array}$ & $\begin{array}{l}\text { West } \\
\text { Sensor } \\
\text { Strikes }\end{array}$ & Total & $\begin{array}{c}\text { East } \\
\text { Sensor } \\
\text { Strikes }\end{array}$ & $\begin{array}{c}\text { East } \\
\text { Sensor } \\
\text { No. }\end{array}$ \\
\hline \multirow{5}{*}{ 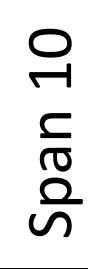 } & 8 & 3 & 25 & 22 & 7 \\
\hline & 2 & 10 & 16 & 6 & 31 \\
\hline & 4 & 3 & 3 & 0 & 3 \\
\hline & 6 & 0 & 0 & 0 & 5 \\
\hline & 10 & 0 & 0 & 0 & 9 \\
\hline & & 16 & 44 & 28 & \\
\hline \multirow{5}{*}{$\begin{array}{l}\sigma \\
\frac{1}{\sigma} \\
\frac{\Omega}{n}\end{array}$} & 18 & 26 & 52 & 26 & 17 \\
\hline & 12 & 3 & 9 & 6 & 11 \\
\hline & 14 & 3 & 3 & 0 & 13 \\
\hline & 16 & 1 & 1 & 0 & 15 \\
\hline & 20 & 2 & 3 & 1 & 19 \\
\hline & & 35 & 68 & 33 & \\
\hline \multirow{6}{*}{$\begin{array}{l}N \\
\frac{1}{\sigma} \\
\stackrel{\Omega}{n}\end{array}$} & 28 & 22 & 28 & 6 & 27 \\
\hline & 22 & 2 & 6 & 4 & 21 \\
\hline & 24 & 2 & 4 & 2 & 23 \\
\hline & 26 & 1 & 3 & 2 & 25 \\
\hline & 30 & 0 & 1 & 1 & 29 \\
\hline & & 27 & 42 & 15 & \\
\hline \multicolumn{2}{|r|}{ Total } & 78 & 154 & 76 & \\
\hline
\end{tabular}

A breakdown of the bird collisions by wire location are shown in Table 12 and Figure 23. These recordings show that $68 \%$ of the collisions were detected on the top most (shield wire) wires, followed by another $20 \%$ on the top two $115 \mathrm{kV}$ conductors. The bottom wires recorded very few bird collisions (2.6\%).

Table 12. Bird collision recordings in 2007 by wire location

\begin{tabular}{|l|c|c|c|}
\hline \multirow{2}{*}{$\begin{array}{c}\text { Sensor } \\
\text { Location }\end{array}$} & \multirow{2}{*}{ Wire } & \multicolumn{2}{|c|}{ Collisions } \\
\cline { 3 - 4 } & & No. & $\%$ \\
\hline Top 2 & Shield Wire & 105 & 68.18 \\
\hline Next 2 & $115 \mathrm{kV}$ & 31 & 20.13 \\
\hline Next 2 & $115 \mathrm{kV}$ & 10 & 6.49 \\
\hline Next 2 & $115 \mathrm{kV}$ & 4 & 2.60 \\
\hline Bottom 2 & $69 \mathrm{kV}$ & 4 & 2.60 \\
\hline & & 154 & 100 \\
\hline
\end{tabular}




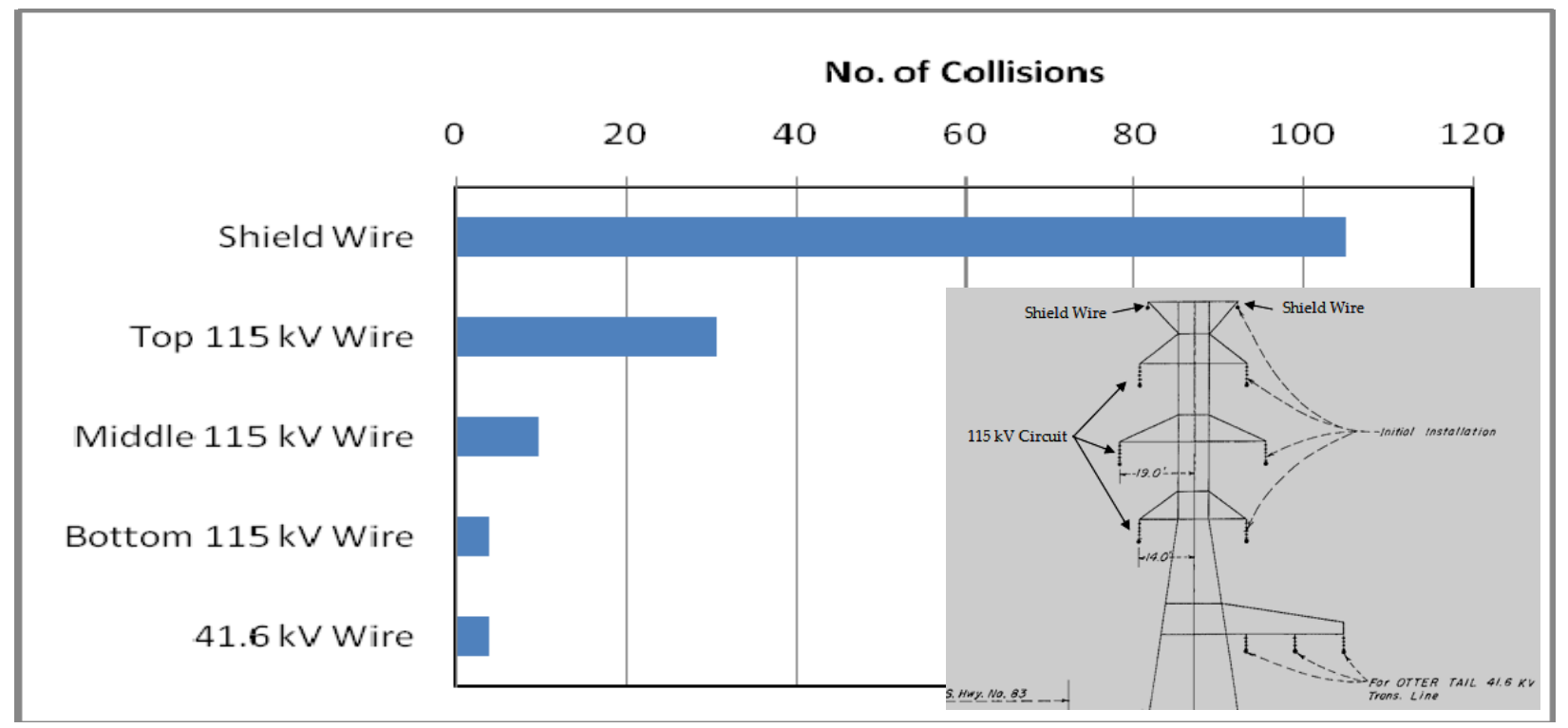

Figure 23. Summary of bird collision recordings in 2007 by wire location

Most of the bird collisions occurred during early morning, evening, and night time as shown in Figure 24. The maximum number of collisions occurred just around dusk, between 21:00 to 22:00. Very few collisions occurred during daylight hours.

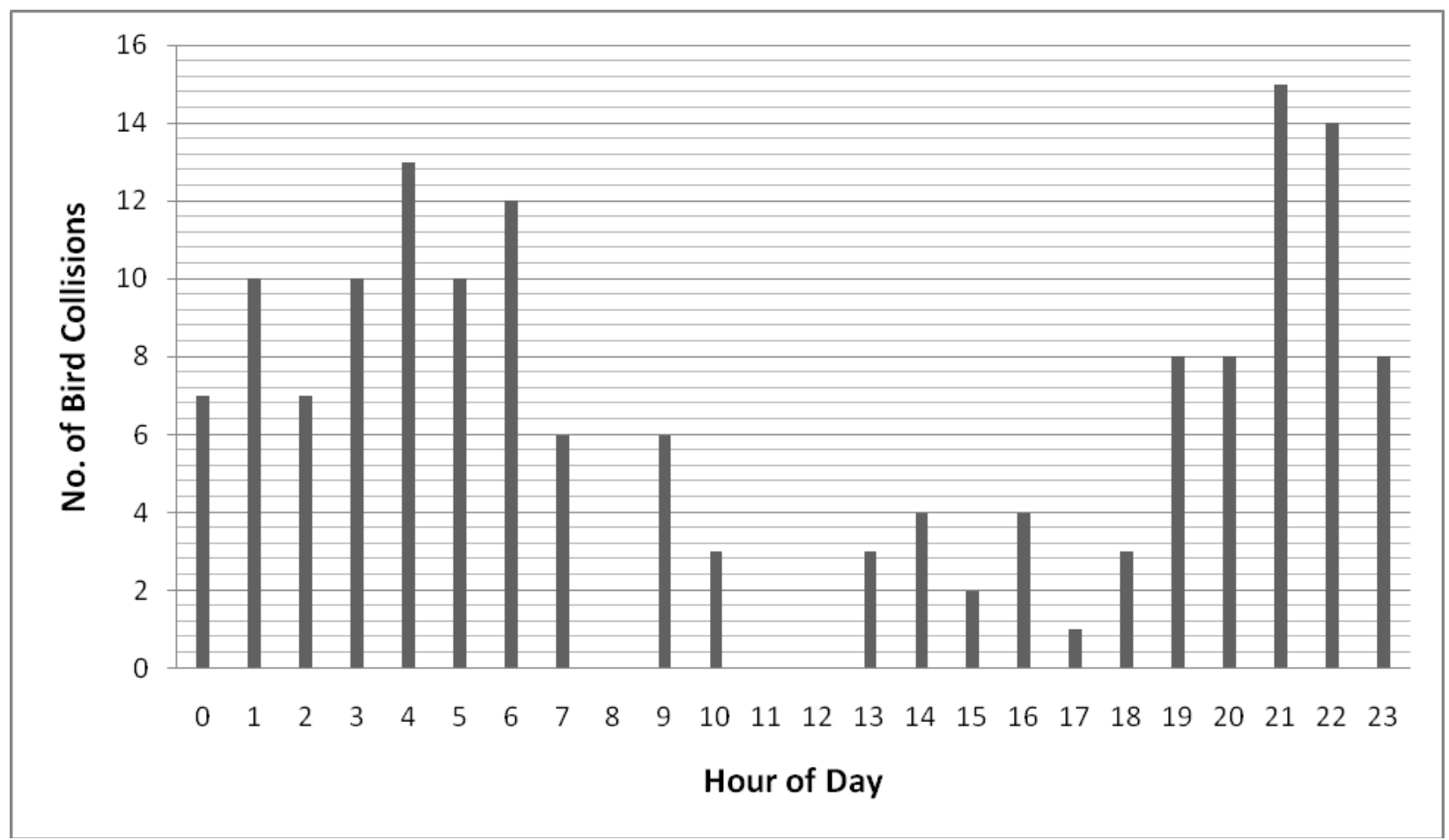

Figure 24. Bird collisions recorded in 2007, by hour of day 
In the beginning of the monitoring season, bird collisions were being detected more often on Span 2, but later the intensity of bird collisions picked up on Span 6 and continued at the same pace until the end of the season. Figure 25 provides a representation of the bird collision recordings over the entire monitoring season, by span.

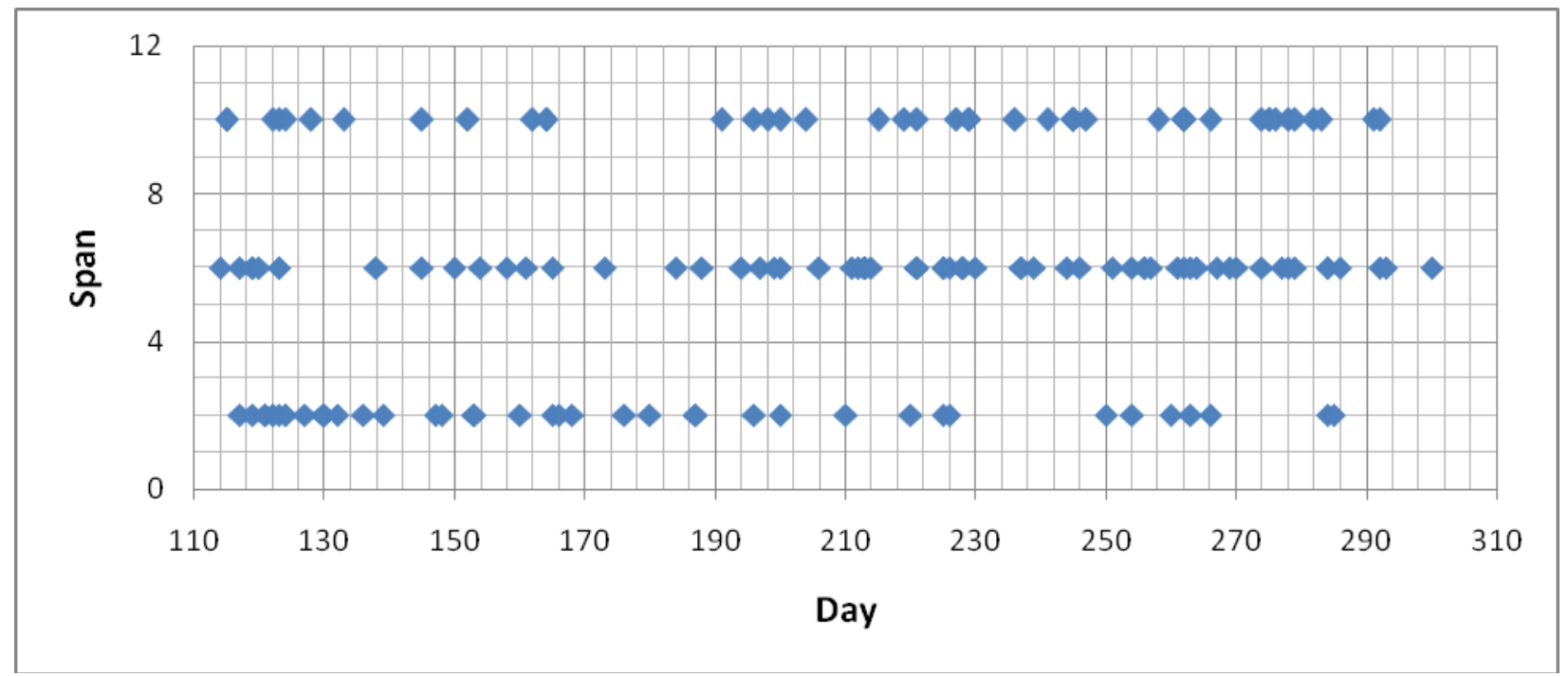

Figure 25. Bird collision recording distribution by day on the three spans

\subsubsection{Weather Related Strikes}

Severe weather events, such as hail and extreme high winds, produced "strikes" detected by the sensors in 2006. Orienting both accelerometers to monitor the horizontal axis eliminated all of the hail- and rain-related vibration recordings, as these events primarily produce vibration in the vertical direction.

However, in 2007 wind-induced vibration was recorded when the wind exceeded moderate levels. Moderate winds are 3 to 4 on the Beaufort Wind Scale $(8-18 \mathrm{mph})$. Higher winds produced vibration recordings that were very different from the bird collision recordings. The wind-induced vibrations also were different compared to the 2006 season because the sensors were installed near the mid-span in 2007 as opposed to near the end of the span in 2006. Figure 26 shows two typical vibration signals recorded by the BSI sensors that were result of windinduced vibration. During the visual field observations, the observer made recordings of wind speed based on the Beaufort Wind Scale. The recorded wind induced vibrations correlated well with high winds, 6 or greater on the Beaufort Wind Scale. 


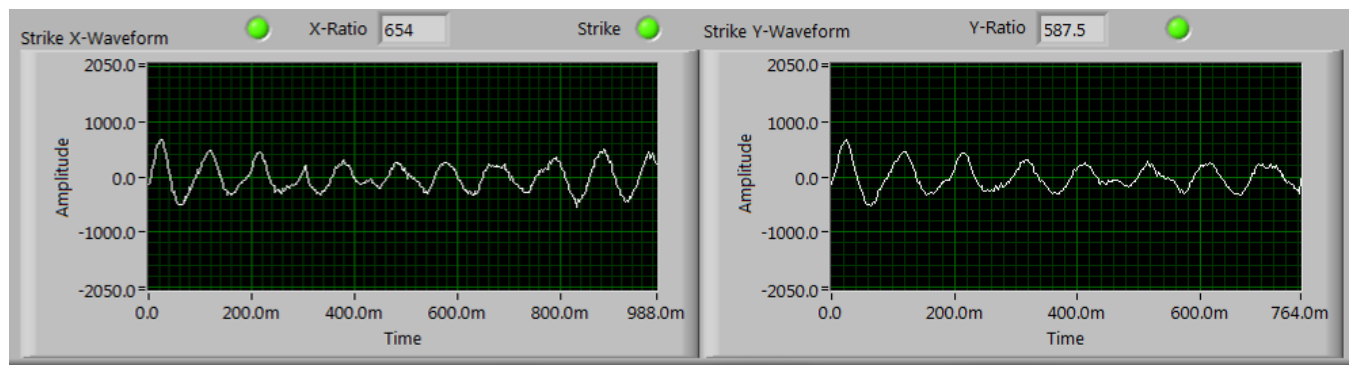

(a) Low frequency, wind-induced vibration

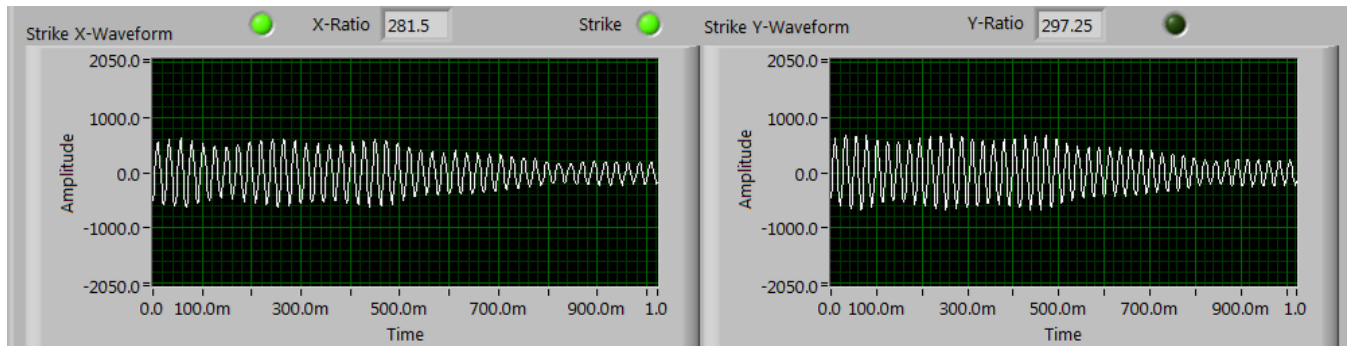

(b) High-frequency, wind-induced vibration

Figure 26. Wind-induced vibration signal recorded by the BSI sensors in 2007

\subsection{Visual Observations and Correlation}

One of the main goals for the 2007 redeployment was to increase the amount of visual observations. The goal was to try to obtain a direct correlation of observed bird collisions with BSI detected collisions.

A technician was deployed to visually monitor line segments instrumented with the BSIs. Visual monitoring was started on May 26, 2007, and continued until September 13, 2007. One of the three spans with BSI sensors was visually monitored in the early morning and late evening five days a week. The morning observations started before sunrise and continued for about four hours. The evening observations were also typically four hours in duration and lasted until it became too dark to see. During the 79-day visual observation period the lines were visually monitored for a total of 446 hours.

The protocol for visual observation was to sit at the south end of the span and watch for bird activity in the vicinity of the span. Bird activity was noted along with weather observations with respect to sky condition and wind speed.

In the beginning, it was difficult to observe any bird collisions, as most of the collisions detected by the BSIs were either occurring outside the observation period and/or on spans that were not being visually observed. Accordingly, visual observation efforts were shifted to the span with most of the collisions being detected by the BSI sensors (Span 2). Near the end of the monitoring season, the activities shifted to Span 6. In the last two weeks of the visual observations, finally several bird collisions were observed. These observations resulted in several successful correlations with BSI-detected collisions. 
During the 79-day long visual observation cycle, three collisions and one glancing collision were observed on the test spans, all on the middle Span 6. The observed collisions as recorded by the observer and their correlation with BSI-recorded collisions are described below. It is important to note that during the visual observation period (consisting of a total of 446 hours of visual observations) there were no collisions recorded by the BSI sensors on the spans being visually observed aside from the collisions described below. The fact that no false strikes were recorded during the visual observations in itself provides further confidence that the BSI sensors worked properly.

\section{Collision Observed on August 1, 2007}

The first collision was observed on August 1, 2007, at 18:20 on Span 6, approximately 75 feet from the BSI sensor. A juvenile Franklin's gull directly struck the uppermost $115 \mathrm{kV}$ wire on the west side installed with BSI sensor 12. After hitting the wire, the bird landed in the water on its back and floated back to the rocks where it died within five minutes.

A review of that day's BSI collision summary data, shown in Figure 27, indicated that there were four collisions detected by the BSI sensors and reported to the base station. All of the collisions were on Span 6 and two of the collisions were recorded during the visual observation period. The first collision during the visual observation period occurred at 18:18:43 on sensor 18 (the uppermost west wire). A comparison of the base station clock with the visual observer's watch indicated that the base station computer's clock is approximately two minutes slower. Thus the recorded collision matched very well in time with the observed collision. However, the observer recorded that the collision likely occurred on the wire with sensor 12 instead of sensor 18 , which is one wire higher up from sensor 12. The view of the wires from the observer's vantage point is shown in Figure 28. As can be seen from Figure 28, it is fairly difficult to tell the wires apart, especially when the collisions occur further away from the observer, which was the case with this collision.

Approximately six minutes after the collision observed by observer, another collision was recorded by sensor 17 (the uppermost east wire) on the same span. This collision was not recorded by the observer, and no carcass was found. The observer had gone down to the rocks and was watching the bird after the initial collision and thus missed observing the second event which occurred within that short time frame. 


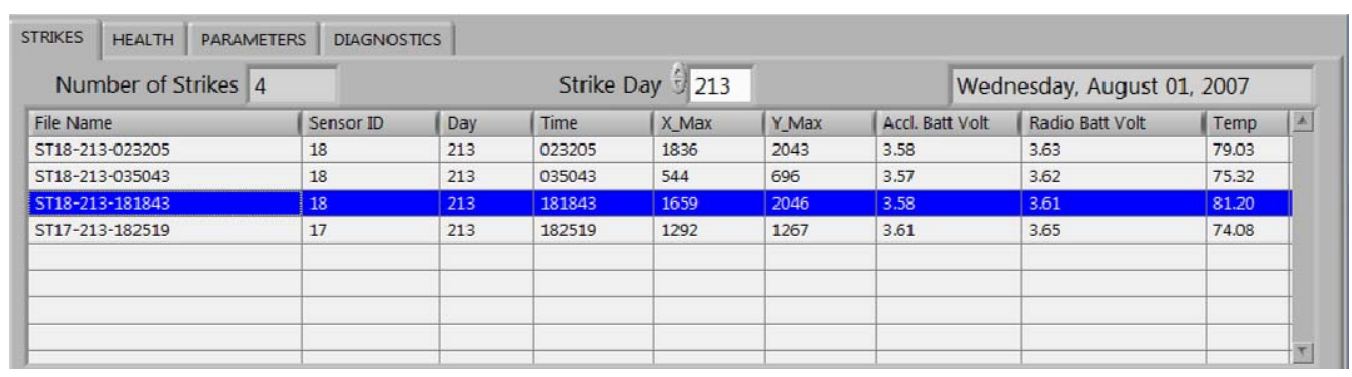

(a) Collision summary for August 1, 2007

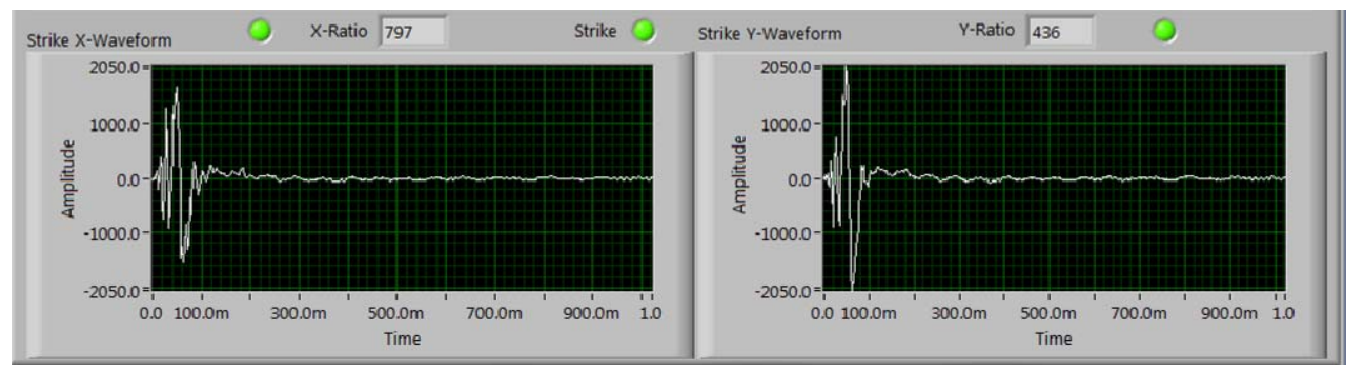

(b) BSI recorded collision at 18:18:43 on sensor 18

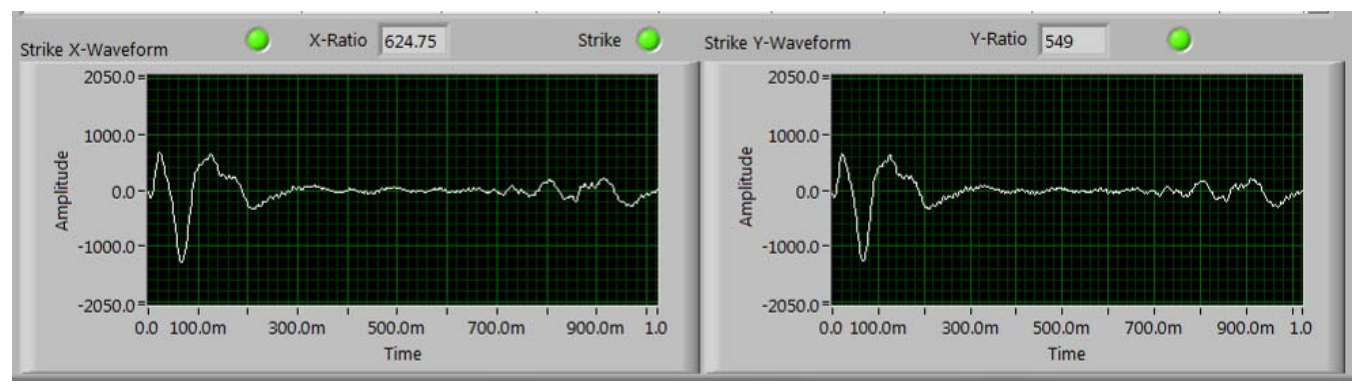

(c) BSI recorded collision at 18:25:19 on sensor 17

Figure 27. BSI recorded collisions on August 1, 2007 


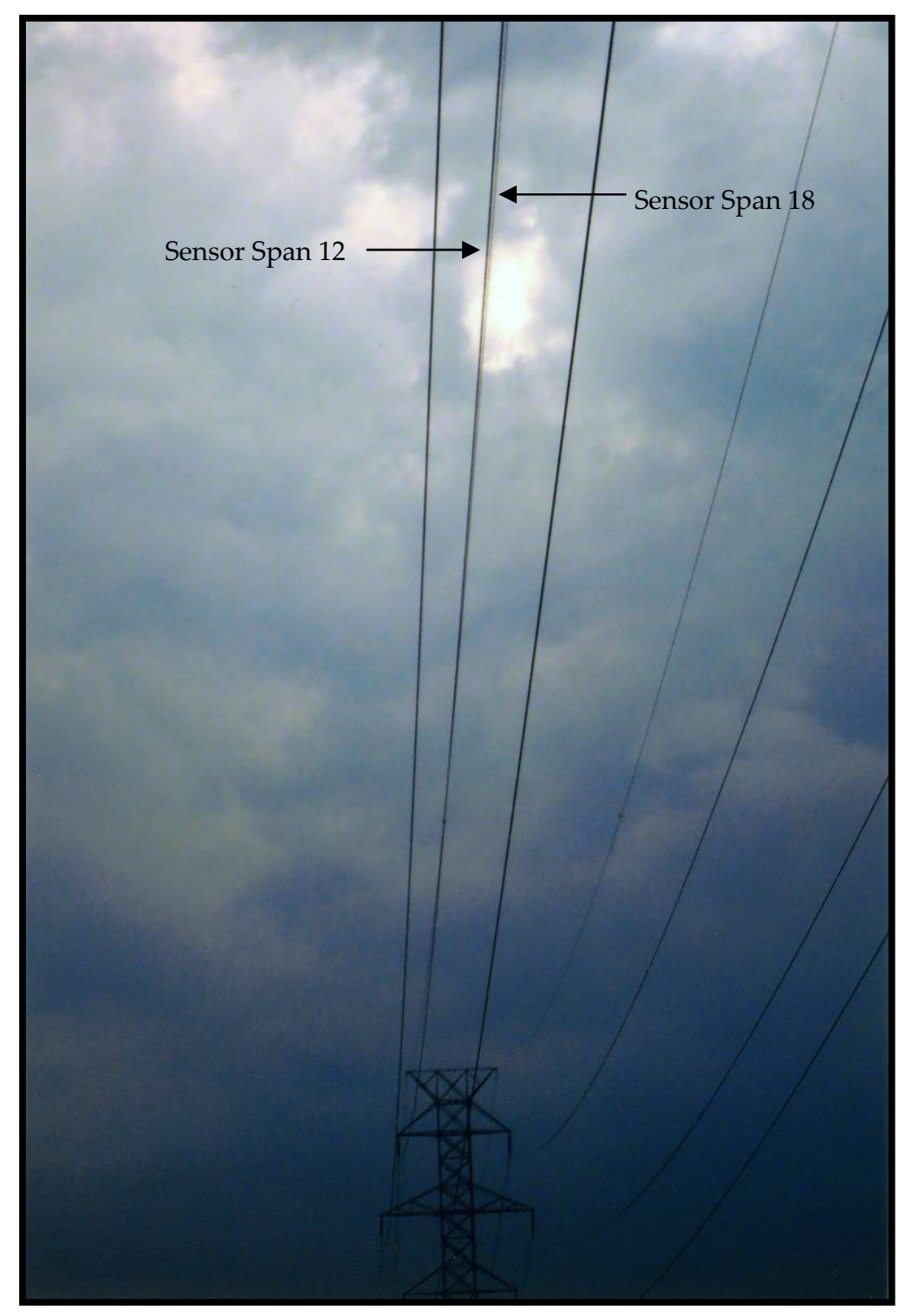

Figure 28. Observer's field of view from his sitting location at the south end of the span

\section{Collision Observed on August 5, 2007}

On August 5, 2007, at 18:04, another Franklin's gull had a glancing collision with the west shield wire (BSI sensor 18). The collision occurred on Span 6, approximately 180 feet from the sensor unit. The gull fluttered and then continued flying east, apparently unimpaired. There were no collisions recorded by the BSI sensors on this day. The observed collision was only a glancing collision that occurred approximately $180 \mathrm{ft}$ from the sensor, so it is not surprising that it was not picked up by the sensors. This suggests that a crippling bias may still be a factor.

\section{Collisions Observed on August 9, 2007}

Two collisions were observed on Span 6 on August 9, 2007. The first strike was observed at 19:06, approximately $75 \mathrm{ft}$ north of the BSI sensor. A double-crested cormorant struck the 
lowermost $115 \mathrm{kV}$ wire on the west (BSI sensor 16). The bird was the last bird in a flock of 13 . It struck the wire and fluttered down approximately 10 feet and then continued flying east.

The second collision was observed again on Span 6 at 19:55. A double-crested cormorant in the middle of the flock struck the top most $115 \mathrm{kV}$ wire on the west side of the span (BSI sensor 12). This was a glancing collision that took place approximately $90 \mathrm{ft}$ north of the BSI sensor. The cormorant continued flying east with the flock.

Both these observed collisions were also recorded by the BSI sensors. Figure 29 provides a summary of collisions recorded by the sensors on August 9, 2007. Time records on the two of the collisions recorded by the BSI sensors (19:04:05 and 19:04:05) are within two minutes of the observed time. However, the observer recorded the second collision taking place on sensor 12, whereas the BSI sensor 14 was the one that recorded a strike at that time. Again, sensor 14 is only one wire below sensor 12 , and it is felt that observer likely mistakenly noted the wrong wire.

In addition to the two visually correlated collisions, there was another collision recorded by the BSI sensor 17 at 16:37:18 on Span 6 which occurred within five minutes of the observer logging in for visual observations. The first note in the observer's log that evening is at 16:53. It is likely the observer was walking to his observing station when this collision took place.

\subsubsection{Visual Observation Correlation Summary}

In the four-month visual observation period consisting of approximately 446 hours of observations, only four collisions were observed. Three of these observed collisions correlated with BSI recorded collisions. The only collision that was not detected by the BSI sensors was a glancing collision approximately $180 \mathrm{ft}$ from the sensor. In addition, there were no false collisions recorded by the sensors during the entire visual observation cycle. These successful correlations provide a greater confidence level in the ability of the BSI sensors to detect collisions. 


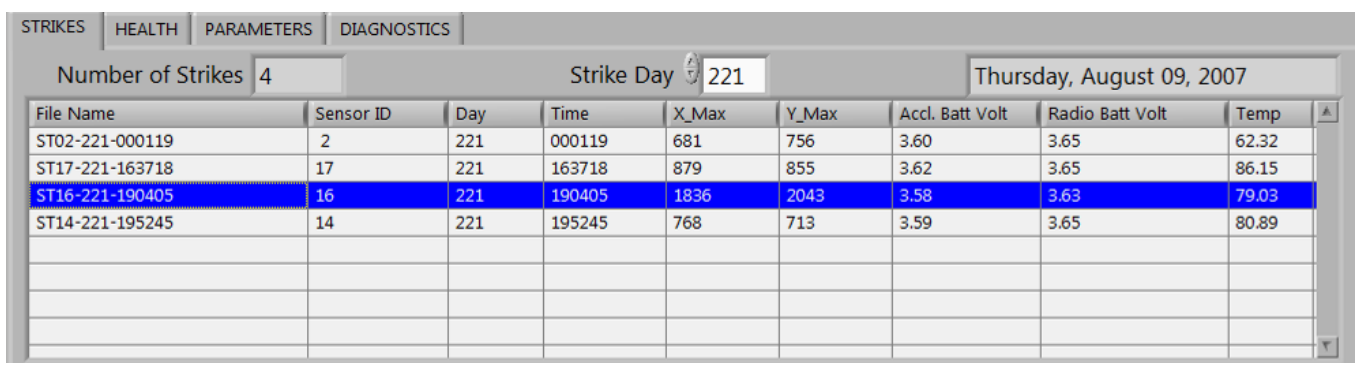

(a) Collision summary for August 9, 2007

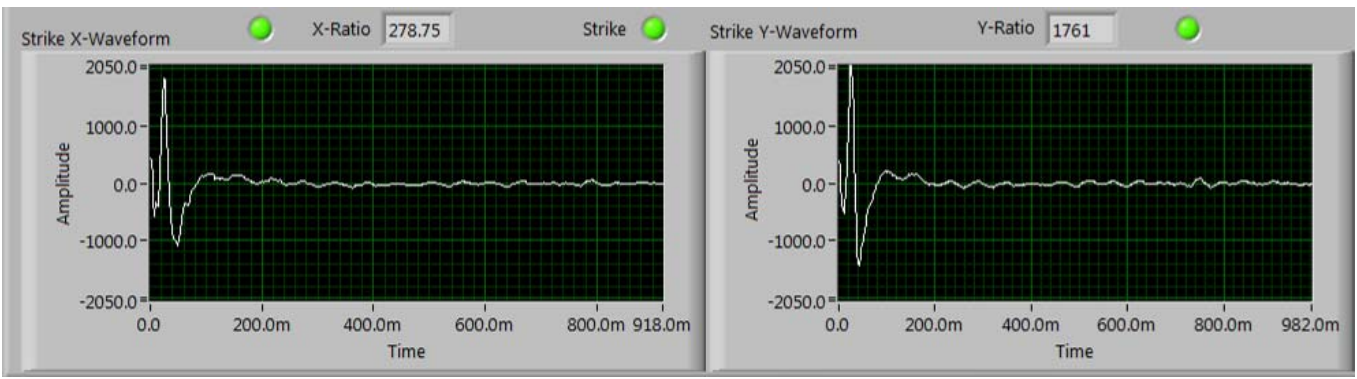

(b) Collision recorded at 19:04:05 on sensor 16

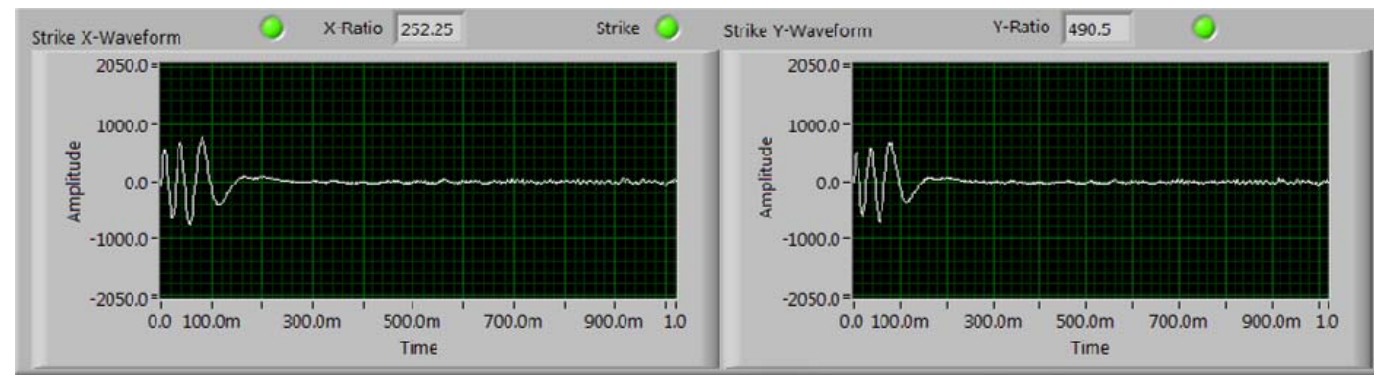

(c) Collision recorded at 19:52:45 on sensor 14

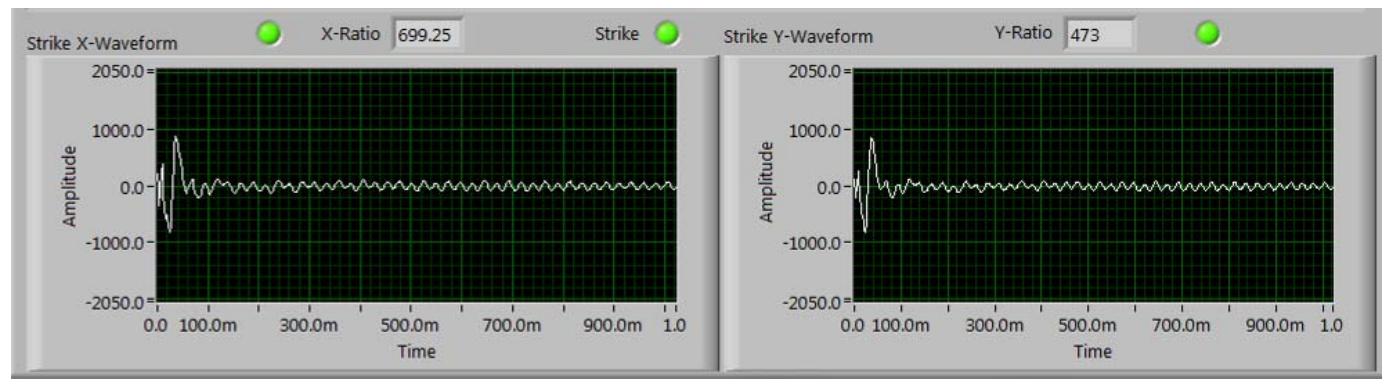

(a) Collision recorded at 16:37:18 on sensor 17

Figure 29. BSI recorded collision from August 9, 2007

\subsection{Summary of BSI Sensor Field Testing: 2007}

The 2007 field season began on April 20, 2007, and ended with the last day of pedestrian survey data collected on October 19, 2007. The field season consisted of 182 days of pedestrian survey data. The protocols for the field surveys were similar to that used in the 2001 and 2002 study, as described in a previous report (CEC 2003). 
A total of 344 bird carcasses were recovered along the causeway during the 2007 field season. Western and APLIC provided the preliminary results of their field efforts, which are discussed briefly below. These efforts are a part of a study being conducted by Western and APLIC. As such, the detailed results of the pedestrian surveys will be presented in their separate report.

The 344 bird fatalities recorded during the 2007 field season, encompassing approximately 65 species, was less than the number of fatalities recorded during the 2001 season (451 dead birds, 63 species), 2002 season (434 dead birds, 77 species), and even the 2006 season (429 dead birds, 67 species).

Table 13 presents necropsy results by span, along with numbers of bird collisions recorded by the BSI sensors for the 2007 season. The number of BSI-detected collisions $(n=154)$ exceeds the total number of bird fatalities $(n=101)$ on the monitored spans. If the birds whose cause of death was identified as "vehicle" are eliminated, the correlation becomes even worse, as there are 64 bird fatalities that have a cause of death of either "Power Line" or "Unknown."

Table 13. Summary of necropsy results for the 2007 field survey season

\begin{tabular}{|c|c|c|c|c|c|c|}
\hline \multirow[b]{2}{*}{ Span ID } & \multirow{2}{*}{$\begin{array}{c}\text { Spans } \\
\text { with BSIs }\end{array}$} & \multirow{2}{*}{$\begin{array}{c}\text { No. of } \\
\text { Strikes } \\
\text { Detected by } \\
\text { BSIs }\end{array}$} & \multirow{2}{*}{$\begin{array}{c}\text { Total } \\
\text { Number of } \\
\text { Bird } \\
\text { Fatalities } \\
\text { per Span }\end{array}$} & \multicolumn{3}{|c|}{ Cause of Death } \\
\hline & & & & Power Line & Vehicle & Unknown \\
\hline 2 & BSIs & 42 & 38 & 9 & 15 & 14 \\
\hline 3 & & & 40 & 13 & 11 & 16 \\
\hline 4 & & & 41 & 13 & 16 & 12 \\
\hline 5 & & & 30 & 8 & 10 & 12 \\
\hline 6 & BSIs & 68 & 31 & 11 & 12 & 8 \\
\hline 7 & & & 19 & 5 & 6 & 8 \\
\hline 8 & & & 32 & 8 & 11 & 13 \\
\hline 9 & & & 28 & 5 & 12 & 11 \\
\hline 10 & BSIs & 44 & 32 & 9 & 10 & 13 \\
\hline 11 & & & 28 & 4 & 12 & 12 \\
\hline 12 & & & 25 & 4 & 6 & 15 \\
\hline Totals & & & 344 & 89 & 121 & 134 \\
\hline $\begin{array}{c}\text { Total for BSI } \\
\text { Spans }\end{array}$ & BSIs & 154 & 101 & 29 & 37 & 35 \\
\hline
\end{tabular}

The nature of the causeway makes it difficult to discern the cause of death for many of the retrieved birds. As mentioned previously, secondary injuries sustained from vehicles may mask power line collision injuries. In addition, it is possible for birds to collide with the power line and continue flying and fall outside the search area, or even to fall into the lake and thus avoid detection. Also, some collisions might not result in bird fatalities as the collision might not be severe enough. In this case, birds might continue flying either unimpaired or somewhat impaired. Both these scenarios have been visually observed on site and might explain the higher number of bird collisions recorded by the sensors. These uncertainties increase the complexity of correlating collision signatures recorded by the BSI sensors to carcasses on the ground. 
There is no definite way of relating a dead bird found on the ground to a particular collision recorded by the BSI sensor. Although strong correlations can be developed, as was done in the 2006 study, causation cannot be determined. Accordingly, the exercise of trying to correlate dead birds to actual collision recordings was dropped for the 2007 season field trials. It was felt that visual observations of the spans and correlating the visual observations to the sensor recordings to identify any false positives or false negatives from the BSI sensors were the best use of the available resources. That effort included watching instrumented spans for 446 hours over 79 days and yielded no false positives. Additionally, three of the four observed collisions positively correlated with BSI records. One glancing collision 180 feet from a sensor was not recorded by the sensor, and the bird flew away. 


\subsection{Conclusions and Recommendations}

\subsection{Field Trials}

The field testing of the BSI sensors at the North Dakota test site shows the BSI sensors are able to successfully detect and record bird collisions with power lines. During the monitoring season, 71 collisions were recorded and 35 were correlated with ground searches. These birds consisted primarily of larger birds such as coots $(n=10)$, gulls $(n=7)$, cormorants $(n=2)$, grebe $(n=2)$, ducks $(n=2)$, terns $(n=2)$, and loon $(n=1)$. Additionally, smaller birds such as common grackles and a least flycatcher also were linked with strikes. The BSIs recorded some collisions that could not be correlated with carcasses found by the surveyors, indicating that some of the carcasses might have fallen outside the search area, as indicated by some of the observed collisions. Despite these successes, some bird collisions were also missed. On three occasions the BSIs failed to log collisions observed by field technicians. In addition, 9 out of 30 sensors failed at some point during the field trials and thus missed recording any collisions after their failure.

The field trial successfully demonstrated the ability to collect collision information remotely and transmit it across the Internet for review and analysis. The system was designed to have the ability to remotely change parameters in the sensors without removing them. During this project, this feature was tested and the sensors were successfully reprogrammed remotely to remove traffic-induced vibrations. Throughout the six-month trial, the battery life was within the expected tolerances, and wireless communication between the sensors and base station was functional. It also was demonstrated that both BSI installation and removal required minimal effort.

This project did encounter unique issues that might not be encountered at most other sites. Notably, the presence of the train and vehicle traffic parallel to the instrumented lines created some unique vibration signal challenges. However, these trials demonstrated that there are unique signal pattern differences between the vibration signatures produced by traffic, weather, and bird collisions. The unique signatures produced by bird collisions made it possible to distinguish bird collisions from other vibrations recorded by the sensors.

The presence of heavy vehicular traffic also presented problems in determining the cause of death for birds detected along the causeway. Despite performing necropsies, it was a challenge to correlate the bird collisions detected by the BSI sensors to the carcasses recovered by field surveys because it was difficult to determine the cause of death when there was a possibility of a secondary vehicle collision after a power line collision.

The field testing did identify some design/fabrication issues affecting the field performance of the sensors. Throughout this study, the BSIs on the upper static wires performed as expected and recorded the most strikes $(n=59)$. The sensors on the $41.6 \mathrm{kV}$ circuit also recorded six strikes. However some sensors on the $115 \mathrm{kV}$ wires and one on the $41.6 \mathrm{kV}$ line encountered some problems. The most significant design/fabrication issue was that some accelerometers became detached from the sensors as the result of glue failure, rendering them dysfunctional. The sensors installed on the $115 \mathrm{kV}$ wires also had damaged antenna tips from corona activity. 
However, this damage did not have any effect on the communication performance of these sensors.

The findings of the field testing were encouraging, especially considering that this was the first installation of the BSI sensors on energized power lines at such a complicated test environment.

After the 2006 testing, additional testing of the BSI sensors was recommended to further determine the effectiveness and sensitivity of the BSI sensors to detect bird collisions. Some of the specific recommendations were as follows:

1. Install the sensors closer to the middle of the span to improve the range and sensitivity of collision detection. This siting could reduce the sensors' sensitivity to traffic-induced vibrations by putting the sensors farther from the towers.

2. Install the accelerometers in a manner that ensures they are permanently attached, and investigate using accelerometers that can be mounted without glue.

3. Reinforce antenna tips or find an alternate metallic antenna with no sharp tips, to minimize corona effects.

4. Use greater precaution during fabrication to ensure that the area around each switch is properly sealed to prevent moisture intrusion.

5. Increase the duration of visual observations to increase the chances of direct verification of bird collisions with BSI-detected collisions.

These recommendations were addressed in the 2007 field trials, as described in the following section.

\subsection{Field Trials}

Design changes incorporating the recommendations from the 2006 season eliminated the problems encountered during the 2006 season. The 2007 physical performance of all 30 sensors had no failures and no moisture ingress. The average battery life of 6.6 months exceeded the design life of six months. Only three sensors' batteries quit before six months.

Increased visual observations during the 2007 field trials provided a preliminary study of the BSI sensors' ability to detect collisions. There were three visually verified bird collisions recorded during the 2007 season, and their unique signature provides confidence that the 154 events recorded throughout the field trials are consistent with bird collisions. During the visual observation period the sensors missed recording a glancing collision that appeared not to impair the bird. Additionally there was one event assigned to the wrong wire, suggesting that even when observing wires it may be difficult without a BSI to determine exactly which wire was struck. It is also important to note there were no false collision recordings (false positives) by the BSI sensors during the visual observation period of 446 hours over 79 days.

Collisions are relatively rare events, and the small number of visually observed collisions highlights the need for a tool like BSI, as it is very difficult and expensive to monitor all the spans at all times. Additionally, the BSI data suggest that many collisions occur during low 
visibility, making it impossible to visually observe them with the unaided eye. The maximum number of events occurred just around dusk, between 21:00 to 22:00 and again around 4:00 . Very few collisions occurred during daylight hours. The large discrepancy in the BSI-recorded events ( $n=154)$ versus the dead birds found during the 2007 field surveys $(n=101)$ also identifies the need for a tool like BSI. Field surveys will obviously miss carcasses falling outside a search area. In addition, collisions that do not result in fatalities will not be detected by field surveys.

The BSI results also demonstrate how events may change throughout a season. In the beginning of the monitoring season, bird collisions were being detected more often on Span 2, but later the intensity of bird collisions picked up on Span 6 and continued at the same pace until the end of the season. The collision recordings also show that $68 \%$ of all events occurred on the upper two shield wires.

The sensors did record several other vibration signals resulting from high wind events. Winds exceeding approximately $30 \mathrm{mph}$ produced enough vibration to be picked up by the sensors. Even though wind-induced vibration signatures are very different, they unnecessarily waste battery life. Because of the difference in their signatures, a digital filter could be implemented in the firmware of the BSI sensors to automatically eliminate most of these vibrations from being recorded. This would significantly enhance the overall usefulness of the BSI sensors.

Although correlations were found between strikes and carcasses as small as sparrows, more still needs to be learned about the sensitivity of detecting bird collisions for various birds. Detecting a collision includes several variables, such as the bird size and flight speed. These factors will determine the amount of energy transferred into a wire. The wire span length, size of the wire, the BSI mounting position (for example, midspan), and the BSI accelerometer sensitivity settings are important variables for detecting the collisions. Controlled bird strike trials using simulated birds or bird carcasses projected at instrumented spans would provide useful information on the overall ability of the BSI to detect strikes for a variety of birds. Finding another study site with less confounding factors but with high-documented bird collisions would also be beneficial. 


\subsection{References}

Avian Power Line Interaction Committee (APLIC). 1994. Mitigating Bird Collisions with Power Lines: The State of the Art in 1994. Edison Electric Institute. Washington D.C.

Brown, W.M. 1993. Avian collisions with utility structures: biological perspectives. In J.W. Huckabee [ed.]. Proceedings: Avian interactions with utility structures, international workshop. Internat. Workshop, Miami, Florida, September 13-16, 1992. Electric Power Research Institute, Inc., Palo Alto, California.

California Energy Commission/PIER (CEC). 2000. Bird Strike Monitor Performance Testing. Public Interest Energy Research Program: Consultant Report. Publication Number: 600-00-027. Publication Date: May 2000.

California Energy Commission/PIER (CEC). 2003. Bird Strike Indicator/Bird Activity Monitor and Field Assessment of Avian Fatalities. Public Interest Energy Research Program: Consultant Report. Publication Number: 500-03-107F. Publication Date: October 2003.

California Energy Commission/PIER (CEC). 2004. Corona Testing of Devices Used to Mitigate Bird Collisions. Public Interest Energy Research Program: Final Project Report. Publication Number: 500-04-086F. Publication Date: September 2004.

California Energy Commission/PIER (CEC). 2007. Bird Strike Indicator Field Deployment at the Audubon National Wildlife Refuge in North Dakota. Public Interest Energy Research Program: Consultant Report. Publication Number: 500-2007-076. Publication Date: September 2007.

Crowder, M. R. 2000. Assessment of devices designed to lower the incidence of avian power line strikes. M.S. Thesis, Purdue University.

EPRI. 2006. Use of the Bird Strike Indicator to Monitor Avian Collisions with Guy Wires on a U.S. Coast Guard Differential GPS Tower. Palo Alto, California. 1010130.

Olendorff, R. R. and R. N. Lehman. 1986. Raptor collisions with utility lines: an analysis using subjective field observations. Prepared by: U.S. Department of the Interior, Bureau of Land Management. Prepared for: Pacific Gas and Electric Co., San Ramone, California. 


\subsection{Glossary}

\begin{tabular}{|c|c|}
\hline APLIC & Avian Power Line Interaction Committee \\
\hline BPA & Bonneville Power Administration \\
\hline BSI & Bird Strike Indicator \\
\hline EPRI & Electric Power Research Institute \\
\hline$g$ & g-force; a measure of acceleration \\
\hline GUI & graphical user interface \\
\hline GPS & Global Positioning System \\
\hline $\mathrm{Hz}$ & hertz \\
\hline $\mathrm{kV}$ & kilovolt \\
\hline $\mathrm{mph}$ & miles per hour \\
\hline PG\&E & Pacific Gas \& Electric \\
\hline PIER & Public Interest Energy Research \\
\hline ROW & right-of-way \\
\hline SCE & Southern California Edison \\
\hline SRP & Salt River Project \\
\hline SwRI & Southwest Research Institute, Inc. \\
\hline Tri-State G\&T & Tri-State Generation \& Transmission Association \\
\hline UPS & uninterruptible power supply \\
\hline USCG & United States Coast Guard \\
\hline USFWS & United States Fish and Wildlife Service \\
\hline Western & Western Area Power Administration \\
\hline
\end{tabular}




\title{
AN UPDATE ON MORTALITY OF FLEDGED WHOOPING CRANES IN THE ARANSAS/ WOOD BUFFALO POPULATION
}

\author{
THOMAS V. STEHN, ${ }^{1}$ U.S. Fish and Wildlife Service, 1 Wildlife Circle, Austwell, TX 77950, USA \\ CAREY L. HARALSON-STROBEL, U.S. Fish and Wildlife Service, 1 Wildlife Circle, Austwell, TX 77950, USA
}

\begin{abstract}
From winter 1950 through spring 2011, 6,364 whooping cranes (Grus americana) overwintered at Aransas National Wildlife Refuge, or rarely, elsewhere. Documented winter losses amounted to 105 birds dead or disappeared. About $20 \%$ of total losses occurred in the wintering area, where birds spend 5 to 6 months of the year including a few birds that over-summer. Losses of white-plumaged whooping cranes on the summering area in Canada appear to be low with only 3 instances documented. The most significant losses seem to occur in migration and may comprise over $80 \%$ of the annual mortality. Migration involves only $17-20 \%$ of the annual cycle but is a period when losses are high because birds are exposed to new hazards as they travel through mostly unfamiliar environments. This paper updates a similar account by Lewis et al. (1992) by adding mortality records of the Aransas/Wood Buffalo population (AWBP) from 1987 through 2010 with information on 50 recovered carcasses.
\end{abstract}

PROCEEDINGS OF THE NORTH AMERICAN CRANE WORKSHOP 12:43-50

Key words: Aransas/Wood Buffalo, Grus americana, mortality, whooping crane.

Understanding mortality factors of a wildlife population is potentially important for effective management. Several authors have reported on aspects of mortality in whooping cranes (Grus americana) of the Aransas/Wood Buffalo population (AWBP). Kuyt (1981) noted that most chick mortality usually occurs during the first 2 weeks of life. Kuyt et al. (1981) and Hunt et al. (1987) described predation of individual juveniles, one of which had avian tuberculosis. In this article we add 24 years of data to update the account by Lewis et al. (1992), which summarized mortality of the AWBP from 1950 to 1987.

\section{METHODS}

The winter whooping crane census at Aransas National Wildlife Refuge (NWR) and nearby areas in coastal Texas began in 1938 and has continued through the present (CWS and USFWS 2007). However, aerial counts were infrequent during World War II. Beginning in 1950, after birds first started arriving (mid-October to mid-December) and in spring (mid-March through end of April) as they departed northward, aerial monitoring was generally conducted weekly, weather permitting (Aransas NWR, unpublished data). Midwinter censuses were conducted 1 or 2 times per month. Starting in 2006, number of census flights done each winter was reduced to 9-12 with emphasis placed on determining the peak flock size.

\footnotetext{
${ }^{1}$ Present address: 1613 S. Saunders St., Aransas Pass, TX 78336, USA
}

Since 1966, flights to estimate numbers of nesting pairs in the Canadian nesting grounds have occurred in May. Additionally, searches in June were conducted during 1976-2009 to determine number of young hatched, and in August/September during 1981-1984 and 1997-2011 to determine the number of fledged juveniles. In recent years, up to 25 hours of aerial surveys conducted over 4-5 days in June have counted up to $82 \%$ of the flock. A census of the entire breeding area in Wood Buffalo National Park (WBNP) and adjacent areas has never been attempted because the area occupied by whooping cranes, particularly by subadults, is too extensive.

We believe the fall censuses provide a nearly complete count of the arriving wintering population and the spring censuses provide a reasonable estimate of the population alive when spring migration begins. However, the death of subadult cranes at Aransas NWR is difficult to determine because subadult groupings and use areas are variable and carcasses are rarely found. Therefore, the spring estimate is less accurate. Winter mortality estimates are based on the number of dead cranes found plus those recognizable birds that disappeared from Aransas NWR during winter. The estimates of birds initiating spring migration are based on winter mortality estimates minus those birds which remained in Texas coastal habitats throughout summer. To calculate April through November losses of adults and subadults which had migrated in a particular year, the peak number of white-plumaged cranes in Texas in early winter was subtracted from the previous year's combined total of cranes migrating northward and 
surviving cranes summering in Texas.

Records of AWBP carcasses recovered were compiled from the Aransas NWR files. A few birds that had been observed with life-threatening injuries such as a broken leg and which subsequently disappeared without a carcass being found were included. The data set used started in 1950 when regular winter flights were begun at Aransas NWR.

\section{RESULTS}

The total of maximum annual winter counts indicates that 6,364 whooping cranes overwintered at Aransas, or rarely elsewhere, from 1950 to 2010 (Table 1). Ninetyeight percent of these cranes survived to migrate northward in spring. Twenty-six birds stayed at Aransas NWR in summer, 3 of which died while summering (Table 1). Winter losses amounted to 105 birds during the 61 -year period. The remains of 16 cranes were found in winter, and 89 others disappeared and are presumed to have died in winter. Carcasses recovered included 9 white-plumaged birds and 7 juveniles. Deaths of the 16 recovered individuals are believed due to a combination of disease and/or predation (7), shooting (2), trauma (1), and unknown (6). Juveniles that died often separated from their parents for unknown reasons several days before they died-abnormal behavior believed indicative of disease. Diseases identified were avian tuberculosis and an unknown herpes virus. One case of avian predation was documented, with talon marks consistent with a great horned owl (Bubo virginianus) found during necropsy. Other predation was caused by bobcat (Lynx rufus), coyote (Canis latrans), and American alligator (Alligator mississippiensis), but disease was also believed to be involved in at least 3 of those instances. The last known shooting loss during winter occurred in the 1988 winter when a waterfowl hunter shot an adult female near San Jose Island.

Four hundred and thirty-six adults and subadults alive in March at the start of the spring migration disappeared or were found dead from April to November 1950-2010, including 3 over-summering birds which died at Aransas NWR (Table 1). Carcasses were recovered for 29 (6.7\%) of the 436 white-plumaged birds that had disappeared between spring and fall. Additionally, 5 juveniles were found dead during fall migration. The most common causes of mortality were collision with power lines and shooting (Figure 1). We also have documentation of an individual colliding with a fence while crossing a small wetland, one being caught in a muskrat trap, one that may have had a heart muscle disease, and one that was hit by a military tanker aircraft taking off from Minot, North Dakota, in June. One of the instances categorized as trauma was from collision with a blunt object where the internal organs were shattered. That bird presumably was either hit by an airplane or died in flight and fell to the ground with great force.

Of the 546 total losses of fledged cranes during 1950-2010, 50 carcasses (9.2\%) were recovered, or in a few instances, birds with severe injuries were observed prior to their disappearance that provided clues as to source of mortality (Table 2). Of the 546 losses, 19.8\% occurred at Aransas during the 5-6 months the whooping cranes annually spent on the wintering grounds, or in 3 instances birds that over-summered at Aransas. Remains of birds that died were more frequently found at Aransas (18.5\%) than during migration or on the nesting grounds $(6.8 \%)$.

Flights in summer at WBNP indicate that summr (May-Sep) losses of adults and subadults are infrequent in the Park; only 3 carcasses have been found there since 1966. This includes 1 radioed adult found dead in WBNP in summer 2011 that was not included in the 1950-2010 data set. One juvenile (named CANUS) with an injured wing was captured and subsequently survived in captivity for 38 years.

\section{DISCUSSION}

Information on when mortality occurs for the AWBP changed very little when 23 years of data (1988-2010) were added to the account by Lewis et al. (1992). Winter losses occurred at about the same rate as that reported in the Lewis paper. Losses north of Aransas NWR when birds are migrating or on the nesting grounds $(n=433)$ were $80.0 \%$ of total mortality, similar to the $81 \%$ reported by Lewis et al. (1992). It is probable that mortality on the nesting grounds is underestimated since observations of cranes in the Park are made only during infrequent flights. The general public has no probability of observing cranes in the Park as it remains for the most part impenetrable wilderness. Thus, the probability of recovering a carcass is lower on breeding areas than during migration or winter. One of 4 radioed carcasses recovered disappeared while on the summering area. With only 3 carcasses ever recovered in WBNP compared to 28 in migration, it appears that most of the April to November mortality occurs during migration. 
Table 1. Flock size and mortality of the Aransas/Wood Buffalo whooping crane population, 1950-2010.

\begin{tabular}{|c|c|c|c|c|c|c|c|c|c|c|c|}
\hline $\begin{array}{c}\text { Winter } \\
\text { beginning }\end{array}$ & $\begin{array}{c}\text { White } \\
\text { plumaged }\end{array}$ & Juvenile & Total & $\begin{array}{l}\text { Winter } \\
\text { losses }\end{array}$ & $\begin{array}{c}\text { Migrating } \\
\text { in spring }\end{array}$ & $\begin{array}{c}\text { Number } \\
\text { over- } \\
\text { summering } \\
\text { at Aransas }\end{array}$ & $\begin{array}{c}\text { Over- } \\
\text { summer } \\
\text { mortality }\end{array}$ & $\begin{array}{c}\text { Total } \\
\text { mortality at } \\
\text { ANWR }\end{array}$ & $\begin{array}{l}\text { Subadult } \\
\text { and adult } \\
\text { mortality } \\
\text { Apr-Nov }\end{array}$ & $\begin{array}{c}\text { Total } \\
\text { recovered } \\
\text { carcasses }^{\mathrm{a}}\end{array}$ & $\begin{array}{c}\text { Total } \\
\text { annual } \\
\text { mortality } \\
\text { Nov-Nov }\end{array}$ \\
\hline 1950 & 26 & 5 & 31 & 1 & 29 & 1 & 1 & 2 & 9 & 1 & 11 \\
\hline 1951 & 20 & 5 & 25 & 2 & 23 & & & 2 & 4 & 4 & 6 \\
\hline 1952 & 19 & 2 & 21 & & 21 & & & 0 & 0 & 0 & 0 \\
\hline 1953 & 21 & 3 & 24 & & 24 & & & 0 & 3 & 0 & 3 \\
\hline 1954 & 21 & 0 & 21 & & 21 & & & 0 & 1 & 1 & 1 \\
\hline 1955 & 20 & 8 & 28 & 1 & 26 & 1 & & 1 & 5 & 1 & 6 \\
\hline 1956 & 22 & 2 & 24 & & 21 & 3 & 1 & 1 & 1 & 1 & 2 \\
\hline 1957 & 22 & 4 & 26 & & 26 & & & 0 & 3 & 0 & 3 \\
\hline 1958 & 23 & 9 & 32 & & 32 & & & 0 & 1 & 0 & 1 \\
\hline 1959 & 31 & 2 & 33 & & 31 & 2 & & 0 & 3 & 0 & 3 \\
\hline 1960 & 30 & 6 & 36 & & 36 & & & 0 & 2 & 0 & 2 \\
\hline 1961 & 34 & 5 & 39 & 1 & 38 & & & 1 & 6 & 1 & 7 \\
\hline 1962 & 32 & 0 & 32 & 4 & 28 & & & 4 & 2 & 0 & 6 \\
\hline 1963 & 26 & 7 & 33 & 1 & 32 & & & 1 & 0 & 1 & 1 \\
\hline 1964 & 32 & 10 & 42 & & 42 & & & 0 & 6 & 1 & 6 \\
\hline 1965 & 36 & 8 & 44 & & 44 & & & 0 & 6 & 0 & 6 \\
\hline 1966 & 38 & 5 & 43 & & 43 & & & 0 & 4 & 0 & 4 \\
\hline 1967 & 39 & 9 & 48 & 1 & 47 & & & 1 & 3 & 2 & 4 \\
\hline 1968 & 44 & 6 & 50 & & 50 & & & 0 & 2 & 0 & 2 \\
\hline 1969 & 48 & 8 & 56 & & 56 & & & 0 & 5 & 0 & 5 \\
\hline 1970 & 51 & 6 & 57 & 1 & 56 & & & 1 & 2 & 0 & 3 \\
\hline 1971 & 54 & 5 & 59 & 1 & 58 & & & 1 & 12 & 0 & 13 \\
\hline 1972 & 46 & 5 & 51 & 1 & 50 & & & 1 & 3 & 0 & 4 \\
\hline 1973 & 47 & 2 & 49 & 1 & 47 & 1 & & 1 & 1 & 0 & 2 \\
\hline 1974 & 47 & 2 & 49 & & 49 & & & 0 & 0 & 0 & 0 \\
\hline 1975 & 49 & 8 & 57 & & 57 & & & 0 & 0 & 0 & 0 \\
\hline 1976 & 57 & 12 & 69 & & 69 & & & 0 & 8 & 1 & 8 \\
\hline 1977 & 61 & 10 & 71 & 1 & 70 & & & 1 & 2 & 0 & 3 \\
\hline 1978 & 68 & 7 & 75 & 1 & 74 & & & 1 & 4 & 0 & 5 \\
\hline 1979 & 70 & 6 & 76 & & 76 & & & 0 & 4 & 0 & 4 \\
\hline 1980 & 72 & 6 & 78 & 1 & 76 & 1 & & 1 & 6 & 1 & 7 \\
\hline 1981 & 71 & 2 & 73 & & 73 & & & 0 & 6 & 2 & 6 \\
\hline 1982 & 67 & 6 & 73 & 2 & 70 & 1 & & 2 & 3 & 3 & 5 \\
\hline 1983 & 68 & 7 & 75 & & 75 & & & 0 & 4 & 1 & 4 \\
\hline 1984 & 71 & 15 & 86 & 2 & 84 & & & 2 & 3 & 1 & 5 \\
\hline 1985 & 81 & 16 & 97 & 1 & 96 & & & 1 & 7 & 1 & 8 \\
\hline 1986 & 89 & 21 & 110 & 1 & 109 & & & 1 & 0 & 0 & 1 \\
\hline 1987 & 109 & 25 & 134 & 3 & 129 & 2 & & 3 & 12 & 1 & 15 \\
\hline 1988 & 119 & 19 & 138 & 6 & 131 & 1 & 1 & 7 & 5 & 3 & 12 \\
\hline 1989 & 126 & 20 & 146 & 4 & 141 & 1 & & 4 & 9 & 1 & 13 \\
\hline 1990 & 133 & 13 & 146 & 11 & 134 & 1 & & 11 & 11 & 2 & 22 \\
\hline 1991 & 124 & 8 & 132 & 1 & 131 & & & 1 & 10 & 1 & 11 \\
\hline 1992 & 121 & 15 & 136 & & 136 & & & 0 & 9 & 1 & 9 \\
\hline 1993 & 127 & 16 & 143 & 7 & 136 & & & 7 & 11 & 1 & 18 \\
\hline 1994 & 125 & 8 & 133 & & 131 & 2 & & 0 & 3 & 0 & 3 \\
\hline 1995 & 130 & 28 & 158 & 1 & 155 & 2 & & 1 & 13 & 1 & 14 \\
\hline 1996 & 144 & 16 & 160 & & 160 & & & 0 & 8 & 1 & 8 \\
\hline 1997 & 152 & 30 & 182 & 1 & $181^{\circ}$ & & & 1 & 16 & 1 & 17 \\
\hline 1998 & 165 & 18 & 183 & & 183 & & & 0 & 12 & 0 & 12 \\
\hline 1999 & 171 & 17 & 188 & 1 & 186 & 1 & & 1 & 16 & 0 & 17 \\
\hline 2000 & 171 & 9 & 180 & 6 & 174 & & & 6 & 13 & 1 & 19 \\
\hline 2001 & 161 & 15 & 176 & 2 & 174 & & & 2 & 5 & 1 & 7 \\
\hline 2002 & 169 & 16 & 185 & 1 & 184 & & & 1 & 15 & 1 & 16 \\
\hline 2003 & 169 & 25 & 194 & 1 & 193 & & & 1 & 10 & 3 & 11 \\
\hline
\end{tabular}


Table 1. Continued.

\begin{tabular}{|c|c|c|c|c|c|c|c|c|c|c|c|}
\hline $\begin{array}{c}\text { Winter } \\
\text { beginning }\end{array}$ & $\begin{array}{l}\text { White } \\
\text { plumaged }\end{array}$ & Juvenile & Total & $\begin{array}{l}\text { Winter } \\
\text { losses }\end{array}$ & $\begin{array}{c}\text { Migrating } \\
\text { in spring }\end{array}$ & $\begin{array}{c}\text { Number } \\
\text { over- } \\
\text { summering } \\
\text { at Aransas }\end{array}$ & $\begin{array}{c}\text { Over- } \\
\text { summer } \\
\text { mortality }\end{array}$ & $\begin{array}{c}\text { Total } \\
\text { mortality at } \\
\text { ANWR }\end{array}$ & $\begin{array}{l}\text { Subadult } \\
\text { and adult } \\
\text { mortality } \\
\text { Apr-Nov }\end{array}$ & $\begin{array}{c}\text { Total } \\
\text { recovered } \\
\text { carcasses }^{\mathrm{a}}\end{array}$ & $\begin{array}{c}\text { Total } \\
\text { annual } \\
\text { mortality } \\
\text { Nov-Nov }\end{array}$ \\
\hline 2004 & 183 & 34 & 217 & 2 & 214 & 1 & & 2 & 25 & 2 & 27 \\
\hline 2005 & 190 & 30 & 220 & 6 & 211 & 3 & & 6 & 22 & 0 & 28 \\
\hline 2006 & 192 & 45 & 237 & & 237 & & & 0 & 10 & 2 & 10 \\
\hline 2007 & 227 & 39 & 266 & & 266 & & & 0 & 34 & 0 & 34 \\
\hline 2008 & 232 & 38 & 270 & 23 & 245 & 2 & & 23 & 5 & 4 & 28 \\
\hline 2009 & 242 & 22 & 264 & 1 & 263 & & & 1 & 3 & 0 & 4 \\
\hline 2010 & 238 & 45 & 283 & 4 & 279 & & & 4 & 25 & 0 & 29 \\
\hline Totals & 5573 & 791 & 6364 & 105 & 6233 & 26 & 3 & 108 & 433 & 50 & 541 \\
\hline
\end{tabular}

${ }^{\text {a }}$ In a few instances, the carcass was not recovered but mortality was deduced from disappearance of an injured crane.

Table 2. Documented mortalities of the Aransas/Wood Buffalo whooping crane flock, 1950-2010.

\begin{tabular}{|c|c|c|c|c|c|c|c|}
\hline Year & Date & Period & Location $^{\mathrm{a}}$ & $\mathrm{Age}^{\mathrm{b}}$ & Recovered & Cause of death & Comments \\
\hline 1950 & Sep & Summer & $\begin{array}{l}\text { Burgentine } \\
\text { Lake, ANWR }\end{array}$ & A & Yes & Unknown & $\begin{array}{l}\text { "Mac" had been captured in Louisiana and released } \\
\text { at ANWR in spring } 1950 .\end{array}$ \\
\hline 1951 & Aug & Summer & $\begin{array}{l}\text { N. Mullet Bay, } \\
\text { ANWR }\end{array}$ & A & Yes & Unknown & Carcass much decayed \\
\hline 1951 & Nov & Winter & $\begin{array}{l}\text { Ratama Mill, } \\
\text { ANWR }\end{array}$ & A & Yes & Shot & $\begin{array}{l}\text { Shattered joint between femur and tibiotarsus, } \\
\text { assumed shot on migration, died at San Antonio Zoo }\end{array}$ \\
\hline 1951 & Dec & Winter & $\begin{array}{l}\text { W. St. Charles, } \\
\text { ANWR }\end{array}$ & A & Yes & Trauma & Unknown, missing 1 foot, leg broken at tibiotarsus \\
\hline 1952 & Oct & $\begin{array}{l}\text { Fall } \\
\text { migration }\end{array}$ & Sharon, Kans. & A & Yes & Unknown & $\begin{array}{l}\text { Had dislocated wing, died en route to San Antonio } \\
\text { Zoo }\end{array}$ \\
\hline 1952 & Nov & $\begin{array}{c}\text { Fall } \\
\text { migration }\end{array}$ & Regina, Sask. & Chick & Yes & Trauma & Injured wing, broken leg, lung conjestion; died \\
\hline 1955 & Fall & $\begin{array}{c}\text { Fall } \\
\text { migration }\end{array}$ & $\begin{array}{l}\text { Sioux Falls, } \\
\text { S.D. }\end{array}$ & WP & & Shot & Snow goose hunter (McNulty 1966) \\
\hline 1956 & May & $\begin{array}{l}\text { Spring } \\
\text { migration }\end{array}$ & $\begin{array}{l}\text { Lampass City, } \\
\text { Tex. }\end{array}$ & SA & Yes & Power line & Broken wing tip \\
\hline 1957 & Oct & $\begin{array}{l}\text { Fall } \\
\text { migration }\end{array}$ & Ketchum, Okla. & WP & No & Trauma & Crippled bird seen, then disappeared \\
\hline 1961 & Dec & Winter & $\begin{array}{l}\text { Matagorda } \\
\text { Island, ANWR }\end{array}$ & & No & Unknown & Ranch foreman discovered carcass (McNulty 1966) \\
\hline 1964 & Mar & Winter & ANWR & & Yes & Unknown & $\begin{array}{l}\text { Bones, feathers, and skin recovered; was } 1 \text { of twin } \\
\text { chicks; lab detected minute traces of DDT }\end{array}$ \\
\hline 1965 & Nov & $\begin{array}{l}\text { Fall } \\
\text { migration }\end{array}$ & $\begin{array}{l}\text { Rawlins Cty., } \\
\text { Kans. }\end{array}$ & SA & Yes & Power line & Distribution (3 wire) \\
\hline 1968 & Jan & Winter & ANWR & A & Yes & Shot & Shot by goose hunter \\
\hline 1968 & Apr & $\begin{array}{l}\text { Spring } \\
\text { migration }\end{array}$ & $\begin{array}{l}\text { Russell Cty., } \\
\text { Kans. }\end{array}$ & A & Yes & Power line & Distribution (3 wire) \\
\hline 1977 & Apr-May & $\begin{array}{l}\text { Spring } \\
\text { migration }\end{array}$ & Sask. & A & No & Muskrat trap & Unconfirmed mortality of death in trap \\
\hline 1981 & 11 Oct & $\begin{array}{l}\text { Fall } \\
\text { migration }\end{array}$ & Glaslyn, Sask. & Chick & Yes & Power line & $\begin{array}{l}\text { Distribution ( } 1 \text { wire, } 9 \mathrm{~m}) \text {, picked up, died later due } \\
\text { to injuries }\end{array}$ \\
\hline 1982 & Jun & $\begin{array}{l}\text { Spring } \\
\text { migration }\end{array}$ & Minton, S.D. & & Yes & Aircraft & Feathers identified on military tanker aircraft \\
\hline 1982 & Oct & $\begin{array}{c}\text { Fall } \\
\text { migration }\end{array}$ & Oglesby, Tex. & A & Yes & Power line & Distribution ( 4 wire, $<8 \mathrm{~m}$ ) \\
\hline 1983 & Jan & Winter & ANWR & Chick & Yes & $\begin{array}{l}\text { Disease, } \\
\text { predated }\end{array}$ & $\begin{array}{l}\text { Found dead on M.I. }{ }^{\mathrm{a}} \text {, assumed avian tuberculosis } \\
\text { (TB) and predation (radioed) }\end{array}$ \\
\hline
\end{tabular}


Table 2. Continued.

\begin{tabular}{|c|c|c|c|c|c|c|c|}
\hline Year & Date & Period & Location $^{\mathrm{a}}$ & Age $^{b}$ & Recovered & Cause of death & Comments \\
\hline 1983 & Jan & Winter & ANWR & Chick & Yes & $\begin{array}{l}\text { Disease, } \\
\text { predated }\end{array}$ & $\begin{array}{l}\text { Separated, disease similar to avian TB, predated by } \\
\text { a coyote (radioed) }\end{array}$ \\
\hline 1983 & May & $\begin{array}{l}\text { Spring } \\
\text { migration }\end{array}$ & Edam, Sask. & SA & No & $\begin{array}{l}\text { Possibly } \\
\text { disease }\end{array}$ & $\begin{array}{l}\text { Unknown, observed by farmer for } 1 \text { week, died, } \\
\text { possibly disease }\end{array}$ \\
\hline 1984 & Oct & $\begin{array}{l}\text { Fall } \\
\text { migration }\end{array}$ & Linton, N.D. & A & Yes & Power line & $\begin{array}{l}\text { Male with multiple fractures in wing, captured but } \\
\text { later died Jan 1985, aspergillosis, and partial paralysis } \\
\text { from running into captive fence during handling }\end{array}$ \\
\hline 1984 & Nov & Winter & ANWR & SA & Yes & Neck trauma & Probable avian predation (radioed) \\
\hline 1986 & 24 May & Summer & WBNP & A & Yes & Unknown & Male found dead at the nest \\
\hline 1988 & Oct & $\begin{array}{l}\text { Fall } \\
\text { migration }\end{array}$ & St. Paul, Nebr. & $\mathrm{A}$ & Yes & Power line & Distribution (2 wire, 11 m) \\
\hline 1989 & Apr & Winter & ANWR & SA & Yes & Avian TB & Avian tuberculosis \\
\hline 1989 & 3 Jan & Winter & ANWR & A & Yes & Shot & Mistaken for snow goose on San Jose Island \\
\hline 1989 & Oct & $\begin{array}{l}\text { Fall } \\
\text { migration }\end{array}$ & Nebr. & SA & Yes & Power line & Flew into 2-wire transmission line, found dead \\
\hline 1990 & 19 Apr & $\begin{array}{l}\text { Spring } \\
\text { migration }\end{array}$ & Leoville, Sask. & A & No & Shot & $\begin{array}{l}\text { Hunter observed with crane in back of truck at gas } \\
\text { station; not convicted because he was "unknowingly" } \\
\text { in possession of an endangered species }\end{array}$ \\
\hline 1991 & Apr & $\begin{array}{l}\text { Spring } \\
\text { migration }\end{array}$ & Bend, Tex. & A & Yes & Shot & Shot \\
\hline 1991 & Jun & Summer & WBNP & WP & Yes & Unknown & Unknown due to decay, not submitted for necropsy \\
\hline 1992 & Jan & Winter & ANWR & A & Yes & Unknown & Pile of feathers in burn area \\
\hline 1993 & Dec & Winter & ANWR & Chick & Yes & $\begin{array}{l}\text { Bobcat } \\
\text { predation }\end{array}$ & Bobcat predation \\
\hline 1996 & Mar & Winter & ANWR & Chick & Yes & $\begin{array}{l}\text { Disease, } \\
\text { predation }\end{array}$ & Probably not bobcat \\
\hline 1997 & Oct & $\begin{array}{l}\text { Fall } \\
\text { migration }\end{array}$ & Zelma, Sask. & Chick & Yes & Power line & Dead under a $14.4-\mathrm{kV}$ power line for 1 week \\
\hline 1998 & Nov & $\begin{array}{l}\text { Fall } \\
\text { migration }\end{array}$ & $\begin{array}{l}\text { Quivira NWR, } \\
\text { Kans. }\end{array}$ & A & No & Broken leg & $\begin{array}{l}\text { Last seen with broken leg, mate appeared at ANWR } \\
\text { without her }\end{array}$ \\
\hline 2001 & Jan & Winter & ANWR & SA & Yes & Unknown & Skull and feathers found \\
\hline 2002 & Apr & $\begin{array}{l}\text { Spring } \\
\text { Migration }\end{array}$ & De Leon, Tex. & A & Yes & Power line & Power line strike \\
\hline 2003 & Nov & $\begin{array}{c}\text { Fall } \\
\text { Migration }\end{array}$ & Dallas, Tex. & A & Yes & Shot & Shot \\
\hline 2004 & Nov & $\begin{array}{c}\text { Fall } \\
\text { Migration }\end{array}$ & $\begin{array}{l}\text { Quivira NWR, } \\
\text { Kans. }\end{array}$ & SA & Yes & Shot & Had a leg amputated, died in captivity 9 Nov \\
\hline 2004 & Nov & $\begin{array}{c}\text { Fall } \\
\text { Migration }\end{array}$ & $\begin{array}{l}\text { Quivira NWR, } \\
\text { Kans. }\end{array}$ & SA & Yes & Shot & $\begin{array}{l}\text { Second bird had a fractured humerus repaired, died } \\
\text { due to complications mid-Nov }\end{array}$ \\
\hline 2004 & Nov & $\begin{array}{l}\text { Fall } \\
\text { migration }\end{array}$ & $\begin{array}{l}\text { Quivira NWR, } \\
\text { Kans. }\end{array}$ & SA & No & Shot & $\begin{array}{l}\text { Shot at, red spot seen on breast, not captured, stayed in } \\
\text { area and was last observed in Dec; assumed mortality }\end{array}$ \\
\hline 2005 & Dec & $\begin{array}{l}\text { Fall } \\
\text { migration }\end{array}$ & Mo. & Chick & Yes & Bacterium & Bacterium obstructing the larynx \\
\hline 2007 & 7 Apr & $\begin{array}{l}\text { Spring } \\
\text { migration }\end{array}$ & N.D. & A & Yes & Collision & Collision with a blunt object \\
\hline 2007 & 8 Oct & $\begin{array}{l}\text { Fall } \\
\text { migration }\end{array}$ & Sask. & Chick & Yes & Unknown & $\begin{array}{l}\text { Scavenged carcass, could not be recovered until } \\
\text { spring due to snow cover }\end{array}$ \\
\hline 2008 & Dec & Winter & ANWR & WP & Yes & $\begin{array}{l}\text { Starvation, } \\
\text { knee }\end{array}$ & Injured knee and starvation \\
\hline 2009 & Jan & Winter & ANWR & Chick & Yes & Predation & Herpes virus and emaciation underlying factors \\
\hline 2009 & Feb & Winter & ANWR & Chick & Yes & $\begin{array}{l}\text { Disease, } \\
\text { predation }\end{array}$ & Separated, possibly diseased; predation near dugout \\
\hline 2009 & Mar & Winter & ANWR & WP & Yes & Unknown & Pile of feathers \\
\hline
\end{tabular}

${ }^{a}$ ANWR $=$ Aransas National Wildlife Refuge, Cty. $=$ County, M.I. = Matagorda Island, WBNP $=$ Wood Buffalo National Park.

${ }^{\mathrm{b}} \mathrm{A}=$ Adult, $\mathrm{SA}=$ Subadult, $\mathrm{WP}=$ White-plumaged. 


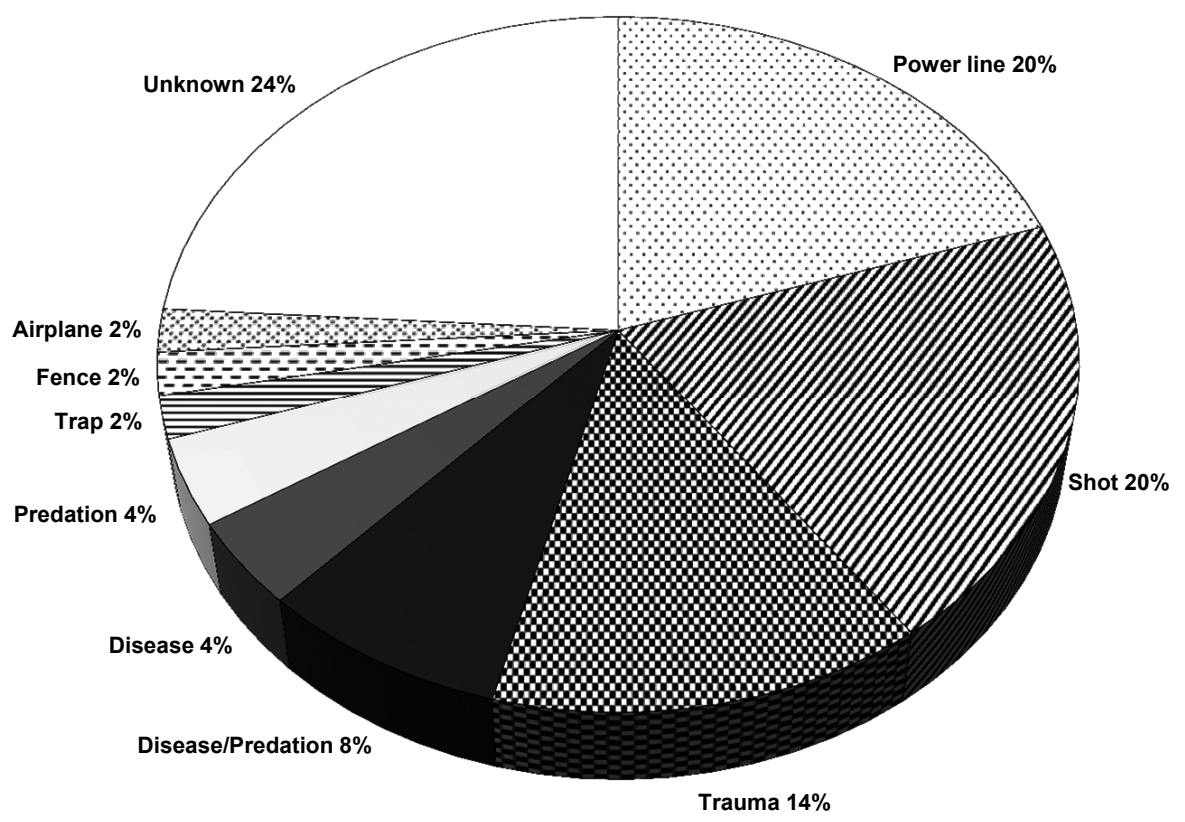

Figure 1. Causes of mortality of 50 carcasses recovered from the Aransas-Wood Buffalo whooping crane flock, $1950-2009$.

For an average whooping crane, fall migration takes about 6 weeks, including the staging period in Saskatchewan. Spring migration on average involves about 2-4 weeks. Thus, migration losses occur during a period comprising about 9 weeks $(17 \%)$ of the annual cycle. Spring and fall migration periods are the periods that should be focused on to further diminish mortality of fledged birds. Such actions are occurring through the Federal-State and Federal-Provincial cooperative plans for protection of whooping cranes (Lewis 1992) and through efforts to diminish collisions with power lines and wind energy developments. However, reducing mortality wherever it occurs benefits the population (CWS and USFWS 2007).

Although the majority of known mortality for the AWBP is split between power lines $(n=10)$, shootings (10), other trauma (7), and disease often linked with predation (6), carcasses are recovered only $9.2 \%$ of the time, leaving the causes for about $90 \%$ of mortality as speculative. An ongoing satellite radio telemetry study should allow more unbiased information to be collected on causes and timing of mortality. Also, much more intensive monitoring has occurred on introduced whooping cranes where all such birds are radioed prior to reintroduction.

From the carcasses recovered, the causes of mortality seem different during winter at Aransas compared with the rest of the year. This makes sense since there is little opportunity, with a few exceptions, for collisions with power lines or trauma during the 6 months the birds reside in the coastal salt marsh. Shootings may occur anywhere except in WBNP where human/crane interactions are practically non-existent. Predation on healthy fledged birds seems to be minimal. However, the impact of disease on the flock needs to be investigated further.

Cole etal. (2009) conducted postmortem evaluations on 17 reintroduced migratory whooping cranes in eastern North America from 2001 to 2006. Causes of death included predation $(n=8)$, trauma (2), capture myopathy (1), and unknown (6). The primary predator was found to be bobcat. Limited roosting habitat or behavior of the naïve captive-raised birds were likely prime factors in predation events. The 2 trauma events were gunshot and power line collision. Infectious disease was not detected in their limited sample.

Predation by bobcats was the primary cause of mortality in nonmigratory whooping cranes in Florida. Whooping cranes were particularly vulnerable during their 44-day flightless molt that occurred every 2-4 years in summer (Spalding et al. 2011). In the early years of the project, juvenile whooping cranes without exposure to roosting ponds in captivity had much higher rates of predation than birds raised in later years with water exposure (Gee et al. 2001). Poor habitat selection (Nesbitt et al. 1997) or limited availability of roosting 
habitat was found in a majority of the predation events (Cole et al.2009). Immaturity, lack of predator avoidance training in captivity, and inappropriate habitat selection may put captive-raised cranes at greater risk than wildraised birds (Spalding et al. 2011). In contrast, predation, except where linked with disease, seems to be relatively uncommon in AWBP whooping cranes. Some mortality in Florida was associated with human activities (crane leg fractured by a golf ball, fishing line wrapped around feet, suspected collision with vehicles) (Folk et al. 2001). Postmortem findings of nonmigratory whooping cranes in Florida include case reports of lead and zinc toxicosis associated with pen construction (Spalding et al. 1997), avian cholera, eastern equine encephalitis, infectious bursal disease, and aspergillosis (Spalding et al. 2004), mycobacteriosis, parasite infections (Spalding 2003), avian tuberculosis and salmonellosis (Stroud et al. 1986), and disseminated visceral coccidiosis (Novilla and Carpenter 2004).

Known causes of mortality in Florida whooping cranes, listed in order from most common to least common, were bobcat predation, power line collision, alligator predation, disease, gunshot, leg fracture, and cattle (Spalding et al. 2011), though the category of missing birds was larger than any other category. Mortality factors for the Florida nonmigratory and eastern migratory flocks seem similar (M. Spalding, University of Florida, unpublished data), with predation mortality of $47 \%$ in the migratory flock and $58 \%$ for the nonmigratory population (Cole et al. 2009). Traumatic injury accounted for $12 \%$ of the mortality in the eastern migratory flock and $7.5 \%$ in the Florida nonmigratory flock (Cole et al. 2009).

Causes of death of 24 Rocky Mountain crossfostered whooping cranes was compiled from necropsy reports $(\mathrm{N}$. Thomas, National Wildlife Health Center, unpublished data). In order of most common to least common, power line and fence collisions $(n=11)$, disease (4), predation (2), injuries related to capture (2), vehicle collisions (1), and poison (1) were documented. Predation included coyote and golden eagle (Aquila chrysaetos) (Windingstad et al. 1981). Diseases included avian tuberculosis and avian cholera (Snyder et al. 1991). Notable was the high incidence of avian tuberculosis (20.8\%) compared with much lower rates reported in sandhill cranes (Grus canadensis) (0.6\%) and waterfowl $(0.3 \%)$. Rocky Mountain whooping cranes were exposed to large concentrations of geese and sandhill cranes on wintering areas and suffered food shortages as crops grown for the birds were depleted, leading to higher incidence of disease.

Whooping cranes are more susceptible to collision with power lines (Stehn and Wassenich 2008) than sandhill cranes (Brown et al. 1987). Power line mortalities have been documented in all reintroduced whooping crane populations as well as the AWBP, with 49 documented fatal collisions in North America (T. Stehn, U.S. Fish and Wildlife Service, unpublished data). Power lines collisions were the greatest (39.0\%) known cause of mortality for fledged whooping cranes in the introduced Rocky Mountain population (Brown et al. 1987). In Florida, males were significantly more vulnerable to power line collisions than females (Spalding et al. 2011).

\section{ACKNOWLEDGMENTS}

The authors thank the many individuals in Canada and the United States who over the past 60 years collected the data which made this analysis possible. Also, gratitude goes to scientists at the National Wildlife Health Center in Madison, Wisconsin, and the National Forensics Laboratory in Ashland, Oregon, for necropsies done. The findings and conclusions in this paper are those of the authors and do not necessarily reflect the views of the U. S. Fish and Wildlife Service.

\section{LITERATURE CITED}

Brown, W. M., R. C. Drewien, and E. G. Bizeau. 1987. Mortality of cranes and waterfowl from power line collisions in the San Luis Valley, Colorado. Pages 128136 in J. C. Lewis, editor. Proceedings of the 1985 crane workshop. Platte River Whooping Crane Maintenance Trust, Grand Island, Nebraska, USA.

Canadian Wildlife Service [CWS] and U.S. Fish and Wildlife Service [USFWS]. 2007. International recovery plan for the whooping crane. Recovery of Nationally Endangered Wildlife (RENEW), Ottawa, Ontario, Canada, and U.S. Fish and Wildlife Service, Albuquerque, New Mexico, USA.

Cole, G. A., N. J. Thomas, M. Spalding, R. Stroud, R. P. Urbanek, and B. K. Hartup. 2009. Postmortem evaluation of reintroduced migratory whooping cranes in eastern North America. Journal of Wildlife Diseases 45:29-40.

Folk, M. J., S. A. Nesbitt, and M. G. Spalding. 2001. Interactions of sandhill cranes and whooping cranes with foreign objects in Florida. Proceedings of the North American Crane Workshop 8:195-197. 
Gee, G. F., J. M. Nicolich, S. A. Nesbitt, J. S. Hatfield, D. H. Ellis, and G. H. Olsen. 2001. Water conditioning and whooping crane survival after release in Florida. Proceedings of the North American Crane Workshop $8: 160-165$.

Hunt, H. E., T. V. Stehn, and R. D. Slack. 1987. Whooping crane mortality during the winter of 1982-83. Pages 219220 in J. C. Lewis, editor. Proceedings of the 1985 crane workshop. Platte River Whooping Crane Maintenance Trust, Grand Island, Nebraska, USA.

Kuyt, E. 1981. Clutch size, hatching success, and survival of whooping crane chicks, Wood Buffalo National Park, Canada. Pages 126-129 in J. C. Lewis and H. Masatomi, editors. Crane research around the world. International Crane Foundation, Baraboo, Wisconsin, USA.

Kuyt, E., B. E. Johnson, and R. C. Drewien. 1981. A wolf kills a juvenile whooping crane. Blue Jay 39:116-119.

Lewis, J. C. 1992. The contingency plan for federal-state cooperative protection of whooping cranes. Pages 293300 in D. A. Wood, editor. Proceedings of the 1988 North American crane workshop. Florida Game and Fresh Water Fish Commission Nongame Technical Report No. 12, Tallahassee, Florida, USA.

Lewis, J. C., E. Kuyt, K. E. Schwindt, and T. V. Stehn. 1992. Mortality in fledged cranes of the AransasWood Buffalo population. Pages 145-148 in D. A. Wood, editor. Proceedings of the 1988 North American crane workshop. Florida Game and Fresh Water Fish Commission Nongame Technical Report No. 12, Tallahassee, Florida, USA.

McNulty, F. 1966. The whooping crane: the bird that defies extinction. E. P. Dutton, New York, New York, USA.

Nesbitt, S. A., M. J. Folk, M. G. Spalding, J. A. Schmidt, S, T, Schwikert, J. M. Nicolich, M. Wellington, J. C. Lewis, and T. H. Logan. 1997. An experimental release of whooping cranes in Florida-the first three years. Proceedings of the North American Crane Workshop 7:79-85.
Novilla, M. N., and J. W. Carpenter. 2004. Pathology and pathogenesis of disseminated visceral coccidiosis in cranes. Avian Pathology 33:275-280.

Snyder, S. B., M. J. Richard, R. C. Drewien, N. Thomas, and J. P. Thilsted. 1991. Diseases of whooping cranes seen during annual migration of the Rocky Mountain flock. Pages 73-79 in R. E. Junge, editor. Proceedings of the American Association of Zoo Veterinarians Annual Conference, 28 September-3 October 1991, Calgary, Alberta, Canada.

Spalding, M. G. 2003. Cranes. Pages 702-740 in D. J. Forrester and M. G. Spalding, editors. Parasites and diseases of wild birds in Florida. University of Florida Press, Gainesville, USA.

Spalding, M. G., S. A. Nesbitt, M. J. Folk, L. R. McDowell, and M. S. Sepulveda. 1997. Metal consumption by whooping cranes and possible zinc toxicosis. Proceedings of the North American Crane Workshop 7:237-242.

Spalding, M. G., H. S. Sellers, B. K. Hartup, and G. H. Olsen. 2004. Infectious bursal disease virus associated with a wasting syndrome in released whooping cranes in Florida. Page 73 in C. K. Bauer, editor. Proceedings of the American Association of Zoo Veterinarians, American Association of Wildlife Veterinarians, and Wildlife Association Disease Joint Conference, 28 August-3 September 2004, San Diego, California, USA.

Spalding, M. G., M. J. Folk, S. A. Nesbitt, and R. Kiltie. 2011. Reproductive health and performance of the Florida flock of introduced whooping cranes. Proceedings of the North American Crane Workshop 11:142-155.

Stehn, T. V., and T. Wassenich. 2008. Whooping crane collisions with power lines: an issue paper. Proceedings of the North American Crane Workshop 10:25-36.

Stroud, R. K., C. O. Thoen, and R. M. Duncan. 1986. Avian tuberculosis and salmonellosis in a whooping crane (Grus americana). Journal of Wildlife Diseases 22: 106110.

Windingstad, R. M., H. E. Stiles, and R. C. Drewien. 1981. Whooping crane preyed upon by golden eagle. Auk 98:393-394. 